\title{
Synopsis of adventive species of Coleoptera (Insedta) recorded from Canada. Part 5: Chrysomeloidea (Cerambycidae, Chrysomelidae, and Megalopodidae)
}

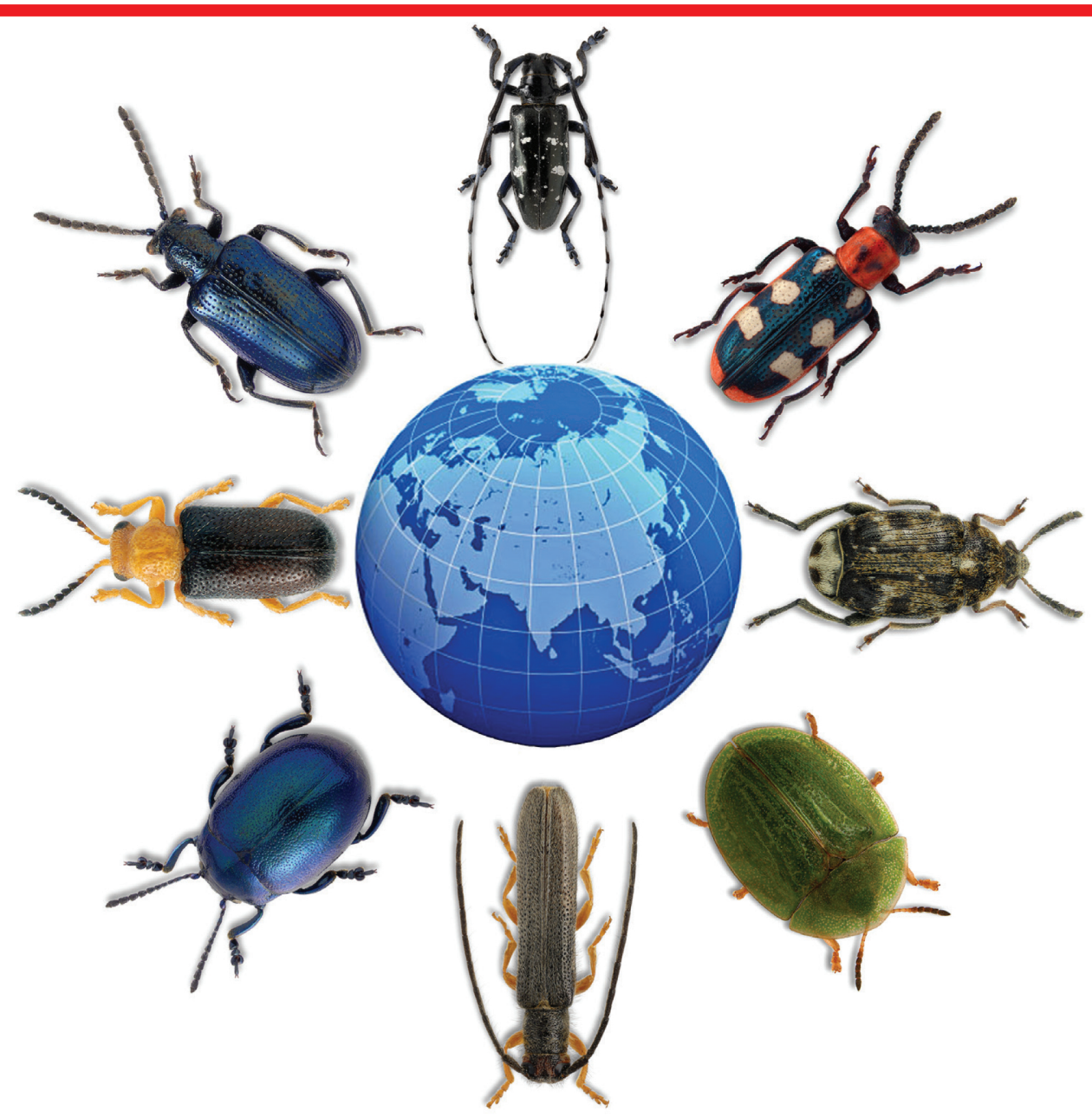

Jan Klimaszewski, E. Richard Hoebeke, David W. Langor, Hume B. Douglas, Lech Borowiec, H.E. James Hammond, Anthony Davies, Caroline Bourdon, Karine Savard

PENSOFI. 

Synopsis of adventive species of Coleoptera (Insecta)

recorded from Canada.

Part 5: Chrysomeloidea (Cerambycidae, Chrysomelidae, and

Megalopodidae) 



\title{
Synopsis of adventive species of Coleoptera (Insecta) recorded from Canada. Part 5: Chrysomeloidea (Cerambycidae, Chrysomelidae, and Megalopodidae)
}

\author{
by \\ Jan Klimaszewski,E. Richard Hoebeke,David W. Langor, \\ Hume B. Douglas, Lech Borowiec, H.E. James Hammond, \\ Anthony Davies, Caroline Bourdon, Karine Savard
}

\author{
है PENSOF. \\ Sofia-Moscow \\ 2020
}


Synopsis of adventive species of Coleoptera (Insecta) Recorded from Canada. Part 5: Chrysomeloidea (Cerambycidae, Chrysomelidae, and Megalopodidae) by Jan Klimaszewski ${ }^{1}$, E. Richard Hoebeke ${ }^{2}$, David W. Langor ${ }^{3}$, Hume B. Douglas ${ }^{4}$, Lech Borowiec $^{5}$, H.E. James Hammond ${ }^{3}$, Anthony Davies ${ }^{4}$, Caroline Bourdon ${ }^{1}$, Karine Savard ${ }^{4}$

1) Natural Resources Canada, Canadian Forest Service, Laurentian Forestry Centre, 1055 du P.E.P.S., P.O. Box 10380, Stn. Sainte-Foy, Québec, Quebec, G1V 4C7, Canada

2) Georgia Museum of Natural History and Department of Entomology, University of Georgia, Athens, Georgia, U.S.A. 30602

3) Natural Resources Canada, Canadian Forest Service, Northern Forestry Centre, 5320-122 Street NW, Edmonton, Alberta, T6H 3S5, Canada

4) Agriculture and Agri-Food Canada, Canadian National Collection of Insects, Arachnids and Nematodes, Ottawa, Ontario, K1A 0C6, Canada

5) University of Wroclaw, Department of Biodiversity and Evolutionary Taxonomy, Wroclaw, Poland

Corresponding author:Jan Klimaszewski (jan.klimaszewski@canada.ca)

Pensoft Series Faunistica No 119

ISSN 1312-0I7

First published 2020

ISBN 978-954-642-993-3 (hardback)

This is an open access book distributed under the terms of the Creative Commons Attribution License (CC BY 4.0), which permits unrestricted use, distribution, and reproduction in any medium, provided the original author and source are credited.

Pensoft Publishers

Prof. Georgi Zlatarski 12, Sofia 1700, Bulgaria

Fax: $+359-2-870-42-82$

info@pensoft.net

www.pensoft.net

Printed in Bulgaria, February 2020 
This work is dedicated to our late colleague Laurent LeSage who initiated this project several years ago, and who devoted his life to studying the insect biota of Canada. 



\title{
Contents
}

\author{
Introduction
}

9

Materials and methods

II

Discussion

13

List of recorded adventive species in Canada

17

Taxonomic review

20

Acknowledgements

99

References

100

Plates

127

Maps

149

Index of taxonomic names listed in the text

213 



\section{Introduction}

This is the sixth volume in a series of monographs in which we treat the adventive species of the insect order Coleoptera in Canada. The first volume provided an overview of all recorded species of adventive Coleoptera in eastern Canada (Klimaszewski et al. 2010), and the four subsequent volumes reviewed in detail the Canadian adventive species of Carabidae (Klimaszewski et al. 2012), Staphylinidae (Klimaszewski et al. 2013), Cucujoidea (Klimaszewski et al. 2015), and Scarabaeoidea to Cleroidea (Klimaszewski et al. 2017). Herein we focus on the 72 adventive species in the families Cerambycidae, Chrysomelidae and Megalopodidae (Chrysomeloidea) recorded from Canada.

The Cerambycidae, commonly called the longhorned beetles because of their very long antennae that typically exceed the body length, is a highly conspicuous family as adults of many species are large and brightly colored. Worldwide there are more than 36,000 known species (Wang 2017), and 377 species are known from Canada (Bousquet et al. 2017). In general, the state of taxonomic knowledge is good, particularly in the Holarctic Region. Adults feed on wood, roots, and pollen, and are rarely carnivorous (Turnbow and Thomas 2002), or may not feed at all, e.g., Tetropium fuscum (Fabricius) (Juutinen 1955). Larvae feed on tissues of woody plants that range from live and healthy, to dead and decomposing, but most larval hosts are weakened or stressed living plants (Hanks 1999). Some species are destructive to trees, cut logs, and seasoned wood, and can be serious economic pests (Gardiner 1975, Haack et al. 2010, Wang 2017).

The Chrysomelidae, or leaf beetles, includes at least 32,500 species worldwide (Slipinski et al. 2011), with 595 known species in Canada (Brunke et al. 2019). Adults in most subfamilies occur mainly in sunny habitats where they usually consume fresh leaves, sometimes pollen, flower parts, or rarely dead plant material. Adults of Bruchinae (seed beetles) are found on foliage, or in stored legumes, and other seeds. The feeding habits of Chrysomelidae larvae are diverse. Many feed in the open on leaves, but leaf or stem miners are common as well. Larvae of most Bruchinae species feed within seeds or seed envelopes. Almost all Eumolpinae larvae are subterranean, mining roots or feeding on other underground plant parts. Many Galerucinae and Alticinae larvae 
are also root miners. Most Cryptocephalinae larvae feed on dead leaves and twigs in the leaf litter. Clytrinae larvae occur in ant nests where they feed on eggs and animal or plant detritus. The aquatic Donaciinae larvae feed on the submerged portions of plants, hooked to them with two long spines (root-piercing hind spiracles), which provide them with oxygen from plant vessel elements (tracheae) and from air spaces of the plant tissue. Many chrysomelids, especially in the Galerucinae, are pests of agricultural crops, and some Bruchinae cause damage to stored seeds (e.g., beans, peas) (Campbell et al. 1989).

The Megalopodidae are a much smaller family with about 350 species known worldwide (Slipinski et al. 2011) and seven species in Canada (Brunke et al. 2019). Larvae are true leaf miners, and are legless and dorsoventrally flattened. Some species utilize willows and poplars (Salicaceae).

Canada is home to over 1930 non-native insect species, which represents about $5.0 \%$ of the known insect fauna of Canada (Langor 2019). About a third of non-native insects are beetles (639 species) which represents about $7.7 \%$ of the beetle fauna (Brunke et al. 2019). The pathways of introduction of non-native species to Canada (and North America) have been well discussed (e.g., Brown 1940, 1950, Lindroth 1957, Sailer 1978, 1983, Langor et al. 2009). Cerambycidae have been transported likely in shipments of untreated logs and in solid wood packing material (Humble 2001, Allen and Humble 2002, Eyre and Haack 2017). Chrysomelids have been transported around the world, and to Canada, likely frequently on nursery plants and associated soil, in produce, and in shipments of beans.

Other non-native species are likely established in Canada and nearby parts of the USA, with spread to Canada inevitable. Most species of adventive chrysomelids are in the Galerucinae where a lack of taxonomic research on many genera inhibits our understanding of native and non-native faunas. This subfamily in particular is expected to yield additional adventive species in Canada. It is possible that other biocontrol agents in the Chrysomelidae may be introduced to Canada for management of weeds.

It may be that some species currently thought to be adventive will eventually be discovered to have natural Holarctic distributions. For example, we have removed Phaedon armoraceae (L.), from the list of adventive Chrysomeloidea species in Canada. According to recent literature (Elias and Crocker 2008), the geographic distribution of $P$. armoraceae in both Eurasia and North America suggests it a Holarctic species. It is widespread in both areas, and more importantly, it is one of the only "steppe-associated" leaf beetles that is common to both sides of the Bering Strait. This distribution suggests that the species was probably present in both the Nearctic and Palearctic during the last glacial maximum, and so should be considered native to North America. 


\section{Materials and methods}

Structure and convention. This review is based largely on the published literature and on information associated with identified specimens mainly in Canadian collections. The arrangement of the species and classification follows that used by Bousquet et al. (2013).

We use the term 'adventive species' for those that arrived in Canada from other countries either through natural dispersal or through inadvertent or deliberate human action during the period since initial arrival of European colonists (Wheeler and Hoebeke 2009, 2017). We do not include coverage of native Canadian species transported to new provinces and territories within Canada. We also do not include arrival of native United States species into Canada.

Images. Images were taken using an image processing system (Nikon SMZ-U stereo-microscope with a ProgRes 3012 digital camera or Nikon SMZ1500 stereoscopic microscope fitted with a Nikon Digit-like camera DXM1200F) and compiled using Adobe Photoshop software.

Distribution. Each species is cited with its currently known distribution in Canada and the USA. Data for distribution maps were extracted from specimens in collections, from literature records and, in a few cases, from authoritatively identified images from the BugGuide website (www.bugguide.net). Geographic coordinates were standardized using NAD83 datum, and maps projected onto a Lambert Conic Conformal using ESRI ArcMap version 10 for Windows.

The following abbreviations are used in the text for Canadian jurisdictions:

AB - Alberta, BC - British Columbia, LB - Labrador, MB - Manitoba, NB New Brunswick, NF - Newfoundland (island), NS - Nova Scotia, NT - Northwest Territories, NU - Nunavut, ON - Ontario, PE - Prince Edward Island, QC - Quebec, SK - Saskatchewan, YT - Yukon Territory. USA state abbreviations follow those of the US Postal Service.

Collection codens. The following collections contained specimens of adventive Coleoptera from Canada used to plot distribution maps in Canada:

AAFC Agriculture and Agri-Food Canada, St. John's, Newfoundland and Labrador, Canada 
ACPE Agriculture and Agri-Food Canada, Charlottetown, Prince Edward Island, Canada

AFCF Atlantic Forestry Centre, Canadian Forest Service, Natural Resources Canada, Fredericton, New Brunswick, Canada

CBG Centre for Biodiversity Genomics, University of Guelph, Guelph, Ontario, Canada

CFIA Canadian Food Inspection Agency collection, Ottawa, Ontario, Canada

CNC Canadian National Collection of Insects, Arachnids and Nematodes, Ottawa, Ontario, Canada

DEBU University of Guelph Insect Collection, Guelph, Ontario, Canada

LEM Lyman Entomological Museum, Sainte-Anne-de-Bellevue, Quebec, Canada

LFC Laurentian Forestry Centre, Canadian Forest Service, Natural Resources Canada, Québec, Quebec, Canada

LRCC Agriculture and Agri-Food Canada, Lethbridge Research Station, Lethbridge, Alberta, Canada

NOFC Northern Forestry Centre, Canadian Forest Service, Natural Resources Canada, Edmonton, Alberta, Canada

NSAC Nova Scotia Agricultural College, Bible Hill, Nova Scotia, Canada

NSMC Nova Scotia Museum, Halifax, Nova Scotia, Canada

PFRC Pacific Forestry Centre, Canadian Forest Service, Natural Resources Canada, Victoria, British Columbia, Canada

RBCM Royal British Columbia Museum, Victoria, British Columbia, Canada

RSM Royal Saskatchewan Museum, Regina, Saskatchewan, Canada

RWC Reginald Webster Collection, Charters Settlement, New Brunswick, Canada

ULQ Université Laval, Quebec City, Quebec, Canada

Faunal composition of adventive Chrysomeloidea (number of species in brackets) 72 recorded species in 38 genera and 3 families:

CERAMBYCIDAE [10]: SPONDYLIDINAE [2]: Arhopalus (1), Tetropium (1); CERAMBYCINAE [5]: Callidium (1), Hylotrupes (1), Phymatodes (1), Poecilium (1), Trichoferus (1); LAMIINAE [3]: Anoplophora (1), Oberea (1), Tetrops (1). CHRYSOMELIDAE [61]: BRUCHINAE [8]: Acanthoscelides (1), Bruchidius (2), Bruchus (3), Callosobruchus (2); CRIOCERINAE [5]: Crioceris (2), Lilioceris (1), Lema (1), Oulema (1); CASSIDINAE [4]: Cassida (4); CHRYSOMELINAE [7]: Chrysolina (4), Gastrophysa (1), Phaedon (1), Plagiodera (1); GALERUCINAE [37]: Altica (1), Aphthona (5), Chaetocnema (2), Epitrix (1), Longitarsus (11), Lythraria (1), Mantura (1), Neocrepidodera (1), Phyllotreta (4), Psylliodes (5), Sphaeroderma (1), Neogalerucella (2), Pyrrhalta (1), Xanthogaleruca (1); MEGALOPODIDAE [1]: Zeugophora (1). 


\section{Discussion}

In Canada, the Chrysomeloidea includes four families and 978 valid species, which represent $11.8 \%$ of the documented national Coleoptera fauna (Brunke et al. 2019). All families except Orsodacnidae have non-native species that are certainly or likely established in Canada, including nine Cerambycidae, one Megalopodidae and 57 Chrysomelidae. There are five species treated herein for which there is no evidence of establishment in Canada, although specimens were collected in Canada or were intentionally introduced to the country as biocontrol agents. The cerambycid, Poecilium lividum (Rossi), was intercepted at a port in ON; the chrysomelid, Bruchus rufimanus (Boheman), is a pest of stored beans and does not appear to breed in Canada; and there are three chrysomelid species that were intentionally introduced to Canada for weed control but appear to be no longer established - Altica carduorum (Guérin-Méneville), Chrysolina varians (Schaller), and Lema cyanella (L.). These apparently non-established species were included in previously published checklists of species in Canada (e.g., Bousquet et al. 2013), but they should not be included in future Canadian faunal lists unless new evidence of establishment is found. Although the Asian longhorned beetle, Anoplophora glabripennis (Motschulsky), was putatively eradicated from Canada (NAPPO 2013), the presence of nearby established populations in NY and MA means that the species may yet again establish in Canada.

The 67 known species of non-native Chrysomeloidea that are certainly or likely established in Canada represents 6.9\% of the species richness of this superfamily (Brunke et al. 2019). This is slightly less than the proportion of Coleoptera species in Canada that is non-native, which is about $8.0 \%$ (Brunke et al. 2019). Within Chrysomeloidea, the Megalopodidae has the highest proportion of non-native species at $14.3 \%$, followed by the Chrysomelidae at $9.6 \%$ and the Cerambycidae at $2.4 \%$. All species feed on plant material.

The nine species of non-native Cerambycidae include Oberea erythrocephala (Schrank), that was introduced as a weed biocontrol agent, and Hylotrupes bajulus (L.), which breeds only in seasoned wood and wood products. The remaining seven species breed in trees, three in conifers and four in hardwoods. Two of these, the brown spruce 
longhorned beetle, T. fuscum, and A. glabripennis, have been the focus of expensive pest management programs. While $A$. glabripennis was putatively eradicated from the country, T. fuscum is still frequently encountered in eastern Canada (Bousquet et al. 2017).

Among the 61 species of established non-native Chrysomelidae are 14 species (including 10 species of Galerucinae) that were intentionally introduced as biocontrol agents of perennial weeds. Almost all species were released in Canada, either directly from populations collected in Europe or translocated from populations established in the USA. The one exception is Bruchidius villosus (Fabricius), which spread naturally to Canada from populations in the USA that were either accidentally introduced (northeastern USA) or intentionally introduced (Pacific Northwest) (Hooper 2002, Coombs et al. 2004, 2008). The non-native chrysomelid fauna of Canada also includes 16 species that are agricultural pests, either field pests of crops (12 spp.), stored beans (2), or both (2). Most pest species cause economically important damage and have wide distributions. Two other species, Lilioceris lilii (Scopoli) and Pyrrhalta viburni (Paykull), cause economic impacts as pests of ornamental plants (lilies) and shrubs (Viburnum), respectively. Most non-native Chrysomelidae (20 spp.) breed on native or non-native herbaceous plants. Only two species of chrysomelids and one megalopodid feed on trees and shrubs.

As is common for the non-native fauna of Canada, nearly all species originated in the Palaearctic, predominantly Europe, reflecting recent European colonization and trade patterns (Lindroth 1957). Of the 52 established chrysomeloid species which are not introduced biocontrol agents, 92\% are native to the Palaearctic. Only four species have non-Palaearctic origins, including the wood-boring A. glabripennis from Asia and three seed beetles (Coleoptera: Bruchinae): Callosobruchus chinensis (Linnaeus) from Asia, Acanthoscelides obtectus (Say) from the Neotropical Region, and Callosobruchus maculatus (Fabricius) from Africa. The latter three species, another seed beetle, Bruchus pisorum (Linnaeus), and the cerambycid pest of seasoned wood, Hylotrupes bajulus (Linnaeus), have been widely distributed by human activities and commerce for centuries and now have cosmopolitan distributions.

Among the 18 species intentionally introduced as biocontrol agents (15 established and three not), all have Palaearctic origins, and source populations were from Europe. These species were introduced to control primarily eight species of perennial weed species of Palaearctic origin: Scotch broom, Cytisus scoparius (L.) Link [one species established]; leafy spurge, Euphorbia esula L. [six established]; bladder campion, Silene vulgaris (Moench) Garcke [one established]; St. John's wort, Hypericum perforatum L. [two established and one not]; tansy ragwort, Jacobaea vulgaris Gaertn. [two established]; houndstongue, Cynoglossum officinale L. [one established]; purple loosestrife, Lythrum salicaria L. [two established]; and Canada thistle, Cirsium arvense (L.) Scop. [two species not established]. 
The highest species richness of non-native Chrysomeloidea (excluding biocontrol agents) in Canada is in ON (42), the Atlantic Provinces (40), and QC (39). This pattern is also typical for other groups of adventive beetles (Klimaszewski et al. 2012, $2013,2015,2017)$ and reflects the fact that these regions have the longest history of European colonization in Canada and were recipients of most European imported goods. Notably, the species richness of non-native chrysomeloids for BC (20) is lower than expected based on data for other beetle groups (Klimaszewski et al. 2012, 2013, $2015,2017)$, but it cannot be ascertained whether this is real or an artifact of inadequate sampling. The northern territories (4 species) and Labrador (1) have the fewest non-native species.

The distribution of biocontrol agents in Canada remains incompletely known. Although original release sites are well documented, and there was occasional resampling of these sites to determine the fate of introduced populations, the spread of agents from release sites is not well documented. Frequently data collected by provinces that can aid documentation of establishment and spread are not readily available, especially after the personnel involved in the biocontrol programs move on or retire.

It is probably impossible to precisely determine arrival dates of adventive species, especially for species introduced before the $20^{\text {th }}$ century when insect surveys and collecting in Canada were uncommon. The date of first detection of a species in Canada, based on collection records, may be decades or centuries after the time of introduction. For example, based on specimens in reference collections, the earliest Canadian record for Bruchus pisorum is from the late 1800s in Welland Co., ON. By 1909, the species appeared to be widespread in ON and QC and the first record from NS was in 1915. Until 2010, there were no records from NF. However, based on paleoentomological evidence gathered during the excavation of an old latrine in Ferryland in southeastern NF, the species was present in material from - 1620-1670 (Bain and Prévost 2010). In another example, the earliest accessioned specimen of Phyllotreta striolata (Fabricius) from Canada is from London, $\mathrm{ON}$ in 1899 , but the species was known to be widespread from $\mathrm{MB}$ to $\mathrm{QC}$ by the early $20^{\text {th }}$ century suggesting a date of introduction much earlier than 1899. Based on paleontological samples, the species was recently discovered to be present in Quebec City, QC by 1759 (Bain et al. 2009).

Three species were documented from Canada prior to 1850, and from 1850-1899, five species were first collected (average rate of 2.5 species per 25 years). From 19001949, 25 species were first collected (12.5 per 25 years), but this much higher rate of discovery is likely due mostly to greatly increased insect survey and collection effort in the 20th century rather than due to a much increased rate of new introductions. During the second half of the $20^{\text {th }}$ century, 13 non-native species were newly collected (6.5 per 25 years), and to date in the $21^{\text {st }}$ century six species have been newly collected.

The site of first collection of an adventive species cannot be assumed to be the site of the first establishment, and this is especially true for species that represent old intro- 
ductions but were not first documented until decades or centuries after establishment. Some species were likely introduced on more than one occasion, especially those associated with synanthropic habitats and human-shipped goods. Nevertheless, for species that were directly introduced to Canada from sites in their native range, it is predicted that the most frequent points of entry and establishment are ports on the east coast and along the St. Lawrence River and Great Lakes, as well as at the major ports on the west coast (Vancouver, Victoria). For species that were first introduced into the USA, and then spread across the border into Canada by their own dispersal powers or by means of human transport, we expect points of first detection predominantly in southern parts of eastern Canada and southwestern British Columbia. The data fit these predictions for the 47 adventive species for which the site of first detection is known; sites of earliest detection were most common in the vicinity of Lake Ontario (11 spp.), along the St. Lawrence River, especially in and around Montreal, QC (7 spp.) and Quebec City (3 spp.), and in close proximity to the USA border in southern Ontario and Quebec (8 spp.). Other sites include Halifax, NS (2 spp.) St. John's, NF (2 spp.), and along the Ottawa River, including Ottawa, ON (2 spp.). In BC, only two species were first detected at ports in the lower mainland and one species in southern Vancouver Island; this is remarkably low compared to other groups of adventive beetles (Klimaszewski et al. 2012, 2013, 2015, 2017).

Results presented here indicate that non-native chrysomeloid beetles have been arriving in Canada since early arrival of Europeans. Continued discovery of new non-native species in Canada suggest that new introductions have continued into recent decades. It is perhaps too early to fully estimate the effectiveness of North American plant protection organizations' efforts to reduce accidental establishments of new non-native Chrysomeloidea in Canada and neighbouring countries. 


\title{
List of recorded adventive species in Canada
}

\author{
Family CERAMBYCIDAE Latreille
}

Subfamily SPONDYLIDINAE Audinet-Serville

Arhopalus rusticus (Linnaeus)

Tetropium fuscum (Fabricius)

Subfamily CERAMBYCINAE Latreille

Tribe Callidiini Kirby

Callidium violaceum (Linnaeus)

Phymatodes testaceus (Linnaeus)

Poecilium lividum (Rossi)

Tribe Hylotrupini Zagajkevich

Hylotrupes bajulus (Linnaeus)

Tribe Hesperophanini Mulsant

Trichoferus campestris (Faldermann)

Subfamily LAMIINAE Latreille

Tribe Monochamini Thomson

Anoplophora glabripennis (Motschulsky)

Tribe Tetropini Portevin

Tetrops praeustus (Linnaeus)

Tribe Obereini Thomson

Oberea erythrocephala (Schrank)

\section{Family CHRYSOMELIDAE Latreille}

Subfamily BRUCHINAE Latreille

Tribe Bruchini Latreille

Acanthoscelides obtectus (Say)

Bruchidius cisti (Fabricius)

Bruchidius villosus (Fabricius) 
Bruchus brachialis Fåhraeus

Bruchus pisorum (Linnaeus)

Bruchus rufimanus (Boheman)

Callosobruchus chinensis (Linnaeus)

Callosobruchus maculatus (Fabricius)

Subfamily CRIOCERINAE Latreille

Tribe Criocerini Latreille

Crioceris asparagi (Linnaeus)

Crioceris duodecimpunctata (Linnaeus)

Lilioceris lilii (Scopoli)

Tribe Lemini Gyllenhal

Lema cyanella (Linnaeus)

Oulema melanopus (Linnaeus)

Subfamily CASSIDINAE Gyllenhal

Tribe Cassidini Gyllenhal

Cassida (Cassida) rubiginosa O.F. Müller

Cassida (Mionycha) azurea Fabricius

Cassida (Mionycha) flaveola Thunberg

Cassida (Odontionycha) viridis Linnaeus

Subfamily CHRYSOMELINAE Latreille

Tribe Chrysomelini Latreille

Chrysolina (C.) staphylaea staphylaea (Linnaeus)

Chrysolina (Hypericia) hyperici hyperici (Forster)

Chrysolina (Hypericia) quadrigemina (Suffrian)

Chrysolina (Sphaeromela) varians (Schaller)

Gastrophysa polygoni (Linnaeus)

Phaedon laevigatus (Duftschmid)

Plagiodera versicolora (Laicharting)

Subfamily GALERUCINAE Latreille

Tribe Alticini Newman

Altica carduorum (Guérin-Méneville)

Aphthona cyparissiae (Koch)

Aphthona czwalinae Weise

Aphthona flava Guillebeau

Aphthona lacertosa Rosenhauer

Aphthona nigriscutis Foudras

Chaetocnema concinna (Marsham)

Chaetocnema hortensis (Geoffroy)

Epitrix pubescens (Koch)

Longitarsus ferrugineus (Foudras) 
Longitarsus flavicornis (Stephens)

Longitarsus ganglbaueri Heikertinger

Longitarsus jacobaeae Waterhouse

Longitarsus lewisii Baly

Longitarsus luridus (Scopoli)

Longitarsus pellucidus (Foudras)

Longitarsus pratensis (Panzer)

Longitarsus quadriguttatus (Pontoppidan)

Longitarsus rubiginosus (Foudras)

Longitarsus succineus (Foudras)

Lythraria salicariae (Paykull)

Mantura chrysanthemi (Koch)

Neocrepidodera ferruginea (Scopoli)

Phyllotreta armoraciae (Koch)

Phyllotreta cruciferae (Goeze)

Phyllotreta punctulata (Marsham)

Phyllotreta striolata (Fabricius)

Psylliodes affinis (Paykull)

Psylliodes chrysocephalus (Linnaeus)

Psylliodes cucullatus (Illiger)

Psylliodes napi (Fabricius)

Psylliodes picinus (Marsham)

Sphaeroderma testaceum (Fabricius)

Tribe Galerucini Latreille

Neogalerucella calmariensis (Linnaeus)

Neogalerucella pusilla (Duftschmid)

Pyrrhalta viburni (Paykull)

Xanthogaleruca luteola (O.F. Müller)

\section{Family MEGALOPODIDAE Latreille}

Zeugophora scutellaris Suffrian 


\section{Taxonomic review}

Family CERAMBYCIDAE Latreille [longhorned beetles]

Diagnosis. Body form usually elongate and cylindrical but sometimes flattened and wide, with broad shoulders, brown, black, or brightly coloured with or without spots or of a complex pattern, pubescent or subglabrous; head variable in form, long, from prognathous with strongly projecting mandibles to hypognathous; antennae long, at least half as long as body (often longer than body), filiform, most with eleven antennomeres, antennal insertions exposed and often on tubercles or swellings in emarginations of eyes (between eyes and mandibles in the Prioninae, and Spondylidinae, or between eyes in the Cerambycinae and Lamiinae), antennae capable of being flexed backwards against body; pronotum variable in shape, cylindrical or flattened, with borders margined at least basally (Prioninae), or completely absent; elytra entire, sometimes very short exposing part or all of abdomen; abdomen usually with five ventrites (rarely six); procoxae from globular to wider than long, their cavities open or closed.

Subfamily SPONDYLIDINAE Audinet-Serville

Tribe Asemini Thomson

1. Arhopalus rusticus (Linnaeus)

(Fig. 1, Map 1)

Diagnosis. [adapted from Bily and Mehl 1989] Body length 10-28 mm, robust; integument brown to red-brown, with very short, gray pubescence; head wider than long with a median groove; antennae slender, reaching middle of elytra in female and longer in male, antennomere 2 less than twice as long as apical width; pronotum slightly wider than long, flattened, with faint median groove and two shallow depressions; 
elytra subparallel, slightly flattened, each elytron with small sutural spine and 2 or 3 indistinct carinae; tarsomere 3 of hind leg deeply incised, almost divided to the base.

Native range. Palearctic: central and northern Europe, Siberia, Mongolia, Japan, Korea, north China, and North Africa (Grilli and Fachinetti 2018); adventive in Canada and the USA (Bousquet et al. 2017). This species was inadvertently introduced into Australia, New Zealand, and Argentina (Wang and Leschen 2003, Grilli and Fachinetti 2018).

Distribution in Canada. ON (Bousquet et al. 2017).

Distribution in USA. "Northeastern USA" (Bousquet et al. 2017; Serge Laplante, personal communication).

First Canadian records. Windsor, ON in 2005 (Bousquet et al. 2017).

First North American records. As above.

Habitat and host data. This species is found mostly on Pinus (Özdikmen 2013, Grilli and Fachinetti 2017, 2018), mainly on Scots pine (P. sylvestris L.), but it also develops in other genera of trees in the families Pinaceae (Picea, Abies, Larix) and Cupressaceae (Cupressus, Cryptomeria, Juniperus) (Wang and Leschen 2003). Larvae infest roots and the base of stems of healthy, stressed, or recently dead trees, and occasionally damage structural timbers (Özdikmen 2013, Grilli and Fachinetti 2017). Arhopalus rusticus is considered a quarantine pest by some countries, and its presence can restrict trade of wood products (Grilli and Fachinetti 2018).

Comments. Arhopalus rusticus is native to the boreal region and coniferous forests of Eurasia. Historically, "A. rusticus” in North America was comprised of four subspecies: rusticus hesperus Chemsak and Linsley, rusticus montanus (LeConte), rusticus nubilus (LeConte), and rusticus obsoletus (Randall) (Linsley 1962, Chemsak 1996, Bezark and Monne 2013). These subspecies have since been elevated to species rank (Bousquet et al. 2017). Previously published records of " $A$. rusticus" in the North American literature refer either to $A$. obsoletus, $A$. nubilus, $A$. montanus, or $A$. hesperus (Bousquet et al. 2017). All pre-2017 eastern North American records refer to $A$. obsoletus (boreal eastern North America west to Oklahoma, south to Guatemala) and A. nubilus (southeastern USA) (Chemsak 1996). 
2. Tetropium fuscum (Fabricius) [brown spruce longhorn beetle] (Fig. 2, Map 1)

Diagnosis. [adapted from Cherepanov 1988] Body length 9-13 mm; integument black, elytra yellow-brown with a broad, velvety, pale, transverse band at base, antennae rust or red-brown, pronotum black, legs yellow-brown, femora usually darker; head between antennae with short deep longitudinal suture, dense punctation, and long pale setae; pronotum broadened anteriorly to middle, narrowing posterad, not longer than wide (female) or slightly longer (male); elytra elongate, parallel, with two longitudinal ridges on disc extending from base almost to broadly rounded apex, with dense punctation and short black or dark brown setae.

Native range. Palearctic: Europe, Asia, western Siberia (Löbl and Smetana 2010); adventive in Canada (Smith and Hurley 2000, Bousquet et al. 2017).

Distribution in Canada. NB, NS (Bousquet et al. 2017; Jon Sweeney, personal communication).

Distribution in USA. No records.

First Canadian records. Halifax, NS in 1990 (Smith and Hurley 2000); Calhoun, NB in 2017 (CFIA; Jon Sweeney, personal communication). The distribution map for this species included in Bousquet et al. (2017) shows two records for NB, and these represent putative records for Sunbury Co. in 2001 and Tracy in 2010 (source: AFCF database). Upon subsequent investigation in 2019, these records were proven incorrect. One beetle was trapped in Kouchibouguac National Park, NB in 2011, and another in 2014, as well as one beetle trapped at Memramcook, NB in 2014, but intensive follow-up surveys revealed no breeding population at either locality (CFIA 2012, 2015). Thus, the earliest record of an established population in NB is from Calhoun. Subsequent management at the Calhoun site included regulation and host removal followed by intensive trapping. There were no detections in 2019, but it is possible that the species is still established there (Ron Neville, personal communication).

First North American records. As above.

Habitat and host data. This species breeds in live spruce trees of low vigor, especially white spruce (Picea glauca (Moench) Voss) and red spruce (Picea rubens Sarg.), and in fresh windfelled or cut trees (Jacobs et al. 2003, Klimaszewski et al. 2010, Bousquet et al. 2017). In Europe, it attacks primarily Norway spruce (Picea abies (L.) Karst.) (Natural Resources Canada 2015). 


\section{Subfamily CERAMBYCINAE Latreille}

\section{Tribe Callidiini Kirby}

3. Callidium violaceum (Linnaeus) [violet tanbark beetle] (Fig. 3, Map 3)

Diagnosis. [adapted from Bily and Mehl 1989] Body length 8-16 mm, flattened, sides subparallel; body metallic violet, rarely black, blue or purple-violet, sometimes legs redbrown; head, pronotum and body venter with long, semierect, brown pubescence and sparse, erect setae; pronotum about twice as wide as long, with very rugose sculpturing consisting of large and very dense, coarse punctures; elytra subparallel, slightly flattened, each elytron rounded apically, with very slight sutural spine; femora swollen.

Native range. Palearctic: widely distributed from Europe to Japan (Löbl and Smetana 2010); adventive in Canada and the USA (Bousquet et al. 2017).

Distribution in Canada. NB, NF, NS, ON, PE, QC (Bousquet et al. 2017).

Distribution in USA. MA, ME, MO, NH, NJ, NY, OH, PA (MacRae 1994, Maier 2009, Klimaszewski et al. 2010, online images at www.bugguide.net).

First Canadian records. Ottawa, ON before 1884 (Harrington 1884b, as the synonym Callidium janthinum LeConte); St-Jean, QC in 1904 (Chagnon 1905, as C. janthinum); St. John's, NF in 1919 (RBCM); Grays Mills, NB in 1921 (AFCF); Kentville, NS in 1923 (LRCC); and Murray Harbour, PE in 1953 (ACPE). There is a published record from BC before 1907 (cited as C. janthinum) (Harvey 1907) but there has been no subsequent record from the province and it is not considered to be established there.

First North American records. New York, NY before 1850 (LeConte 1850, as C. janthinum).

Habitat and host data. Pinus, Larix, and Picea are preferred hosts (Yanega 1996). Larvae feed under bark of dry, seasoned wood, especially posts, and occasionally in standing recently dead trees (Bily and Mehl 1989).

Comments. While some (e.g., Langor et al. 2009, Maier 2009, Klimaszewski et al. 2010, Bousquet et al. 2017) consider C. violaceum native to the Palearctic and adventive in North America (northeast USA and adjacent Canada), others (e.g., McCorquodale 2010) have treated it as a naturally occurring Holarctic species. 
4. Phymatodes testaceus (Linnaeus) [tanbark beetle] (Fig. 4, Map 4)

Diagnosis. [adapted from Downie and Arnett 1996] Body length 8-17 mm; pale redbrown to dark brown with elytra and legs and antennae paler or dark brown with thorax and legs red-brown and elytra blue; pronotum rounded, disc finely and sparsely punctate with indistinct median and lateral callosities; elytra finely but not closely punctate.

Among all North American Phymatodes, and in spite of its highly variable color, P. testaceus is distinguishable by the long metatarsomere 1 , which is longer than the remaining tarsomeres combined (Swift and Ray 2010).

Native range. Palearctic: Europe and northern Africa to the Caucasus and Central Asia (Löbl and Smetana 2010); adventive in Canada and the USA (Bousquet et al. 2017).

Distribution in Canada. BC, NB, NS, ON, QC (Bousquet et al. 2017).

Distribution in USA. CA, FL, IA, IN, MA, MD, ME, MI, MN, NC, NH, NJ, NY, OH, OR, PA, TN, WA, WI (Linsley 1964, Cope 1984, Downie and Arnett 1996, LaBonte et al. 2005, Klimaszewski et al. 2010, Klingeman et al. 2017).

First Canadian records. Hemmingford, QC in 1916 (ULQ); St. Davids, ON in 1921 (DEBU); Petite Rivière, NS in 1957 (NSMC); Vancouver Island [unspecified locality], BC before 1899 (Harrington 1899, Hatch 1971, cited as the synonym Phymatodes variabilis (L.)). The earliest record from BC supported by a known accessioned specimen is from Richmond in 1997 (PFRC).

First North American records. Eastern USA before 1845 (Haldeman, 1847, cited as P. variabilis and var. ventralis).

Habitat and host data. Adults are usually found on dead trees, woodpiles, and firewood (Bousquet et al. 2017). Larvae are found in and under the bark of hardwoods, including Quercus (preferred), Carya, and Malus, and occasionally of conifers (Yanega 1996, Bousquet et al. 2017).

Comments. While some (e.g., Langor et al. 2009, Maier 2009, Klimaszewski et al. 2010, Bousquet et al. 2017) consider P. testaceus native to the Palearctic Region and adventive in North America (eastern USA and BC), others (e.g., McCorquodale and Bondrup-Nielsen 2004, McCorquodale 2010) have treated it as a naturally occurring Holarctic species. 


\section{Poecilium lividum (Rossi)}

(Fig. 5)

Diagnosis. [adapted from Bense 1995] Body length 5-10 mm; head usually black, pronotum yellow-brown to red-brown, on most specimens with dark edges, and occasionally uniformly yellow to black, elytra uniformly shining blue-black, legs brown or yellow-brown; pronotal edges with wrinkled punctation; elytra elongate with short setae, at most with a few erect setae at base.

Most similar in appearance to Phymatodes testaceus, but differs by having tarsomere 1 equal in length to 2 and 3 combined, by the densely and coarsely punctate elytra, and by the dark lateral markings on the pronotum (Swift and Ray 2010).

Native range. Western Palearctic: Europe, the Caucasus, North Africa (Algeria), Middle East (Israel, Lebanon and Syria) and Asian Turkey (Löbl and Smetana 2010, Özdikmen 2016); mostly Mediterranean (Cebeci et al. 2011); adventive in Canada and the USA (Swift and Ray 2010, cited as Phymatodes lividus).

Distribution in Canada. Found in "hoops of wine cask" at Ottawa, ON (Harrington 1884a, Hamilton 1894; cited as Phymatodes thoracicus Mulsant). Undated vouchers of this material are in the CNC. This sole Canadian record is from imported goods, and the species is not known to be established in Canada. The species is included herein because it is established in adjacent parts of the northeastern USA and may eventually spread to Canada.

Distribution in USA. MA, NY, PA, VA where it has been established for decades in many widespread localities (Swift and Ray 2010).

First Canadian records. Ottawa, ON before 1884 (Harrington 1884a).

First North American records. "Middle States" before 1894 (Hamilton 1894, cited as Phymatodes lividus).

Habitat and host data. This species is found mostly on broadleaf trees, especially Quercus and Castanea, but also on Fagus, Ulmus, and Salix. Larvae feed in dry twigs and branches (Bense 1995, Sama et al. 2011). 
Tribe Hylotrupini Zagajkevich

6. Hylotrupes bajulus (Linnaeus) [old house borer] (Fig. 6, Map 2)

Diagnosis. [adapted from Linsley 1964] Body length 8-20 mm; integument black or brown-black, rarely brown, antennae dark red-brown; pubescence pale, long, erect, dense on thorax and femora, short on elytra, with patches of appressed pubescence; head densely and moderately, coarsely punctate; pronotum wider than long, very coarsely and densely punctate at sides, disc more finely and sparsely punctate, with three prominent polished, impunctate longitudinal calli; elytra parallel-sided, finely and sparsely punctate at the base, rugose over apical two-thirds, with a pair of finely, densely punctate foveae on each side at basal one-third, foveae densely covered with appressed pale pubescence; legs with femora clavate; abdomen glossy, finely and sparsely punctate.

Native range. Palearctic: widespread across Europe and northern Africa to Siberia (Löbl and Smetana 2010); adventive in Canada and the USA (Bousquet et al. 2017). It has been inadvertently introduced and established in many other countries including Australia, New Zealand, South Africa, and parts of South America (Robinson 2005).

Distribution in Canada. QC (Bousquet et al. 2017).

Distribution in USA. DC, FL, GA, IL, IN, KS, LA, MD, MI, MN, MS, NJ, NY, OH, PA, RI, TN, TX, VA (Linsley 1964, Downie and Arnett 1996, Bousquet et al. 2017, Klingeman et al. 2017).

First Canadian records. Sherbrooke, QC in 1917 (Chagnon 1917; verified by Laplante 1989).

First North American records. PA [unspecified locality] before 1806 (F.V. Melsheimer 1806, cited as Callidium bajulum).

Habitat and host data. In the USA, it has been found in seasoned coniferous lumber (structural wood) stored outdoors, but not in natural habitats (Robinson 2005). In western Europe and South Africa (adventive), it is found in tree stumps and dead branches, and outside Eurasia it is found almost always in seasoned wood in buildings (Robinson 2005). 


\section{Tribe Hesperophanini Mulsant}

7. Trichoferus campestris (Faldermann) [velvet longhorned beetle] (Fig. 7, Map 5)

Diagnosis. [adapted from Lee and Lee 2018] Body length 10-19 mm; entire body brown with dense pale yellow pubescence; frons without any tubercles; pronotum regularly punctured, spherical, slightly wider than long, edge somewhat uneven; elytra longer than wide, almost parallel-sided, with conjointly rounded apex, scutellum semicircular, densely setose with pale yellow pubescence; distal one-third of femora weakly swollen.

Native range. Palearctic: southeastern Armenia and southeastern European Russia to Russian Far East and China, Korean peninsula, and Japan (Löbl and Smetana 2010); adventive in Canada and the USA (Grebennikov et al. 2010, Bousquet et al. 2017).

Distribution in Canada. ON, QC (Bousquet et al. 2017).

Distribution in USA. CO, IL, NJ, NY, OH, PA, WI, UT (Burfitt et al. 2015, Maier 2017, Pfister and Valdez 2017, CERIS 2019, Cowan and Wang 2019).

First Canadian records. Repentigny (near Montreal), QC in 2002 (Grebennikov et al. 2010); Mississauga, ON in 2010 (Bullas-Appleton et al. 2014).

First North American records. New Brunswick, NJ in 1997 (Cocquempot 2006, Grebennikov et al. 2010); Torrington, CT in 2002 (adults found in boxes of antique willow-woven baskets originating from China; Maier 2017).

Habitat and host data. In its native range, this species is found in forests and orchards on both living trees (fruit trees, particularly wild and cultivated apples and mulberries) and dead dry wood from many different host species, including Betula, Fagus, Juglans, Gleditsia, Malus (preferred), Morus (preferred), Salix, Robinia, Zelkova, Picea, and Pinus.

Comments. Many records of T. campestris in North America are based on port interceptions (44 interceptions at 13 ports) in wood packing materials and domestic detections (Pfister and Valdez 2017). Among the domestic detections and inland interceptions, most specimens were captured in traps near residential and commercial sites, with evidence for established populations in IL and UT (Pfister and Valdez 2017). It is also considered established in CO, NJ, NY, OH, PA, and WI (Cowan and Wang 2019) and in Montreal, QC (Bousquet et al. 2017). In UT, reproducing populations 
were found established in four counties since 2013, infesting live cherry and peach trees in fruit orchards (Watson et al. 2016, Pfister and Valdez 2017).

Subfamily LAMIINAE Latreille

Tribe Monochamini Thomson

8. Anoplophora glabripennis (Motschulsky) [Asian longhorned beetle] (Fig. 8)

Diagnosis. [adapted from Lingafelter and Hoebeke 2002] Body length 19-39 mm; head mostly glabrous, black, with short fine setae around genae and eye edges; antennae 2.5 times body length in males; 1.3 times body length in females, antennomeres variably annulate in pale blue or white at basal one-third to one-half, annulations becoming more conspicuous on distal antennomeres; pronotum black, glabrous with inconspicuous coating of fine, appressed setae at posterior of lateral pronotal spine and ventrally; elytra black, either with glossy or matte surface, weak iridescent copper, blue, or violet sheen, each elytron with 10-20 irregularly-sized and distributed patches of white; legs black with iridescent white to pale blue pubescence on tarsomeres 1-3 and tibiae, tarsi with iridescent blue pubescence dorsally in fresh specimens, white and weakly iridescent in older or worn specimens; abdomen black with short-fine pale appressed setae.

Native range. East Asia: broadly distributed in China, north to the Beijing region, west through Gansu Province, and south into Sichuan Province, throughout Korean peninsula and in Russian Far East (Lingafelter and Hoebeke 2002, Löbl and Smetana 2010); adventive in Canada and the USA (Bousquet et al. 2017).

Distribution in Canada. ON. It was first identified as an international trade interception from specimens taken from packing crates shipped to a industry in Waterloo, $\mathrm{ON}$ in June 1998. Populations were established outdoors in northwest Toronto and Vaughan, ON by September 2003 (McCorquodale et al. 2007, Natural Resources Canada 2019). Following an apparently successful eradication campaign at these two places (NAPPO 2013), A. glabripennis was detected again near Pearson International Airport (Mississauga, ON) in December 2013. An eradication campaign with tree removal was initiated immediately, and no further specimens have been detected since initial tree removal (Mireille Marcotte, personal communication). If no further specimens are detected, the Canadian Food Inspection Agency could re-declare eradication by the spring of 2020 . 
Distribution in USA. Anoplophora glabripennis was accidentally introduced into the USA in the 1990s with a population discovered in Brooklyn (Greenpoint), New York City in August 1996. Populations have been declared fully eradicated from the five boroughs of New York City as of October 2019, but some populations still persist on Long Island (Anonymous 2019). There were subsequent detections in Chicago, IL in 1998 (now eradicated), in Jersey City and Carteret, NJ in 2002 and 2004, respectively (now eradicated), in Worcester, MA in 2008 (current restricted distribution), and in Clermont County, $\mathrm{OH}$ in 2011 (current restricted distribution).

First Canadian records. Toronto and Vaughan, ON in 2003; Mississauga, ON in 2013 (Turgeon et al. 2015).

First North American records. New York, NY in 1996; Chicago, IL in 1998 (Lingafelter and Hoebeke 2002).

Habitat and host data. In China, A. glabripennis infests primarily Acer, Populus, and Salix (Natural Resources Canada 2019). In North America, it was reported breeding in 18 deciduous hardwood tree species, including Acer, Aesculus, Betula, Fraxinus, Populus, Salix, Tilia, and Ulmus. Larvae bore into living trees of nearly any age and size (Lingafelter and Hoebeke 2002).

\section{Tribe Tetropini Portevin}

9. Tetrops praeustus (Linnaeus) [plum beetle]

(Fig. 9, Map 6)

Diagnosis. [adapted from Bily and Mehl 1989]. Body length 4-6 mm, parallel-sided, subcylindrical; body black with pale orange-brown, black-tipped bristly elytra, antennae brown-black to black; pronotal sides with short, dense, erect, white pubescence; elytra with outer apical angle rounded; legs bright red-brown, mid and hind femora brown-black.

Native range. Palearctic: widespread in Europe, Mediterranean region, North Africa, the Caucasus, and western Siberia (Löbl and Smetana 2010); adventive in Canada and the USA (Bily and Mehl 1989, Bousquet et al. 2017).

Distribution in Canada. NB, ON, QC (Bousquet et al. 2017). 
Distribution in USA. ME, NH, NY, VT, south at least to MA (McCabe and Huether 1986, Klimaszewski et al. 2010, Bousquet et al. 2017, online images at www.bugguide.net).

First Canadian records. Domaine de la Baie Missisquoi à St-Armand, QC in 1999 (Landry 2001); Milton, ON in 2001 (DEBU); Belleville, NB in 2005 (RWC).

First North American records. Colonie, NY in 1965 (Tim McCabe, personal communication); Albany (Pine Bush), NY in 1981 and 1982 (McCabe and Huether 1986); Augusta, ME in 2000 (Howden and Howden 2001).

Habitat and host data. Hosts in North America are unknown. In Europe, T. praeustus attacks many shrubs of the Rosaceae such as Crataegus, Prunus, Pyrus, and Rosa, but also other deciduous trees including Acer, Malus, Populus, and Quercus (Bily and Mehl 1989, Sama 2002, Bousquet et al. 2017). Larvae bore in dead twigs and branches.

\section{Tribe Obereini Thomson}

10. Oberea erythrocephala (Schrank) [leafy spurge stem boring beetle, red-headed leafy spurge stem borer]

(Fig. 10, Map 7)

Diagnosis. [adapted from Schroeder 1980] Body length 6.0-14.0 mm, narrow-bodied; generally dark gray (including pronotum) yet sometimes red-brown, legs yellow-orange, head red-brown, antennae black with dark brown pubescence, anterior and posterior edges of pronotum, scutellum, elytra, and sterna all black with gray pubescence, mesepisternum and metaepisternum covered with dense yellow-brown pubescence, first three abdominal ventrites with a large central black band (reduced in width from 1st to 3rd ventrites), part of 5th ventrite brown-black, venter with a few red-brown marks; head and pronotum densely punctate; pronotum wider than long, no pronotal calli; elytra very long (three times head and pronotum length combined), parallel-sided, densely and coarsely punctate.

Native range. Palearctic: central and southern Europe, central Asia, and southwest Siberia (Schroeder 1980, Löbl and Smetana 2010); introduced as a biocontrol agent to Canada and the USA (Bousquet et al. 2017).

Distribution in Canada. AB, MB, ON, QC, SK (Schroeder 1980, Bousquet et al. 2017; Rob Bourchier, personal communication). 
Distribution in USA. Although released in 15 states across the northern USA (19801986), established populations are apparently present only in CO, MN, MT, ND, NE, OR, SD, WI, and WY, but persist at very low numbers (Schroeder 1980, Rees et al. 1986, Nowierski and Pemberton 2002, online images at www.bugguide.net).

First Canadian records. This species was released at Cardston and Galt Island (near Medicine Hat), AB in 1979 and 1986 and eventually established (Bourchier et al. 2002), and in Windsor, ON in 1979 and Braeside, ON in 1982 where it also established (Bousquet et al. 2017). Releases were also made in SK in 1981 and 1990, and in MB in 1986-1987, but were reported as not established (Bourchier et al. 2002). However, in 2017, the species was found near Moose Jaw, SK and near Shilo, MB (these are not the original release sites) and appear to be established in those provinces (Rob Bourchier, personal communication). The presence of this biocontrol agent in Bristol Mines, QC as early as 2006 (Bousquet et al. 2017) probably represents natural spread from the release site at Braeside, $\mathrm{ON}(<6 \mathrm{~km}$ away) as there were no known releases in QC.

First North American records. As above. From 1988 to 1995 it was released in CO, IA, ID, MI, MN, MT, ND, NE, NH, NM, NV, NY, OR, RI, SD, UT, WA, WI, WY and established in nine states (see Distribution in USA section).

Habitat and host data. Oberea erythrocephala was approved for release in North America for the control of leafy spurge (Euphorbia esula L.), a Eurasian perennial weed that was introduced into North America in the $19^{\text {th }}$ century (Bourchier et al. 2002). Its host range is restricted to the subgenus Esula of the genus Euphorbia, and it appears to feed only on leafy spurge, cypress spurge (Euphorbia cyparissias L.) and a few other closely related Euphorbia spp. in its native Europe (Schroeder 1980).

Family CHRYSOMELIDAE Latreille, 1802 [leaf beetles]

Diagnosis (excluding Bruchinae).

Body form diverse, from oval to elongate and subparallel, cylindrical, convex or flattened; coloration and pubescence diverse, head short, oval convex or depressed, to elongate and cylindrical; antennae with 10-11 antennomeres, filiform, sometimes broadening apically, less than half as long as body in most species, insertions not on prominences; eyes entire in most species; procoxae round to wider than long, often prominent, their cavities open or closed, mesocoxae wider than long; legs with a 5-5-5 
tarsomere formula, tarsomere 4 minute and hidden at base of lobes of tarsomere 3 , and tarsomere 1 often enlarged in males; abdomen with five ventrites.

Diagnosis (Bruchinae).

Body compact, egg-shaped in dorsal view, broadening posterad; integument black or brown, often mottled or marked with patches of pale or brown pubescence; head prolonged into a short broad snout, closely applied to thorax in resting position, concealed from above; eyes shallowly to deeply emarginate at antennal insertions; antennae with 11 antennomeres, clubbed, serrate or pectinate; pronotum narrower than elytra; elytra short, exposing pygidium and separately rounded at apex, elytral disc with ten punctate striae; procoxae elongate, procoxal cavities partially closed behind; abdomen with five ventrites, first and fifth the longest.

Subfamily BRUCHINAE Latreille

Tribe Bruchini Latreille

\section{Acanthoscelides obtectus (Say) [bean weevil]}

(Fig. 11, Map 8)

Diagnosis. Body length 1.8-3.0 mm, oval; dorsum mostly with yellow-brown pubescence; integument of head, pronotum and elytra black except red-brown apices of elytra, pygidium and rest of abdomen and legs red-brown, basal four and last antennomeres red-brown, antennomere 5 usually red-brown basally and black apically, antennomeres 6-10 brown to black; eyes deeply emarginate in the middle; pronotum widest posterad, with rounded sides and convex disc, surface of disc coarsely and densely punctate, uniformly covered with pubescence; scutellum grooved mesally and emarginate posterad; elytral disc flattened with regular, narrow, impressed striae and irregularly punctate interstriae, surface covered with dense pubescence forming yellow-brown and brown pattern, usually on second interval one to two elongate spots of yellow setae contrastingly reflecting from the darker surrounding pubescence; hind femora swollen, on underside with one large spine followed by one to two small spines.

Native range. Probably of Neotropical origin (Mesoamerica or northern South America) (Hatch 1971, Alvarez et al. 2005, Oliveira et al. 2013); adventive in Canada and the USA (Bousquet et al. 2013); now a cosmopolitan pest of beans (Downie and Arnett 1996). 
Distribution in Canada. BC, MB, NB?, NF, NS, ON, PE?, QC, SK? (Kingsolver 2004, Klimaszewski et al. 2010, Majka and Langor 2011, Bousquet et al. 2013). Although Campbell et al. (1989) reported this species from PE and Beirne (1971) reported it from agricultural fields in NB and SK, we have not seen verified specimens from localities in these three jurisdictions so its presence there is uncertain.

Distribution in USA. AL, CA, CT, DC, DE, FL, GA, HI, IA, IL, IN, KS, LA, MA, MD, ME, MO, MS, NE, NH, NJ, NY, OH, OK, OR, PA, RI, SC, SD, TN, TX, VA (Klimaszewski et al. 2010).

First Canadian records. Chambly Bassin, QC in 1919 (CNC); Cornwall, ON in 1924 (Gibson 1924, as Mylabris obtectus); Langley, BC in 1930 (CNC); NS (undisclosed locality) in 1937 (McNay 1950, Majka and Langor 2011).

First North American records. This species was recognized in North America at least since its original description by Thomas Say in 1831 (type locality, USA: LA) (Say 1831). The first report of economic impacts of this species is from NY in 1860 (Essig 1929).

Habitat and host data. It is a pest of beans (particularly Phaseolus and Vigna) (Bousquet 1990), and is found in association with stored beans and also infests growing crops (Campbell et al. 1989).

Comments. The name Acanthoscelides obsoletus (Say) for many years was applied to the bean bruchid, $A$. obtectus (Say), an application that persisted until the 1960s, and even by the early 2000s it appears in the Old World literature as the name for that species (Kingsolver 2004). Confusion in the usage of these two names was discussed by Bottimer (1968) and Kingsolver (2004: 132). Acanthoscelides obtectus was described by Thomas Say (1831, in the genus Bruchus) from "Louisiana," but virtually all of the authorities we have consulted in the literature consider it an immigrant, cosmopolitan species, having been transported by man to most continents through the transport of the common bean. Bean shipments at the end of the $19^{\text {th }}$ century introduced this species to Europe (possibly from Mesoamerica) where it subsequently spread around the globe. Now, it is found in Europe, Asia, North and South America, Africa, Australia, and elsewhere, and is a major pest in bean storage facilities (Alvarez et al. 2005). 


\section{Bruchidius cisti (Fabricius)}

(Fig. 12, Map 12)

Diagnosis. Body length 2.3-3.0 mm, oval; dorsum with grey pubescence; integument black throughout; pronotum conical, sides weakly arcuate, surface of disc with large punctures separated by $0.2-0.3$ times puncture diameter; scutellum grooved mesally and emarginate posterad; base of elytra with one or two small tubercles, elytral disc slightly convex, with regular, narrow impressed striae and irregularly punctate interstriae; antennae of male longer than of female, apical antennomeres as long as or slightly longer than wide, hind femora on underside without spines, apex of hind tibiae surrounded by small spines, the innermost spine not longer than lateral spines.

Native range. Palearctic: Europe (Löbl and Smetana 2010); adventive in Canada and the USA (Kingsolver 2004, Bousquet et al. 2013).

Distribution in Canada. BC (Hatch 1971 - cited as the synonym Bruchidius unicolor (Olivier), Klimaszewski et al. 2010, Bousquet et al. 2013).

Distribution in USA. MT (Hewitt and Burleson 1976, Kingsolver 2004)

First Canadian records. Nicola, BC in 1922 (Bottimer 1968, Hatch 1971).

First North American records. As above.

Habitat and host data. Hosts plants include Cynoglossum, Onobrychis viciifolia Scop., and Spartium junceum L. (Kingsolver 2004).

Comments. Until recently, B. cisti was referred to in the primary literature as $B$. unicolor, a junior synonym of $B$. cisti. Interpretation of the usage of names was provided by Aldridge and Pope (1986).

\section{Bruchidius villosus (Fabricius)}

(Fig. 13, Map 9)

Diagnosis. Body length $2.0-3.5 \mathrm{~mm}$, oval; dorsum with greyish and sparse pubescence; whole body black including antennae and legs, only antennomeres $2-4$ partly red-brown; pronotum widest posterad, sides slightly rounded, surface of disc coarsely and densely punctate; scutellum grooved mesally and emarginate posterad; base of elytra without tubercles, elytral disc flattened, with regular, narrow, impressed striae and irregularly punc- 
tate interstriae; antennae not sexually dimorphic, apical antennomeres wider than long, hind femora swollen, on underside without or with minute spine, apex of hind tibiae surrounded by small spines, the innermost spine longer than lateral spines.

The egg stage is described by Frick (1962a), and Parnell (1964) has illustrated larvae, prepupa, and pupa.

Native range. Palearctic: Europe (Löbl and Smetana 2010); adventive in Canada and both adventive and introduced in the USA (Hooper 2002).

Distribution in Canada. BC, NB, NS, ON, QC (Majka and Langor 2011, Bousquet et al. 2013, Webster et al. 2016, online images at www.bugguide.net).

Distribution in USA. DE, FL, GA, IL, IN, MA, MD, MI, NC, NJ, NY, OR, PA, VA, WA (Bottimer 1968, Downie and Arnett 1996 (cited as Bruchidius ater Marsham, a synonym), Kingsolver 2004, Coombs et al. 2008, online images at www.bugguide.net).

First Canadian records. Orsainville, QC in 1967 (Chantal 1972, as B. ater); Victoria, BC in 2001 (Hooper 2002); Shelburne Co. (two localities), NS in 2003 (Majka and Langor 2011); Lambdon Co., ON in 2006 (DEBU). It has subsequently been collected from sites in $\mathrm{BC}$, and transferred to other sites in that province, particularly in the Kootenays, where populations became established (Anonymous 2018a).

First North American records. The species was presumably accidentally introduced into the eastern USA during the early 1900s (Coombs et al. 2008). It was reported in MA in 1918 (Olsen 1918). The population in NC was established as a result of release of specimens from the United Kingdom. Subsequently, NC specimens were introduced into OR in 1998 and in WA in 1999 where they became established (Coombs et al. 2004), and presumably spread to BC from there (Hooper 2002).

Habitat and host data. This species specializes on genistoid legumes, especially on Scotch broom, Cytisus scoparius (L.) Link., and North American hosts include a number of plants in the Fabaceae (Kingsolver 2004, Hoebeke et al. 2009). Common host plants in Europe include C. scoparius, Laburnum alpinum Presl, Laburnum anagyroides Medik, Petteria ramentacea (Sieber) Presl, Spartium junceum L., but several other host plants are recorded from Europe (Frick 1962b). Adults feed in flowers of C. scoparius (Kingsolver 2004).

Comments. Bruchidius villosus has appeared in the economic entomology literature under several names, including the junior synonym $B$. ater. Southgate (1963) incorrectly concluded that $B$. ater was the valid name, and others (including Bottimer 1968) followed this interpretation until recently. 


\section{Bruchus brachialis Fåhraeus [vetch bruchid]}

(Fig. 14 a, b, Map 10)

Diagnosis. Body length $2.0-3.5 \mathrm{~mm}$, oval; dorsum with mixed greyish, yellow-brown and brown pubescence, moderately dense on pronotum and denser on elytra, forming a pattern, most with pale patch anterad of scutellum, and marbled pattern on sides of elytra, pygidium uniformly pale pubescent; head, elytra, thorax, abdomen, mid and hind legs black, fore legs yellow, antennae in male uniformly yellow, female with somewhat darker antennomeres 5-10; pronotum wider than long, sides on posterior half almost parallel-sided then rounded, with small lateral spine near midlength, surface with large dense punctures forming net-like pattern; scutellum emarginate posterad; elytral disc flattened, with regular, narrow, impressed striae and irregularly punctate interstriae; antennae, fore and mid tibiae sexually dimorphic, in male antennomeres very broad, flattened, fore tibia thicker, mid tibia somewhat curved, apically on inner edge with thin, long lamella emarginate apically, in female antennomeres less broad and less flattened than in male, fore tibiae not thickened, mid tibia curved, without apical lamella; apex of hind tibiae in both sexes surrounded by small spines, the innermost spine not longer than lateral spine.

Bruchus brachialis may be readily distinguished from the other two adventive species of Bruchus (pisorum, rufimanus) now established in North America by its smaller size, pronotum much wider than long, greatly reduced pale pubescence, particularly on the elytra, and the coloration of the antennae (all antennomeres pale in male, but only basal antennomeres and terminal antennomere pale in the female). These three species may be distinguished from other North American Bruchinae by the emarginate side of the pronotum and by the small tooth before the emargination (Bridwell and Bottimer 1933). Descriptions of immature stages are available for the final instar larva (Pfaffenberger 1977), larva (Pfaffenberger 1991: 564), and egg (Kingsolver 2004).

Native range. Palearctic: Europe, Mediterranean area (Löbl and Smetana 2010); adventive in Canada and the USA (Kingsolver 2004, Bousquet et al. 2013).

Distribution in Canada. BC, ON, QC (Hatch 1971, Bousquet et al. 2013). In the CNC, there are two specimens with handwritten labels from: NS, Cecil, 23 April 1939, M. Robinson. This is the first and only apparent record of the species from NS. However, we cannot find a historical record of a place name or geographical feature called "Cecil" in NS. There was a Mark Robinson who lived in PA and collected beetles in Cecil, NJ in this time period, and we believe that these specimens are from there rather than from NS. 
Distribution in USA. AL, AR, CA, CO, CT, DC, DE, FL, GA, IA, ID, IN, KS, LA, MA, MD, MI, MO, MS, NC, NE, NJ, NY, OH, OK, OR, PA, SC, TN, TX, VA, WA, WY (Hatch 1971, USDA 1971, Kingsolver 2004).

First Canadian records. Westminster, $\mathrm{BC}$ in 1941, in seed from Oregon (CNC); from seed grown in Norfolk Co., ON in 1953 (CNC).

First North American records. The species was first detected in 1930 in NJ and in 1931 in DE, MD, NC, OR and WA (Bottimer 1931, Bridwell and Bottimer 1933, Downie 1950). It was also found in DC, MA, MD, and VA in 1932 (Bridwell and Bottimer 1933; CNC) and in OR in 1936 (Hatch 1971).

Habitat and host data. Hosts of this species include Fabaceae, and it breeds outdoors in some vetch species: Lathyrus sativus L., Vicia benghalensis L., Vicia caroliniana Walt., Vicia cracca L., Vicia grandiflora Scop., Vicia pannonica Crantz, Vicia sativa nigra Roots, Vicia sativa sativa L., Vicia sepium L., Vicia villosa dasycarpa Ten., and Vicia villosa villosa Roth (Hatch 1971, Kingsolver 2004). Waterworth (1986) listed several other host records of this species based on infestations of seeds imported from Europe. Adults have been found on Daucus carota L. flowers (Kingsolver 2004).

\section{Bruchus pisorum (Linnaeus) [pea weevil]}

(Fig. 15, Map 11)

Diagnosis. Body length 3.8-5.2 mm, oval; dorsum with mixed white, greyish, yellow-brown and brown pubescence, moderately dense on pronotum and elytra, forming a pattern, most with pale setal patch before scutellum, white narrow, elongate patch on third interval before the middle of elytra and transverse white patch posterolaterally (or series of circular patches), the white patches usually surrounded by brown patches, rest of elytral surface with marbled pattern of pale, brown and yellow-brown setae, pygidium with white dense pubescence and two large, brown, oval patches posterad; surface of head, elytra; thorax and abdomen black, fore legs with brown to black, femora and tibiae and tarsi red-brown, mid femora and tibiae mostly black usually with red-brown apices of tibiae, mid tarsi red-brown to brown, hind legs completely black, antennomeres 1-4 red-brown, 5-10 black, 11 mostly brown to black with red-brown apex; pronotum wider than long, sides on posterior half almost parallel then rounded, at midlength with lateral spine, surface of disc coarsely and densely punctate; scutellum grooved emarginate posterad; elytral disc flattened, with regular, narrow, impressed striae and irregularly 
finely punctate interstriae; antennae sexually dimorphic, in male slightly longer than in female; mid tibiae sexually dimorphic, in male strongly curved, apically on inner edge with spine, in female straight and without apical spine, apex of hind tibiae in both sexes surrounded by small spines, the innermost spine not longer than lateral spine.

Several descriptions are available for the larval stage (Riley 1892, Pfaffenberger 1977, 1991).

Native range. Palearctic: Europe (Löbl and Smetana 2010); adventive in Canada and the USA (Kingsolver 2004, Bousquet et al. 2013); cosmopolitan (Löbl and Smetana 2010).

Distribution in Canada. AB, BC, MB, NB, NF, NS, ON, PE?, QC, SK? (Bridwell and Bottimer 1933; McLeod 1962; Clausen 1978; Wendt 1986, Bousquet 1990; McNamara 1991; Kingsolver 2004; Klimaszewski et al. 2010, Majka and Langor 2011, Bousquet et al. 2013). Kingsolver (2004) reported this species from PE and SK without providing specific localities, and we have not yet seen specimens from localities in these two jurisdictions.

Distribution in USA. AL, CA, CO, CT, DC, FL, GA, ID, KS, KY, MA, MI, MN, MO, MS, MT, NC, NH, NJ, NM, NY, OR, PA, SC, SD, TX, UT, WA, WI (Kingsolver 2004, Klimaszewski et al. 2010).

First Canadian records. Ferryland, NF ca. 1622 (archeological excavation, Bain and Prévost 2010); Ridgeway, ON before 1900 (DEBU); Albanel, QC in 1909 (CNC); Dot (Railway Station), BC in 1926 (CNC); Lethbridge, AB in 1935 (CNC).

First North American records. As above. Massachusetts Bay Colony in the mid-1600s to 1675 (archaeological excavations: Bain and Prévost 2010); as early as 1748 in the eastern USA (Brindley et al. 1946); causing serious damage to garden peas in PA, NJ, and southern NY (Hatch 1971); OR in 1891 (Hatch 1971); and WA in 1893 (Hatch 1971).

Habitat and host data. This species is a pest of cultivated and stored peas (Fabaceae). Adults and larvae feed on the seeds of several pea species. The species is most destructive to the common varieties of Pisum sativum L. and adults usually emerge when peas are in storage. It does not, however, reinfest stored pea seeds because it must oviposit on green pods in the field. It has only one generation each year (Kingsolver 2004). Host plant records in the literature include Lathyrus sativus L., Pisum sativum arvense, Pisum elatius (L.), Vicia faba L., and Vigna radiata (L.) var. radiata Wilczek (Kingsolver 2004). It is unclear if the Vicia and Vigna records are valid; they may be the result of misidentifications of either the bruchine weevil or of the host plant (Kingsolver 2004), but probably the latter. 


\section{Bruchus rufimanus (Boheman) [broadbean weevil]}

(Fig. 16)

Diagnosis. Body length 3.2-4.6 mm, oval; dorsum with mixed white, greyish, yellow-brown and red-brown pubescence, dense on pronotum and elytra, forming a pattern, most with pale patch before scutellum, and two irregular pale bands one-third and two-thirds along length of elytral disc, rest of elytral surface with marbled pattern of pale, and dark setae, pygidium with dense pale pubescence and two small dark, oval patches posterad; integument of head, elytra, thorax and abdomen black, fore legs redbrown, middle legs in male usually completely black, in female usually black but often with red-brown tibial apices and tarsi, hind legs completely black, antennomeres 1-4 red-brown, 5-11 black; pronotum trapezoidal, at midlength with lateral spine, surface of disc with densely packed punctures of varying size; scutellum emarginate posterad; elytral disc flattened, with regular, narrow, impressed striae and irregularly finely punctate interstriae; antennae of male slightly longer than in female, middle femora and tibiae sexually dimorphic, in male femora thickened, tibiae strongly curved, apically on inner edge with spine, in female femora not thickened, tibiae straight and without apical spine, apex of hind tibiae in both sexes surrounded by small spines, the innermost spine longer than lateral spine.

Descriptions of immature stages were provided by Chittenden (1912a) and Pfaffenberger $(1977,1991)$.

Native range. Africa (Beenen and Roques 2010); adventive in Canada and the USA (Kingsolver 2004, Bousquet et al. 2013); cosmopolitan.

Distribution in Canada. It was collected on imported beans in BC, MB, ON, QC, SK (Kingsolver 2004, Klimaszewki et al. 2010, Bousquet et al. 2013), but B. rufimanus is probably not established in Canada (Campbell et al. 1989). Nonetheless, it is included here in the event that it is established but undetected or will become established in the future.

Distribution in USA. CA, HI, LA, NH, NJ (Johnson and Kingsolver 1982, Kingsolver 2004). It is likely that this species is established in the USA based on a record from CA (www.inaturalist.org/observations/153137)

First Canadian records. The earliest museum specimens are from Montreal, QC in 1921 (CNC); Winnipeg, MB in 1935 (CNC); Toronto, ON before 1960 (CNC). All records are from shipments of imported beans. 
First North American records. Reported as established in 1909 in CA (San Luis Obispo) and probably present not later than 1888 due to reported history of damage to stored Vicia beans (Campbell 1920).

Habitat and host data. The species is a pest of stored broad beans, Vicia faba L. and Vicia sativa L. in the USA. Twenty other legumes have been reported as hosts in the Old World, but many of these records are questionable (Kingsolver 2004).

17. Callosobruchus chinensis (Linnaeus) [lesser cowpea weevil, adzuki bean bruchid, Chinese bruchid, mung-bean bruchid]

(Fig. 17, Map 12)

Diagnosis. Body length 2.4-3.0 mm, oval; dorsum with mixed white, yellow-brown and brown pubescence, dense on pronotum and elytra, forming a pattern, most with pale pronotal patch before scutellum, two large brown patches laterally at midlength of elytral disc surrounded by pale setae always forming elongate patch before half length of second interval, and large brown patches at apex of elytra, anterior half of elytral disc mostly with yellow-brown setae but often humeral area with darker patch, pygidium with dense white pubescence, with two darker patches posterad in some; integument of surface of head and pronotum red-brown to brown, surface of elytra red-brown or brown with broad diffuse paler areas, thorax and abdomen mostly red-brown to dark brown, but surface colour and setae vary and so specimens vary from strongly contrasting to nearly uniform, legs red-brown, antennae uniformly red-brown or darker apically; pronotum flared posterad, without lateral spines, surface of pronotal disc covered with nearly overlapping shallow punctures of greatly variable size; scutellum emarginate posterad; elytral disc flattened, with regular, narrow, impressed striae and irregularly finely punctate interstriae; antennae in male strongly serrate to pectinate from fourth antennomere, in female not serrate or pectinate; legs not sexually dimorphic, femora with large ventral tooth on anterior and posterior sides, apex of hind tibiae in both sexes surrounded by small spines, the innermost spine longer than lateral spine.

Native range. Palearctic: China, Korea, Japan, Taiwan (Beenen and Roques 2010, Löbl and Smetana 2010); adventive in Canada and the USA (Kingsolver 2004, Bousquet et al. 2013); cosmopolitan throughout tropical and subtropical regions (Kingsolver 2004).

Distribution in Canada. MB, NS, ON, QC (Majka and Langor 2011) New collection records: MB: Brandon, 28.XII.1940, D.S. Smith (CNC); Fort Garry, August 16, 1939, J.M. Linrock (CNC); ON: Kitchener, 18.V.1993, indoors (DEBU). It is unknown whether the species breeds in stored peas in all of these provinces or whether some or all 
of these records represent interception records. Although records are mapped, this should not be interpreted as necessarily representing established populations.

Distribution in USA. AL, CA, DC, FL, GA, HI, LA, MD, MS, NH, NY, OH, PA, SC, VA, WA (Hatch 1971, Kingsolver 2004, Majka and Langor 2011).

First Canadian records. Fort Garry, MB in 1939 (CNC); Saskatoon, SK in 1969 (CNC); Halifax, NS in 1982 (NSMC; Majka and Langor 2011); Varennes, QC in 2007 (Claude Chantal, personal communication).

First North American records. New Orleans, LA, bred from beans at the Exposition in 1885 (Riley and Howard, 1893), but it is not clear if the beans were imported or domestic.

Habitat and host data. This species is a pest of stored products and does not occur in the wild in Canada (Campbell et al. 1989). Primary hosts in the Old World and New World are in the genera Phaseolus and Vigna (Fabaceae), but its host range is quite broad (Kingsolver 1979, 2004), including also chickpeas, lentils, green gram, broad beans, soybean, adzuki bean, and cowpeas. A full list of host plants can be found in Udayagiri and Wadhi (1989).

18. Callosobruchus maculatus (Fabricius) [southern cowpea weevil or cowpea seed beetle]

(Fig. 18, Map 13)

Diagnosis. Body length 2.4-3.2 mm, elongate oval; dorsum with mixed white, yellow-brown and brown pubescence, forming pattern, most with pale pronotal patch before scutellum, elongate pale patch at midlength of third interval, and white patch behind diffuse spots of dark integument laterally; integument elytra and abdomen mostly red-brown with sides of elytra and apices black, the black areas larger in female than in male, pygidium extends from beneath obliquely emarginate elytra, female pygidium with two black lateral bands of dark integument, unmarked in male, legs red-brown, antennae with basal four antennomeres red-brown, then black, but last antennomere usually partly red-brown; antennae sexually dimorphic, in male longer and serrate, in female shorter and not serrate; femora with large ventral tooth on anterior and posterior sides, apex of hind tibiae in both sexes surrounded by small spines, the innermost spine longer than lateral spine; two wing morphs known, flightless (short-winged) and flying (long-winged). 
Native range. Most likely originated in West Africa (Beenen and Roques 2010); adventive in Canada and the USA (Kingsolver 2004); cosmopolitan, recorded from Africa, Europe, Northern Asia excluding China, North and Central America, and Hawaii (Löbl and Smetana 2010).

Distribution in Canada. BC, NF, NS, ON, PE, QC, SK (Majka and Langor 2011). At least the records from $\mathrm{BC}$ and $\mathrm{QC}$ are interception records in imported beans. While this species likely does not breed in the wild in Canada, populations may be occasionally established in stores of dried legume seeds.

Distribution in USA. AK, AR, AZ, CA, DC, FL, GA, HI, IA, ID, KS, LA, MD, MO, MS, NC, NH, NM, NY, OH, OK, PA, SC, SD, TN, TX, VA (Kingsolver 2004, Majka and Langor 2011).

First Canadian records. Montreal, QC in 1924 (CNC); Saskatoon, SK in 1924 (CNC); Victoria, BC in 1958 (CNC); St. John's, NF in 1968 (AAFC; Majka and Langor 2011).

First North American records. Earliest records of Callosobruchus maculatus (cited as Bruchus quadrimaculatus Fabricius, a synonym) "date no farther back than in 1885, when this species was found at the first Atlanta Cotton Exposition where it was infesting "black-eyed table beans" from Texas" (Chittenden 1897:28).

Habitat and host data. This species is a pest of stored seeds of legumes (Fabaceae) including pigeon pea, chickpea, soybean, hyacinth bean, yellow pea, Spanish vetchling, blue sweet pea, lentil, tepary bean, lima bean, common bean, pea, broad bean, yellow vetch, common vetch, black bean, mung bean, and crowder pea (Chittenden 1912b, Kingsolver 2004).

Subfamily CRIOCERINAE Latreille

Tribe Criocerini Latreille

19. Crioceris asparagi (Linnaeus) [asparagus beetle]

(Fig. 19, Map 14)

Diagnosis. Body length 5.0-6.5 mm, elongate, elytra almost parallel-sided and at least two times as long as wide; head black often with metallic blue reflection, pronotum uniform red at centre with black pattern composed with three spots, varying to hav- 
ing center of pronotal disc black, elytra metallic blue with yellow or orange pattern, in the most common form pale areas forms humeral spot, vitta around elytral sides and transverse spots near sides at one-third to two-thirds length of elytra, lateral spots usually combined with lateral vitta, ventral surfaces and antennae black, legs of most black with red-brown base of tibiae, or nearly entire femora and tibiae red-brown; pronotum almost cylindrical, shallowly constricted posterad, sides almost parallel to slightly convex, surface of disc with sparse punctation, in forms with dark pattern of pronotum punctation on spots denser than punctation on red parts of disc; elytral disc with regular rows of punctures, interstriae smooth and glossy; tarsal claws fused at base.

Native range. Palearctic: Europe (Löbl and Smetana 2010); adventive in Canada and the USA (Clausen 1956, 1978, Beirne 1971, White 1993, Riley et al. 2003, LeSage et al. 2008).

Distribution in Canada. AB?, BC, MB?, NB, NS, ON, PE?, QC, SK? (LeSage et al. 2008, Klimaszewski et al. 2010, Bousquet et al. 2013). Although this species has been recorded from $\mathrm{AB}, \mathrm{MB}$ and SK by some (e.g., Bousquet et al. 2013), fieldwork and examination of the holdings of collections have failed to uncover any specimens of this species (Vincent Hervet, personal communication). It appears that this species does not occur in the Prairie Provinces or is very rare. As well, although recorded from PE (Bousquet et al. 2013), we have not seen specimens from there, and examination of asparagus plants there in 2019 did not reveal beetles (Vincent Hervet, personal communication), so we consider its presence in the province as questionable.

Distribution in USA. AL, AR, AZ, CA, CO, CT, DC, DE, GA, IA, ID, IL, IN, KY, MA, MD, ME, MI, MN, MO, MT, NC, NH, NJ, NM, NV, NY, OH, OK, OR, PA, RI, SC, TN, TX, UT, VA, VT, WA, WI, WV (Riley et al. 2003, Klimaszewski et al. 2010).

First Canadian records. Quebec City, QC before 1877 (Provancher 1877, LeSage et al. 2008); Queenston, ON in 1898 (Fletcher 1899); Vancouver, BC in 1933 (Hatch 1971); Truro, NS in 1950 (NSAC; LeSage et al. 2008).

First North American records. PA before 1806 (F.V. Melsheimer 1806); Albany, NY in 1856 (Fitch 1862); Astoria, Long Island, NY in 1859 (Fitch 1865, Chittenden 1917). Additional early records in the northwestern USA are cited in Hatch (1971).

Habitat and host data. Larvae and adults feed on Asparagus spp. (Liliaceae). Larvae feed on shoots in spring. In North America, it feeds exclusively on Asparagus officinalis L., but in Asia it feeds on several Asparagus species (White 1983). 
20. Crioceris duodecimpunctata (Linnaeus) [twelve-spotted asparagus beetle] (Fig. 20, Map 15)

Diagnosis. Body length 5.0-6.5 mm, elongate but stout, elytra almost parallel-sided, less than twice as long as wide; head and pronotum red, scutellum black, elytra orange to red-brown with 12 black, round or slightly wider than long spots spread over the disc, ventral surfaces bicolored with somewhat darker metaventrite and central part of anterior abdominal ventrites, antennae, trochanters and tarsi black, femora and tibiae red-brown with black apices; pronotum almost spherical, shallowly constricted posterad, surface of disc with fine and sparse punctation; elytral disc with regular rows of punctures, interstriae smooth and glossy; tarsal claws fused at base.

Native range. Palearctic: Europe (Löbl and Smetana 2010); adventive in Canada and the USA (White 1983, LeSage et al. 2008, Bousquet et al. 2013).

Distribution in Canada. AB, BC, MB, NB, NS, ON, PE, QC, SK (Riley et al. 2003, LeSage et al. 2008, Bousquet et al. 2013).

Distribution in USA. CA, CO, CT, DC, IA, ID, IL, IN, MA, MD, ME, MI, MN, MO, MT, NJ, NV, NY, OH, OR, PA, RI, SD, UT, VA, WA, WI, WV, WY (Riley et al. 2003, Klimaszewski et al. 2010).

First Canadian records. Queenston, ON in 1898 (Fletcher 1899); Winnipeg, MB in 1948 (CNC); Saskatoon, SK in 1949 (CNC); Truro, NS in 1950 (LeSage et al. 2008); Oliver and Osoyoos, BC in 1958 (CNC).

First North American records. Baltimore, MD in 1881 (Chittenden 1917, Hatch 1971); Buffalo, NY and Berrien County, MI before 1898 (Chittenden 1898). Additional early records in the northwestern USA are cited in Hatch (1971).

Habitat and host data. This species is the main pest of asparagus crops, Asparagus officinalis L. Larvae feed inside berries and adults on shoots and foliage (LeSage et al. 2008).

21. Lilioceris (Lilioceris) lilii (Scopoli) [scarlet lily beetle, lily leaf beetle] (Fig. 21, Map 16)

Diagnosis. Body length 6-8 mm, stout-bodied, elytra on posterior half almost parallel-sided then gradually rounded; head, scutellum, ventral surfaces, antennae and legs black, pronotum and elytra uniformly orange to red; head strongly constricted be- 
hind eyes; pronotum deeply constricted at midlength, mostly impunctate, with row of punctures along midline and a few punctures anterolaterally; elytral disc with regular rows of punctures, interstriae glossy; tarsal claws not fused at base.

Native range. Palearctic: northern Africa to Scandinavia and east to Siberia and China (Gold 2003, Löbl and Smetana 2010); adventive in Canada and the USA (LeSage 1992, Majka and LeSage 2008b).

Distribution in Canada. AB, MB, NB, NF, NS, ON, PE, QC, SK (Bousquet et al. 2013).

Distribution in USA. CT, MA, ME, NH, NJ, NY, RI, VT (Livingston 1996, Riley et al. 2003, Klimaszewski et al. 2010, Majka and Kirby 2011, Cappuccino et al. 2013).

First Canadian records. Near Montreal, QC in 1943 (CNC); Ottawa, ON in 1981 (CNC); several localities in NS in 1992 (CNC, NSMC); Portage la Prairie, MB in 1999 (LeSage and Elliot 2003).

First North American records. As above. Earliest records in the USA include Cambridge, MA in 1992, ME and NH in 1997, RI in 1999, CT in 2001, VT in 1998, and NY in 2000 (Gold 2003, Majka and Kirby 2011).

Habitat and host data. The scarlet lily beetle is a serious pest of native and cultivated lilies (Liliaceae) (Livingston 1996, Cappuccino et al. 2013). Adults lay their eggs most often on Lilium and Fritillaria species (Gold et al. 2001) including the following taxa: Fritillaria imperialis L., F. melaeagris L., Lilium aurantum L., L. candidum L., L. formosanum Wallace, L. giganteum Wallich, L. hansonii Leicht ex Baker, L. henryi Baker, L. lancifolium Thunb. L. longiflorum Thunb., L. martagon L., L. philippinense Baker, L. regale Wils., L. speciosum Thunb., L. superbum L., and L. testaceum Lindl. (Majka and LeSage 2008b).

Tribe Lemini Gyllenhal

22. Lema cyanella (Linnaeus)

(Fig. 22)

Diagnosis. Body length 4.0-4.5 mm, elongate, elytra almost parallel-sided; body metallic blue, antennae and legs black to metallic blue; frontal grooves of head converging at acute angle; pronotum deeply constricted at midlength, with impunctate elevated section along midline, punctures on either side of the line often coarsely rugose; ely- 
tral disc with regular rows of punctures, interstriae smooth and glossy with a few fine punctures anteriorly and laterally; tarsal claws fused at base.

Native range. Palearctic: Eurasia - Spain to Korea (Löbl and Smetana 2010); released as a biocontrol agent in Canada and USA (Riley et al. 2003, Bousquet et al. 2013, cited as the synonym Lema puncticollis (Curtis)).

Distribution in Canada. This species was released as a biocontrol agent of Canada thistle, Cirsium arvense (L.) Scop. (Asteraceae) in Regina, SK in 1982, Indian Head, SK in 1983, Sussex, NB in 1983-1986 (White 1993), Vegreville, AB in 1993-1994, and Edmonton, $\mathrm{AB}$ in 1994 and 1997 (McClay et al. 2002). Its establishment is doubtful (White 1993, Cripps et al. 2011; Peter Mason, personal communication).

Distribution in USA. SD [Riley et al. 2003, cited as L. puncticollis]. Lema cyanella was never released in the USA (Cripps et al. 2011) so the record from SD could represent inadvertent human-assisted dispersal from either Canada or its native range. The current status of the species in the USA is unknown.

First Canadian records. As above.

First North American records. Unknown locality in SD before 2003 (Riley et al. 2003).

Habitat and host data. Recorded hosts in its native range are $C$. arvense, and Cirsium drummondii Torr. \& Gray (White 1993). In the laboratory and under experimental conditions, L. cyanella breeds on species in the genera Cirsium, Carduus, Onopordum, and Silybum (Peschken 1984, Clark et al. 2004). Eggs are laid on leaves of the host plant, larvae feed on the foliage, pupation occurs in the soil or litter, and adults overwinter (Zwölfer and Pattullo 1969, McClay 1996).

23. Oulema (Oulema) melanopus (Linnaeus) [cereal leaf beetle] (Fig. 23, Map 17)

Diagnosis. Body length 4.0-4.5 mm, elongate, elytra almost parallel-sided; head and elytra black, metallic green or blue, pronotum reddish, abdominal ventrites black with metallic blue reflection, antennae black, basal four antennomeres usually with metallic 
blue or green reflection, legs mostly red with black tarsi, often apex of tibiae black; head with frontal grooves converging at obtuse angle; pronotum spherical, constricted posterad, sides and anterior edge punctate, and midline with row of punctures, constricted posterior part with fine and dense punctation; elytral disc with regular strial rows of punctures, interstriae mostly smooth, with a few fine punctures near base and sides; tarsal claws fused at base.

Native range. Palearctic: Europe, North Africa, and central Asia (Bezdek and Baselga 2015); adventive in Canada and the USA (White 1993, LeSage et al. 2007, Bousquet et al. 2013).

Distribution in Canada. AB, BC, MB, NB, NS, ON, PE, QC, SK (White 1993, LeSage et al. 2007, Bousquet et al. 2013).

Distribution in USA. AL, AR, CO, CT, DE, GA, IA, ID, IL, IN, KS, KY, MA, MD, ME, MI, MN, MO, MS, MT, NC, ND, NH, NJ, NV, NY, OH, OR, PA, RI, SC, TN, UT, VA, WA, WI, WV, WY (Bailey et al. 1991, Riley et al. 2003, Klimaszewski et al. 2010).

First Canadian records. Harrington, PE in 1944 (CNC); near Harrow, ON in 1965 (CNC); Aylmer, QC in 1972 (CNC); Grand Falls, NB in 1980 (CNC); Creston Valley, BC in 1998; Taber and Lethbridge, AB in 2005 (CNC; CFIA 2013).

First North American records. As above. The species may have arrived in the USA from Europe between 1947 and 1949 (Haynes and Gage 1981, LeSage et al. 2007, DiFonzo 2009). It was first identified in Berrien Co., MI in 1962 (McClanahan et al. 1968) and later the same year in IN (Webster 1977). In Muskegon, MI in 1960, specimens were found on plants in the trunk of a passenger car originating from Europe (Spears 1964, LeSage et al. 2007). In the west, it was first found in UT in 1984 and has since spread to surrounding states (Royce and Simko 2000). Numerous interceptions in the USA have been made since the earliest known interception record in 1936 at Baltimore, MD (Spears 1964, LeSage et al. 2007).

Habitat and host data. The species is an important pest of cereals, grains and grass forage crops, and is also a vector of viruses affecting Gramineae (LeSage et al. 2007). One generation is produced per year. Larvae are the greatest threat to crops as they eat the surface layer of leaves, hindering photosynthetic potential (DiFonzo 2009). 


\section{Subfamily CASSIDINAE Gyllenhal}

\section{Tribe Cassidini Gyllenhal}

24. Cassida (Cassida) rubiginosa O.F. Müller [thistle tortoise beetle] (Fig. 24, Map 18)

Diagnosis. Body length $6.0-7.5 \mathrm{~mm}$, broadly oval bodied with shield-like flared pronotum and elytra; dorsum green in life, fading to yellow in dried specimens, often with small brown to black spot on elytral suture behind scutellum and small dark spots along base of elytra, sometimes base of elytra with large red-brown triangular spot along suture, ventral side black and pronotum, elytra and appendages, basal six antennomeres yellow, remaining antennomeres gradually more brown to black, legs mostly yellow, basal half to two-thirds length of femora black; clypeus longer than wide, with fine grooves converging at obtuse angle, clypeal plate coarsely and densely punctate, interspaces microreticulate, irregular to rugose; pronotum with acute posterior corners, pronotal disc and explanate edges coarsely and densely punctate, punctation of elytra mostly scattered but forming irregular rows on sides of disc, basal third of each elytra often with two low, longitudinal elevations; tarsal claws simple and long, reaching beyond edge of third tarsomere.

Native range. Palearctic: Europe, North Africa, and Asia (Löbl and Smetana 2010); adventive in Canada and the USA (Majka and LeSage 2008c).

Distribution in Canada. AB, BC, MB, NB, NS, ON, PE, QC, SK (LeSage 1991, Majka and LeSage 2008c, Klimaszewski et al. 2010, Bousquet et al. 2013, Ratzlaff et al. 2016).

Distribution in USA. CO, CT, DE, IA, ID, IL, IN, MA, MD, ME, MI, MN, MT, NH, NJ, NY, OH, OR, PA, RI, SD, VA, VT, WA, WI, WV, WY (Riley et al. 2003, Klimaszewski et al. 2010, online images at www.bugguide.net).

First Canadian records. Lévis, QC in 1902 (Fyles 1902, cited as the synonym Cassida viridis L.; CNC); Ottawa, ON in 1930 (CNC); Shediac, NB in 1939 (CNC); Kamloops, BC in 2012 (CNC).

First North American records. As above.

Habitat and host data. From the extensive literature review of Clark et al. (2004), it is clear that C. rubiginosa is polyphagous, but it prefers the Cardueae in the Asteraceae (Majka and LeSage 2008c). In North America, it was first reported on burdock, Arc- 
tium minus (Hill.) Bernh. (Asteraceae) (Majka and LeSage 2008c). According to Majka and LeSage (2008c), only $A$. minus and Cirsium arvense (L.) Scop. are true hosts of $C$. rubiginosa in eastern Canada. In SK, Maw (1976a) reared C. rubiginosa from C. arvense, Centaurea jacea L., Arctium sp. and Carduus sp. In BC, an adult was found on a Carduus acanthoides L. leaf (CNC). This species is used in biological control of thistles, but its impact is usually restricted by parasitoids. This species was not approved for biological control release in Canada (McClay et al. 2002).

25. Cassida (Mionycha) azurea Fabricius [azurea tortoise beetle] (Fig. 25 a, b, Map 19)

Diagnosis. Body length 4.5-6.0 mm, subcircular to broadly oval with shield-like flared pronotum and elytra; dorsum yellow, in live specimens part of elytra covering body red, or forming triangular red spot behind scutellum, or oblique spot from humerus to the middle of the elytron, and vitta along sides of disc, sometimes the red pattern reduced to several small red-brown spots spread over the disc, in dry specimens, the pattern can partially or completely disappear, ventral surface mostly brown to black (living or dead specimens), clypeus sometimes partly yellow-brown, antennae and legs yellow, femora at base yellow to black; clypeus wider than long, with deep clypeal grooves converging in triangle, clypeal plate with a few punctures, interspaces microreticulate, dull; pronotum with round posterior corners, disc finely and sparsely punctate; punctation of elytra mostly in regular striae, interstriae not elevated, explanate sides of elytra form a shallow gutter, gutter surface rugose and irregularly punctate; tarsal claws simple, not reaching beyond edge of third tarsomere.

Native range. Palearctic: Europe to Siberia (Löbl and Smetana 2010); released as a biocontrol agent in Canada (Majka and LeSage 2008c, Bousquet et al. 2013).

Distribution in Canada. AB, MB, SK (Peschken et al. 2002, Riley et al. 2003, Majka and LeSage 2008c, Bousquet et al. 2013).

Distribution in USA. Not recorded.

First Canadian records. Released in AB (13 localities), MB (10), and SK (2) during 1989-1994 (Peschken et al. 2002), and recovered from 1990-1999 in all three provinces.

First North American records. As above. 
Habitat and host data. Intentionally released in AB, MB, and SK in 1989 as part of experiments to control the perennial weed, bladder campion, Silene vulgaris (Moench) Garcke (Caryophyllaceae) (Maw 1976b, Julien and Griffiths 1998, Peschken et al. 2002, Chaboo 2007, Majka and LeSage 2008c). Larvae defoliate the upper leaves and consume most of the flower. This beetle reduces seed production but does not control the weed. This species was initially misidentified in Canada as Cassida hemisphaerica Herbst (Maw and Steinhausen 1980).

26. Cassida (Mionycha) flaveola Thunberg [pale tortoise beetle] (Fig. 26, Map 21)

Diagnosis. Body length 4-6 mm, short oval to oval with shield-like flared pronotum; elytra dorsum yellow, often with small diffuse yellow-brown patches, occasionally pronotal and elytral discs mostly brown, clypeus yellow, ventral surface except for edges of pronotum and elytra brown to black centrally and yellow-brown laterally, basal six antennomeres yellow, remainder gradually brown, legs completely yellow; clypeus wider than long, with fine grooves converging at obtuse angle, clypeal plate with few small punctures, interspaces microreticulate but glossy; pronotum with rounded posterior corners, disc impunctate with broad shallow punctures on explanate sides, some with fine aciculate teeth; elytra punctation forming regular striae, second interstiae elevated in most, explanate sides of elytra form a shallow gutter with shallowly punctate surface; tarsal claws simple, stout and long, reaching back beyond edge of third tarsomere.

Adults of C. flaveola are smaller $(4-5 \mathrm{~mm})$ than those of C. rubiginosa $(6-8 \mathrm{~mm})$, and their elytral punctures are arranged in regular rows whereas in C. rubiginosa they are not.

Native range. Palearctic: Europe (Löbl and Smetana 2010); questionably adventive in Canada and the USA (Bousquet et al. 2013). The present range of $C$. flaveola in North America might be a composite of indigenous, Holarctic populations, and more recent adventive ones, and further research is required to resolve this question (Majka and LeSage 2008c).

Distribution in Canada. AB, BC, MB, NS, NT, ON, PE, QC, SK, YT (Brown 1940, Majka and LeSage 2008c, Bousquet et al. 2013).

Distribution in USA. MA, MD, MN, MT, ND, NH, NY, OH, PA, VT, WI, WV (LeSage 1991, Riley et al. 2003, Majka and LeSage 2008c, Klimaszewski et al. 2010, online images at www.bugguide.net). 
First Canadian records. Rigaud, QC in 1902 (Barber 1916); Husavick, MB in 1912 (CNC); Nicola, BC in 1932 (UBC); Waskesiu, SK in 1937 (RSM); Fort Smith, NT in 1946 (CNC); Seebe, AB in 1973 (CNC); Truro, NS in 1982 (NSAC).

First North American records. Earliest USA records are Beaver Dam, WI in 1896 and Duluth and Dora, MN in 1907 (Barber 1916).

Habitat and host data. Little is known of the biology of $C$. flaveola in North America (Majka and LeSage 2008c). Open habitats are apparently preferred. Most Nova Scotia specimens were collected in pastures, but one was found on coastal dunes, and one CNC specimen was collected in an alvar in Almonte, ON (Majka and LeSage. 2008c). Cassida flaveola is a polyphagous species, associated with many plants in the Caryophyllaceae (Majka and LeSage 2008c) including Arenaria peploides L., Cerastium vulgatum L., Honckenya peploides (L.), Malachium aquaticum (L.) Fr., Minuartia sp., Myosoton aquaticim (L.) Moench, Sagina sp., Silene latifolia Poiret, Silene vulgaris (Moench) Garcke, Spergula arvensis L., Stellaria graminea L., Stellaria holostea L., Stellaria media (L.) Vill., Stellaria nemorum L., and Stellaria uliginosa Murr. (Kosior 1975, Clark et al. 2004). Kosior (1975) reported that the preferred hosts were species in the genera Stellaria, Spergula, and Honckenya, and the most preferred species is Stellaria graminea.

27. Cassida (Odontionycha) viridis Linnaeus [green tortoise beetle] (Fig. 27 a, b, Map. 20)

Diagnosis. Body length 7-10 mm, broadly oval-bodied with shield-like flared pronotum; elytra dorsum of live specimens uniformly green, fading to yellow in dried specimens, ventral surfaces black except yellow sides of abdominal ventrites, basal six antennomeres yellow, remaining antennomeres gradually brown to black, legs yellow; clypeus with fine grooves converging at obtuse angle, clypeal plate coarsely and densely punctate, interspaces microreticulate, irregular to rugose; pronotum with rounded sides in dorsal view, no posterior corners, pronotal disc and explanate margin finely punctate; punctation of elytral disc completely irregular (not forming strial rows), explanate margin of elytra coarsely and sparsely punctate; tarsal claws with basal tooth.

Cassida viridis may be distinguished from the similar $C$. rubiginosa by the rounded sides of the pronotum which lacks a basal angle, completely irregular elytral punctation, and large and appendiculate tarsal claws.

Native range. Palearctic: Europe and North Africa to Russia Far East and China (Löbl and Smetana 2010); adventive in Canada (Marshall and Paiero 2015). 
Distribution in Canada. ON (Marshall and Paiero 2015).

Distribution in USA. Not recorded.

First Canadian records. Guelph, ON in 1970 (Marshall and Paiero 2015).

First North American records. As above.

Habitat and host data. Cassida viridis occurs on plants in the family Lamiaceae, mainly Mentha, Salvia, and Lycopus. The ON specimens were captured on Monarda sp. (Marshall and Paiero 2015).

\section{Subfamily CHRYSOMELINAE Latreille}

Tribe Chrysomelini Latreille

28. Chrysolina (Chrysolina) staphylaea staphylaea (Linnaeus) [brown mint leaf beetle] (Fig. 28, Map 22)

Diagnosis. Body length $6.5-9.0 \mathrm{~mm}$, oval; dorsum red-brown to brown, often with delicate metallic reflection, ventral surfaces, antennae and legs red-brown; pronotum wider than long, in basal third almost parallel-sided, then gradually narrowed anterad with straight basal and subangulate anterior corners, sides of disc slightly convex, separated from the disc by groove (deep posterad), elevated sides with several coarse punctures, disc finely and sparsely punctate; elytra punctation mostly irregular, some punctures tending to form semi-regular rows.

Native range. Palearctic: Eurasia (Löbl and Smetana 2010); adventive in Canada (Majka and LeSage 2008a, Bousquet et al. 2013).

Distribution in Canada. NF, NS, QC (Evans 1899, Brown 1950, 1962, Chantal 1972, Riley et al. 2003, Majka and LeSage 2008a).

Distribution in USA. Not recorded.

First Canadian records. Halifax, NS in 1897 (Evans 1899, Brown 1940); St. John's, NF in 1949 (Brown 1962); Lévis and Pintendre, QC in 1965 (Chantal 1972; LEM).

First North American records. As above. 
Habitat and host data. According to Jolivet (1990), the true hosts of C. staphylaea are restricted to the Lamiaceae, Plantaginaceae and Ranunculaceae, with preferences for Plantago spp. and Ranunculus spp. Later, Jolivet (1991) reinterpreted these data and stated that the Ranunculaceae are probably preferred. Direct observation of the feeding of the adults is difficult because they feed at dusk or at night (Jolivet 1990), otherwise hiding at the base of plants (Read 1984). Larvae were successfully reared by Marshall (1979) on Achillea sp. and Ranunculus repens L. Read (1984) found adults and larvae on Plantago lanceolata L., Plantago maritima L., and Aster tripolium L. Little is known about the biology of $C$. staphylaea in North America except that it prefers moist open habitats and is primarily nocturnal (Majka and LeSage 2008a).

29. Chrysolina (Hypericia) hyperici hyperici (Forster) [St. John's wort beetle] (Fig. 29, Map 23)

Diagnosis. Body length 5-7 mm, oval; dorsum metallic green, blue, yellow-green, occasionally black with metallic reflection, ventral surfaces, antennae and legs black with metallic reflection; dorsal surface of male slightly glossy, in female somewhat dull, both sexes with isodiametric microsculpture; pronotum wider than long, sides slightly convex, with straight basal and subangulate anterior corners, sides of disc not elevated, divided from the centre of the disc by a deep punctate impression only in basal one-quarter to one-third, surface of disc finely and sparsely punctate; elytra with large and sparse punctures that form somewhat regular rows that tend to run in pairs separated by wider interstriae, distance between large punctures in rows several times larger than puncture diameter, not forming grooved striae, space between striae and in interstriae with completely irregular, smaller secondary punctation.

Native range. Palearctic: Europe, western Asia (Löbl and Smetana 2010); introduced as a biocontrol agent into Canada and the USA (McLeod 1962, Harris et al. 1969, Harris and Peschken 1971, Campbell and McCaffrey 1991, LeSage 1996).

Distribution in Canada. BC, NB, NF, NS, ON, PE, QC (Riley et al. 2003, Bousquet et al. 2013). New jurisdictional record: NL: Corner Brook, 48 57.355'N, 5754.681'W, 10.vii.2008, fallow field, Goulet, Boudreault \& Badiss, sweeping \#11 (7 specimens, MUN).

Distribution in USA. CA, CO, ID, MN, MT, NV, NY, OR, WA (Campbell and McCaffrey 1991, Riley et al. 2003, Klimaszewski et al. 2010). 
First Canadian records. It was introduced to BC (Fruitvale) in 1951 using material from CA, and to Edgewood in 1952 using material from OR, and established (Smith 1956). It was subsequently redistributed to numerous locations in the southern interior of BC, establishing in many places (Smith 1958, Harris and Peschken 1971, Anonymous 2018f)). Using the established population from Fruitvale, BC as a source, the species was first introduced into ON (Picton) and NS (Pictou Co., Annapolis Co.) in 1969, into NB (Tay Creek, Lime Kiln) in 1971, and into MB in 1990-1997 (Harris and Maw 1984). The species established and spread and had naturally dispersed to QC (along Ottawa River) by 1996 (LeSage 1996) and to NF (Corner Brook) by 2008 (MUN).

First North American records. The first USA introductions were in CA in 1945 and in WA in 1948 (Hatch 1971, Andres 1985, Durbecq 2014, Winston et al. 2014).

Habitat and host data. This species was introduced for biological control of the perennial weed St. John's wort, Hypericum perforatum L. (Hypericaceae) (Campbell and McCaffrey 1991). In northern Idaho, C. hyperici occurred in a meadow in a forest opening on St. John's wort (Campbell and McCaffrey 1991).

30. Chrysolina quadrigemina (Suffrian) [Klamath weed beetle] (Fig. 30, Map 22)

Body length $6.5-8.5 \mathrm{~mm}$, oval; dorsum metallic violet, blue, or occasionally black with metallic reflection, ventral surfaces, antennae and legs black; dorsal surface of male glossy, in female slightly dull; pronotum wider than long, sides converging from posterior to anterior, only in anterior one-third slightly convex, with subangulate anterior corners, sides of disc not elevated, only in basal one-quarter separated from the rest of the disc by deep impression and in anterior part with group of punctures, surface of disc finely and sparsely punctate; elytra with large and dense punctures that form somewhat regular rows that tend to run in pairs separated by wider interstriae, not forming grooved striae, distance between large punctures in rows 3-5 times diameter of a puncture diameter, remainder of surface with completely irregular, fine secondary punctuation.

Native range. Palearctic: Eurasia (Löbl and Smetana 2010); released as a biological control agent in Canada and the USA (Hoebeke 1993).

Distribution in Canada. BC, ON (Hoebeke 1993, Bousquet et al. 2013). Although recorded from NS and QC by Bousquet et al. (2013), specimens or verified locality records could not be located. A release in NB did not establish (Jensen et al. 2002). This species should be removed from the provincial species lists for NB, NS and QC. 
Distribution in USA. CA, CO, ID, MD, MN, MT, NJ, NV, NY, OH, OR, PA, UT, VA, WA, WV (Hoebeke 1993, Riley et al. 2003, Staines and Staines 2006, online images at www.bugguide.net).

First Canadian records. It was first introduced in 1951 to BC (near Christina Lake and Westbank) using source material reared in CA, and to Fife and Edgewood, BC in 1952 using material from ID (Smith 1956). It was subsequently redistributed to numerous locations in the southern interior of BC, resulting in establishment in many places (Smith 1956, 1958, Harris and Peschken 1971, Anonymous 2018f). Material from BC was released and established near Picton, ON in 1969 and Sidney Twp., ON in 1971 (Harris and Maw 1984, BCMF 2019). The CNC has specimens from Vernon, BC (collector: LJ Ward) with a handwritten year of "1933" overwriting another date that is illegible. Since this year greatly pre-dates the first releases in BC (1952) and North America (1945 in CA), we assume that the handwritten year is an error.

First North American records. First introduced into the USA (CA) from Australia in 1945 to control Klamath weed (or St. John's wort), Hypericum perforatum L. (Hypericaceae) (Hatch 1971, Andres 1985, Winston et al. 2014), and is now established in many localities (Holloway and Huffaker 1951).

Habitat and host data. Chrysolina quadrigemina is generally specific to $H$. perforatum (Hoebeke 1993). This species was reported feeding on some native Hypericum species in NY and CA (Andres 1985, Tingle et al. 2016), but it is not known if it can complete its life cycle on species other than $H$. perforatum.

\section{Chrysolina (Sphaeromela) varians (Schaller)}

(Fig. 31)

Diagnosis. Body length 4.5-6.0 mm, oval; dorsum metallic green, blue, violet, copper or yellow-green, ventral surfaces, antennae and legs black with metallic reflection; pronotum wider than long, narrowed anterad, sides almost straight to slightly convex, with angulate posterior and anterior corners, sides of disc not elevated, densely punctate, only at posterior, separated from the rest of the disc by short, shallow impression, central part of disc finely punctate; punctation of elytra completely irregular, interspaces generally not wider or slightly wider than puncture diameter, glossy with shallow fine microsculpture.

Native range. Palearctic: Europe, Siberia (Löbl and Smetana 2010); introduced as a biocontrol agent to Canada and the USA (Hatch 1971). 
Distribution in Canada. BC (Riley et al. 2003, Bousquet et al. 2013). This species has not been recovered at release sites or elsewhere in Canada (Harris and Peschken 1971, Peter Mason, personal communication). It is unlikely that this species now occurs in Canada.

Distribution in USA. CA, ID (Hatch 1971, Riley et al. 2003), but there is no evidence of establishment.

First Canadian records. Specimens from Sweden were released at Westbrook, BC in 1957 and at Castlegar, BC in 1958 (MacLeod 1962, Hatch 1971).

First North American records. First introduced into the USA (CA) from Australia in 1950 (Andres 1985).

Habitat and host data. Used for biological control of St. John's wort, Hypericum perforatum L. (Hypericaceae) (Harris and Peschken 1971).

32. Gastrophysa (Gastrophysa) polygoni (Linnaeus) [knotweed leaf beetle] (Fig. 32a, b, Map 24)

Diagnosis. Body length 4-5 mm, elongate, almost parallel-sided; head and elytra metallic green or blue, pronotum orange to red, most of ventral surface black with metallic reflection, antennomeres 1-4 usually completely red, often first antennomere partly black or antennomeres 1-4 red basally and black apically, antennomere 5 mostly-to-completely black, antennomeres 6-11 black, occasionally whole antennae black, femora and tibiae red-brown, tarsi red-brown basally and black apically; pronotum wider than long, sides feebly convex, with rounded basal and anterior corners, whole surface of disc convex without swollen sides, surface of disc finely and sparsely punctate; punctation of elytra completely irregular, distance between punctures 1-2 times as wide as puncture diameter, surface between punctures glossy.

Gastrophysa polygoni can be confused with Oulema melanopus (L.) as they occur in the same habitats and are superficially similar. However, G. polygoni possesses a lateral bead on the pronotum and elytral punctures are not arranged in regular rows, whereas the sides of the pronotum are rounded in $O$. melanopus and its elytral punctures are arranged in regular rows (LeSage et al. 2007, Fig. 1).

Native range. Palearctic: Europe east to Siberia, China, and Turkmenistan (LeSage and Majka 2009, Löbl and Smetana 2010); adventive in Canada and the USA (Jolivet 
1951, LeSage and Majka 2009, Bousquet et al. 2013). Hatch (1971) lists this species as naturally Holarctic.

Distribution in Canada. AB, BC?, MB, NB, NS, ON, PE, QC, SK (Riley et al. 2003, LeSage and Majka 2009, Bousquet et al. 2013). Hatch (1971) recorded it from northeastern BC, but specific locality records are unknown and no specimens have been seen by the authors, so we consider this record questionable.

Distribution in USA. CT, DE, IA, ID, IL, IN, KS, KY, MA, ME, MI, MN, MO, MT, ND, NE, NH, NJ, NY, OH, PA, RI, SD, VT, WI, WV, WY (Riley et al. 2003, Sauer 2009, Klimaszewski et al. 2010, online images at www.bugguide.net).

First Canadian records. Undisclosed locality in NS in approximately 1827 (Kirby 1837, cited as Phaedon polygoni); Quebec City, QC in 1864 (Couper 1864); Sudbury, ON in 1893 (CNC); Aweme, MB in 1903 (DEBU); Ghost Dam, AB in 1922 (CNC); Saskatoon, SK in 1927 (CNC). A historical review of additional collections and early published reports are summarized by LeSage and Majka (2009).

First North American records. The earliest records in North America are from IN before 1826, described under the name Chrysomela caeruleipennis Say (Say 1826). It was listed from MA by 1833, under the same name (Harris 1833).

Habitat and host data. Gastrophysa polygoni is one of the commonest leaf beetles in cereal fields where it feeds on Polygonum spp., Fallopia spp., and Rumex spp. (LeSage and Majka 2009), and other unrelated, secondary or incidental hosts (Clark et al. 2004).

\section{Phaedon (Phaedon) laevigatus (Duftschmid) [watercress leaf beetle]}

(Fig. 33, Map 25)

Diagnosis. Body length 2.5-4.0 mm, almost circular in dorsal view; dorsum black with metallic brass or copper reflections, ventral surfaces black, or with part of abdominal ventrite 5 red-brown, antennae mostly black, basal three to four antennomeres often on underside or apically red-brown, legs brown-black, tarsi red-brown to brown; pronotum wider than long, sides feebly and regularly convex, with obtuse-to-curved basal and anterior corners, whole surface of disc slightly convex without swollen sides, surface of disc finely and sparsely punctate; punctation of elytra with completely regular rows of punctures, forming impressed striae in some places, with finely and sparsely punctate interstriae, surface between punctures glossy, humeral callus weak. 
Native range. Palearctic: Europe (Löbl and Smetana 2010); adventive in Canada and the USA (Bousquet et al. 2013).

Distribution in Canada. AB, BC, MB, NB, NS, NT, ON, PE, QC, SK, YT (Riley et al. 2003, Bousquet et al. 2013, Webster 2016). New jurisdictional record: Yukon, Gravel Lake, 58 mi E. Dawson, 6348'31.33”N 13753'58.93”W, 2050', 12 August 1962, R.E. Leech (9 specimens, CNC).

Distribution in USA. AK, AZ, CA, CO, DC, IA, IL, IN, MA, ME, MI, MN, MO, MS, MT, ND, NH, NJ, NY, OH, OR, PA, RI, SD, UT, VA, WA, WI, WV (Hatch 1971 - as the synonym P. carri Hatch, Riley et al. 2003, online image at bugguide.net/ node/view/897310).

First Canadian records. Edmonton, AB in 1918 (CNC); Onah, MB in 1920 (CNC); Laprairie, QC in 1927 (CNC); Summerland, BC in 1931 (CNC); Prince Edward Co., ON in 1933 (CNC); Yorkton, SK in 1945 (CNC); Reindeer Depot, NT in 1948 (CNC).

First North American records. New York, NY in 1917 (Hatch 1928).

Habitat and host data. In North America, this species is associated with cultivated horseradish, Armoracia rusticana (Lam.) Gaertn., Mey., \& Scherb., and watercress, Nasturtium officinale (Aiton) (Brassicaceae) (Clark et al. 2004). In Europe, it is reported from Galeopsis ladanum L., Galeopsis pubescens Besser (Lamiaceae), Salix cinerea L., Salix fragilis L., and Salix nigricans Smith (Salicaceae) (Clark et al. 2004).

34. Plagiodera (Plagiodera) versicolora (Laicharting) [imported willow leaf beetle] (Fig. 34, Map 26)

Diagnosis. Body length 2.5-4.5 mm, male short-oval, female oval, flattened; dorsum black with metallic blue, violet or green elytra, ventral surfaces black or black with green metallic reflection, antennomeres 1-2 brown dorsally and red-brown ventrally, antennomeres 3-6 usually red-brown to gradually darker, apical antennomeres black, femora and tibiae black, tarsi from red-brown to dark brown; pronotum wider than long, sides feebly, regularly convex, with obtuse to curved basal and anterior corners, disc slightly convex without swollen sides or sublateral basal impressions, finely and sparsely punctate; punctation of elytra moderate, completely irregular, humeral callus strong.

Native range. Palearctic: Eurasia (Löbl and Smetana 2010); adventive in Canada and the USA (Bousquet et al. 2013). Urban (2005) recorded it as Holarctic. 
Distribution in Canada. AB, MB, NB, NS, ON, QC (LeSage 1991, Bousquet et al. 2013).

Distribution in USA. CT, DC, DE, IA, IL, IN, KY, MA, MD, ME, MI, MN, NC, NH, NJ, NY, OH, PA, RI, SC, TN, VA, WV (Mattson et al. 1994, Staines 1999, Riley et al. 2003, Klimaszewski et al. 2010).

First Canadian records. Prince Edward Co., ON in 1941 (CNC); undisclosed locality in QC in 1942 (Lechevalier 1944); Oka, QC in 1943 (CNC); Dawson Cabin, MB in 1964 (NOFC); 7 km S of Tatamagouche, NS in 1983 (CNC).

First North American records. Staten Island, NY and an undisclosed locality in NJ from 1911-1915 (Schaeffer 1915, Weiss and Dickerson 1917, Hood 1940).

Habitat and host data. This species, including Palearctic populations, is associated with Salicaceae and has been reported from Populus deltoides Marshall, Populus nigra L., and numerous species of Salix, including S. alba L., S. babylonica L., S. caprea L., S. caroliniana Michx., S. discolor Muhl., S. interior Rowlee, S. fragilis L., S. integra Thunb., S. lasiolepis Benth., S. lucida Muhl., S. miyabeana Seemen, S. nigra Marsh., S. nigricans Smith, S. pentandra L., S. phylicifolia L., and S. sachalinensis Fr. Schm. (Clark et al. 2004).

\section{Subfamily GALERUCINAE Latreille}

\section{Tribe Alticini Newman}

\section{Altica (Altica) carduorum (Guérin-Méneville)} (Fig. 35)

Diagnosis. Body length 3.3-4.0 mm, oval; dorsum metallic green, antennae, legs and ventral surfaces black, often with green metallic reflection; pronotum wider than long, at posterior with deep transverse impression, disc finely and sparsely punctate, glossy between punctures; base of elytra only slightly wider than posterior of pronotum, elytral disc finely, completely, and irregularly punctate, interspaces glossy, humeral callus present; legs not robust, hind femora slightly swollen, first tarsomere of fore and mid tarsi broader in male than in female.

Native range. Palearctic: Eurasia (Löbl and Smetana 2010); introduced as a biocontrol agent to Canada and the USA (Zwölfer 1965, Bousquet et al. 2013). 
Distribution in Canada. Released in AB, BC, NS, and ON but did not establish (Peschken et al. 1970, Peschken 1971).

Distribution in USA. CA, CO, DE, ID, IN, MD, MN, MT, NJ, NV, OR, SD, WA, WI (Riley et al. 2003, Klimaszewski et al. 2010).

First Canadian records. The earliest releases occurred in AB and ON in 1963, BC in 1964, and NS in 1966 to aid in the control of the perennial adventive weed Canada thistle, Cirsium arvense (L.) Scopoli. Most did not survive in open fields with the exception of a small colony at Lacombe, AB that survived only until 1968 (Harris 1964, Peschken et al. 1970, Peschken 1971). This species has not been recovered recently from any release sites, or elsewhere in Canada (Peter Mason, personal communication). It is unlikely that this species is established in Canada (Peschken 1971).

First North American records. As above.

Habitat and host data. Adults and larvae feed on leaves of Canada thistle (Clark et al. 2004).

36. Aphthona (Aphthona) cyparissiae (Koch) [brown dot leafy spurge flea beetle] (Fig. 36, Map 27)

Diagnosis. Body length $2.8-4.0 \mathrm{~mm}$, oval; dorsum yellow-brown to orange-brown, head and hind femora usually slightly darker than pronotum and elytra, sutural edge of elytra and scutellum often (and ventral surfaces usually) orange-brown, antennae completely pale or 4-5 apical antennomeres slightly darker; head with strong frontal tubercles; pronotum wider than long, without transverse impression, surface of disc extremely finely and sparsely punctate, glossy between punctures; base of elytra not or only slightly wider than posterior of pronotum, elytral disc finely, completely and irregularly punctate, interspaces glossy, humeral callus weak; legs with hind femora swollen, in male first tarsomere of foreleg slightly broader than in female.

Preliminary DNA characterization with multiple genes suggests that morphological identification may not be reliable for distinguishing some Aphthona species introduced into Canada and the USA for biocontrol of leafy spurge (Floate et al. 2016). The aedeagus of this species is most like that of $A$. flava.

Native range. Palearctic: Europe (Löbl and Smetana 2010); introduced as a biocontrol agent to Canada and the USA (Pemberton and Johnson 1986, Bourchier et al. 2002). 
Distribution in Canada. AB, BC, MB, ON, QC, SK (LeSage and Paquin 1996, Riley et al. 2003, Bousquet et al. 2013). Although the species was released in NS, it does not appear to be established there (Peter Mason, personal communication).

Distribution in USA. CO, IA, ID, MN, MT, ND, NE, NM, NV, OR, RI, SD, WA, WI, WY (Riley et al. 2003, Klimaszewski et al. 2010).

First Canadian records. First releases in 1982 were near Cardston, AB; Caron, SK; Cypress River, MB; Braeside, ON; and Baie-Saint-Paul, QC (Williamson 1986, McClay et al. 1995, LeSage and Paquin 1996, Bourchier et al. 2002). It was first released in the East Kootenay area of BC in 1989 (Bourchier et al. 2002). It is established in all of those provinces.

First North American records. As above. During 1986 to 1995, it was widely released in leafy spurge infestations in 17 states across the northern USA (Hansen 2011a). Large populations are present in several states, including WY, MT, CO, and WI (Hansen 2011a)

Habitat and host data. Aphthona cyparissiae is used as a biocontrol agent against the perennial weed, leafy spurge (Euphorbia esula L.). The host range of $A$. cyparissiae appears restricted to plants in the subgenus Esula of the genus Euphorbia. This species, including Palearctic populations, is associated with several Euphorbia species, including E. cyparissias L., E. esula, E. peplus L., E. seguieriana Neck., and E. virgata Waldst. \& Kit. (Euphorbiaceae) (Clark et al. 2004). In Europe, this beetle feeds on leafy spurge and several other closely related spurge species. There are a few native Euphorbia spp. in the USA that could potentially be hosts for $A$. cyparissiae, though no feeding has yet been documented under field conditions.

37. Aphthona (Aphthona) czwalinae Weise [black leafy spurge flea beetle] (Fig. 37, Map 28)

Diagnosis. Body length 2.8-3.5 mm, oval; dorsum dark metallic green or blue, or black with metallic reflections, legs and basal antennomeres yellow, apical antennomeres somewhat darker and hind femora brown to black; head with strong frontal tubercles; pronotum only slightly wider than long, without transverse impression, surface of disc extremely fine and sparsely punctate, glossy between punctures; elytra in anterior third almost parallel-sided, then converging posterad, base of elytra wider than posterior of pronotum, elytral disc finely and irregularly punctate, interspaces glossy, 
humeral callus strong; legs with hind femora swollen, in male first tarsomere slightly broader than in female.

Native range. Palearctic: Eurasia (Löbl and Smetana 2010); introduced as a biocontrol agent to Canada and the USA (Nowierski and Pemberton 2002).

Distribution in Canada. AB, BC, MB, ON, SK (Riley et al. 2003, Bousquet et al. 2013, Peter Mason, personal communication).

Distribution in USA. CO, IA, ID, MI, MN, MO, MT, ND, NE, OR, SD, WA, WI, WY (Riley et al. 2003, Roehrdanz et al. 2009).

First Canadian records. The species was first released at Spring Coulee, AB in 1985 and again in 1993 (McClay et al. 1995, Julien and Griffiths 1998, Bourchier et al. 2002); Regina and Maxim, SK in 1995 (Sarazin and Hamilton 1988, LeSage and Paquin 1996); Marshall Bay and Horning's Mills, ON in 1985 (Peter Harris, unpublished data); Cypress River, MB in 1986 and Shilo, MB in 1987 (Peter Harris, unpublished data); and Spallumcheen and near Clinton, BC in 1995 (Anonymous 2018b).

First North American records. See above. First released in USA in MT and SD in 1998 (Butler et al. 2006).

Habitat and host data. Aphthona czwalinae is used as a biocontrol agent against the rangeland weed, leafy spurge, Euphorbia esula L. (Hansen et al. 1997, Kalischuk et al. 2004). This species, including Palearctic populations, is associated with several Euphorbia species: E. cyparissias L., E. esula, E. lucida Waldst. \& Kit., E. seguieriana Neck., and E. virgata Waldst. \& Kit. (Euphorbiaceae) (LeSage 1996, LeSage and Paquin 1996, Clark et al. 2004).

38. Aphthona (Aphthona) flava Guillebeau [copper leafy spurge flea beetle] (Fig. 38 a, b, Map 29)

Diagnosis. Body length 2.8-4.3 mm, oval; whole dorsum yellow to orange yellow, hind femora usually slightly darker than pronotum and elytra, sutural edge and scutellum not darker than surface of elytral disc; head with strong frontal tubercles; pronotum wider than long, without transverse impression, surface of disc extremely finely and sparsely punctate, glossy between punctures; base of elytra not or only slightly wider 
than posterior of pronotum, elytral disc finely, irregularly punctate, interspaces glossy, humeral callus weak; legs with hind femora swollen, male with first tarsomere of foreleg slightly broader than in female.

Preliminary DNA characterization with multiple genes suggests that morphological identification may not be reliable for distinguishing some Aphthona species introduced into Canada and the USA for biocontrol of leafy spurge (Floate et al. 2016). The aedeagus of this species is most like that of $A$. cyparissiae.

Native range. Palearctic: Eurasia (Löbl and Smetana 2010); introduced as a biocontrol agent to Canada and the USA (Winston et al. 2017).

Distribution in Canada. AB, BC, MB, NS?, ON, QC, SK? (Pemberton and Rees 1990, LeSage 1996, LeSage and Paquin 1996, Bousquet et al. 2013). The species was reported as established in $\mathrm{AB}, \mathrm{BC}$, and $\mathrm{ON}$ by Julien and Griffiths (1998). The recent collection of specimens from $\mathrm{MB}$ and $\mathrm{QC}(\mathrm{CNC})$ suggests it is established there. The status of the releases in NS and SK is unknown.

Distribution in USA. CO, IA, ID, MI, MN, MT, ND, NE, NH, NM, NV, NY, OR, RI, SD, UT, WA, WI, WY (Riley et al. 2003, Klimaszewski et al. 2010).

First Canadian records. The first releases were in 1982 near Cardston, AB; Caron, SK; Cypress River, MB; Braeside, ON; and Sainte-Anne-de-Bellevue, QC (Sommer and Maw 1982, McClay and Harris 1984, Williamson 1986, McClay et al. 1995, LeSage and Paquin 1996, Bourchier et al. 2002). The first releases in BC were near Clinton in 1990 (no establishment) and near Kamloops from 1992-1995 (established) (Anonymous 2018c).

First North American records. As above. It was first released into the USA in ND in 1985, MT in 1985-1987, and ID in 1986 (Pemberton and Rees 1990).

Habitat and host data. Like other Aphthona species that feed on Euphorbia species, the adults of $A$. flava feed on leaves and flower bracts, and the larvae feed upon the root hairs and roots. Mature larvae overwinter and pupate in late spring or early summer (Pemberton and Rees 1990). In North America, this species is used for biological control of Euphorbia esula L. and Euphorbia cyparissias L. (Pemberton and Rees 1990). 
39. Aphthona (Aphthona) lacertosa Rosenhauer [black flea beetle, brown-legged leafy spurge flea beetle]

(Fig. 39, Map 30)

Diagnosis. Body length 2.5-3.4 mm, body elongate-oval, elytra converging posterad; dorsum black with metallic green, brass or blue reflections, legs and basal antennomeres yellow, apical antennomeres and femora somewhat darker; head with strong frontal tubercles; pronotum only slightly wider than long, without transverse impression, surface of disc finely and sparsely punctate, glossy between punctures; base of elytra not or only slightly wider than posterior of pronotum, elytral disc finely and irregularly punctate, interspaces glossy, humeral callus weak; legs with hind femora swollen, in male first tarsomere slightly broader than in female.

Preliminary DNA characterization with multiple genes suggests that morphological identification may not be reliable for distinguishing some Aphthona species introduced into Canada and the USA for biocontrol of leafy spurge (Floate et al. 2016). The aedeagus of this species is most like that of $A$. nigriscutus.

Native range. Palearctic: Eurasia (Löbl and Smetana 2010); introduced as a biocontrol agent to Canada and the USA (Riley et al. 2003, Winston et al. 2016).

Distribution in Canada. AB, BC, MB, SK (LeSage 1996, Julien and Griffith 1998, Kalischuk 2001, Riley et al. 2003, Bousquet et al. 2013, Anonymous 2018d, Peter Mason, personal communication).

Distribution in USA. ID, MT, ND, OR, WA, WY (Riley et al. 2003).

First Canadian records. First released near Spruce Grove, AB in 1990 (Sarazin 1991, Kalischuk 2001); at Regina, Buffalo Pound Park, Edenwold, and Milestone, SK in 1990 (Sarazin 1991, LeSage and Paquin 1996); at Rossendale, MB in 1990 (Peter Mason, personal communication); and at Spallumcheen and northwest of Clinton, BC in 1999 (Anonymous 2018d).

First North American records. As above. Aphthona lacertosa was originally approved for release in the USA in 1993. Through 1995, it had been widely released in mixed populations with $A$. czwalinae in leafy spurge infestations across the northern USA (Nowierski and Pemberton 2002, Hansen 2011b).

Habitat and host data. Aphthona lacertosa is a biological control agent for leafy spurge, Euphorbia esula L. (Kalischuk 2001, Kalischuck et al. 2004). This species, including Palearctic populations, is associated with several Euphorbia species, including E. cyparissias 
L., E. esula, E. lucida Waldst. \& Kit., E. pannonica Host, E. salicifolia Host, E. seguieriana Neck., E. stepposa Zoz ex Prokh., and E. virgata Waldst. \& Kit. (Euphorbiaceae) (LeSage and Paquin 1996, Clark et al. 2004). Larvae of $A$. lacertosa cause the most damage to leafy spurge by feeding on the plant roots in the spring and fall (Rees et al. 1996).

40. Aphthona (Aphthona) nigriscutis Foudras [black dot leafy spurge flea beetle] (Fig. 40, Map 31)

Diagnosis. Body length 3.0-4.1 mm, oval; whole dorsum yellow to orange-yellow, apical antennomeres somewhat darker, mouth parts, hind femora and scutellum always darker than disc of pronotum and elytra, abdomen usually partly black; head with strong frontal tubercles; pronotum wider than long, without transverse impression, surface of disc extremely finely and sparsely punctate, glossy between punctures; base of elytra not or only slightly wider than posterior of pronotum, elytral disc finely and irregularly punctate, interspaces glossy, humeral callus weak; legs with hind femora swollen, in male first tarsomere not broader than in female.

Preliminary DNA characterization with multiple genes suggests that morphological identification may not be reliable for distinguishing some Aphthona species introduced into Canada and the USA for biocontrol of leafy spurge (Floate et al. 2016). The aedeagus of this species is most like that of $A$. lacertosa.

Native range. Palearctic: Europe (Löbl and Smetana 2010); introduced as a biocontrol agent to Canada and the USA (Winston et al. 2017).

Distribution in Canada. AB, BC, MB, NS, ON, QC, SK (Riley et al. 2003, Bousquet et al. 2013). Although there is no record of this species being released in QC, Aphthona cyparissiae was released there (Bourchier 2002) and it is possible that $A$. nigriscutis was among released material but was not recognized at the time. Clearly the species is established in the vicinity of Bristol Mines in QC and specimens have been collected as recently as 2015 (CNC). It is uncertain whether this species remains established in all provinces where releases occurred.

Distribution in USA. CO, IA, ID, MI, MN, MT, ND, NE, NH, NM, NV, NY, OR, RI, SD, UT, WA, WI, WY (Riley et al. 2003, Klimaszewski et al. 2010).

First Canadian records. The earliest releases were near Cardston, AB in 1983 (Kalischuk 2001, Bourchier et al. 2002), and Guelph, ON in 1983 (Sarazin and Hamilton 1988, LeSage and Paquin 1996). Other early release sites are Hanceville (near Alexis Creek), 
BC in 1986 (Anonymous 2018e), eight localities in MB in 1986, Broadview and Caronport, SK in 1986, and Mt. Thomas, NS in 1992 (Peter Harris, unpublished data).

First North American records. See above. It was first released in the USA in MT in 1989 (http://mtwow.org/Aphthona-nigriscutis.htm).

Habitat and host data. Aphthona nigriscutis is a biological control agent used in Canada for control of leafy spurge, Euphorbia esula L. (Euphorbiaceae). This species feeds on the roots of host plants. Palearctic populations of this species are associated with several Euphorbia species, including E. cyparissias L. E. esula, E. gracilis Elliott, E. pannonica Host, E. seguieriana Neck, and E. virgata Waldst. \& Kit. (LeSage 1996, LeSage and Paquin 1996, Clark et al. 2004).

41. Chaetocnema concinna (Marsham) [brassy flea beetle] (Fig. 41, Map 32)

Diagnosis. Body length $1.8-2.4 \mathrm{~mm}$, oval; head and pronotum metallic brass, copper, elytra sometimes dark green, elytra black with faint metallic reflections, first antennomere dorsally brown, antennomeres $2-10$ gradually darker from yellow-brown to brown, last antennomere brown to black, femora black, tibiae and tarsi red-brown, tibiae often darker at midlength; frons with two groups of fine punctures near edge of eye; pronotum only slightly wider than long, at posterior with two short sublateral longitudinal impressions but without transverse impression, pronotal disc densely punctate, interspaces glossy to microreticulate; base of elytra only slightly wider than posterior of pronotum, elytral disc with regular impressed strial rows of dense punctures, interspaces glossy with very fine, sparse, and irregular punctation, humeral callus weak; legs with hind femora strongly swollen, hind tibiae with dorsal edge emarginate near apex, in male first tarsomere broader than in female. For genitalic illustrations, see LeSage and Majka (2010) and Konstantinov et al. (2011).

Native range. Palearctic: throughout Europe (Konstantinov et al. 2011); adventive in Canada and the USA (Bousquet et al. 2013).

Distribution in Canada. BC, NB, NS, ON, PE, QC, SK (LeSage 1990, Riley et al. 2003, LeSage and Majka 2010, Bousquet et al. 2013). New jurisdictional records: BC: Surrey, 16 September 2003, in a commercial blueberry field, R. Costello (15 specimens, CNC); Abbotsford, 7 July 2008 (1 specimen, CNC); Nicomen Island, $49^{\circ} 9^{\prime} 57.60^{\prime \prime} \mathrm{N} 122^{\circ} 7^{\prime} 8.40^{\prime \prime} \mathrm{W}, 17$ May 2015, T. Hueppelsheuser (9 specimens, CNC). NF: St. Andrews, sweep of field, $59.232^{\circ} \mathrm{W}, 47.793^{\circ} \mathrm{N}, 17$ June 2004,. Col. Henri 
Goulet (2 specimens, CNC). SK: Avonlea, 22 June 2009, yellow sticky traps, ex. canola, J.J. Soroka (10 specimens, CNC).

Distribution in USA. MA, ME, OR, TX (White 1996, Riley et al. 2003, Westcott et al. 2006, LeSage and Majka 2010).

First Canadian records. Hatfield Point, NB in 1981 (CNC); Igonish Center, NS in 1983; Charlottetown, PE in 1985 (LeSage 1990, LeSage and Majka 2010); undisclosed localities in QC in 1987-1989 (Lévesque and Lévesque 1998); Surrey, BC in 2003 (CNC).

First North American records. This species was first reported in North America from a female specimen collected on sudangrass (Sorghum sudanense (Piper) Stapf) on a farm in Hingham, MA in 1979 (Hoebeke 1980, Hoebeke and Wheeler 1983).

Habitat and host data. Chaetocnema concinna occurs in a wide variety of habitats, in forests, fields, and prairies (LeSage and Majka 2010). It was found in association with many host plants, especially in the Polygonaceae (Newton 1929, Clark et al. 2004, Konstantinov et al. 2011). In Europe, larvae have been found feeding on the roots of buckwheat (Fagopyrum spp.), hemp (Cannabis sativa L.), sorrel (Rumex spp.), and rhubarb (Rheum spp.), and adults have often been reported to damage seedlings of sugar beets (Beta vulgaris L.) (Clark et al. 2004). In North America, C. concinna has no recorded economic importance, although it was observed in potato fields, in vineyards, and in strawberry fields (LeSage and Majka 2010).

42. Chaetocnema hortensis (Geoffroy) [cereal stem flea beetle]

(Fig. 42 a, b, Map 33)

Diagnosis. Body length 1.7-2.2 mm, oval; color metallic brass, copper or slightly green, first four antennomeres yellow, antennomeres 5-7 gradually darker from yellow-brown to brown, last antennomere brown to black, tibiae and tarsi yellow to yellowish brown, occasionally tibiae infuscate in the middle, fore and mid femora the same colour as tibiae or slightly darker yellowish-brown, hind femora dark brown to black; frons on whole surface with moderately coarse punctation; pronotum wider than long, without sublateral longitudinal or transverse impressions, pronotal disc coarsely and densely punctate, interspaces as wide as punctures, microreticulate; base of elytra not wider than posterior of pronotum, elytral disc in postscutellar area with numerous irregular punctures, laterally and posteriorly with more or less regular impressed strial rows of dense punctures, interspaces glossy with very fine and sparse, 
irregular punctation, humeral callus weak; legs with hind femora strongly swollen, hind tibiae with dorsal edge emarginate near apex, in male first tarsomere distinctly broader than in female.

Native range. Palearctic: widespread across the region (Konstantinov et al. 2011); adventive in Canada (Pentinsaari et al. 2019).

Distribution in Canada. BC, LB, NF, NS, ON (Pentinsaari et al. 2019).

Distribution in USA. Not recorded.

First Canadian records. Elmwood, NS in 2005 (Pentinsaari et al. 2019).

First North American records. As above.

Habitat and host data. Chaetocnema hortensis mainly feeds on various grasses (Poaceae), including cereal crop species (Koch 1992, Konstantinov et al. 2011). It has been recorded as a minor pest of wheat and barley in Europe (Pavlov 1960, Vappula 1965). Most of the barcoded Canadian specimens were collected with Malaise traps in suburban environments (Pentinsaari et al. 2019). A few records are from grassland and forest habitats in Canadian national parks (Pentinsaari et al. 2019).

Comments. Chaetocnema hortensis has previously been confused with $C$. borealis White in Canada (Pentinsaari et al. 2019). Most Canadian specimens in CNC identified as $C$. borealis actually represent $C$. hortensis (Pentinsaari et al. 2019). The elytral punctation of the two species is similarly irregular basally. In $C$. borealis, the basal antennomeres are brown rather than pale yellow, and the dorsal surface has a blue rather than bronze or green lustre. The aedeagus is differently shaped in the two species [see illustrations in Konstantinov et al. (2011)].

\section{Epitrix pubescens (Koch)}

(Fig. 43 a, b, Map 34)

Diagnosis. Body length $1.5-2.0 \mathrm{~mm}$, oval; body black, legs and antennae mostly yellowish to reddish only hind femora reddish-brown to dark brown and last 2-4 antennomeres infuscate; pronotum transverse, anterior corners form blunt denticle, sides rounded, disc moderately convex with two basal, deep longitudinal furrows and deeply impressed area between the furrows, surface of disc mostly coarsely and densely punctate, interspaces with alutaceous microsculpture; base of elytra wider than base of 
pronotum, disc with regular rows of moderately coarse but dense punctures, interspaces with alutaceous microsculpture, whole surface of elytra with long, erect, white hair; humeral callus marked; antennae long, longer than half length of body, legs slim, hind femora strongly swollen, hind tibiae straight, without apical notches or spurs; sexual dimorphism indistinct, first segment of fore tarsi in male only slightly wider than in female, antennae in male slightly longer than in female.

Native range. Palearctic: widespread across much of Europe and Russia (Döberl 2000, Bienkowski and Orlova-Bienkowskaja 2016); adventive in Canada and the USA (Deczynski 2014, 2019).

Distribution in Canada. NS, ON, QC (Deczynski 2019).

Distribution in USA. IL, MA, NH, NY, OR, WI (Deczynski 2014, 2019).

First Canadian records. Montreal, QC and Wellington County, ON in 1975 (Deczynski 2019).

First North American records. As above. The earliest USA record is from Rochester, NY in 1983 (Deczynski 2019).

Habitat and host data. Adults and larvae are oligophagous, and in the Palearctic they attack solanaceous hosts, mostly Solanum dulcamara L. and Hyoscyamus niger L., and occasionally Atropa belladonna L.; adults recently were observed also on potato in Portugal (Highet and Pearson 2015). Other solanaceous plants in the genera Nicotiana, Lycopersicon, Lycium, and Datura also are listed as hosts in the Palearctic (Bienkowski and Orlova-Bienkowskaja 2016). In ON and WI, the only hosts recorded for E. pubescens are European bittersweet ( $S$. dulcamara), a common weed that was introduced into North America from Europe, and an unidentified Solanum sp. in Toronto (Deczynski 2019).

44. Longitarsus ferrugineus (Foudras) [mint flea beetle]

(Fig. 44, Map 35)

Diagnosis. Body length 2.0-2.5 mm, oval; whole dorsum orange-brown or amber-yellow, with head brown-black in some, basal antennomeres yellow, from sixth antennomere gradually darker to apex, legs yellow, femora usually slightly darker than tibiae, orange-brown; frontal tubercles separated from remainder of frons by transverse furrows; pronotum wider than long, without impressions, surface of disc punctate, interspaces from glossy to slightly microreticulate; base of elytra slightly wider than 
posterior of pronotum, elytral disc with irregular, fine punctures, not aligned into striae, interspaces glossy, humeral callus weak; hind femora strongly swollen, hind tibiae almost straight, with long apical spur, only slightly shorter than width of apex of hind tibia, first tarsomere of foreleg not sexually dimorphic.

Native range. Palearctic: Europe, Caucasus, North Africa (Löbl and Smetana 2010); adventive in Canada and the USA (LeSage 1988).

Distribution in Canada. ON, PE, QC (LeSage 1988, Riley et al. 2003, Bousquet et al. 2013). Although LeSage (1988) listed it from NF, citing the source as "unpublished data," we have not seen specimens from that province, so we consider this record questionable and choose to omit it.

Distribution in USA. ID, IN, MI, NY, OR, WA (Downie and Arnett 1996, Riley et al. 2003, Klimaszewski et al. 2010).

First Canadian records. Prince Edward County, ON in 1920 (CNC); Montreal, QC in 1979 (CNC); Chappell, PE in 1982 (CNC).

First North American records. As above. The earliest records for the USA are from near Fennville and Decatur, MI in 1922, possibly introduced on mint roots (Mentha sp.) imported from England (cited as Longitarsus waterhousei Kutschera (Gentner 1928), a synonym of L. ferrugineus, and as Longitarsus menthaphagus Gentner (Gentner 1926a), a replacement name for Longitarsus menthae Genter; also LeSage 1988, 1991). The first record from western North America is from OR in 1936 (as L. waterhousei; Hatch 1971, Riley et al. 2003).

Habitat and host data. This species feeds on Mentha spp., and is a pest of cultivated varieties. It is also on species of Lycopus and Teucrium in Europe (Lamiaceae) (Clark et al. 2004, Bukejs 2010, Klimaszewski et al. 2010). Adults feed on leaves and larvae on roots.

45. Longitarsus flavicornis (Stephens) [ragwort flea beetle] (Fig. 45, Map 36)

Diagnosis. Body length 2.6-3.4 mm, oval; almost whole body ochre to red-brown, apical antennomeres not or slightly darker, hind femora slightly darker than tibiae; frontal tubercles weak, not separated from the remaining surface of frons by transverse furrows; pronotum slightly wider than long, without impressions, surface of disc finely and sparsely punctate, interspaces glossy; elytra base wider than posterior of pronotum, 
disc with irregularly spaced fine punctures, not aligned into striae, interspaces somewhat dull, humeral callus absent; hind femora strongly swollen, hind tibiae almost straight, with short apical spur, shorter than width of apex of hind tibia, first tarsomere of male foreleg only slightly broader than in female, first tarsomere of hind leg longer than tarsomeres 2-5 combined.

Adults of Longitarsus flavicornis and Longitarsus jacobaeae (Waterhouse) closely resemble one another. Longitarsus flavicornis appears more red-brown than the paler yellow L. jacobaeae, has reduced humeral calli while in L. jacobaeae humeral calli are distinct, the aedeagus is more constricted at midlength than in L. jacobaeae, and the ventral membrane of the aedeagus on the posterior half is striated laterally while in $L$. jacobaeae the membrane is without striation or with very short, indistinct striation.

Native range. Palearctic: Europe, North Africa (Löbl and Smetana 2010); released as a biocontrol agent in Canada and the USA (Wilkinson 1986, Harris and Crozier 2006, Bousquet et al. 2013).

Distribution in Canada. BC (Wilkinson 1986, Harris and Crozier 2006, Bousquet et al. 2013, Turner and Cesselli 2013). It is uncertain whether this species still occurs in Canada.

Distribution in USA. MT, OR (Rees et al. 1996, Turner and Cesselli 2013). It is not known if these populations were from releases. The status of establishment in the USA remains uncertain.

First Canadian records. The first release of L. flavicornis is believed to have been near Nanaimo, BC in 1974 and was an inadvertent release of specimens included in a shipment of L. jacobaeae from England (Anonymous 2015). Subsequent collections were made from the established Nanaimo site and released on the lower mainland, but there was no attempt to sort out the two species so it is assumed that the translocations included both species (Anonymous 2015).

First North American records. As above.

Habitat and host data. Introduced in the Coastal Douglas-fir Biogeoclimatic Zone of BC for biological control of tansy ragwort, Jacobaea vulgaris Gaertn (Asteraceae) (Turner and Cesselli 2013). Adults create ragged shot-hole feeding patterns on leaves and larvae feed on roots. Longitarsus flavicornis requires sunny locations with a high density of plants growing in well-drained soils. It does not tolerate flooding, heavy shade or elevation over $400 \mathrm{~m}$. Areas with long, moist autumns are required. 


\section{Longitarsus ganglbaueri Heikertinger}

(Fig. 46, Map 36)

Diagnosis. Body length 2.3-2.5 mm, oval; head, ventral surfaces and apical 6-7 antennomeres black, basal antennomeres, pronotum and elytra yellow to yellow-brown, elytra bordered by brown longitudinal stripe along suture in most, sometimes also pronotal sides with diffuse brown patches, legs yellow, tarsi at least with tarsomeres 3-5 darker, hind femora brown to black dorsally and yellow-brown ventrally; frontal tubercles weak, not separated from the remaining surface of frons by transverse furrow; pronotum slightly wider than long, without transverse impressions, surface of disc finely and sparsely punctate, interspaces usually slightly dull and often microreticulate; base of elytra wider than posterior of pronotum, disc with irregular punctures, punctures not arranged into striae, interspaces glossy, humeral callus weak; hind femora strongly swollen, hind tibiae straight, with short apical spur, shorter than width of apex of hind tibia, first tarsomere of foreleg sexually dimorphic, in male broader than in female, first tarsomere of hindleg longer than tarsomeres $2-5$ combined.

Native range. Palearctic: Europe (Löbl and Smetana 2010); adventive in Canada and the USA (Bousquet et al. 2013).

Distribution in Canada. MB, NB, NS, PE?, QC? (Westcott et al. 1985, Riley et al. 2003, Hoebeke and Wheeler 2005, Bousquet et al. 2013, Webster 2016). Bousquet et al. (2013) recorded it from PE and QC but we were unable to locate specimens or verified records so these jurisdictional records are questionable.

Distribution in USA. OR (Westcott et al. 1985, Riley et al. 2003).

First Canadian records. Glenlea, MB in 1978 (Westcott et al. 1985); Halifax, NS in 1993 (Hoebeke and Wheeler 2005).

First North American records. Linn Co., OR in 1976 (Westcott et al. 1985).

Habitat and host data. In Europe and North America, this species is recorded from various ragwort species, Senecio spp. (Asteraceae) (LeSage 1988).

47. Longitarsus jacobaeae (Waterhouse) [tansy ragwort flea beetle] (Fig. 47, Map 37)

Diagnosis. Body length 2.5-4.0 mm, oval; almost whole body orange-brown or amber-yellow, only antennomeres 5-11 gradually darker, mouthparts and tarsomeres 3-5 
brown, hind femora not or only slightly darker than tibiae; frontal tubercles weak, not separated from the remaining surface of frons by transverse furrows; pronotum slightly wider than long, without impressions, surface of disc finely and sparsely punctate, interspaces glossy; base of elytra wider than posterior of pronotum, elytral disc with irregular, fine punctures which are not arranged into striae, interspaces somewhat dull, humeral calli absent; hind femora strongly swollen, hind tibiae almost straight, with short apical spur, shorter than width of apex of hind tibia, first tarsomere of male foreleg only slightly broader than in female, first tarsomere of hindleg longer than tarsomeres 2-5 combined.

Native range. Palearctic: Europe (Löbl and Smetana 2010); introduced as a biocontrol agent to Canada and the USA (Harris et al. 1984, Bousquet et al. 2013).

Distribution in Canada. BC, NB?, NS, PE (Riley et al. 2003, Hoebeke and Wheeler 2005, Bousquet et al. 2013). Although released near Cambridge, ON in 1984 (Peter Harris, unpublished data), there is no evidence the species is established in ON. Specimens and verified locality records from NB have not been encountered beyond the release site at Fredericton; however, it seems likely the species is present in NB given how widespread it is in NS.

Distribution in USA. CA, OR, WA (Frick 1970, Westcott et al. 1985, Riley et al. 2003).

First Canadian records. This species was first released (and established) in Canada at Vancouver, BC in 1971 using stock from California that had originated near Rome, Italy (Harris et al. 1984). Other material was released at Abbotsford, Chilliwack and Nanaimo, BC between 1971-1978 with apparent establishment. Material from established populations in BC was released in PE (Mt. Herbert and Charlottetown) in 1978 and 1981, in NB (Fredericton) in 1981, and in ON (near Cambridge) in 1984, with apparent establishment in PE and uncertain establishment in $\mathrm{NB}$ and $\mathrm{ON}$.

First North American records. Releases in the USA began in 1969 in CA (Frick 1970, Julien and Griffiths 1998).

Habitat and host data. This species was introduced to Canada as a biocontrol agent targeting the perennial weed tansy ragwort, Jacobaea vulgaris Gaertn. It also occasionally breeds on other Jacobaea spp. (Frick 1970, LeSage 1988). 


\section{Longitarsus lewisii Baly}

(Fig. 48 a, b, Map 38)

Diagnosis. Body length 1.8-2.1 mm, oval; head yellowish-brown to black, pronotum and elytra yellow to yellow-brown, elytral suture in posterior two-thirds or more black, scutellum and ventral surfaces brown to black, antennomeres 1-3 yellow, more distal antennormeres gradually darker, legs yellow with hind femora brown to black, in dark specimens whole suture, basal margin of pronotum and lateral margins of elytra black; frontal tubercles not separated from the remaining surface of frons by transverse furrows; pronotum distinctly wider than long, without impressions, surface of disc finely and sparsely punctate, interspaces with diffused microreticulation; base of elytra wider than posterior of pronotum, elytral disc with irregular, fine punctures, punctures not arranged into striae, interspaces microreticulate, humeral callus variably present; hind femora strongly swollen, hind tibiae straight, with apical spur shorter than width of apex of hind tibia, first tarsomere of fore leg broader in male than female, first tarsomere of hind leg longer than tarsomeres 2-5 combined.

Native range. Palearctic: widespread in Europe, throughout Eurasia to China and the Russian Far East (Pentinsaari et al. 2019); adventive in Canada and the USA (Pentinsaari et al. 2019).

Distribution in Canada. ON (Pentinsaari et al. 2019).

Distribution in USA. Not recorded.

First Canadian records. Cornwall, ON in 2016 (Pentinsaari et al. 2019).

First North American records. As above.

Habitat and host data. This species feeds on Plantago species, especially P. major L. (Koch 1992, Rutanen and Martikainen 2014). In Finland, it is most often collected in dry, barren habitats (Rutanen and Martikainen 2014). The Canadian specimens were collected with a Malaise trap in a suburban residential area (Pentinsaari et al. 2019).

\section{Longitarsus luridus (Scopoli)}

(Fig. 49, Map 39)

Diagnosis. Body length 1.6-2.4 mm, oval; colour extremely variable, in the most common form dorsum uniformly yellow-brown, with yellow-brown basal antenno- 
meres and legs, and brown apical antennomeres and hind femora, but other specimens almost uniformly yellow to nearly dark brown with paler basal antennomeres tibiae and tarsi, or bicoloured, red-brown with dark brown stripe along suture and paler spots on humeri and in apices of elytra; frontal tubercles weak, not separated from the remaining surface of frons by transverse furrows; pronotum slightly wider than long, without impressions, surface of disc punctate, interspaces from glossy to microreticulate, dull; base of elytra slightly wider than posterior of pronotum, elytral disc with irregular punctures, which are not arranged into striae, interspaces from glossy to slightly dull, humeral callus absent; hind femora strongly swollen, hind tibiae curved, with short apical spur, shorter than width of apex of hind tibia, first tarsomere of male foreleg broader than in female, first tarsomere of hindleg longer than tarsomeres 2-5 combined.

Native range. Palearctic: Europe (Löbl and Smetana 2010); adventive in Canada and the USA (Riley et al. 2003, Bousquet et al. 2013).

Distribution in Canada. NB, NF, NS, ON, PE, QC (Riley et al. 2003, Bousquet et al. 2013).

Distribution in USA. CT, ME, VT (Riley et al. 2003).

First Canadian records. Truro, NS in 1913 (CNC specimens); Lauzon, QC in 1921 (CNC); Prince Edward Co., ON in 1925 (CNC); Bathurst, NB in 1939 (CNC); widespread in NF in 1949 (CNC).

First North American records. As above. The first published USA record is Amston, Tolland Co., CT in 1979 (Anonymous 1981, Hoebeke and Wheeler 1983).

Habitat and host data. Larvae are reported as leafminers of Plantago in Europe (LeSage 1988). The primary host plants of L. luridus has not been confirmed in North America (LeSage 1988). In the United Kingdom, adult hosts include members of the families Boraginaceae and Urticaceae (LeSage 1988).

\section{Longitarsus pellucidus (Foudras)}

(Fig. 50, Map 40)

Diagnosis. Body length 2.0-2.4 mm, oval; almost whole body pale yellow-brown, only antennomeres 5-11 gradually darker, and ventral surfaces and hind femora darker; frontal tubercles weak, not separated from the remaining surface of frons by transverse 
furrows; pronotum wider than long, without impressions, surface of disc finely and sparsely punctate, interspaces glossy; base of elytra not or only slightly wider than posterior of pronotum, elytral disc with irregular, fine punctures which are not arranged into striae, but forming irregular rows in some, interspaces glossy, humeral callus weak; hind femora strongly swollen, hind tibiae slightly curved, with short apical spur, spur shorter than width of apex of hind tibia, first tarsomere of male foreleg broader than in female, first tarsomere of hindleg longer than tarsomeres 2-5 combined.

Native range. Palearctic: Europe (Löbl and Smetana 2010); adventive in Canada (Bousquet et al. 2013).

Distribution in Canada. ON, QC? (Riley et al. 2003, Bousquet et al. 2013). Although recorded from QC in some checklists (e.g., Riley et al. 2003, Bousquet et al. 2013), we have not seen specimens or verified locality records; thus, this jurisdictional record is questionable.

Distribution in USA. Not recorded. As it is known from adjacent parts of Canada, it possibly occurs in the northeastern USA.

First Canadian records. Prince Edward Co., ON from sometime between 1926 to 1955 (CNC; LeSage 1988); Chatham, ON in 1933 (CNC).

First North American records. As above.

Habitat and host data. In Europe, this species is recorded mostly from Convolvulus spp. and Calystegia spp. (Convolvulaceae) (LeSage 1988, Clark et al. 2004).

\section{Longitarsus pratensis (Panzer)}

(Fig. 51, Map 41)

Diagnosis. Body length $1.4-1.8 \mathrm{~mm}$, oval; head brown to black, pronotum and elytra yellow to yellow-brown, scutellum and ventral surfaces brown to black, antennomeres 1-5 yellow, more distal antennomeres gradually darker, legs yellow with hind femora brown to black and last two tarsomeres somewhat darker, in dark specimens pronotum often partly darker and elytral suture narrowly brown; frontal tubercles softly marked, not separated from the remaining surface of frons by transverse furrows; pronotum distinctly wider than long, without impressions, surface of disc finely and sparsely punctate, interspaces microreticulate; base of elytra wider than posterior of pronotum, elytral disc with irregular, fine punctures, punctures not 
arranged into striae, interspaces microreticulate, humeral callus strong; legs short, hind femora strongly swollen, hind tibiae straight, with apical spur shorter than width of apex of hind tibia, first tarsomere of foreleg broader in male than female, first tarsomere of hindleg longer than tarsomeres 2-5 combined.

Native range. Palearctic: Europe (Löbl and Smetana 2010); adventive in Canada and the USA (LeSage 1988, Riley et al. 2003, Bousquet et al. 2013).

Distribution in Canada. ON, PE, QC (LeSage 1988, Riley et al. 2003, Bousquet et al. 2013).

Distribution in USA. NC, NY, TN, VA, WV (Riley et al. 2003).

First Canadian records. Aylmer, QC in 1924 (CNC); Southampton, ON in 1939 (CNC; LeSage 1988); Charlottetown, PE in 1987 (LeSage 1988).

First North American records. As above. The earliest published USA record is from Ithaca, NY in 1928 (Heikertinger 1929, LeSage 1988).

Habitat and host data. In Europe, most collections are from Plantago spp. (Plantaginaceae). In North America, it is associated with Plantago major L. and P. lanceolata L. (LeSage 1988; E.R. Hoebeke, unpublished data).

\section{Longitarsus quadriguttatus (Pontoppidan)}

(Fig. 52, Map 42)

Diagnosis. Body length 2.5-3.3 mm, short oval; head, pronotum and ventral surfaces black, elytra black, with four diffuse yellow-red spots in most specimens, two on humeri and two apically, sometimes humeral and apical spots elongated and connected together to form a lateral stripe, occasionally whole elytra black, antennomeres 1-5 yellow, more distal antennomeres gradually darker, apical antennomeres black, legs mostly yellow, hind femora brown to black and tarsomeres 3-5 darker; frontal tubercles lightly marked, separated from the remaining surface of frons by shallow transverse furrows; pronotum slightly wider than long, without impressions, surface of disc finely and sparsely punctate, interspaces glossy; elytra base wider than posterior of pronotum, disc with irregular punctures, punctures not arranged in striae, interspaces glossy, humeral callus weak; hind femora strongly swollen, hind tibiae straight, with short apical spur, shorter than width of apex of hind tibia, first tarsomere of male foreleg broader than in female, first tarsomere of hindleg longer than tarsomeres 2-5 combined. 
Native range. Palearctic: Europe (Löbl and Smetana 2010); introduced as a biocontrol agent to Canada (Bousquet et al. 2013, DeClerck-Floate 2013).

Distribution in Canada. AB, BC (Riley et al. 2003, Bousquet et al. 2013). Although the species is established at multiple localities in $\mathrm{BC}$, it is not clear whether the previously established population in $\mathrm{AB}$ is still present as the last confirmation of its presence was in 2009 (DeClerck-Floate 2013).

Distribution in USA. The species was not released in the USA, and natural spread from established populations in Canada to the USA has not yet been documented.

First Canadian records. The first releases were in Kamloops, BC in 1998-1999 and Lethbridge, $\mathrm{AB}$ in 1999 for control of the perennial weed, houndstongue, Cynoglossum officinale L. (Boraginaceae) (DeClerck-Floate 2013, Winston et al. 2016).

First North American records. As above.

Habitat and host data. Adults feed on aerial plant parts of houndstongue while the larvae mine in the cortex of the taproot and in secondary roots (Schwarzländer 2000).

\section{Longitarsus rubiginosus (Foudras)}

(Fig. 53, Map 43)

Diagnosis. Body length 1.8-2.7 mm, oval; almost whole body yellow to yellow-brown, including legs and antennae, sometimes hind femora and apical antennomeres orange-brown, autumn generation usually darker than summer generation; frontal tubercles somewhat elevated, not separated from the remaining surface of frons by transverse furrows; antennae long, in male as long as in female, slightly shorter than body length; pronotum wider than long, without impressions, surface of disc fine and sparsely punctate, interspaces glossy; elytra base not wider than posterior of pronotum, disc with irregular punctures, not arranged into striae, interspaces glossy, humeral callus weak; hind femora strongly swollen, hind tibiae slightly curved, with short apical spur, shorter than width of apex of hind tibia, first tarsomere of male foreleg slightly broader than in female, first tarsomere of hindleg longer than tarsomeres $2-5$ combined.

Native range. Palearctic: Europe (Löbl and Smetana 2010); adventive in Canada (Riley et al. 2003, Bousquet et al. 2013). 
Distribution in Canada. NB, NS, ON, PE, QC (Riley et al. 2003, Hoebeke and Wheeler 2005, Bousquet et al. 2013, Webster et al. 2016). New jurisdictional records: PE: Chappell, 27 Aug. 1982, yellow pan trap in potato field, L.S. Thompson (CNC); Harrington, 5 Sept. 1986 (1 specimen, CNC); New London Bay, 2 Sept. 2001 (5 specimens, CNC).

Distribution in USA. Not yet recorded but it is expected that spread from Canada will occur.

First Canadian records. Prince Edward Co., ON in 1957 (LeSage 1988); Nicolet, QC in 1975 (CNC); Chappell, PE in 1982 (CNC); Shelburne, NS in 1994 (Hoebeke and Wheeler 2005).

First North American records. As above.

Habitat and host data. In Europe, this species is recorded mostly from Convolvulus spp. and Calystegia spp. (Convolvulaceae) (LeSage 1988, Clark et al. 2004).

54. Longitarsus succineus (Foudras) [chrysanthemum flea beetle] (Fig. 54, Map 44)

Diagnosis. Body length 1.7-2.4 mm, oval; almost whole body yellow-brown, including legs and antennae, sometimes hind femora and apical antennomeres darker; frontal tubercles weak, not separated from the remaining surface of frons by transverse furrows; antennae very long, as long as or slightly longer than body length; pronotum wider than long, without impressions, surface of disc extremely fine and sparsely punctate, interspaces glossy; elytra base not wider than posterior of pronotum, disc with irregular, fine and sparse punctures, not arranged into striae, interspaces glossy, humeral callus weak; hind femora strongly swollen, hind tibiae slightly curved, with short apical spur, shorter than width of apex of hind tibia, first tarsomere of male foreleg not broader than in female, first tarsomere of hindleg longer than tarsomeres 2-5 combined.

Native range. Palearctic: Europe (Löbl and Smetana 2010); adventive in Canada (Riley et al. 2003, Bousquet et al. 2013).

Distribution in Canada. NF (Riley et al. 2003, Bousquet et al. 2013). 
Distribution in USA. Not recorded.

First Canadian records. St. John's, NF before 1926 [as Longitarsus ovalis Genter, a synonym of L. succineus (CNC; Gentner 1926b, Brown 1967)].

First North American records. As above.

Habitat and host data. In Europe, hosts include mostly composites, such as Achillea, Artemesia, Chrysanthemum, Eupatorium, and Jacobaea. In North America, host plants are not yet determined (LeSage 1988).

55. Lythraria salicariae (Paykull) [loosestrife flea beetle]

(Fig. 55 a, b, Map 45)

Diagnosis. Body length 1.8-2.3 mm, short-oval; whole body, including legs and antennae, yellowish to rusty, in the darkest specimens red-brown, sutural margin in posterior two-thirds or more brown to black; frons impunctate, glossy; pronotum much wider than long, without impressions, surface of disc finely and sparsely punctate, interspaces smooth and more or less glossy; base of elytra wider than posterior of pronotum, elytral disc with regular, moderately coarse punctures, arranged into striae, interspaces smooth and more or less glossy; hind femora moderately swollen, hind tibiae straight, without apical excavation and spurs, first tarsomere of foreleg broader in male than female, first tarsomere of hindleg shorter than tarsomeres $2-5$ combined.

Native range. Palearctic: Widespread in Europe, scattered records in Asia to East Siberia and Japan (Döberl 2010); adventive in Canada and the USA (Pentinsaari et al. 2019).

Distribution in Canada. ON (Pentinsaari et al. 2019).

Distribution in USA. Not recorded.

First Canadian records. Cambridge, ON in 2017 (Pentinsaari et al. 2019).

First North American records. As above.

Habitat and host data. Lythraria salicariae occurs in wetland and marshy shoreline habitats as well as in forest depressions (Koch 1992). The larvae develop on Lysimachia species, and the adults occasionally feed also on Lythrum salicaria L. (Koch 1992, Dol- 
govskaya et al. 2004). The Canadian specimens were collected with pan traps in a grassy wetland and a mixed habitat of agricultural fields and forest (Pentinsaari et al. 2019).

\section{Mantura chrysanthemi (Koch)}

(Fig. 56, Map 46)

Diagnosis. Body length 1.8-2.5 mm, elongate; dorsum usually red-brown to brownblack with brass or copper reflection, pale specimens often red-brown with indistinct metallic reflection, basal six antennomeres red-brown, first two often brown dorsally, distal five antennomeres brown to black, legs mostly red-brown, hind femora brown; antennae $<50 \%$ length of body; pronotum wider than long, sides regularly rounded, disc convex with two basal, longitudinal furrows, but without transverse furrow, surface of disc with coarse punctures separated by twice their average diameter, interspaces somewhat microreticulate; elytra base not wider than posterior of pronotum, disc with regular impressed rows of strial punctures, interspaces from glossy to dull, humeral callus low; hind femora strongly swollen, hind tibiae narrow in basal half then broadened apically, without apical spur, first tarsomere of male foreleg broader than in female.

Native range. Palearctic: Europe (Löbl and Smetana 2010); adventive in Canada and the USA (Riley et al. 2003, Bousquet et al. 2013).

Distribution in Canada. AB, MB, NB, NF, NS, ON, PE, QC, SK (Levesque and Levesque 1998, Riley et al. 2003, Majka 2010, Webster et al. 2012, Bousquet et al. 2013).

Distribution in USA. MA, MD, ME, NH, NJ, NY, OH, PA, RI (Riley et al. 2003, online images at www.bugguide.net).

First Canadian records. Prince Edward County, ON in 1900 (CNC); Aweme, MB in 1908 (CNC); Lethbridge, AB in 1939 (CNC); Imperoyal, NS in 1947 (CNC); several localities in NF in 1949 (CNC); Hull, QC in 1954 (CNC); Saskatoon, SK in 1976 (CNC).

First North American records. As above. The first published USA record is from Framingham, MA before 1950 (Brown 1950).

Habitat and host data. This species appears to be oligophagous on a small number of plants in the genus Rumex (Polygonaceae) (Harms and Grodowitz 2009), including sheep sorrel, Rumex acetosella L. (Brown 1950, Clark et al. 2004, Saroli et al. 2016). 
57. Neocrepidodera ferruginea (Scopoli) [European rusted flea beetle, wheat flea beetle] (Fig. 57, Map 47)

Diagnosis. Body length 2.7-3.6 mm, elongate; body uniformly yellow-red to red, including legs and antennae; antennae $>50 \%$ length of body; pronotum wider than long, sides rounded, disc convex with two posterior, deep longitudinal impressions and connected by a deep transverse impression, surface of disc finely and sparsely impunctate and glossy; elytra base wider than posterior of pronotum, disc with regular impressed strial rows of punctures, interstriae glossy, humeral callus low; hind femora strongly swollen, hind tibiae straight, without apical spur, first tarsomere of male foreleg broader than in female.

Native range. Palearctic: Europe (Löbl and Smetana 2010); adventive in Canada (LeSage and Savard 2012, Bousquet et al. 2013).

Distribution in Canada. ON, PE, QC (LeSage and Savard 2012, Bousquet et al. 2013). New jurisdictional record: PE: Crapaud, 15 Sept. 2011, pitfall trap, C. Noronha (1 specimen, $\mathrm{CNC}$ ).

Distribution in USA. Not recorded.

First Canadian records. Niagara Falls, ON in 1977 (CNC; LeSage and Savard 2012); Aylmer, QC in 2003 (CNC).

First North American records. As above.

Habitat and host data. Adults are polyphagous and larvae attack several cultivated cereals (Poacaeae). Little is known about its biology in North America. Although numerous "hosts" are reported for adults of $N$. ferruginea, most cannot be considered larval hosts since larval development was observed only in a few species of Poaceae (LeSage and Savard 2012).

58. Phyllotreta armoraciae (Koch) [horseradish flea beetle] (Fig. 58, Map 49)

Diagnosis. Body length 2.5-3.5 mm, oval; head, pronotum and scutellum black, elytra mostly yellow with broad, black stripe along suture and narrow black stripe surrounding disc, humeri yellow, antennomeres 1-3 yellow, first antennomere sometimes darker dorsally, antennomeres 4-11 black, tibiae and tarsi yellow, fore and mid femora 
mostly brown to black with yellow-brown apex, hind femora black, sometimes also last two tarsomeres darker; frons with group of small punctures; pronotum wider than long, sides regularly rounded, disc convex, without impressions, surface of disc finely and sparsely punctate, interspaces about two times puncture diameter and glossy or with diffuse microreticulation; elytra base slightly wider than posterior of pronotum, disc with completely irregular, fine punctation not arranged into strial rows, interspaces glossy, humeral callus weak; hind femora swollen, hind tibiae straight, without apical spur, first tarsomere of male foreleg broader than in female.

Native range. Palearctic: Europe (Löbl and Smetana 2010); adventive in Canada and the USA (Riley et al. 2003, Bousquet et al. 2013).

Distribution in Canada. AB, BC, MB, NB, NS, ON, PE?, QC, SK (Riley et al. 2003, Klimaszewski et al. 2010, Bousquet et al. 2013). Although listed from PE in various checklists (e.g., Bousquet et al. 2013), we have not seen specimens or verified locality records; thus, this jurisdictional record should be treated as questionable. However, given its wide distribution, it seems likely it occurs in PE. New jurisdictional record: AB: Medicine Hat, 8 May 1965, Lot 3, Carr (1 specimen, CNC).

Distribution in USA. CT, DE, IA, ID, IL, IN, MA, ME, MI, MN, MO, MS, ND, NE, NH, NJ, NY, OH, OR, PA, SD, WA, WI, WV (Riley et al. 2003, online images at www.bugguide.net).

First Canadian records. The earliest accessioned specimen in a collection is from Montreal, QC in 1910 (CNC); however, the earliest published record from Canada is from an undisclosed locality in ON in 1908 (Beirne 1971). Other early records include Creston, BC in 1928 (UBC); Rock Lake, MB in 1929 (CNC); Fredericton, NB in 1930 (CNC); Moose Jaw, SK in 1944 (Burgess 1980, 1981); and Kentville, NS in 1956 (CNC).

First North American records. Chicago, IL in 1893 (Chittenden 1895, Chittenden 1927, Burgess 1981).

Habitat and host data. In its native range, $P$. armoraciae is considered a monophagous species feeding only on horseradish, Armoracia lapathifolia Usteri (Brassicaecae) (Vig and Verdyck 2001). Phyllotreta armoraciae is not monophagous under laboratory conditions, and may utilize other hosts; adults feed on several cruciferous plants to the same extent as on horseradish (Vig and Verdyck 2001), including radish, cabbage, and turnip in Canada (Beirne 1971). Larvae are stem miners, restricted to the petiole and midribs of horseradish leaves, and rarely mine the roots (Chittenden 1923). 
59. Phyllotreta cruciferae (Goeze) [crucifer flea beetle, cabbage flea beetle] (Fig. 59, Map 50)

Diagnosis. Body length $1.8-2.5 \mathrm{~mm}$, elongate to elongate-oval; dorsum black with green or blue metallic reflection, antennomeres $1-4$ yellow but often antennomeres 1 and 4 partly darker, antennomeres 5-11 black, legs mostly black, apex of femur, basal parts of tibiae and tarsi often red-brown to brown; frons with group of small punctures; pronotum wider than long, sides regularly rounded, disc convex, without impressions, surface of disc finely punctate with punctures separated by 1.0-1.5 times average puncture diameter, interspaces with diffuse microreticulation; elytra base slightly wider than posterior of pronotum, disc mostly with irregular punctation, punctures often tend to form somewhat regular rows but strial rows not coherent for entire length of elytra, interspaces glossy, humeral callus weak; hind femora swollen, hind tibiae straight, without apical spur, first tarsomere of male foreleg slightly broader than in female.

Native range. Palearctic: Europe (Löbl and Smetana 2010); adventive in Canada and the USA (Riley et al. 2003, Bousquet et al. 2013).

Distribution in Canada. AB, BC, MB, NB, NS, ON, PE, QC, SK (Riley et al. 2003, Bousquet et al. 2013).

Distribution in USA. CA, CO, CT, DE, ID, IL, MA, MD, ME, MN, MT, ND, NH, NY, OH, OR, PA, RI, SD, UT, WI, WV, WY (Riley et al. 2003, online images at www.bugguide.net)

First Canadian records. Agassiz, BC in 1921 (CNC; Brown 1967); Sandy Cove, NS in 1931 (CNC). It was reported from all three prairie provinces in the 1940s but was undoubtedly there in the 1930s (Brown 1967), although the earliest specimen from the prairie provinces accessioned in a collection is from Yorkton, SK in 1946 (RSM). Brown (1967) reported the species from eastern ON and southwestern QC in 1954; however, there are specimens from Prince Edward County, ON in 1946 (CNC) and Guelph, ON in 1948 (CNC).

First North American records. As above. The earliest published USA records include Friday Harbor, WA in 1926 (Hatch 1971); OR in 1935; MN in 1947; and DE in 1951 (Milliron 1953).

Habitat and host data. Host plants include mainly mustards and related plants (Brassicaceae), but especially canola (Palaniswamy and Lamb 1992). It is an important agricul- 
tural pest of canola in the northern Great Plains of the USA and Canada. Adult flea beetles emerge in the spring and feed on the cotyledons and leaves (Palaniswamy and Lamb 1992).

60. Phyllotreta punctulata (Marsham) [radish flea beetle]

(Fig. 60, Map 48)

Diagnosis. Body length 1.6-2.0 mm, elongate to elongate-oval; dorsum black without metallic reflection, antennomeres $1-4$ yellow but often antennomeres 1 and 4 partly darker, antennomeres 5-11 black, legs mostly black, basal parts of tibiae and first tarsomere often red-brown to brown; frons with group of small punctures; pronotum wider than long, sides regularly rounded, disc convex, without impressions, surface of disc finely but densely punctate, interspaces with microreticulation; elytra base slightly wider than posterior of pronotum, disc with completely irregular punctation, not arranged into strial rows, interspaces microreticulate, humeral callus weak; hind femora swollen, hind tibiae straight, without apical spur, first tarsomere of male foreleg slightly broader than in female.

Native range. Palearctic: Europe (Löbl and Smetana 2010); adventive in Canada and the USA (Riley et al. 2003, Bousquet et al. 2013).

Distribution in Canada. NB?, ON, QC (Bousquet et al. 2013). Although recorded (as the synonym Phyllotreta aerea Allard) from NB by Bousquet et al. (2013), we could not find specimens or locality records; thus, this jurisdictional record is questionable.

Distribution in USA. NY, PA (cited as P. aerea, Chittenden 1927, Riley et al. 2003). Records also exist in the literature for MI and SD (Riley et al. 2003) but these are probably in error.

First Canadian records. Vineland, ON in 1937 (CNC; Beirne 1971, cited as P. aerea); Dunham, QC in 1997 (CNC).

First North American records. Rochester, NY in 1919-1921 (Chittenden 1927, cited as $P$. aerea).

Habitat and host data. The species is associated mainly with various Brassicaceae. The junior synonym, $P$. aerea, was reported from Alliaria, Arabis, Armoracia rusticana G. Gaertn., B. Mey., \& Scherb. (synonym: Armoracia lapathifolia Gilib.), Brassica spp., Bunias spp., Cakile maritima Scop., Erysimum verrucosum Boiss \& Gaill., Isatis tinctoria 
L., Lepidium campestre (L.) R. Br., Raphanus sativus L. Rapistrum rugosum (L.) All., Sinaspis arvensis L., and Sisymbrium altissimum L. (Clark et al. 2004, cited as P. punctulata).

61. Phyllotreta striolata (Fabricius) [striped flea beetle] (Fig. 61, Map 51)

Diagnosis. Body length 1.8-2.2 mm, elongate-oval; head, pronotum and scutellum black, elytra black with yellow pattern forming elongate patch on each elytron, sutural area black, broad with parallel sides at midlength and narrowed anteriorly and posteriorly, black colour surrounds disc, humeri always black, yellow patch deeply emarginate laterally by black colour, not reaching apex or side of elytra, antennomeres 1-3 from yellow to black, remaining antennomeres black, legs mostly black, knee, basal parts of tibiae and tarsi sometimes red-brown to brown; frons with group of small punctures; antennomere 5 as long as 2 and 3 combined in male, slightly flattened; pronotum wider than long, sides regularly rounded, disc convex, without impressions, surface of disc with punctures separated by 0.7 to 1.5 times average puncture diameter, interspaces glossy or with with diffuse microreticulation; elytra base slightly wider than posterior of pronotum, disc with fine punctation, irregular but slightly arranged in short rows in some, interspaces glossy, humeral callus weak; hind femora swollen, hind tibiae straight or slightly curved, without apical spur, first tarsomere of male foreleg broader than in female.

Native range. Palearctic: Europe (Löbl and Smetana 2010); adventive in Canada and the USA (Riley et al. 2003, Bousquet et al. 2013).

Distribution in Canada. AB, BC, MB, NB, NF, NS, NT, ON, PE, QC, SK, YT (Riley et al. 2003, Bousquet et al. 2013).

Distribution in USA. AK and lower 48 states (Riley et al. 2003).

First Canadian records. Quebec City, QC before 1759 (Bain et al. 2009); London, $\mathrm{ON}$ in 1899 (DEBU); Aweme, MB in 1903 (DEBU); Fredericton, NB and Portaupique, NS in 1929 (CNC); Saskatoon, SK in 1926 (CNC); Calgary, AB in 1945 (CNC); Reindeer Depot, NT in 1948 (CNC); Stephenville, NF in 1949; Moberly Lake, BC in 1968 (CNC).

First North American records. Boston, MA from 1675-1740 (Bain 1998, Bain and King 2011). It was first reported from "Carolina" in 1801 and reached the northwestern USA by commerce or an independent introduction before 1923 (Chittenden 1923, Smith 1985, Campbell et al. 1989). 
Habitat and host data. Phyllotreta striolata is a specialist on plants of the family Brassicaceae, attacking cabbage as well as broccoli, Brussels sprouts, cauliflower, Chinese cabbage, collards, horseradish, kale, kohlrabi, mustards, radish, rutabaga, turnip, and also other garden plants (Palaniswamy and Lamb 1992). Most damage is caused by overwintering adults destroying the first leaves as they appear above ground in the spring. Larvae feed on roots of the host plants and often do considerable injury (Beirne 1971). Interestingly, an aggregation of millions of adults of this species was found above treeline at an elevation of ca. $2900 \mathrm{~m}$ in the Rocky Mountains of southwestern Alberta (Askevold 1988).

\section{Psylliodes affinis (Paykull) [European potato flea beetle]}

(Fig. 62, Map 52)

Diagnosis. Body length 2.0-2.6 mm, oval; head red-brown to black, scutellum brownblack, pronotum and elytra from yellow to orange-brown, elytral suture narrowly black, fore and mid legs yellow to orange-brown, femora sometimes darker basally, hind femora brown to black, hind tibiae and tarsi yellow to orange-brown, antennae with 10 yellow antennomeres; frons microreticulate, without punctures; pronotum wider than long with angulate to acute anterior corners, sides softly, regularly rounded, disc convex, without impressions, surface of disc with punctures separated by 1.0-1.5 times average diameter, interspaces glossy or microreticulate; elytra base wider than posterior of pronotum, disc with regular strial rows of punctures that are weakly impressed, interspaces glossy with or with weak microreticulation, humeral callus weak; hind femora strongly swollen, hind tibiae curved, with short apical spur, hind tarsus attached to tibia at four-fifths tibial length (i.e., apex of tibia extends beyond attachment), first tarsomere of male foreleg broader than in female.

Native range. Palearctic: Europe (Löbl and Smetana 2010); adventive in Canada and the USA (Wheeler and Hoebeke 1983, Bousquet et al. 2013).

Distribution in Canada. BC, NB, NS, ON, PE?, QC (Wheeler and Hoebeke 1983, LeSage 1991, Webster et al. 2012, Bousquet et al. 2013, online images at bugguide. net). Although recorded from PE in some checklists, we have not seen specimens or verified locality records; thus, this jurisdictional record is treated as questionable. New jurisdictional record: BC: Abbotsford, 4902'49.14” N 122¹1'37.81”, w/\# 57 Potato field, Heuppelheuser, 3 June 2008 (2 specimens, CNC).

Distribution in USA. MA, MD, ME, MI, NH, NY, OH, PA, RI, UT, WA, WI, WV (Wheeler and Hoebeke 1983, Wheeler 1992, Cavey 1994, Riley et al. 2003, online images at www.bugguide.net). 
First Canadian records. Guelph, ON in 1972 (DEBU); Montreal, QC in 1980 (CNC); Halifax, NS in 2001 (CNC); Abbotsford, BC in 2008 (CNC).

First North American records. Albany and Greene Counties, NY in 1968 (Anonymous 1968, Wheeler and Hoebeke 1983).

Habitat and host data. Psylliodes affinis, a specialized feeder on Solanaceae, prefers bitter nightshade, Solanum dulcamara L., but often feeds on potato, S. tuberosum L. It is usually only a minor pest of potato but sometimes causes severe local infestations. Adults may attack other solanaceous hosts, including tobacco, tomato, black henbane, and Lycium sp., and occasionally hops (Cannabinaceae) (Wheeler and Hoebeke 1983).

63. Psylliodes chrysocephalus (Linnaeus) [cabbage stem flea beetle, rape flea beetle] (Fig. 63, Map 53)

Diagnosis. Body length 3.2-4.6 mm, elongate-oval; head at least partly red-brown, pronotum, scutellum and elytra in most specimens metallic green or blue, some with whole head and pronotum red-brown, or pronotum metallic green and elytra yellow to yellow-brown, fore and mid legs yellow, hind femora brown to black, hind tibiae and tarsi yellow, antennae with 10 antennomeres, antennomeres 1-3 yellow, more distal antennomeres gradually darker; frons microreticulate, without punctures; pronotum wider than long with obtuse anterior corners, sides regularly rounded, disc convex, without impressions, surface of disc with punctures separated by about 1.0 to 1.5 times average puncture diameter, interspaces glossy; elytra base wider than posterior of pronotum, disc with regular strial rows of punctures, striae not impressed, interstriae glossy, humeral callus weak; hind femora strongly swollen, hind tibiae almost straight, with short apical spur, hind tarsus attached to tibia at four-fifths tibial length (i.e., apex of tibia extends beyond attachment), first tarsomere of male foreleg broader than in female.

Native range. Palearctic: Eurasia, North Africa, northern and western Asia (Bonnemaison 1965, Löbl and Smetana 2010); adventive in Canada and the USA (Riley et al. 2003, Bousquet et al. 2013).

Distribution in Canada. NF (Bousquet et al. 2013).

Distribution in USA. NY (Riley et al. 2003).

First Canadian records. St. John's, NF in 1950 (AAFC, CNC); Topsail, NF in 1951 (MacNay 1952: 227). 
First North American records. As above. The specific locality and the date for the NY record is unknown.

Habitat and host data. This species is highly injurious to cultivated crucifers (Brassicaceae) in the Palearctic Region. It was reported to attack rape at Topsail, NF (MacNay 1952: 227). Adults feed on seed leaves of young plants and the larvae tunnel in stems of plants and midribs of leaves (MacNay 1954).

\section{Psylliodes cucullatus (Illiger)}

(Fig. 64, Map 54)

Diagnosis. Body length 2.0-3.0 mm, oval; dorsum metallic brass or copper, or brownblack with weak iridescence, fore and mid legs yellow to yellow-brown, hind femora brown to black, hind tibiae and tarsi yellow to yellow-brown, antennae with 10 antennomeres, antennomeres 1-4 yellow, more distal antennomeres gradually darker; frons punctate; pronotum only slightly wider than long with angulate anterior corners, sides regularly rounded, disc convex, without impressions, surface of disc with punctures separated by a distance approximately equal to the puncture diameter, interspaces glossy or in female with diffuse microreticulation; elytra base slightly wider than posterior of pronotum, elytra converging posterad, disc with regular strial rows of dense punctures, striae impressed on outer parts of elytra, interstriae glossy or in female with diffuse microreticulation, humeral callus not marked; hind wings reduced; hind femora strongly swollen, hind tibiae almost straight, with short apical spur, hind tarsus attached to tibia at two-thirds tibial length (i.e., apex of tibia extends beyond attachment), first tarsomere of male foreleg broader than in female.

Native range. Palearctic: Eurasia (Löbl and Smetana 2010); adventive in Canada and the USA (Riley et al. 2003, Bousquet et al. 2013).

Distribution in Canada. NB, NS, ON?, QC (Riley et al. 2003, Bousquet et al. 2013). Although recorded from $\mathrm{ON}$ in various checklists (e.g., Riley et al. 2003, Bousquet et al. 2013), we have not seen specimens or verified locality records; thus, this jurisdictional record is questionable.

Distribution in USA. NH (Riley et al. 2003).

First Canadian records. Chatham, NB in 1928 (CNC); multiple locations in QC in 1954 (CNC). 
First North American records. As above. The specific locality and the date for the NH record is unknown.

Habitat and host data. This species, including Palearctic populations, is apparently associated with Poaceae, and has been recorded from Agropyron cristatum (L.) P. Gaertn., Agropyron desertorum (F.E.L. Fischer ex Link) Schult., Eremopyrum cristatum (L.) Willk. \& Lange, Festuca ovina L., and Poa pratensis (L.) (Clark et al. 2004).

\section{Psylliodes napi (Fabricius)}

(Fig. 65, Map 55)

Diagnosis. Body length 2.1-3.3 mm, oval; dorsum black with metallic blue reflections, legs yellow except for brown to black hind femora, antennae with 10 antennomeres, antennomeres 1-3 yellow, more distal antennomeres gradually darker; frons finely punctate; pronotum wider than long with angulate anterior corners, sides regularly rounded, elytral disc convex, without impressions, surface of disc with punctures separated by 1.0-1.5 puncture diameters, interspaces glossy or with diffuse microreticulation; elytra base wider than posterior of pronotum, disc with regular strial rows of punctures, interstriae glossy or with diffuse microreticulation, humeral callus weak; hind femora strongly swollen, hind tibiae almost straight, with short apical spur, hind tarsus attached to tibia at three-quarters tibial length (i.e., apex of tibia extends beyond attachment), first tarsomere of male foreleg broader than in female.

Native range. Palearctic: Europe (Löbl and Smetana 2010); adventive in Canada and the USA (Riley et al. 2003, Bousquet et al. 2013).

Distribution in Canada. NB, NF, ON, PE, QC (Riley et al. 2003, Bousquet et al. 2013).

Distribution in USA. CT, DE, IN, MA, MD, MI, NH, NY, OH, VA, WV (Riley et al. 2003; E. R. Hoebeke, unpublished data).

First Canadian records. Dresden, ON in 1966 (DEBU); Rustico, PE in 1967 (CNC); Carillon, QC in 1975 (CNC); Kouchibouguac National Park, NB in 1977 (CNC); St. John's, NF in 1980 (CNC).

First North American records. Albany Co., NY in 1916 (CNC); Ithaca, NY in 1966 (Tahvanainen and Root 1970); Berkshire Co., MA in 1968 (Hoebeke and Wheeler 1983). 
Habitat and host data. This species feeds on the cruciferous weed Barbarea vulgaris W.T. Aiton in NY (Tahvanainen and Root 1970). In Europe, it feeds on various wild crucifers, including species of Nasturtium, Alliaria, and Cardamine.

\section{Psylliodes picinus (Marsham)}

(Fig. 66, Map 56)

Diagnosis. Body length 2.2-2.8 mm, short-oval; dorsum red-brown to brown, without metallic colour or only in the darkest form with very subtle brass reflection, legs orange to red-brown, hind femora not or somewhat darker than tibiae, antennomeres 1-5 yellow, more distal antennomeres gradually darker; frons impunctate; pronotum wider than long with angulate anterior corners, sides regularly rounded, disc convex, without impressions, surface of disc with punctures separated by 1.0-1.5 times puncture diameter, interspaces glossy; elytra base wider than posterior of pronotum, disc with regular strial rows of fine to moderate and dense punctures, striae impressed on basal two-thirds, interspaces glossy; humeral callus weak; legs with hind femora strongly swollen, hind tibiae short and strongly curved, with short apical spur, hind tarsus attached to tibia at two-thirds tibial length (i.e., apex of tibia extends beyond attachment), first tarsomere of male foreleg broader than in female.

Native range. Palearctic: Europe (Löbl and Smetana 2010); adventive in Canada and the USA (Riley et al. 2003, Bousquet et al. 2013).

Distribution in Canada. NB, NS, ON, QC (Riley et al. 2003, Bousquet et al. 2013, Webster et al. 2016).

Distribution in USA. CT, NH, PA, WV (Riley et al. 2003).

First Canadian records. Elora and Guelph, ON in 1976 (DEBU); Iberville, QC in 1997 (CNC), although LeSage (1991) had already reported it from QC but did not give specific locality records; Caribou, Pictou Co., NS in 2002 (CNC).

First North American records. As above. The earliest USA record is from Bradford Co., near Ulster, PA in 1978 (Hoebeke 1979).

Habitat and host data. This species is known to feed on the thistle, Cirsium palustre (L.) Scop., garden loosestrife (Lysimachia vulgaris L.), and purple loosestrife (Lythrum salicaria L.) (Hoebeke 1979). 


\section{Sphaeroderma testaceum (Fabricius)}

(Fig. 67, Map 57)

Diagnosis. Body length 2.8-4.0 mm, almost spherical; whole body red-brown, including legs and antennae; frons finely punctate; pronotum wider than long, convex, with obtuse anterior corners, sides regularly rounded, disc without impressions, surface of disc finely punctate with punctures separated by $0.7-1.5$ times puncture diameter, interspaces glossy; elytra base wider than posterior of pronotum, disc with fine and sparse, irregular punctation (not arranged into striae) but some punctures tend to form somewhat regular rows, interspaces glossy, humeral callus weak; legs with hind femora swollen, hind tibiae straight to weakly curved, with short apical spur, hind tarsus attached to tibia near apex, first tarsomere of male foreleg strongly enlarged, broader than in female.

Native range. Palearctic: Europe (Löbl and Smetana 2010); adventive in Canada (Hoebeke and Wheeler 2003, Bousquet et al. 2013).

Distribution in Canada. NS, QC (Hoebeke and Wheeler 2003, Bousquet et al. 2013).

Distribution in USA. Not recorded.

First Canadian records. Shubenacadie, NS in 1997 (Majka and LeSage 2006); Quebec City, QC in 2005 (CNC).

First North American records. As above.

Habitat and host data. Adults feed on foliage of the composites Carduus nutans L., Carduus crispus L., Carduus personatus (L.) Jacq., Carduus defloratus L. and species of the genera Cirsium, Carlina, Onopordum, and Silybum (Batra et al. 1981). Larvae mine the leaves of their hosts, especially species of Carduus and Cirsium (Hoebeke and Wheeler 2003). To date, S. testaceum has only been found along major transportation corridors (highway and railway) in Canada (Majka and LeSage 2006).

Tribe Galerucini Latreille

68. Neogalerucella calmariensis (Linnaeus) [black-margined loosestrife beetle] (Fig. 68, Map 58)

Diagnosis. Body length 3.5-5.0 mm, elongate-oval, depressed and covered with short and sparse pubescence; dorsum mostly yellow-brown, or red-brown to brown, head with 
black spot on vertex, pronotum with broad black stripe along middle sometimes reduced to small, black central spot, scutellum often partly brown to black, elytra usually with dark, brown to black stripe along sides, legs orange, or yellow-brown, antennomeres 1-3 yellow-brown, often darker dorsally, remaining antennomeres somewhat gradually darker to black; vertex punctate; pronotum wider than long with angulate anterior and posterior corners, sides regularly rounded, disc depressed, laterally with shallow impressions, surface of disc coarsely punctate (punctures separated by 0.2 to 0.7 puncture diameters), interspaces from slightly glossy to somewhat dull; elytra base wider than posterior of pronotum, almost parallel-sided, disc with irregular coarse and dense punctation, not arranged into strial rows, interspaces from slightly glossy to somewhat dull, humeral callus strong; hind femora not swollen, tibiae straight, without apical spurs; sexual dimorphism in last sternite, in male with deep and narrow posterior emargination, broad and shallow in female.

Native range. Palearctic: Europe (Löbl and Smetana 2010); introduced as a biocontrol agent in Canada and the USA (Riley et al. 2003, Bousquet et al. 2013).

Distribution in Canada. AB, BC, MB, NB, NS?, ON, PE, QC, SK (Riley et al. 2003, Bousquet et al. 2013). It is unknown if this species is established in NS.

Distribution in USA. AL, CO, CT, DC, DE, IA, ID, IL, IN, KS, MA, MD, ME, MI, MN, MO, MT, NH, NY, OH, OR, PA, RI, SD, TN, UT, VA, VT, WA, WI, WV, WY (Riley et al. 2003, Klimaszewski et al. 2010).

First Canadian records. Releases occurred in every province except NF from 19921999 (Lindgren et al. 2002, Denoth and Myers 2005). The earliest releases took place in Wellington Co., ON in 1992 (Hight et al. 1995).

First North American records. As above. There were releases in ID, MD, MN, NY, OR, PA, VA, and WA in 1992, and these had established by 1993-1994 (Hight et al. 1995).

Habitat and host data. This species was imported from Europe as a biological control agent against purple loosestrife (Lythrum salicaria L.) and was successful in controlling the weed (Hight et al. 1995).

\section{Neogalerucella pusilla (Duftschmid)}

(Fig. 69, Map 59)

Diagnosis. Body length 3.5-4.5 mm, body elongate-oval, depressed and covered with short and sparse pubescence; dorsum mostly yellow-brown, head with small black spot 
on vertex in some, pronotum unicoloured, scutellum often partly brown to black, elytra in most with brown-black spot on humerus, some without spots, legs orange to yellow-brown, antennomeres 1-3 yellow to yellow-brown, often darker on dorsal side, remaining antennomeres somewhat gradually darker to black; vertex punctate; pronotum wider than long with angulate anterior and posterior corners, sides regularly rounded, disc depressed, laterally with impressions, surface of disc coarsely punctate, punctures separated by $0.2-0.7$ of puncture diameter, interspaces from slightly glossy to somewhat dull; elytra base wider than posterior of pronotum, elytra with slightly rounded sides, disc with irregular coarse and dense punctation, interspaces from slightly glossy to somewhat dull, humeral callus strong; hind femora not swollen, tibiae straight, without apical spurs; male with broad and deep emargination in ventrite 5 , broad and shallow in female.

Native range. Palearctic: Europe (Löbl and Smetana 2010); introduced as a biocontrol agent in Canada and the USA (Riley et al. 2003, Bousquet et al. 2013).

Distribution in Canada. AB, BC?, MB, NB, NS?, ON, PE?, QC (Riley et al. 2003, Bousquet et al. 2013). Although releases occurred in BC, NS and PE, establishment is uncertain and it is unknown whether populations occur in those jurisdictions currently.

Distribution in USA. AL, CO, CT, DC, DE, IA, IL, IN, KS, MA, MD, ME, MI, MN, MO, MT, NH, NY, OH, OR, PA, RI, SD, TN, UT, VA, VT, WA, WI, WV (Riley et al. 2003).

First Canadian records. Releases occurred in every province except NF and SK from 1992-1999 (Lindgren et al. 2002). The earliest releases took place in Wellington Co., ON in 1992 (Hight et al. 1995).

First North American records. As above. There were releases in ID, MD, MN, NY, OR, PA, VA, and WA in 1992, and these had established by 1993-1994 (Hight et al. 1995).

Habitat and host data. This species was imported from Europe as a biological control agent against purple loosestrife (Lythrum salicaria L.) and was successful in controlling the weed (Hight et al. 1995).

70. Pyrrhalta viburni (Paykull) [viburnum leaf beetle]

(Fig. 70, Map 60)

Diagnosis. Body length 4.5-6.5 mm, elongate-oval, depressed and covered with short and dense pubescence; dorsum mostly yellow-brown, head with black spot of diffuse 
borders on vertex, pronotum with broad black stripe along middle and along sides, scutellum often partly brown to black, elytra usually with small, dark spot on humeri, legs orange to red-brown, antennomeres bicoloured, yellow-brown basally, black apically; vertex finely punctate; pronotum wider than long with angulate anterior and posterior corners, sides regularly rounded, disc depressed, laterally with shallow impressions, surface of disc finely punctate, interspaces slightly glossy to slightly dull; elytra base wider than posterior of pronotum, elytra almost parallel-sided with narrowly explanate margins, disc with irregular fine punctation, interspaces from slightly glossy to somewhat dull, humeral callus strong; hind femora not swollen, tibiae straight, without apical spurs, sexual dimorphism indistinct.

Native range. Palearctic: Europe (Löbl and Smetana 2010); adventive in Canada and the USA (Riley et al. 2003, Bousquet et al. 2013).

Distribution in Canada. BC, NB, NF, NS, ON, PE, QC (Riley et al. 2003, Majka and LeSage 2007, Bousquet et al. 2013).

Distribution in USA. CT, IL, IN, MA, MD, ME, MI, NH, NJ, NY, OH, PA, VT, WA (Riley et al. 2003, Weston and Hoebeke 2003, Murray 2004, Klimaszewski et al. 2010, Murray et al. 2016, online images at www.bugguide.net).

First Canadian records. Annapolis Royal, NS in 1924 (CNC; Majka and LeSage 2007); Fonthill, ON in 1947 (Becker 1979); Kettle Island, Gatineau, QC in 1974 (CNC); St. John's, NF and Victoria, BC in 2001 (Gillespie 2001).

First North American records. As above. The earliest published USA records are from $\mathrm{ME}$ in 1994, NY in 1996, VT and PA in 2000, OH in 2002, and WA in 2004 (Weston and Hoebeke 2003, Majka and LeSage 2007, Murray et al. 2016).

Habitat and host data. Pyrrhalta viburni was recorded from diverse native and cultivated Viburnum spp. (Weston et al. 2007) whose susceptibility to the beetle varies (Majka and LeSage 2007). Based on field observations, Weston and Desurmont (2002) reported that Viburnum trilobum Marshall, V. opulus L., V. sargentii Koehne, $V$. rafinesquianum Schultes, $V$. recognitum Fernald, and $V$. dentatum L. were the most susceptible hosts. In the Maritime Provinces, $P$. viburni was recorded on $V$. opulus 'Sterile', V. nudum L., V. acerifolium L., V. dentatum L., V. lanata L., V. lentago L., and V. recognitum Fernald (Clark et al. 2004, Majka and LeSage 2007). 
71. Xanthogaleruca luteola (O.F. Müller) [elm leaf beetle]

(Fig. 71, Map 61)

Diagnosis. Body length 5.5-7.5 mm, elongate-oval, dorsoventrally flattened and covered with short and dense pubescence; dorsum mostly yellow-green to yellow-brown, head with black spot on vertex, pronotum with broad black stripe along middle and round spot on each side, scutellum pale, elytra usually with short, broad, black stripe along sides, antennomeres bicoloured, yellow-brown basally and ventrally, black apically or dorsally; vertex of head punctate; pronotum wider than long with rounded anterior and posterior corners, sides regularly rounded, disc slightly convex, laterally with impressions, surface of disc with punctures separated by $0.2-0.5$ puncture diameters, interspaces usually slightly glossy to leathery; base of elytra wider than posterior of pronotum, elytra widest in posterior third, then rounded to apex, with narrowly explanate margins, disc with irregular fine and dense punctation, not aligned into rows, interspaces slightly glossy to leathery, humeral callus strong; hind femora not swollen, tibiae straight, without apical spurs, sexual dimorphism slight.

Native range. Palearctic: Eurasia (Löbl and Smetana 2010); adventive in Canada and the USA (Riley et al. 2003, Bousquet et al. 2013).

Distribution in Canada. BC, NB, NF, NS?, ON, PE, QC (Riley et al. 2003, Klimaszewski et al. 2010, Bousquet et al. 2013). Although listed from NS in various checklists, e.g., Bousquet et al. (2013), we have not seen specimens or verified locality records; thus, this jurisdictional record is treated as questionable. However, given its wide distribution, it seems likely that this species would occur in NS. Bousquet et al. (2013) also reported the species from AB based on a specimen in the CNC that was collected in Calgary in 1990; however, the specimen is affixed with a label "introduced from Spokane?" which suggests it represents an interception rather than an established population. Thus, there is no evidence this species is established in AB.

Distribution in USA. All states except AK and HI (Riley et al. 2003, CAB International 2019).

First Canadian records. St. Catharines, ON in 1945 (CNC); Milltown, NB in 1949 (CNC); Huntingdon, QC in 1965 (CNC); Kelowna, BC in 1988 (DEBU).

First North American records. Baltimore, MD in 1834, 1838-1839 (Hatch 1971, Dreistadt and Dahlsten 1990, Lovett 1916); CA around 1924 (University of California Riverside 2011); near Portland, OR in 1911 or 1912 (Lovett 1916). A summary of the chronological spread in the northwestern USA is found in Hatch (1971). 
Habitat and host data. This species is an important urban forest pest in North America. Adults and larvae feed exclusively on elms (Ulmus spp.) (Clark et al. 2004), and occasionally on Zelkova serrata (Thumb.) Makino (Ulmaceae), with most damage done by larvae. Adult feeding damage consists of small round holes in the leaves. Larvae skeletonize the underside of leaves and this causes leaves to turn brown and eventually fall from the tree.

\section{Family MEGALOPODIDAE Latreille}

Diagnosis. Body shape variable, elongate, subparallel, subcylindrical to depressed, colour variable but mostly non-metallic in Nearctic species; hairs sparse to dense, and appressed to erect; head short to slightly elongate, exposed in dorsal view; eyes large, coarsely or finely faceted; antennae with 11 antennomeres, short to moderately long, antennomeres 5-11 subserrate, insertion lateral between eyes and base of mandibles; pronotum subequal to or broader than head, laterally weakly arcuate or strongly angled, with a weak to strong basal constriction; elytra entire, apically rounded, surface smooth to punctuate, epipleura narrow throughout, mesosternum with stridulatory file; abdomen with five free ventrites, 1-4 subequal in length, 5 somewhat longer; procoxae contiguous, transverse and protruding, their cavities closed behind, mesocoxae subconical and small, metacoxae transverse, all tibiae with paired apical spurs.

72. Zeugophora (Zeugophora) scutellaris Suffrian [cottonwood leaf-mining beetle, poplar leaf-mining beetle]

(Fig. 72, Map 62)

Diagnosis. Body length 3-4 mm, dorsal surface flattened; head, pronotum, scutellum and legs red, elytra black, antennomeres 1-3 (sometimes 4) orange, remainder black; vertex punctate; pronotum approximately as wide as long, sides with a large, triangular projection at midlength, dorsal surface with coarse scattered punctures separated by 0.7-3.0 times average puncture diameter; elytra almost parallel-sided, base wider than posterior of pronotum, disc punctate with irregular coarse punctation not arranged into rows, interspaces glossy, humeral callus strong; hind femora not swollen, tibiae almost straight, with short apical spurs, sexual dimorphism slight.

Native range. Palearctic: north and central Europe, central Asia, western Siberia, China (Löbl and Smetana 2010); adventive in Canada and the USA (Lindroth 1957, Bousquet et al. 2013). 
Distribution in Canada. AB, BC, MB, NB, NT, ON, SK, QC? (Riley et al. 2003, Klimaszewski et al. 2010, Majka et al. 2011, Bousquet et al. 2013, Webster et al. 2016). Although listed from QC in various checklists, e.g., Riley et al. (2003) and Bousquet et al. (2013), we have not seen specimens or verified locality records; thus, this jurisdictional record should be treated as questionable. However, given its wide distribution, it seems likely that this species would occur in QC.

Distribution in USA. CA, CO, CT, IL, IN, KS, MD, ME, MI, MN, MO, MT, ND, NJ, NM, NY, OH, OR, RI, SD, TX, WA, WV, WY (Riley et al. 2003).

First Canadian records. Prince Edward Co., ON in 1909 (CNC); undisclosed locality in AB in 1920 (Strickland 1920); Aweme, MB in 1924 (CNC); 54 miles SW of Rae and 30 miles NE of Fort Providence, NT in 1964 (CNC); several locations in SK in 1966 (NOFC). Strickland (1920) also noted credible reports of this species from Manitoba in 1903 but no specimens seem to have been accessioned.

First North American records. IL before 1873 (Crotch and Cantab 1873); MI before 1889 (Hamilton 1889); WY around 1912 (Grave 1917).

Habitat and host data. Hosts are Salicaceae, including Populus spp. and Salix spp. (Clark et al. 2004). Larvae feed individually in the inner tissues of the leaf creating large, black blotchy mines. Adults feed on the surface of leaves, making meandering skeletonizing injuries. 


\section{Acknowledgements}

Information about status of biocontrol agents and locality records for established populations was provided by Rob Bourchier, Rose DeClerck-Floate, Vincent Hervet, and Peter Mason (AAFC, Lethbridge). We thank Claude Chantal (Quebec) for QC records of some Bruchinae; Claudia Copley (Royal British Columbia Museum), Vincent Hervet, Steve Marshall (University of Guelph), Cory Sheffield (Royal Saskatchewan Museum), Geoff Scudder (University of British Columbia), and Terry Wheeler (deceased, McGill University) for data from their collections; Serge Laplante (AAFC, Ottawa), Ron Neville (Canadian Food Inspection Agency), Jon Sweeney (Canadian Forest Service (CFS), Fredericton), and Doug Yanega (University of California - Riverside) for clarification of records of some Cerambycidae; Edward G. Riley (Texas A\&M University) and Donald S. Chandler (University of New Hampshire) for clarification of some USA records for Chrysomelidae; and Timothy L. McCabe (New York State Museum) for providing the earliest Nearctic records of Tetrops praeustus. Specimens and locality data from recent collections of Bruchidius villosus in BC were kindly provided by Laura Hooper (District of Sooke). We thank Diane Paquet (CFS, Ste.-Foy) for formatting the first draft of this manuscript. The first author thanks Anthony Hopkin (CFS, Victoria), Elisabeth Gauthier (CFS, Ste.-Foy), and Jacinthe Leclerc (CFS, Ste-Foy), for supporting this study under the Forest Invasive Alien Species Project. Photographic credits for color images are to Klaus Bolte and some Chrysomelidae to Lech Borowiec. This project was funded by Natural Resources Canada, Canadian Forest Service. 


\section{References}

Aldridge, R.J.W., and Pope, R.D. 1986. The British species of Bruchidius Schilsky (Coleoptera: Bruchidae). Entomologist's Gazette 37: 181-193.

Allen, E.A., and Humble, L.M. 2002. Nonindigenous species introductions: a threat to Canada's forests and forest economy. Canadian Journal of Plant Pathology 24: 103-110.

Alvarez, N., McKey, D., Hossaert-McKey, M., Born, C., Mercier, L., and Benrey, B. 2005. Ancient and recent evolutionary history of the bruchid beetle, Acanthoscelides obtectus Say, a cosmopolitan pest of beans. Molecular Ecology 14: 1015-1024. DOI:10.1111/j.1365-294X.2005.02470.x

Andres, L.A. 1985. Interaction of Chrysolina quadrigemina and Hypericum spp. in California. Pp. 235-239, In: Delfosse, E.S (ed.): Proceedings of the VI International Symposium on the Biological Control of Weeds, 19-25 August 1984, Vancouver, British Columbia. Agriculture Canada, Ottawa, Ontario.

Anonymous. 1968. European potato flea beetle (Psylliodes affinis (Paykull)). United States Department of Agriculture, Cooperative Economic Insect Report 18(41): 960, 965.

Anonymous. 1981. Longitarsus luridus extends range. United States Department of Agriculture, Plant Pest News 1: 2.

Anonymous. 2015. Longitarsus flavicornis Steph. Government of British Columbia. Available at: https://www2.gov.bc.ca/assets/gov/farming-natural-resources-and-industry/forestry/agents/longitarsus_flavicornis.pdf

Anonymous. 2018a. Bruchidius villosus (F.). Government of British Columbia. Available at: https://www2.gov.bc.ca/assets/gov/farming-natural-resources-and-industry/forestry/agents/bruchidius_villosus.pdf

Anonymous. 2018b. Aphthona czwalinae (Weise). Government of British Columbia. Available at: https://www2.gov.bc.ca/assets/gov/farming-natural-resources-and-industry/forestry/agents/aphthona_czwalinae.pdf

Anonymous. 2018c. Aphthona flava Guill. Government of British Columbia. Available at: https://www2.gov.bc.ca/assets/gov/farming-natural-resources-and-industry/forestry/agents/aphthona_flava.pdf 
Anonymous. 2018d. Aphthona lacertosa (Rosh). Government of British Columbia. Available at: https://www2.gov.bc.ca/assets/gov/environment/plants-animals-and-ecosystems/invasive-species/biocontrol/biocontrol-agents/aphthona_ lacertosa.pdf

Anonymous. 2018e. Aphthona nigriscutis (Foundras). Government of British Columbia. Available at: https://www2.gov.bc.ca/assets/gov/environment/plants-animals-and-ecosystems/invasive-species/biocontrol/biocontrol-agents/aphthona_nigriscutis.pdf

Anonymous. 2018f. Chrysolina quadrigemina (Suffr.). Government of British Columbia. Available at: https://www2.gov.bc.ca/assets/gov/farming-natural-resources-and-industry/forestry/agents/chrysolina_quadrigemina.pdf

Anonymous. 2019. Asian Longhorned Beetle Alert: NYC Parks. Available at: https:// www.nycparks.org/trees/beetle-alert

Askevold, I.S. 1988. Aggregation of Phyllotreta striolata (Fab.) at high altitude in southwest Alberta, Canada (Coleoptera: Chrysomelidae: Alticinae). The Coleopterists Bulletion 42: 10.

Bailey, W.C., Carlson, C.E., Puttler, B., and Stoltenow, C.R. 1991. Expansion of the range of the cereal leaf beetle, Oulema melanopus (L.) (Coleoptera: Chrysomelidae), in Missouri and Iowa. Journal of the Kansas Entomological Society 64: 455-457.

Bain, A. 1998. A Seventeenth-Century beetle fauna from colonial Boston. Historical Archaeology 32: 38-48.

Bain, A., and King, G. 2011. Asylum for wayward immigrants: historic ports and colonial settlements in northeast North America. Journal of the North Atlantic 1: $109-124$.

Bain, A., and Prévost, M.A. 2010. Environmental archeology and landscape transformation at the $17^{\text {th }}$ century Ferryland Site, Newfoundland. Historical Archaeology 45: 21-35.

Bain, A., Bouchard-Perron, J-A., Auger, R., and Simoneau, D. 2009. Bugs, seeds and weeds at the Intendent's Palace: a study of an evolving landscape. Post-Medieval Archaeology 43: 187-197.

Barber, H.S. 1916. A review of North American tortoise beetles. Proceedings of the Entomological Society of Washington 18: 113-127.

Batra, S.W.T., Coulson, J.R., Dunn, P.H., and Boldt, P.E. 1981. Insects and fungi associated with Carduus thistles (Compositae). Technical Bulletin 1616, United States Department of Agriculture, Washington, DC, 100 pp.

BCMF [British Columbia Ministry of Forests, Lands, and Natural Resource Operations]. 2019. Chrysolina quadrigemina (Suffr.) Available at: https://www.for.gov.bc. ca/hra/plants/biocontrol/detailed_bioagent_pages/Chrysolina_quadrigemina.htm

Becker, E.C. 1979. Pyrrhalta viburni (Coleoptera: Chrysomelidae), a Eurasian pest of Viburnum recently established in Canada. The Canadian Entomologist 111: 417-419. 
Beenen, R., and Roques, A. 2010. Leaf and seed beetles (Coleoptera, Chrysomelidae). Biorisk 4: 267-292.

Beirne, B.P. 1971. Pest insects of annual crop plants in Canada. Part III. Coleoptera. Memoirs of the Entomological Society of Canada 78: 71-124.

Bense, U. 1995. Longhorn beetles: illustrated key to the Cerambycidae and Vesperidae of Europe. Margraf Verlag, Weikersheim, Germany, 512 pp.

Bezdek, J., and Baselga, A. 2015. Revision of western Palearctic species of the Oulema melanopus group, with description of two new species from Europe (Coleoptera: Chrysomelidae: Criocerinae). Acta Entomologica Musei Nationalis Pragae 55: 273-304.

Bezark, L.G., and Monné, M.A. (compilers). 2013. Checklist of the Oxypeltidae, Vesperidae, Disteniidae and Cerambycidae (Coleoptera) of the Western Hemisphere. 484 pp. Available at: https://www.zin.ru/animalia/coleoptera/pdf/checklist_cerambycoidea_2013.pdf (Accessed 7 March 2019).

Bienkowski, A.O., and M.J. Orlova-Bienkowskaja. 2016. Key to Holarctic species of Epitrix flea beetles (Coleoptera: Chrysomelidae: Galerucinae: Alticini) with review of their distribution, host plants and history of invasions. Zootaxa 4175(5): 401-435.

Bily, S., and Mehl, O. 1989. Longhorn beetles (Coleoptera, Cerambycidae) of Fennoscandia and Denmark. Fauna Entomologica Scandinavica 22, 203 pp.

Bonnemaison, L. 1965. Insect pests of crucifers and their control. Annual Review of Entomology 10: 233-256.

Bottimer, L.J. 1931. A vetch bruchid established in the Middle Atlantic States. United States Department of Agriculture, The Insect Pest Survey Bulletin 11: 347.

Bottimer, L.J. 1968. On the two species of Bruchidius established in North America. The Canadian Entomologist 100: 139-145.

Bourchier, R., Erb, S., McClay, A., and Gassman, A. 2002. Euphorbia esula (L.) (Leafy spurge) and Euphorbia cyparissias (L.) (Cypress Spurge) (Ephorbiaceae). Pp. 346358, In: Mason, P.G, Huber, J.T. (eds): Biological control programmes against insects and weeds in Canada 1981-2000. CABI Publishing, Wallingford, United Kingdom.

Bousquet, Y. 1990. Beetles associated with stored products in Canada. Publication 1837, Agriculture Canada, Research Branch, Ottawa, Ontario, 214 pp.

Bousquet, Y., Bouchard, P., Davies, A.E., and Sikes, D.S. 2013. Checklist of beetles (Coleoptera) of Canada and Alaska. Second edition. Pensoft, Sofia-Moscow, 402 pp. Bousquet, Y., Laplante, S., Hammond, H.E.J., and Langor, D.W. 2017. Cerambycidae (Coleoptera) of Canada and Alaska: identification guide with nomenclatural, taxonomic, distributional, host-plant, and ecological data. Nakladatelstvi Jan Farkač, Prague, Czech Republic, 300 pp. 
Bridwell, J.C., and Bottimer, L.J. 1933. The hairy-vetch bruchid, Bruchus brachialis Fahraeus, in the United States. Journal of Agricultural Research 46: 739-751.

Brindley, T.A., Chamberlin, J.C., and Hinman, F.G. 1946. The pea weevil and methods for its control. Farmers' Bulletin No. 1971, United States Department of Agriculture, Washington, DC, 23 pp.

Brown, W.J. 1940. Notes on the American distribution of some species of Coleoptera common to the European and North American continents. The Canadian Entomologist 72: 65-78.

Brown, W.J. 1950. The extralimital distribution of some species of Coleoptera. The Canadian Entomologist 72: 197-205.

Brown, W.J. 1962. The American species of Chrysolina Mots., (Coleoptera: Chrysomelidae). The Canadian Entomologist 94: 1-16.

Brown, W.J. 1967. Notes on the extralimital distribution of some species of Coleoptera. The Canadian Entomologist 99: 85-93.

Brunke, A.J., Bouchard, P., Douglas, H.B., and Pentinsaari, M. 2019. Coleoptera of Canada. In: Langor, D.W., Sheffield, C.S. (eds): The Biota of Canada - A Biodiversity Assessment. Part 1: The Terrestrial Arthropods. ZooKeys 819: 361-376.

Bukejs, A. 2010. To the knowledge of flea beetles (Coleoptera: Chrysomelidae: Alticinae) of the Latvian fauna. 6. Genus Longitarsus Latreille, 1829. Acta Biologica Universitatis Daugavpiliensis 10: 53-70.

Bullas-Appleton, E., Kimoto, T., and Turgeon, J.J. 2014. Discovery of Trichoferus campestris (Coleoptera: Cerambycidae) in Ontario, Canada and first host record in North America. The Canadian Entomologist 146: 111-116.

Burfitt, C.E., Watson, K., Pratt, C.A., and Caputo, J. 2015. Total records of velvet longhorn beetle Trichoferus campestris Faldermann (Coleoptera, Cerambycidae) from Utah. [Poster]. Utah Department of Agriculture and Food. Available at: https://ipmsymposium.org/2015/Documents/Posters/130_Watson.pdf

Burgess, L. 1980. The horseradish flea beetle in Saskatchewan. Blue Jay 38(1): 11-13. Burgess, L. 1981. Crucifer-feeding flea beetles (Coleoptera: Chrysomelidae) occurring in the province of Saskatchewan, Canada. The Coleopterists Bulletin 35: 307-309.

Butler, J.L., Parker, M.S., and Murphy, J.T. 2006. Efficacy of flea beetle control of leafy spurge in Montana and South Dakota. Rangeland Ecology and Management 59: 453-461.

CAB International. 2019. Pyrrhalta luteola (elm leaf beetles). Available at: https:// www.cabi.org/isc/datasheet/44619.

Campbell, C.L., and McCaffrey, J.P. 1991. Population trends, seasonal phenology and impact of Chrysolina quadrigemina, C. hyperici (Coleoptera: Chrysomelidae) and Agrilus hyperici (Coleoptera: Buprestidae) associated with Hypericum perforatum in northern Idaho. Environmental Entomology 20: 303-315. 
Campbell, J.M., Sarazin, M.J., and Lyons, D.B. 1989. Canadian beetles (Coleoptera) injurious to crops, ornamentals, stored products and buildings. Publication 1826, Agriculture Canada, Ottawa, Ontario, iv + 491 pp.

Campbell, R.E. 1920. The broad-bean weevil. Bulletin 807, United States Department of Agriculture, Washington, DC, 22 pp.

Cappuccino, N., Haye, T., Tewksbury, L., and Casagrande, R. 2013. Lilioceris lilii (Scopoli), lily leaf beetle (Coleoptera: Chrysomelidae). Pp. 208-213, In: Mason, P.G., Gillespie, D.R. (eds): Biological control programmes in Canada 2001-2012. CABI Publishing, Oxfordshire, United Kingdom.

Cavey, J.F. 1994. Annotated new distributional records for North American Chrysomelidae (Coleoptera). The Coleopterists Bulletin 48: 1-9.

Cebeci, H., Özdikmen, H., and Turgut, S. 2011. Callidiine species in Turkey with zoogeographical remarks and some interesting and rare records (Coleoptera: Cerambycidae: Cerambycinae). Journal of Natural History 45: 475-483.

CERIS [Center for Environmental and Research Information Systems]. 2019. Survey status of velvet longhorned beetle - Trichoferus campestris 2018. Available at: http://pest.ceris.purdue.edu/map.php?code=INALQPA\&year $=2018$

CFIA [Canadian Food Inspection Agency]. 2012. Plant protection survey report 2011-12. Canadian Food Inspection Agency, Ottawa, ON, 21 pp. + maps. Available at: http://publications.gc.ca/collections/collection_2017/acia-cfia/A101-112012-eng.pdf

CFIA [Canadian Food Inspection Agency]. 2013. RMD-07-02: Cereal Leaf Beetle (Oulema melanopus). Available at: http://www.inspection.gc.ca/plants/plant-pests-invasive-species/directives/risk-management/rmd-07-02/eng/1304823919909/1304824849671

CFIA [Canadian Food Inspection Agency]. 2015. Plant protection survey report 2014-15. Canadian Food Inspection Agency, Ottawa, ON, 25 pp. + maps. Available at: http://publications.gc.ca/collections/collection_2017/acia-cfia/A101-112015-eng.pdf

Chaboo, C.S. 2007. Biology and phylogeny of the Cassidinae Gyllenhal sensu lato (tortoise and leaf-mining beetles) (Coleoptera: Chrysomelidae). Bulletin of the American Museum of Natural History 305, 250 pp.

Chagnon, G. 1905. Longicornes de la Province de Québec. Le Naturaliste Canadien 32: $25-29$.

Chagnon, G. 1917. A preliminary list of the insects of the province of Quebec. Part III - Coleoptera. Report of the Quebec Society for the Protection of Plants. Supplement 1917: 161-277.

Chantal, C. 1972. Additions à la faune Coléoptèrologique du Québec. Le Naturaliste Canadien 99: 243-244. 
Chemsak, J.A. 1996. Illustrated revision of the Cerambycidae of North America. Volume I: Subfamilies Parandrinae, Spondylidinae, Aseminae, Prioninae. Wolfsgarden Press, Burbank, California, ix +150 pp. +10 pls.

Cherepanov, A.I. 1988. Cerambycidae of Northern Asia. Vol. 1. Prioninae, Disteniinae, Lepturinae, Aseminae. Amerind Publishing Co., New Delhi, India, 642 pp.

Chittenden, F.H. 1895. The horseradish flea-beetle. Insect Life 7: 404-406.

Chittenden, F.H. 1897. Some little-known insects affecting stored vegetable products. Bulletin No. 8 - New Series. United States Department of Agriculture, Division of Entomology, Washington, DC, 45 pp.

Chittenden, F.H. 1898. Insects that affect asparagus. Bulletin $10-$ New Series. United States Department of Agriculture, Division of Entomology, Washington, DC, pp. 54-62.

Chittenden, F.H. 1912a. The broadbean weevil. United States Government Printing Office, Washington, DC.

Chittenden, F.H. 1912b. The cowpea weevil. United States Government Printing Office, Washington, DC.

Chittenden, F.H. 1917. The asparagus beetles and their control. Farmers' Bulletin 837, United States Department of Agriculture, Bureau of Entomology, Washington, DC, 15 pp.

Chittenden, F.H. 1923. Notes on the distribution and habits of North American Phyllotreta (Coleop.). Proceedings of the Entomological Society of Washington 25: 131-139.

Chittenden, F.H. 1927. The species of Phyllotreta north of Mexico. Entomologica Americana (new series) 8: 1-63.

Clark, S.M., LeDoux, D.G, Seeno, T.N., Riley, E.G., Gilbert, A.J., and Sullivan, J.M. 2004. Host plants of leaf beetle species occurring in the United States and Canada (Coleoptera: Megalopodidae, Orsodacnidae and Chrysomelidae, excluding Bruchinae). Coleopterists Society Special Publication 2: 1-476.

Clausen, C.P. 1956. Biological control of insect pests in the continental United States. Technical Bulletin 1139, United States Department of Agriculture, Washington, DC, $151 \mathrm{pp}$.

Clausen, C.P. (ed.) 1978. Introduced parasites and predators of arthropod pests and weeds: a world review. Agriculture Handbook No. 480, United States Department of Agriculture, Washington, DC, 545 pp.

Cocquempot, C. 2006. Alien longhorned beetles (Coleoptera: Cerambycidae): original interceptions and introductions in Europe, mainly in France, and notes about recently imported species. Redia 89: 35-50.

Coombs, E.M., Markin, G.P., and Andreas, J. 2008. Release and establishment of the Scotch broom seed beetle, Bruchidius villosus, in Oregon and Washington, USA. Pp. 516-520, In: Julien, M.H., Storza, R., Bon, M.C., Evans, H.C., Hatcher, P.E., Hinz, H.L., Rector, B.G. (eds): Proceedings of the XII International Symposium 
on Biological Control of Weeds, La Grande Motte, France, 22-27 April 2007. CABI Publishing, United Kingdom.

Coombs, E.M., Markin, G.P., and Forest, T.G. 2004. Scotch broom. Pp. 160-168, In: Coombs, E.M., Clark, J.K., Piper, G.L., Cofrancesco, A.F., Jr. (eds): Biological control of invasive plants in the United States. Oregon State University Press, Corvallis, Oregon.

Cope, J. 1984. Notes on the ecology of western Cerambycidae. The Coleopterists Bulletin 38: 27-36.

Couper, W. 1864. List of Coleoptera and Diptera taken at Quebec, and other parts of Lower Canada. Transactions of the Literary and Historical Society of Quebec (New Series) 2: 75-93.

Cowan, D., and Wang, B. 2019. Evaluation of potential host species for velvet longhorned beetle, Trichoferus campestris. Pp. 43-44, In: Trepanowski, N., Vieira, K., Heller, S., Booth, E. (eds): Otis Laboratory 2018 Annual Report. United States Department of Agriculture, Animal and Plant Health Inspection Service, Buzzard's Bay, Massachusetts, 99 pp.

Cripps, M.G., Gassmann, A., Fowler, S.V., Bourdot, G.W., McClay, A.S., and Edward, G.R. 2011. Classical biological control of Cirsium arvense: lessons from the past. Biological Control 57: 165-174.

Crotch, G.R., and Cantab, M.A. 1873. Materials for the study of the Phytophaga of the United States. Proceedings of the Academy of Natural Sciences, Philadelphia 25: 19-83.

DeClerck-Floate, R.A. 2013. Cynoglossum officinale (L.), Houndstongue (Boraginaceae). Pp. 309-315, In: Mason, P.G, Gillespie, D.R. (eds): Biological Control Programmes in Canada 2001-2012. CABI Publishing, Oxfordshire, United Kingdom.

Deczynski, A. 2014. A preliminary revision of the genus Epitrix Foudras (Coleoptera: Chrysomelidae: Galerucinae: Alticini) in America north of Mexico. Available at: http://dspace.udel.edu/bitstream/handle/19716/13155/Deczynski\%2c\%20A nthony.pdf?sequence $=1$

Deczynski, A.M. 2019. The Palearctic flea beetle Epitrix pubsecens (Koch) (Coleoptera: Chrysomelidae: Galerucinae: Alticini) established in North America. Insecta Mundi 0721: 1-5.

Denoth, M., and Myers, J.H. 2005. Variable success of biological control of Lythrum salicaria in British Columbia. Biological Control 32: 269-279.

DiFonzo, C. 2009. Cereal Leaf Beetle. Michigan State University, MSU Extension. Available at: https://www.canr.msu.edu/news/cereal_leaf_beetle

Döberl, M. 2000. Beitrag zur Kenntnis der Gattung Epitrix Foudras, 1860 in der Paläarktis. (Coleoptera: Chrysomelidae: Alticinae). Mitteilungen des Internationalen Entomologischen Vereins e. V. (Frankfurt a. Main) 25: 1-23. 
Döberl, M. 2010. Subfamily Alticinae Newman, 1835. Pp. 491-563, In: Lobl, I., Smetana, A. (eds.): Catalogue of Palaearctic Coleoptera, Volume 6. Chrysomeloidea. Apollo Books, Stenstrup, Denmark, 924 pp.

Dolgovskaya, M.Y., Konstantinov, A.S., Reznik, S.Y., Spencer, N.R., and Volkovitsh, M.G. 2004. Flea beetles (Coleoptera: Chrysomelidae) associated with purple loosestrife, Lythrum salicaria, in Russia. Pp. 96-101, In: Cullen, J.M., Briese, D.T., Kriticos, D.J., Lonsdale, W.M., Morin, L., Scott, J.K. (eds): Proceedings of the XI International Symposium on Biological Control of Weeds, Canberra, Austrailia, 27 April - 2 May 2003. CSIRO Entomology, Canberra, Australia.

Downie, N.M. 1950. Notes on the distribution of Bruchus brachialis Fåhraeus and Malachius aeneus (L.). The Coleopterists Bulletin 4: 20-21.

Downie, N.M., and Arnett, R.H., Jr. 1996. The beetles of Northeastern North America. Volume II. Polyphaga: Scarabaeoidea through Curculionoidea. Sandhill Crane Press, Gainsville, Florida, 831 pp.

Dreistadt, S.H., and Dahlsten, D.L. 1990. Distribution and abundance of Erynniopsis antennata [Dipt.: Tachinidae] and Tetrastichus brevistigma [Hym.: Eulophidae], two introduced elm leaf beetle parasitoids in northern California. Entomophaga 35: $527-536$.

Durbecq, C. 2014. The secret life of a bio-control agent: the St. John's wort beetle. Benton Soil and Water Conservation District, Corvallis, Oregon. Available at: https://www.bentonswcd.org/secret-life-bio-control-agent-st-johnswort-beetle/

Elias, S.A., and Crocker, B. 2008. The Bering land bridge: a moisture barrier to the dispersal of steppe-tundra biota? Quaternary Science Reviews 27: 2473-2483. DOI: 10.1016/j.quascirev.2008.09.011.

Essig, E.O. 1929. Origin of the bean weevil, Mylabris obtectus (Say). Journal of Economic Entomology 22: 858-861.

Evans, J.D. 1899. List of Coleoptera from Halifax. The Canadian Entomologist 31: 320-321.

Eyre, D., and Haack, R.A. 2017. Invasive cerambycid pests and biosecurity measures. Pp. 563-607, In: Wang, Q. (ed.): Cerambycidae of the world: biology and pest management. CRC Press, Boca Raton, Florida.

Fitch, A. 1862. The asparagus beetle. The Country Gentleman (July 3) 20: 81-82.

Fitch, A. 1865. Eighth report on the noxious and other insects of the state of New York. C. van Benthuysen, Albany, New York, pp. 177-186.

Fletcher, J. 1899. Injurious insects in Ontario during 1899. Entomological Society of Ontario, Annual Report 30: 106-111.

Floate, K.D, Boucher, R.S., Coghlin, P., Dunlop, B., Ostrander, D., and LeSage, L. 2016. Assessment of the diversity of Aphthona flea beetles for biological control of leafy spurge on the prairies. International Congress of Entomology 25: Post- 
er D3459. Available at: https://esa.confex.com/esa/ice2016/meetingapp.cgi/Paper/111113.

Frick, K.E. 1962a. Seed beetle that attacks the seeds of Cytisus scoparius in the eastern United States. Unpublished report, New Jersey Biocontrol Laboratory, Moorestown, New Jersey.

Frick, K.E. 1962b. A three-week study of Bruchidius villosus, the seed beetle that attacks the seeds of Cytisus scoparius in the eastern United States. Special Report, United States Department of Agriculture, Washington, DC.

Frick, K.E. 1970. Longitarsus jacobaeae (Coleoptera: Chrysomelidae), a flea beetle for the biological control of tansy ragwort. 1. Host plants specificity studies. Annals of the Entomological Society of America 63: 284-296.

Fyles, T.W. 1902. A tortoise beetle new to Québec. The Canadian Entomologist 34: 273-274.

Gardiner, L.M. 1975. Insect attack and value loss in wind-damaged spruce and jack pine stands in northern Ontario. Canadian Journal of Forest Research 5: 387-398.

Gentner, L.G. 1926a. The mint flea-beetle. Special Bulletin of the Agricultural Experiment Station, Michigan State College 155: 1-13.

Gentner, L.G. 1926b. New North American Halticinae (Coleoptera) with notes on other species. The Canadian Entomologist 58: 149-154.

Gentner, L.G. 1928. The systematic status of the mint flea beetle (Chrysom., Coleop.), with additional notes. The Canadian Entomologist 60: 264-266.

Gibson, A. 1924. The bean weevil. The Canadian Insect Pest Review 2: 14.

Gillespie, D.R. 2001. Arthropod introductions into British Columbia - the past 50 years. Journal of the Entomological Society of British Columbia 98: 91-97.

Grilli, M.P., and Fachinetti, R. 2017. The role of sex and mating status in the expansion process of Arhopalus rusticus (Coleoptera: Cerambycidae) - an exotic cerambycid in Argentina. Environmental Entomology 46: 714-721.

Grilli, M.P., and Fachinetti, R. 2018. Can forest pattern affect the distribution and abundance of Arhopalus rusticus (Coleoptera: Cerambycidae)? A landscape perspective in central Argentina. International Journal of Pest Management 265: 68-75. DOI: $10.1080 / 09670874.2018 .1498559$

Gold, M.S. 2003. Biological control of the lily leaf beetle, Lilioceris lilii in North America. Ph.D Dissertation. University of Rhode Island, Kingston, Rhode Island. Available at: http://digitalcommons.uri.edu/dissertations/AAI3112117.

Gold, M.S., Casagrande, R.A., Tewksbury, L.A., Livingston, S.B., and Kenis, M. 2001. European parasitoids of Liliocerus lilii (Coleoptera: Chrysomelidae). The Canadian Entomologist 133: 671-674.

Grave, B.H. 1917. Zeugophora scutellaris (Suffr.). Journal of Morphology 30: 245-259. 
Grebennikov, V.V., Gill, B.D., and Vigneault, R. 2010. Trichoferus campestris (Faldermann) (Coleoptera: Cerambycidae), an Asian wood-boring beetle recorded in North America. The Coleopterists Bulletin 64: 13-20.

Haack, R.A., Herard, F., Sun, J., and Turgeon, J.J. 2010. Managing invasive populations of Asian longhorned beetle and citrus longhorned beetle: a worldwide perspective. Annual Review of Entomology 55: 521-546.

Haldeman, S.S. 1847. Material towards a history of the Coleoptera longicornia of the United States. Transactions of the American Philosophical Society (Series 2) 10: 27-66.

Hamilton, J. 1889. Catalogue of the Coleoptera common to North America, northern Asia and Europe, with the distribution and bibliography. Transactions of the American Entomological Society 16: 88-162.

Hamilton, J. 1894. Catalogue of the Coleoptera common to North America, northern Asia and Europe, with distribution and bibliography. Transactions of the American Entomological Society 21: 345-416.

Hanks, L.M. 1999. Influence of the larval host plant on reproductive strategies of cerambycid beetles. Annual Review of Entomology 44: 483-505.

Hansen, R. 2011a. Aphthona cyparissiae (Coleoptera: Chrysomelidae). In: Shelton, T. (ed.): Biological control: a guide to natural enemies in North America. Cornell University, College of Agriculture and Life Sciences, Ithaca, New York. Available at: https://biocontrol.entomology.cornell.edu/weedfeed/AphthonaCyparissiae.php

Hansen, R. 2011b. Aphthona lacertosa (Coleoptera: Chrysomelidae). In: Shelton, T. (ed.): Biological control: a guide to natural enemies in North America. Cornell University, College of Agriculture and Life Sciences, Ithaca, New York. Available at: https://biocontrol.entomology.cornell.edu/weedfeed/AphthonaLacertosa.php

Hansen, R.W., Richard, R.D., Parker, P.E., and Wendel, L.E. 1997. Distribution of biological control agents of leafy spurge (Euphorbia esula L.) in the United States 1988-1996. Biological Control 10: 129-142.

Harms, N., and Grodowitz, M.J. 2009. Insect herbivores of aquatic and wetland plants in the United States: a checklist from the literature. Journal of Aquatic Plant Management 47: 73-96.

Harrington, W.H. 1884a. Additions to Canadian lists of Coleoptera. The Canadian Entomologist 16: 44-47, 70-73, 96-98.

Harrington, W.H. 1884b. List of Ottawa Coleoptera. Transactions - Ottawa Field Naturalists' Club 2: 67-85.

Harrington, W.H. 1899. A few Canadian longicorns. The Canadian Entomologist 31: 107-108.

Harris, P. 1964. Host specificity of Altica carduorum Guer. (Col. Chrysomelidae). Canadian Journal of Zoology 42: 857-862. 
Harris, P., and Crozier, S. 2006. Classical biological control of weeds - established biocontrol agent Longitarsus jacobaeae (Waterhouse) L. flavicornis Stephen and L. succineus Foudras. Ragwort root beetles. Agricuture and Agri-Food Canada, Ottawa, Ontario.

Harris, P., Dunn, P.H., Schroeder, D., and Vonmoos, R. 1985. Biological control of leafy spurge in North America. Pp. 79-92, In: Watson, A.K. (ed.): Leafy spurge. Science Society of America Monograph Series No. 3. Weed Science Society of America, Champaign, Illinois.

Harris, P., and Maw, M. 1984. Hypericum perforatum L., St. John's wort (Hypericaceae). Pp. 171-177, In: Kelleher, J.S., Hulme, M.A. (eds): Biological control programmes against insects and weeds in Canada 1969-1980. Commonwealth Agricultural Bureaux, Farnham Royal, United Kingdom.

Harris, P., and Peschken, D.P. 1971. Hypericum perforatum L., St. John's wort (Hypericaceae). Pp. 89-94, In: Biological control programmes against insects and weeds in Canada 1959-1968. Technical Communication No. 4, Commonwealth Institute of Biological Control. Commonwealth Agricultural Bureaux, Farnham Royal, United Kingdom.

Harris, P., Peschken, D.P., and Milroy, J. 1969. The status of biological control of the weed Hypericum perforatum in British Columbia. The Canadian Entomologist 101: $1-15$.

Harris, P., Wilkinson, A.T.S., and Myers, J.H. 1984. Senecio jacobaea L., Tansy Ragwort (Compositae). Pp. 195-201, In: Kelleher, J.S., Hulme, M.A. (eds): Biological control programmes against insects and weeds in Canada 1969-1980. Commonwealth Agricultural Bureaux, Farnham Royal, England.

Harris, T.W. 1833. Part IV. A catalogue of the animals and plants in Massachusetts - VIII. Insects. Report of the geology, mineralogy, botany, and zoology of Massachusetts. J.S. and C. Adams, Amherst, Massachusetts, pp. 566-595.

Harvey, R.L. 1907. The British Columbia List. Coleoptera. Family Cerambycidae. Quarterly Bulletin of the British Columbia Entomological Society 6 (June 1907): 3-4.

Hatch, M.H. 1928. The Nearctic and European species of the subgenus Phaedon (Chrysomelidae). Pan-Pacific Entomologist 5: 59-62.

Hatch, M.H. 1971. The Beetles of the Pacific Northwest. Part V: Rhipiceroidea, Sternoxi, Phytophaga, Rhynchophora, and Lamellicornia. University of Washington Publications in Biology, Vol. 16. University of Washington Press, Seattle and London, xiv + [1] + 662 pp.

Haynes, D.L., and Gage, S.H. 1981. The cereal leaf beetle in North America. Annual Review of Entomology 26: 259-287.

Heikertinger, F. 1929. Eine fahrt zum IV. Internationalen entomologen-kongress in Ithaca N.Y., U.S.A. Koleopterologische Rundschau 15: 42-61. 
Hewitt, G.B., and Burleson, W.H. 1976. A preliminary survey of the arthropod fauna of sainfoin in central Montana. Bulletin No. 693, Montana Agricultural Experiment Station, Bozeman, Montana, 11 pp.

Highet, F., and K. Pearson. 2015. Epitrix pubescens can cause damage to potato (Solanum tuberosum). EPPO Bulletin 45(2): 221-222.

Hight, S., Blossey, B., Lang, J., and DeClerck-Floate, R. 1995. Establishment of insect biological control agents from Europe against Lythrum salicaria in North America. Environmental Entomology 24: 967-977.

Hoebeke, E.R. 1979. A chrysomelid beetle (Psylliodes picina (Marsham)). United States Department of Agriculture, Cooperative Plant Pest Report 4: 202.

Hoebeke, E.R. 1980. A chrysomelid beetle [Chaetocnema concinna (Marsham)]. United States Department of Agriculture, Cooperative Plant Pest Report 5: 374.

Hoebeke, E.R. 1993. Establishment of Urophora quadrifasciata (Diptera: Tephritidae) and Chrysolina quadrigemina (Coleoptera: Chrysomelidae) in portions of eastern United States. Entomological News 104: 143-152.

Hoebeke, H.R., and Wheeler, A.G., Jr. 1983. Exotic insects reported new to northeastern United States and eastern Canada since 1970. Journal of the New York Entomological Society 91: 193-222.

Hoebeke, E.R., and Wheeler, A.G., Jr. 2003. Sphaeroderma testaceum (F.) (Coleoptera: Chrysomelidae), a Palearctic flea beetle new to North America. Proceedings of the Entomological Society of Washington 105: 991-995.

Hoebeke, E. R., and Wheeler, A.G., Jr. 2005. Establishment of three European flea beetles in Nova Scotia: Longitarsus ganglbaueri Heikertinger, L. jacobaeae (Waterhouse), and L. rubiginosa (Foudras) (Coleoptera: Chrysomelidae: Alticinae). Proceedings of the Entomological Society of Washington 107: 319-322.

Hoebeke, E.R., Wheeler, A.G., Jr., Kingsolver, J.M., and Stephan, D.L. 2009. First North American records of the east Palearctic seed beetle Bruchidius terrenus (Coleoptera: Chrysomelidae: Bruchinae), a specialist on mimosa (Albizia julibrissin, Fabaceae). Florida Entomologist 92: 434-440.

Holloway, J.K., and Huffaker, C.B. 1951. The role of Chrysolina gemellata in the biological control of Klamath weed. Journal of Economic Entomology 44: 244-247.

Hood, C.E. 1940. Life history and control of the imported willow leaf beetle. Circular 572, United States Department of Agriculture, Washington, DC, 9 pp.

Hooper, L.R.E. 2002. Discovery of Bruchidius villosus F. (Coleoptera: Bruchidae) on Scotch broom in Canada. Pan-Pacific Entomologist 78: 286-288.

Howden, H., and Howden, A. 2001. Tetrops praeusta (L.) (Coleoptera: Cerambycidae), a potential pest? Insecta Mundi 14 [2000]: 220.

Humble, L.M. 2001. Invasive bark and wood-boring beetles in British Columbia, Canada. Pp. 69-77, In: Alfaro, R., Day, K., Salom, S., Nair, K.S.S., Evans, H., 
Liebhold, A., Lieutier, F., Wagner, W., Futai, K., Suzuki, K. (eds): Protection of World Forests from Insect Pests: Advances in Research. Papers presented at the XXI IUFRO World Congress, IUFRO World Series, Vol. 11. Vienna, Austria.

Jacobs, K., Seifert, K.A., Harrison, K.J., and Kirisits, K. 2003. Identity and phylogenetic relationships of ophiostomatoid fungi associated with invasive and native Tetropium species (Coleoptera: Cerambycidae) in Atlantic Canada. Canadian Journal of Botany 81: 316-329.

Jensen, K.I.N., Harris, P., and Sampson, M.G. 2002. Hypericum perforatum L. St. John's Wort (Clusiaceae). Pp. 361-368, In: Mason, P.G., Huber, J.T. (eds): Biological Control Programmes in Canada, 1981-2000. CABI Publishing, Wallingford, United Kingdom.

Johnson, C.D., and Kingsolver, J.M. 1982. Checklist of the Bruchidae (Coleoptera) of Canada, United States, Mexico, Central America, and the West Indies. The Coleopterists Bulletin 35 [1981]: 409-422.

Jolivet, P. 1951. Contribution à l'étude du genre Gastrophysa Chevrolat (Coleoptera Chrysomelidae), 2 me note. Bulletin de l'Institut royal des Sciences naturelles de Belgique 27: 1-12.

Jolivet, P. 1990. Distribution et plantes-hôtes de Chrysolina staphylea (Linné, 1758). Bulletin et Annales de la Société royale belge d'Entomologie 126: 123-130.

Jolivet, P. 1991. Distribution et plantes-hôtes de Chrysolina banksi (Fabricius 1775) (Coleoptera, Chrysomelidae). Nouvelle Revue d'Entomologie (N.S.) 8: 151-157.

Julien, M.H., and Griffiths, M.W. 1998. Biological control of weeds. A world catalogue of agents and their target weeds. 4th ed. CAB International, Wallingford, United Kingdom, 223 pp.

Juutinen, P. 1955. Zur Biologie und forstlichen Bedeutung der Fichtenböcke (Tetropium Kirby) in Finnland. Acta Entomologica Fennica 11: 1-112.

Kalischuk, A.R. 2001. Density and efficacy of the flea beetle Aphthona lacertosa (Rosenhauer), an introduced biocontrol agent for leafy spurge, in Alberta. M.Sc Dissertation, University of Lethbridge, Lethbridge, Alberta, Canada.

Kalischuk, A.R., Bourchier, R.S., and McClay, A.S. 2004. Post hoc assessment of an operational biocontrol program: efficacy of the flea beetle Aphthona lacertosa Rosenhauer (Chrysomelidae: Coleoptera), an introduced biocontrol agent for leafy spurge. Biological Control 29: 418-426.

Kingsolver, J.M. 1979. A new host record for Callosobruchus chinensis (L.) (Coleoptera: Bruchidae). The Coleopterists Bulletin 33: 438.

Kingsolver, J.M. 2004. Handbook of the Bruchidae of the United States and Canada (Insecta, Coleoptera). Volume 1. Technical Bulletin 1912, United States Department of Agriculture, Agricultural Research Service, Washington, DC, $324 \mathrm{pp}$.

Kirby, W. 1837. Part IV: The Insects. In: Richardson, J. (ed.): Fauna boreali-americana; or the zoology of the northern parts of British America: containing descriptions 
of the objects of natural history collected on the late Northern Land Expeditions, under command of captain Sir John Franklin. R.N. Josiah Fletcher, Norwich, England, xxxix +325 pp +8 pls.

Klimaszewski, J., Brunke, A., Assing, V., Langor, D.W., Newton, A.F., Bourdon, C., Pelletier, G., Webster, R.P., Herman, L., Perdereau, L., Davies, A., Smetana, A., Chandler, D.S., Majka, C., and Scudder, G.G.E. 2013. Synopsis of adventive species of Coleoptera (Insecta) recorded from Canada. Part 2: Staphylinidae. Pensoft Series Faunistica No. 104. Pensoft, Sofia-Moscow, 360 pp.

Klimaszewski, J., Langor, D.W., Batista, R., Dorval, J.A, Majka, C.G., Scudder, G.G.E., and Bousquet, Y. 2012. Synopsis of adventive species of Coleoptera (Insecta) recorded from Canada. Part 1: Carabidae. Pensoft Series Faunistica No. 103. Pensoft, Sofia, Bulgaria. 96 pp.

Klimaszewski, J., Langor, D.W., Hammond, H.E.J., Pelletier, G., Bousquet, Y., Bourdon, C., Webster, R.P., Borowiec, L. Scudder, G.G.E., and Majka, C.G. 2015. Synopsis of adventive species of Coleoptera (Insecta) recorded from Canada. Part 3: Cucujoidea. Pensoft Series Faunistica No. 113, Pensoft, Sofia-Moscow, 171 pp. Klimaszewski, J., Langor, D.W., Majka, C.G., Bouchard, P., Bousquet, Y., LeSage, L., Smetana, A., Sylvestre. P., Pelletier, G, Davies, A., DesRochers, P., Goulet, H., Webster, R., and Sweeney, J. 2010. Review of adventive species of Coleoptera (Insecta) recorded from eastern Canada. Pensoft Series Faunistica No. 94. Pensoft, Sofia-Moscow, 272 pp.

Klimaszewski, J., Langor, D.W., Smith, A.B.T., Hoebeke, E.R., Davies, A., Pelletier, G., Douglas, H.B., Webster, R.P., Bourdon, C., Borowiec, L., and Scudder, G.G.E. 2017. Synopsis of adventive species of Coleoptera (Insecta) recorded from Canada. Part 4: Scarabaeoidea, Scirtoidea, Buprestoidea, Byrrhoidea, Elateroidea, Derodontoidea, Bostrichoidea, and Cleroidea. Pensoft Series Faunistica No. 116. Pensoft, Sofia-Moscow, 215 pp.

Klingeman, W.E., Youssef, N.N., Oliver, J.B., and Basham, J.P. 2017. The longhorned beetles (Coleoptera: Cerambycidae) of Tennessee: distribution of species, seasonal adult activity, and new state records. Florida Entomologist 100: 292-302.

Koch, K. 1992. Die Käfer Mitteleuropas, Ökologie Vol. 3. Goecke \& Evers Verlag, Krefeld, 389 pp.

Konstantinov, A.S., Baselga, A., Grebennikov, V.V., Prena, J., and Lingafelter, S.W. 2011. Revision of the Palearctic Chaetocnema species (Coleoptera: Chrysomelidae: Galerucinae: Alticini). Pensoft, Sofia-Moscow, 363 pp.

Kosior, A. 1975. Biology, ecology, and economic importance of cassids (Coleoptera, Chrysomelidae, Cassidinae) of the Ojców National Park. Acta Zoologica Cracoviensia 20: 251-393.

LaBonte, J.R., Mudge, A.D., and Johnson, K.J.R. 2005. Nonindigenous woodboring Coleoptera (Cerambycidae, Curculionidae: Scolytinae) new to Oregon and Wash- 
ington, 1999-2002: consequences of the intracontinental movement of raw wood products and solid wood packing materials. Proceedings of the Entomological Society of Washington 107: 554-564.

Landry, L.-P. 2001. Tetrops praeusta (Linné), une addition à la faune des Cerambycidae (Coleoptera) du Québec. Fabreries 26: 26-27.

Langor, D.W. 2019. The diversity of terrestrial arthropods in Canada. In: Langor, D.W., Sheffield, C.S. (eds): The Biota of Canada - A Biodiversity Assessment. Part 1: The Terrestrial Arthropods. ZooKeys 819: 9-40.

Langor, D.W., DeHaas, L.J., and Foottit, R.G. 2009. Diversity of non-native terrestrial arthropods on woody plants in Canada. Biological Invasions 11: 5-19.

Laplante, S. 1989. Contribution a l'inventaire des Cerambycidae (Coleoptera) de la province de Quebec. Fabreries 14: 56-83.

Lechevalier, H. 1944. Un nouvel ennemi pour les saules du Québec. Le Naturaliste Canadien 71: 210.

LeConte, J.L. 1850. An attempt to classify the longicorn Coleoptera of the part of America north of Mexico. Journal of the Academy of Natural Sciences of Philadelphia (second series) 1: 311-340, 2: 5-38.

Lee, S., and Lee, S. 2018. Review of the genus Trichoferus Wollaston (Coleoptera: Cerambycidae) in Korea. Journal of Asia-Pacific Biodiversity 11: 76-79.

LeSage, L. 1988. Notes on European Longitarsus species introduced in North America (Coleoptera: Chrysomelidae: Alticinae). The Canadian Entomologist 120: 11331145 .

LeSage, L. 1990. Chaetocnema concinna (Marsham, 1802), a European flea beetle introduced in North America (Coleoptera: Chrysomelidae: Alticinae). The Canadian Entomologist 122: 647-650.

LeSage, L. 1991. Family Chrysomelidae - leaf beetles. Pp. 301-323, In: Bousquet, Y. (ed.): Checklist of beetles of Canada and Alaska. Publication 1861/E, Research Branch, Agriculture Canada, Ottawa, Ontario, vi + 430 pp.

LeSage L. 1992. The lily beetle, Lioceris lilii (Scopoli), in Canada (Coleoptera: Chrysomelidae). La Revue Canadienne des Insectes Nuisibles aux Cultures 70: 88-96.

LeSage, L. 1996. Expansion de l'aire de répartition de Chrysolina hyperici (Forster) depuis son introduction en Ontario (Coleoptera: Chrysomelidae). Proceedings of the Entomological Society of Ontario 127: 127-130.

LeSage, L., and Elliot, B. 2003. Major range extension of the lily leaf beetle (Coleoptera : Chrysomelidae), a pest of wild and cultivated Liliaceae. The Canadian Entomologist 135: 587-588.

LeSage, L., and Majka, C.G. 2009. Introduced leaf beetles of the Maritime Provinces, 8: Gastrophysa polygoni Linnaeus (Coleoptera: Chrysomelidae). Zootaxa 2047: 48-62. 
LeSage, L., and Majka, C.G. 2010. Introduced leaf beetles of Maritime Provinces, 9: Chaetocnema concinna (Masham, 1802) (Coleoptera: Chrysomelidae). Zootaxa 2610: $27-49$.

LeSage, L., and Paquin, P. 1996. Identification keys for Aphthona flea beetles (Coleoptera: Chrysomelidae) introduced in Canada for the control of spurge (Euphorbia spp., Euphorbiaceae). The Canadian Entomologist 128: 593-603.

LeSage, L., and Savard, K. 2012. First record of the European rusted flea beetle, Neocrepidodera ferruginea (Scopoli, 1763), in North America (Coleoptera: Chrysomelidae: Galerucinae: Alticini). Psyche: A Journal of Entomology 2012: Article 387564. 11 pp. DOI:10.1155/2012/387564

LeSage, L., Dobesberger, E.J., and Majka, C.G. 2007. Introduced leaf beetles of the Maritime Provinces, 2: The cereal leaf beetle Oulema melanopus (Linnaeus) (Coleoptera: Chrysomelidae). Proceedings of the Entomological Society of Washington 109: 286-294.

LeSage, L., Dobesberger, E., and Majka, C. 2008. Introduced leaf beetles of the Maritime Provinces, 6: the common asparagus beetle, Crioceris asparagi (Linnaeus), and the twelve-spotted asparagus beetle, Crioceris duodecimpunctata (Linnaeus) (Coleoptera: Chrysomelidae). Proceedings of the Entomological Society of Washington 110: 602-621.

Levesque, C., and Levesque, G.-Y. 1998. Faunal composition, wing polymorphism and seasonal abundance of some flea beetles (Coleoptera: Chrysomelidae) in southern Quebec (Canada). Great Lakes Entomologist 31: 39-48.

Lindgren, C.J., Corrigan, J., and DeClerck-Floate, R. 2002. Lythrum salicaria L., purple loosestrife (Lythraceae). Pp. 383-390, In: Mason, P.G., Huber, J.T. (eds): Biological Control Programmes in Canada, 1981-2000. CABI Publishing, Wallingford, United Kingdom.

Lindroth, C.H. 1957. The faunal connections between Europe and North America. John Wiley \& Sons, New York, New York, 344 pp.

Lingafelter, S.W., and Hoebeke, E.R. 2002. Revision of the genus Anoplophora (Coleoptera: Cerambycidae). The Entomological Society of Washington, Washington, DC, 236 pp. + 41 pls.

Linsley, E.G. 1962. The Cerambycidae of North America. Part II. Taxonomy and classification of the Parandrinae, Prioninae, Spondylinae, and Aseminae. University of California Publication in Entomology 19, Berkeley, California, v + 102 pp.

Linsley, E.G. 1964. The Cerambycidae of North America. Part V. Taxonomy and classification of the subfamily Cerambycinae, tribes Callichromini through Ancylocerini. University of California Publication in Entomology No. 22, Berkeley, California, viii + 197 pp. 
Livingston, S.S. 1996. Biology, control, and host range of Lilioceris lilii: a new ornamental pest in the USA. M.Sc thesis, University of Rhode Island, Kingston, Rhode Island, $78 \mathrm{pp}$.

Löbl, L., and Smetana, A. 2010. Catalogue of Palaearctic Coleoptera, Volume 6, Chrysomeloidea. Apollo Books, Stenstrup, 924 pp.

Lovett, A.L. 1916. The elm leaf-beetle (Galerucella luteola Mull.). College Bulletin No. 226 (Extension Series 2, No. 47), Oregon Agricultural College, Extension Service, $4 \mathrm{pp}$.

MacNay, C.G. 1950. A summary of the more important insect infestations and occurrences in Canada in 1950. Annual Report of the Entomological Society of Ontario 81 [1950]: 106-125.

MacNay, C.G. (compiler). 1952. Canadian Insect Pest Review 30(6). Canada Department of Agriculture, Ottawa, Ontario.

MacNay, C.G. 1954. New records of insects in Canada in 1952: a review. The Canadian Entomologist 86: 55-60.

MacRae, T.C. 1994. Annotated checklist of the long-horned beetles (Coleoptera: Cerambycidae and Disteniidae) occurring in Missouri. Insecta Mundi 7: 223-252.

Maier, C.T. 2009. Distributional and host records of Cerambycidae (Coleoptera) associated with Cupressaceae in New England, New York, and New Jersey. Proceedings of the Entomological Society of Washington 111: 438-453.

Maier, C.T. 2017. Cerambycidae (Coleoptera) accidentally introduced into Connecticut from China or from other areas in the United States. Proceedings of the Entomological Society of Washington 119: 423-429.

Majka, C.G. 2010. Beetles in old growth forests: perspectives from the Townshend Woodlot, Prince Edward Island. Journal of the Acadian Entomological Society 6: 39-43.

Majka, C.G., and Kirby, C. 2011. Lily leaf beetle, Lilioceris lilii (Coleoptera: Chrysomelidae), in Maine and the Maritime Provinces: the continuing dispersal of an invasive species. Journal of the Acadian Entomological Society 7: 70-74.

Majka, C.G., and Langor, D.W. 2011. The bean weevils (Coleoptera: Chrysomelidae: Bruchinae) of Atlantic Canada. Journal of the Acadian Entomological Society 7: 75-82.

Majka, C.G., and LeSage, L. 2006. Introduced leaf beetles of the Maritime Provinces, 1: Sphaeroderma testaceum (F.) (Coleoptera: Chrysomelidae). Proceedings of the Entomological Society of Washington 108: 243-247.

Majka, C.G., and LeSage, L. 2007. Introduced leaf beetles of the Maritime Provinces, 3: The viburnum leaf beetle, Pyrrhalta viburni (Paykull) (Coleoptera: Chrysomelidae). Proceedings of the Entomological Society of Washington 109: 454-462. 
Majka, C.G., and LeSage, L. 2008a. Introduced leaf beetles of the Maritime Provinces, 4: Chrysolina staphylaea (Linnaeus) (Coleoptera: Chrysomelidae). Proceedings of the Entomological Society of Washington 110: 79-86.

Majka, C.G., and LeSage, L. 2008b. Introduced leaf beetles of the Maritime Provinces, 5: the lily leaf beetle, Lilioceris lilii (Scopoli) (Coleoptera: Chrysomelidae). Proceedings of the Entomological Society of Washington 110: 186-195.

Majka, C.G., and LeSage, L. 2008c. Introduced leaf beetles of the Maritime Provinces, 7: Cassida rubiginosa Müller and Cassida flaveola Thunberg (Coleoptera: Chrysomelidae). Zootaxa 1811: 37-56.

Marshall, J.E. 1979. The larvae of the British species of Chrysolina (Chrysomelidae). Systematic Entomology 4: 409-417.

Marshall, S., and Paiero, S.M. 2015. Cassida viridis (Coleoptera: Chrysomelidae), a Palearctic leaf beetle newly recorded from North America. The Canadian Entomologist 148: 140-142.

Mattson, W.J., Niemelä, P., Millers, I., and Inguanzo, Y. 1994. Immigrant phytophaous insects on woody plants in the United States and Canada: an annotated list. General Technical Report NC-169, United States Department of Agriculture, Forest Service, North Central Forest Experiment Station, St. Paul, Minnesota, 169 pp.

Maw, M.G. 1976a. An annotated list of insects associated with Canada thistle (Cirsium arvense) in Canada. The Canadian Entomologist 108: 235-244.

Maw, M.G. 1976b. Biology of the tortoise beetle, Cassida hemisphaerica (Coleoptera: Chrysomelidae), a possible biological control agent for bladder campion, Silene cucubalus (Caryophyllaceae), in Canada. The Canadian Entomologist 108: 945-954.

Maw, M.G., and Steinhausen, W.R. 1980. Cassida azurea (Coleoptera: Chrysomelidae - not $C$. hemisphaerica - as a possible biocontrol agent of bladder campion, Silene cucubalus (Caryophyllaceae) in Canada. Zeitschrift für Angewandte Entomologie 90: 420-422.

McCabe, T. L., and J. P. Huether. 1986. An annotated list of Pine Bush Cerambycidae (Insecta: Coleoptera). Skenectada 3: 19-23.

McClanahan, R.J., Boyce, H.R., and Code, W.R. 1968. The cereal leaf beetle-a new insect in Ontario. Proceedings of the Entomological Society of Ontario 98 [1967]: 21-26.

McClay, A.S. 1996. Biological control in a cold climate: temperature responses and climatic adaptation of weed biocontrol agents. Pp. 377-383, In: Moran, V.C., Hoffmann, J.H. (eds): Proceedings of the IX International Symposium on Biological Control of Weeds, 19-26 January 1996, Stellenbosch, South Africa. University of Cape Town, Cape Town, South Africa.

McClay, A.S., Bourchier, R.S., Butts, R.A., and Peschken, D.P. 2002. Cirsium arvense (L.) Scopoli, Canada Thistle (Asteraceae). Pp. 318-330, In: Mason, P.G., Huber, 
J.T. (eds): Biological Control Programmes in Canada, 1981-2000. CABI Publishing, Wallingford, United Kingdom.

McClay, A.S., Cole, D.E., Harris, P., and Richardson, C.J. 1995. Biological control of leafy spurge in Alberta: progress and prospects. Publication Number AECV95-R2, Alberta Environmental Centre, Vegreville, Alberta, 63 pp.

McClay, A.S., and Harris, P. 1984. Biological control of leafy spurge in Canada. Pp. 18-20, In: Lorenz, R. (ed.): Proceedings of the 1984 Leafy Spurge Annual Meeting, Dickinson, North Dakota. Great Plains Agricultural Council.

McCorquodale, D.B. 2010. Longhorn beetles (Coleoptera: Cerambycidae) of the Atlantic Maritime Ecozone. Pp. 465-476, In: McAlpine, D.F., Smith, I.M. (eds): Assessment of species diversity in the Atlantic maritime ecozone. NRC Research Press, Ottawa, Ontario.

McCorquodale, D.B., and Bondrup-Nielsen, S. 2004. Do we know beetles? Lessons from new records of Cerambycidae (Coleoptera) for Nova Scotia. Proceedings of the Nova Scotian Institute of Science 42: 209-223.

McCorquodale, D.B., Brown, J.M., and Marshall, S.A. 2007. A decline in the number of long-horned wood boring beetle (Coleoptera: Cerambycidae) species in Ontario during the 20th century? Journal of the Entomological Society of Ontario 138: $107-135$.

McLeod, J.H. 1962. Part I. Biological control of pests of crops, fruit trees, ornamentals, and weeds in Canada up to 1959. Pp. 1-33, In: A review of the biological control attempts against insects and weeds in Canada. Technical Communications 2, Commonwealth Institute for Biological Control. Commonwealth Agricultural Bureaux, Farnham Royal, United Kingdom.

McNamara, J. 1991. Family Bruchidae seed beetles. Pp. 300-301, In: Bousquet, Y. (ed.): Checklist of beetles of Canada and Alaska. Publication 1861/E, Agriculture Canada, Research Branch, Ottawa, Ontario.

Melsheimer, F.V. 1806. A catalogue of insects of Pennsylvania. Part first. Hannover, Pennsylvania, [published by the author, printed by W.D. Lepper], vi + 60 pp.

Milliron, H.E. 1953. A European flea beetle injuring crucifers in North America. Journal of Economic Entomology 46: 179.

Murray, T. 2004. Pest alert: Viburnum leaf beetle. In: Weeder's Digest Newsletter of the Whatcom County Master Gardeners. Available at: http://whatcom.wsu. edu/ch/documents/newsletter/WD_2004_06.pdf_

Murray, T., LaGasa, E., Looney, C., and Aflitto, N. 2016. Pest Watch: Viburnum Leaf Beetle. Home Garden Series. Washington State University Extension FS202E, 6 pp. Available at: http://cru.cahe.wsu.edu/CEPublications/FS202E/FS202E.pdf

NAPPO [North American Plant Protection Organization]. 2013. Phytosanitary Pest Alert System. Official Pest Reports. Canada (2013-04-08). Asian Long-horned 
Beetle (Anoplophora glabripennis) - Eradication from the cities of Toronto and Vaughn, Ontario. Available at: https://gd.eppo.int/reporting/article-2538.

Natural Resources Canada. 2015. Brown spruce longhorn beetle. Available at: https:// tidcf.nrcan.gc.ca/en/insects/factsheet/1000096

Natural Resources Canada. 2019. Asian Longhorned Beetle. Available at: https://www. nrcan.gc.ca/asian-longhorned-beetle/13369 (Accessed 20 June 2019).

Newton, H.C.F. 1929. Observations on the biology of some flea-beetles of economic importance. Journal of the South-Eastern Agricultural College, Wye 26: 145-164.

Nowierski, R. M., and Pemberton, R.W. 2002. Leafy spurge. Pp. 181-194, In: Van Driesche, R., Blossey, B., Hoddle, M., Lyon, S., Reardon, R. (eds): Biological control of invasive plants in the eastern United States. Publication FHTET-2002-04, United States Department of Agriculture, Forest Service. Available at: https:// www.invasive.org/weedcd/pdfs/biocontrol.pdf

Oliveira, M.R.C., Correa, A.S., de Souza, G.A., Guedes, R.N.C., and Oliveira, L.O. de. 2013. Mesoamerican origin and pre- and post-Columbian expansions of the ranges of Acanthoscelides obtectus Say, a cosmopolitan insect pest of the common bean. Plos/One e70039. Available at: https://doi.org/10.1371/journal.pone.0070039

Olsen, C.E. 1918. [Exhibition of specimens]. Journal of the New York Entomological Society 26: 234.

Özdikmen, H. 2013. The longicorn beetles of Turkey (Coleoptera: Cerambycidae) Part V. South-eastern Anatolian Region. Munis Entomology and Zoology 8: 67-123.

Özdikmen, H. 2016. An improved review of Turkish saproxylic Cerambycidae (Coleoptera) from the European red list with additional twenty-one species. Munis Entomology and Zoology 11: 542-572.

Palaniswamy, P., and Lamb, R.J. 1992. Host preferences of the flea beetles Phyllotreta cruciferae and P. striolata (Coleoptera: Chrysomelidae) for crucifer seedlings. Journal of Economic Entomology 85: 743-752.

Parnell, J.R. 1964. The external morphology of the larvae and notes on the pupae of Bruchidius ater (Marsh.) (Col., Bruchidae) and Apion fuscirostre F. (Col., Curculionidae). The Entomologist's Monthly Magazine 100: 83-87.

Pavlov, I.E. 1960. Ecology of cereal-stem flea-beetles (Coleoptera, Chrysomelidae, Halticinae) and measures for their control [In Russian]. Entomologicheskoe Obozrenie 39: 775-795.

Pemberton, R.W., and Johnson, G.R. 1986. Aphthona cyparissiae, a new flea beetle for leafy spurge control in the United States. Pp. 42-48, In: 1986 Leafy Spurge Symposium Proceedings, Riverton, Wyoming, 9-10 July 1986.

Pemberton, R.W., and Rees, N.E. 1990. Host specificity and establishment of Aphthona flava Guill. (Chrysomelidae), a biological control agent for leafy spurge (Euphorbia escula L.) in the United States. Proceedings of the Entomological Society of Washington 92: 351-357. 
Pemberton, R.W., and Wang, R. 1989. Survey for natural enemies of Euphorbia esula L. in northern China and Inner Mongolia. Chinese Journal of Biological Control 5: 64-67.

Pentinsaari, M., Anderson, R., Borowiec, L., Bouchard, P., Brunke, A., Douglas, H., Smith, A.B.T., and Hebert, P.D.N. 2019. DNA barcodes reveal 63 overlooked species of Canadian beetles (Insecta: Coleoptera). ZooKeys 894: 53-150.

Peschken, D.P. 1971. Cirsium arvense (L.) Scop., Canada thistle (Compositae). Pp. 7983, In: Biological control programmes against insects and weeds in Canada, 19591968. Technical Communication 4, Commonwealth Institute of Biological Control. Commonwealth Agricultural Bureaux, Farnham Royal, United Kingdom.

Peschken, D.P. 1984a. Host range of Lema cyanella (Coleoptera: Chrysomelidae), a candidate for biocontrol of Canada thistle, and of four stenophagous, foreign thistle insects in North America. The Canadian Entomologist 116: 1377-1384.

Peschken, D.P., Friensen, H.A., Tonks, N.V., and Banham, F.L. 1970. Releases of Altica carduorum (Chrysomelidae: Coleoptera) against the weed Canada thistle (Cirsium arvense) in Canada. The Canadian Entomologist 102: 264-271.

Peschken, D.P., McClay, A.S., and DeClerck-Floate, R.A. 2002. Silene vulgaris (Moench) Garcke, bladder campion (Carophyllaceae). Pp. 411-416, In: Mason, P.G., Huber, J.T. (eds): Biological Control Programmes in Canada, 1981-2000. CABI Publishing, Wallingford, United Kingdom.

Pfaffenberger, G.S. 1977. Comparative descriptions of the final larval instar of Bruchus brachialis, B. rufimanus, and B. pisorum (Coleoptera: Bruchidae). The Coleopterists Bulletin 31:133-142.

Pfaffenberger, G.S. 1991. Bruchidae (Chrysomeloidea). Pp. 561-568, In: F.W. Stehr (ed.): Immature Insects, vol. 2. Kendall Hunt Publishing, Dubuque, Iowa.

Pfister, S. and Valdez, R. 2017. Velvet longhorned beetle status in the United States. National Plant Board Annual Meeting, 13-17 August 2017, Savannah, Georgia. Available at: https://nationalplantboard.org/wp-content/uploads/docs/2017_meeting/pfister_furniturebeetle.pdf

Provancher. L. 1877. Petite faune entomologique du Canada et particulièrement de la province de Québec. Volume 1 - Les Coleopteres. Québec, Des Press de C. Darveau. No. 82, rue de la Montagne.

Ratzlaff, C.G., Needham, K.M., and Scudder, G.G.E. 2016. Notes on insects recently introduced to Metro Vancouver and other newly recorded species from British Columbia. Journal of the Entomological Society of British Columbia 113: 79-89.

Read, R.W.J. 1984. On the foodplants of Chrysolina staphylea L. (Col.: Chrysomelidae). The Entomologist's Record and Journal of Variation 96: 185.

Rees, N.E., Pemberton, R.W., Rizza, A., and Pecora, P. 1986. First recovery of Oberea erythrocephala on the leafy spurge complex in the United States. Weed Science 34: 395-397. 
Rees, N.E., Pemberton, R.W., Spencer, N.R., Quimby, P.C., and Nowierski, R.M. 1996. Spurge. Pp.1-36, In: Rees, N.E., Quimby, P.C., Piper, G.L., Turner, C.E., Coombs, E.M., Spencer, N.R., Knutson, L.V. (eds): Biological control of weeds in the West. Western Society of Weed Science, Bozeman, Montana.

Riley, C.V. 1892. The first larval or post-embryonic stage of the pea and bean weevils. The Canadian Entomologist 24: 185-186.

Riley, C.V., and Howard, L.O. 1893. Food plants of North American species of Bruchus. Insect Life 5: 165-166.

Riley, E.G., Clark, S.M., and Seeno, T.N. 2003. Catalog of the leaf beetles of America north of Mexico (Coleoptera: Megalopodidae, Orsodacnidae and Chrysomelidae, excluding Bruchinae). Coleopterists Society Special Publication No. 1, 290 pp.

Robinson, W.H. 2005. Urban Insects and Arachnids: a Handbook of Urban Entomology. Cambridge University Press, United Kingdom, 480 pp.

Roehrdanz, R., Olson, D., Fauske, G., Bourchier, R., Cortilet, A., and Sears, S. 2009. New DNA markers reveal presence of Aphthona species (Coleoptera: Chrysomelidae) believed to have failed to establish after release into leafy spurge. Biological Control 49: 1-5. DOI: 10.1016/j.biocontrol.2008.12.008

Roland, A.E. 1998. Roland's Flora of Nova Scotia. Revised by M. Zinck. Nova Scotia Museum, Halifax, Nova Scotia, 1297 pp.

Royce, L.A., and Simko, B. 2000. Identification, Control, and California Quarantine Alert. Publication EM8762, Oregon State University Extension Service, 4 pp. Available at: https://ir.library.oregonstate.edu/downloads/rf55z808j

Rutanen, I., and Martikainen, P. 2014. Longitarsus pratensis (Panzer) -ryhmän lajit Suomessa [Longitarsus pratensis (Panzer) species group in Finland]. Sahlbergia 20: 28-35.

Sailer, R.I. 1978. Our immigrant fauna. Bulletin of the Entomological Society of America 24: 3-11.

Sailer, R.I. 1983. History of insect introductions. Pp.15-38, In: Wilson, C.L., Graham, C.L. (eds): Exotic Plant Pests and North American Agriculture. Academic Press, New York, New York.

Sama, G. 2002. Atlas of the Cerambycidae of Europe and the Mediterranean area. Vol. I: North and Central Europe. Pensoft Press, Zlin, Czech Republic, 173 pp.

Sama, G., Jansson, N., Avcı, M., Sarıkaya, O., Coşkun, O., Kayış, T., and Özdikmen, H. 2011. Preliminary report on a survey of the saproxylic beetle fauna living on old hollow oaks (Quercus spp.) and oak wood in Turkey (Coleoptera: Cerambycidae). Munis Entomology and Zoology 6: 819-831.

Sarazin, M.J. 1991. Insect liberations in Canada, 1990. For classical biological control purposes. Liberation Bulletin 54: 1-39.

Sarazin, M.J., and Hamilton, N.A. 1988. Insect liberations in Canada, 1983. Parasites and predators. Liberation Bulletin 47: 1-21. 
Saroli, J.A., Cutler, G.C., and Hillier, N.K. 2016. Morphological comparison of Altica sylvia Malloch, 1919 and Mantura chrysanthemi (Koch, 1803) (Coleoptera: Chrysomelidae: Galerucinae: Alticini), with a focus on sexual dimorphism. The Coleopterists Bulletin 70: 892-902.

Sauer, S.B. 2009. New state records of Chrysomelidae (Coleoptera) for Wisconsin (U.S.A.), with notes on selected species and special attention to possible prairie-dependent fauna. Entomological News 120: 25-40.

Say, T. 1826. Descriptions of new species of coleopterous insects inhabiting the United States. Journal of the Academy of Natural Sciences of Philadelphia 5 [1825-1827]: 237-284, 293-304.

Say, T. 1831. Pp. 1-8, In: Descriptions of North American curculionides $\&$ an arrangement of some of our known species agreeably to the method of Schoenherr. School Press, New Harmony, Indiana, 30 pp.

Schaeffer, C. 1915. New Coleoptera and miscellaneous notes. III. Journal of the New York Entomological Society 23: 235-238.

Schroeder, D. 1980. Investigations on Oberea erythrocephala (Schrank) (Col.: Cerambycidae), a possible biocontrol agent of leafy spurge, Euphorbia spp. (Euphorbiaceae) in Canada. Zeitschrift für Angewandte Entomologie 90: 237-254.

Schwarzländer, M. 2000. Host specificity of Longitarus quadriguttatus Pont., a below-ground herbivore for the biological control of houndstongue. Biological Control 18: 18-26.

Slipinski, S.A., Leschen, R.A.B., and Lawrence, J.F. 2011. Order Coleoptera Linnaeus, 1758. In: Zhang, Z.-Q. (ed.): Animal biodiversity: an outline of higher-level classification and survey of taxonomic richness. Zootaxa 3148: 203-207.

Smith, E.H. 1985. Revision of the genus Phyllotreta Chevrolat of America north of Mexico. Part I. The maculate species (Coleoptera: Chrysomelidae: Alticinae). Fieldiana Zoology (new series) 28: i-v, 1-168.

Smith, G., and Hurley, J.E. 2000. First North American record of the Palearctic species Tetropium fuscum (Fabricius) (Coleoptera: Cerambycidae). The Coleopterists Bulletin 54: 540.

Smith, J.M. 1951. Biological control of weeds in Canada. Canadian National Weed Commission, East Sector Proceedings 5: 95-97.

Smith, J.M. 1958. Biological control of Klamath weed, Hypericum perforatum L., in British Columbia. Pp. 561-565, In: Becker, E.C. (ed.): Proceedings of the $10^{\text {th }}$ International Congress of Entomology Volume 4, 17-25 August 1956, Montreal, Quebec.

Sommer, G., and Maw, E. 1982. Aphthona cyparissiae (Koch) and A. flava Guill. (Coleoptera: Chrysomelidae): Two candidates for the biological control of cypress and leafy spurge in North America. Unpublished report. Commonwealth Institute of Biological Control, Delemont, Switzerland, $60 \mathrm{pp}$. 
Southgate, B.J. 1963. The true identity of the broom bruchid (Coleoptera) and synonymic notes on other species of Bruchidius. Annals of the Entomological Society of America 56: 795-798.

Spears, J.F. 1964. Cereal leaf beetle menaces America’s grain producing areas. (re-print) Agricultural Chemicals, October 1964, 4 pp.

Staines, C.L. 1999. Chrysomelidae (Coleoptera) new to North Carolina. The Coleopterists Bulletin 53: 27-29.

Staines, C.L., and Staines, S.L. 2006. Additional eastern US records of the introduced leaf beetle Chrysolina quadrigemina (Suffrian) (Coleoptera: Chrysomelidae). The Coleopterists Bulletin 60: 72.

Strickland, E.H. 1920. Popular and Practical Entomology. The cottonwood leaf-mining beetles in Southern Alberta. The Canadian Entomologist 52: 1-5.

Swift, I.P., and Ray, A.M. 2010. Nomenclatural changes in North American Phymatodes Mulsant (Coleoptera: Cerambycidae). Zootaxa 2448: 35-52.

Tahvanainen, J.O., and Root, R.B. 1970. The invasion and population outbreak of Psylloides [sic] napi (Coleoptera: Chrysomelidae) on yellow rocket (Barbarea vulgaris) in New York. Annals of the Entomological Society of America 63: 1479-1480.

Tingle, J.L., Cook-Patton, S.C., and Agrawal, A.A. 2016. Spillover of a biological control agent (Chrysolina quadrigemina) onto native St. Johnswort [sic] (Hypericum punctatum). Peer J: e1886. DOI: 10.7717/peerj.1886

Turgeon, J.J., Orr, M., Grant, C., Wu, Y., and Gasman, B. 2015. Decade-old satellite infestation of Anoplophora glabripennis Motschulsky (Coleoptera: Cerambycidae) found in Ontario, Canada outside regulated area of founder population. The Coleopterists Bulletin 69: 674-678.

Turnbow R.H., Jr., and Thomas, M.C. 2002. Cerambycidae Leach 1815. Pp. 568601, In: Arnett, R.H., Jr., Thomas, M.C., Skelley, P.E., Frank, J.H. (eds): American Beetles. Volume 2. CRC Press, Boca Raton, Florida.

Turner, S., and Cesselli, S. 2013. Operational field guide to the establishment of tansy ragwort biocontrol agents in British Columbia. Province of British Columbia Victoria, British Columbia.

Udayagiri, S., and Wadhi, S.R. 1989. Catalog of Bruchidae. Memoirs of the American Entomological Institute 45, iii + 301 pp.

University of California Riverside. 2011. Elm leaf beetle. University of California, Center For Invasive Species Research, Riverside, California. Available at https:// cisr.ucr.edu/elm_leaf_beetle.html

Urban, J. 2005. Contribution to the knowledge of development and harmfulness of imported willow leaf beetle (Plagiodera versicolora) (Coleoptera, Chrysomelidae). Journal of Forest Science 51: 481-507.

USDA [United States Department of Agriculture]. 1971. Distribution of vetch bruchid Bruchus brachialis. Cooperative Economic Insect Report No. 21: 736. 
Vappula, N.A. 1965. Pests of cultivated plants in Finland. Acta Entomologica Fennica 19: 1-239.

Vig, K., and Verdyck, P. 2001. Data on the host plant selection of the horseradish flea beetle, Phyllotreta armoraciae (Koch, 1803) (Coleoptera, Chrysomelidae, Alticinae). Mededelingen van de Faculteit Landbouwwetenschappen Universiteit Gent 66: 277-283.

Wang, Q., and Leschen, R.A. 2003. Identification and distribution of Arhopalus species (Coleoptera: Cerambycidae: Aseminae) in Australia and New Zealand. New Zealand Entomologist 26: 53-59.

Wang, Q. 2017. Cerambycidae of the world: biology and pest management. CRC Press, Boca Raton, Florida, 628 pp.

Waterworth, P.D. 1986. Internal seed infesting insects. Report APHIS 81-48, United States Department of Agriculture, Animal and Plant Health Inspection Service, Washington, DC, 136 pp.

Watson, K., Pratt, C.A., and Caputo, J. 2016. Total records of velvet longhorned beete Trichoferus campestris Faldermann (Coleoptera, Cerambycidae) from Utah. Utah Department of Agriculture and Food, Salt Lake City, Utah. Available at: https:// ag.utah.gov/documents/Insect_Velvet_Longhorn_Beetle.pdf

Webster, J.A. 1977. The cereal leaf beetle in North America: breeding for resistance in small grains. Annals of the New York Academy of Sciences 287: 230-273.

Webster, R.P. 2016. Checklist of the Coleoptera of New Brunswick, Canada. ZooKeys 573: 387-512.

Webster, R.P., LeSage, L., and DeMerchant, I. 2012. New Coleoptera records from New Brunswick, Canada: Megalopodidae and Chrysomelidae. ZooKeys 179: 321-348.

Weiss, H.B., and Dickerson, E.L. 1917. Plagiodera versicolora Laich., an imported poplar and willow pest. The Canadian Entomologist 49: 104-109.

Wendt, H. 1986. Beiträge zur Insektenfauna der DDR: Coleoptera-Bruchidae (Chrysomeloidea). I. Zur Biologie und Verbreitung. Mitteilungen aus dem Zoologischen Museum in Berlin 62: 103-133.

Westcott, R.L., Brown, R.E., Sharratt, D.B., and White, R.E. 1985. Longitarsus: a new species from Oregon and a new record for North America (Coleoptera: Chrysomelidae). The Pan-Pacific Entomologist 61: 323-330.

Westcott, R.L., LaBonte, J.R., Parsons, G.L., and Johnson, P.J. 2006. New records and other notes for Oregon Coleoptera. Zootaxa 1142: 1-33.

Weston, P.A., and Desurmont, G. 2002. Suitability of various species of Viburnum as hosts for Pyrrhalta viburni, an introduced leaf beetle. Journal of Environmental Horticulture 20: 224-227.

Weston, P.A., Desurmont, G., and Hoebeke, E.R. 2007. Viburnum leaf beetle (Coleoptera: Chrysomelidae): biology, invasion history in North America, and management options. American Entomologist 53: 96-101. 
Weston, P.A., and Hoebeke, E.R. 2003. Viburnum leaf beetle, Pyrrhalta viburni (Paykull) (Coleoptera: Chrysomelidae): dispersal pattern of a Palearctic landscape pest in New York and its distribution status in the northeastern U. S. and eastern Canada. Proceedings of the Entomological Society of Washington 105: 889-895.

Wheeler, A.G., Jr. 1992. Holarctic insects adventive in Michigan: new and additional records (Homoptera, Heteroptera, Coleoptera, Neuroptera). The Great Lakes Entomologist 25: 99-106.

Wheeler, A.G., Jr., and Hoebeke, E.R. 1983. New records of a Palearctic flea beetle, Psylliodes affinis, in eastern North America (Coleoptera: Chrysomelidae). Proceedings of the Entomological Society of Washington 85: 594-597.

Wheeler, A.G., Jr., and Hoebeke, E.R. 2009. Adventive (non-native) insects: importance to science and society. Pp. 475-521, In: Footitt, R.G., Adler, P.H. (eds): Insect Biodiversity: Science and Society, First Edition. Blackwell Publishing.

Wheeler, A.G., Jr., and Hoebeke, E.R. 2017. Adventive (non-native) insects and the consequences for science and society of species that become invasive. Pp. 641-711, In: Footitt, R.G., Adler, P.H. (eds): Insect Biodiversity: Science and Society, Second Edition. John Wiley \& Sons.

White, R. 1983. A Field Guide to the Beetles. Houghton Mifflin Company, Boston, Massachusetts, 368 pp.

White, R.E. 1993. A revision of the subfamily Criocerinae (Chrysomelidae) of North America north of Mexico. Technical Bulletin 1805, United States Department of Agriculture, Washington, DC, 158 pp.

White, R.E. 1996. A revision of the genus Chaetocnema of America north of Mexico (Coleoptera: Chrysomelidae). Contributions of the American Entomological Institute 29: $1-158$.

Wilkinson, A.T.S. 1986. Biological control of tansy ragwort with Longitarsus jacobaea (L.) and L. flavicornis Steph. In: Canadex Weed Control 641.613. Agriculture Canada, Ottawa, Ontario.

Williamson, G.D. 1986. Insect liberations in Canada, 1982. Parasites and predators. Liberation Bulletin 46: 1-15.

Winston, R.L., Randall, C.B., Blossey, B., Tipping, P.W., Lake, E.C., and Hough-Goldstein, J. 2017. Field Guide for the Biological Control of Weeds in Eastern North America. FHTET-2016-04, United States Department of Agriculture, Forest Service, Forest Health Technology Enterprise Team, Morgantown, West Virginia, 338 pp.

Winston, R.L., Randall, C.B., DeClerck-Floate, R., McClay, A., Andreas, J., and Schwarzländer, M. 2016. Field Guide for the Biological Control of Weeds in the Northwest. FHTET-2014-08, United States Department of Agriculture, Forest Service, Forest Health Technology Enterprise Team, Morgantown, West Virginia, 332 pp.

Winston, R.L., Schwarzländer, M., Hinz, H.L., Day, M.D., Cock, M.J., and Julien, M.H. 2014. Biological control of weeds: a world catalogue of agents and their 
target weeds, $5^{\text {th }}$ Editon. FHTET-2014-04. United States Department of Agriculture, Forest Service, Forest Health Technology Enterprise Team, Morgantown, West Virginia, 838 pp.

Yanega, D. 1996. Field Guide to Northeastern Longhorned Beetles (Coleoptera: Cerambycidae), Manual 6, Illinois Natural History Survey, Champaign, Illinois, $\mathrm{x}+$ $174 \mathrm{pp}$.

Zwölfer, H. 1965. Observations on distribution and ecology of Altica carduorum Guer. (Coleoptera: Chrysomelidae). Commonwealth Institute of Biological Control, Technical Communication 5: 129-141.

Zwölfer, H., and Pattullo, W. 1969. Zur Lebensweise und Wirtsbindung des Distel-Blattkäfers Lema cyanella L. (puncticollis Curt.) (Col. Chrysomelidae). Anzeiger für Schädlingskunde 42: 53-59. 
Plates 


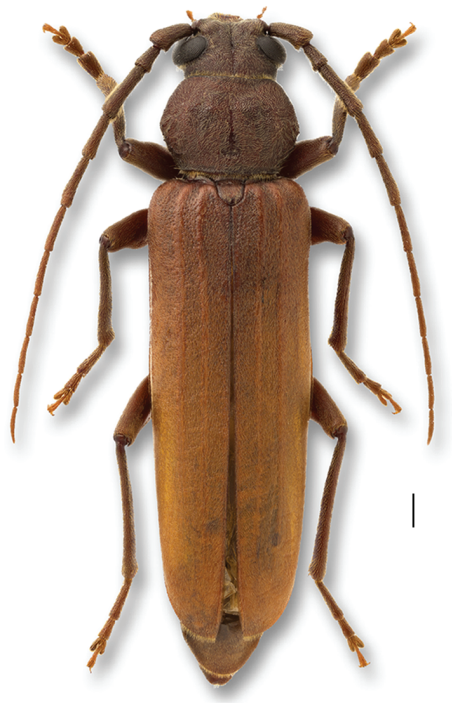

1. Arhopalus rusticus

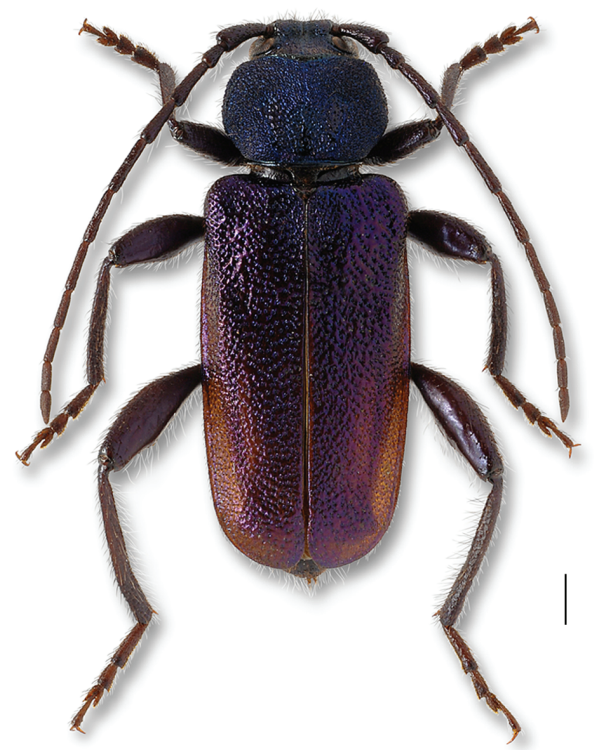

3. Callidium violaceum

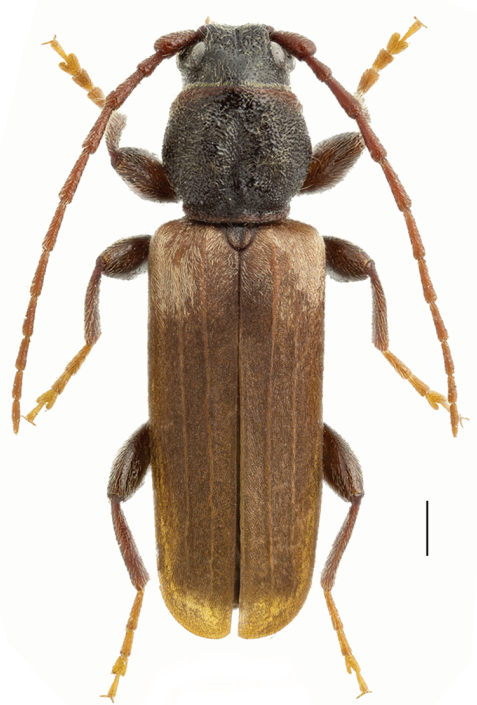

2. Tetropium fuscum

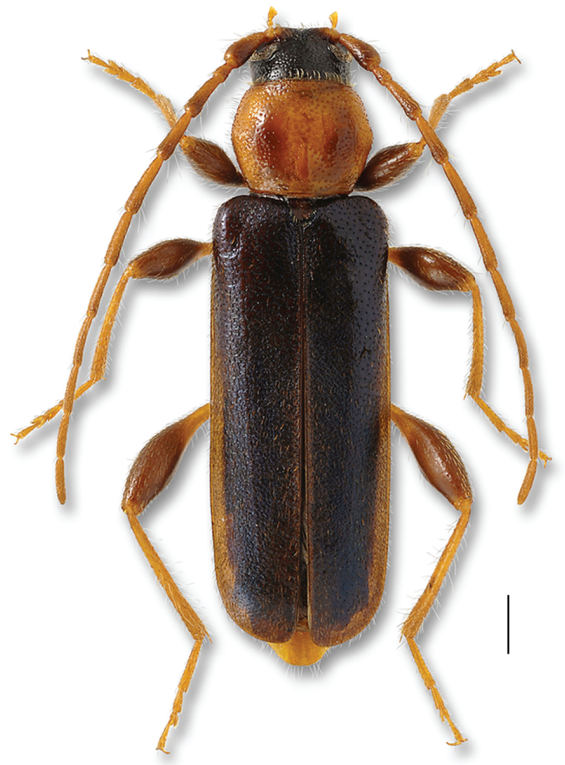

4. Phymatodes testaceus

Figures 1-4. Body images in dorsal view: 1, Arhopalus rusticus (Linnaeus); 2, Tetropium fuscum (Fabricius); 3, Callidium violaceum (Linnaeus); 4, Phymatodes testaceus (Linnaeus). Scale bar $=1 \mathrm{~mm}$. 


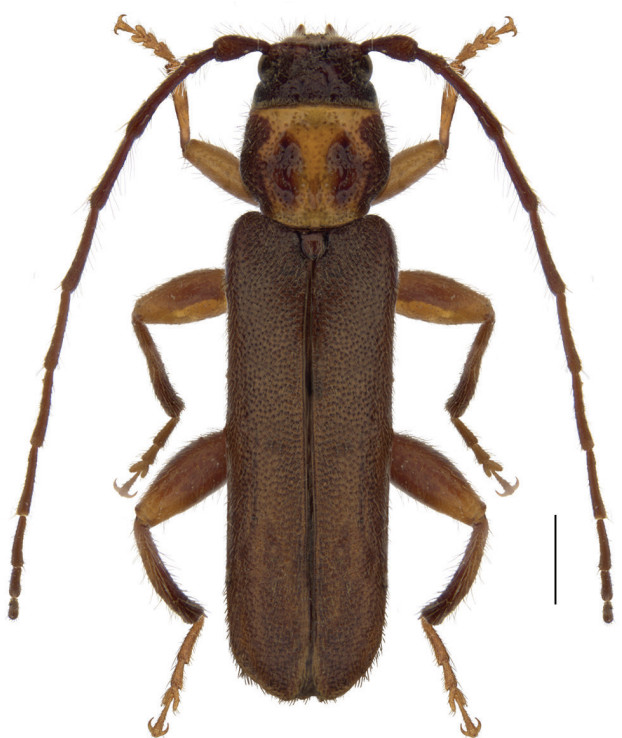

5. Poecilium lividum

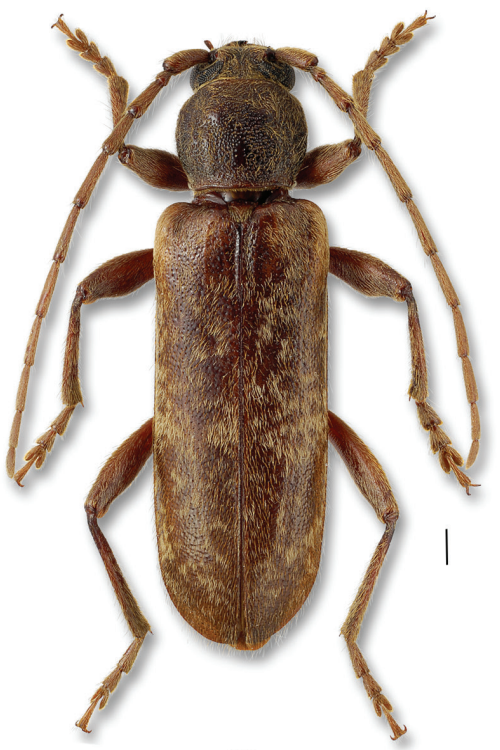

7. Trichoferus campestris

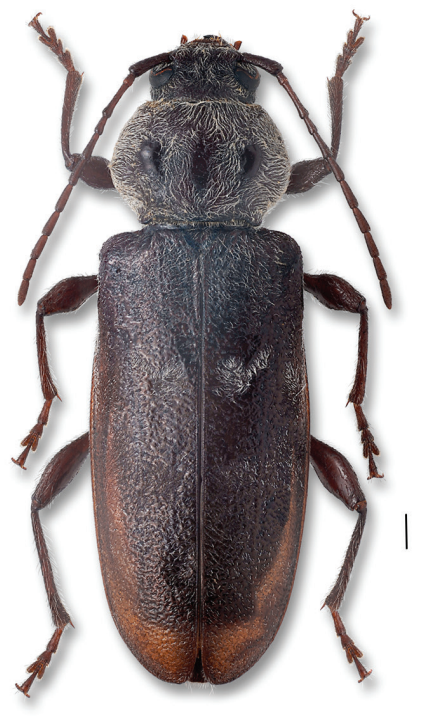

6. Hylotrupes bajulus

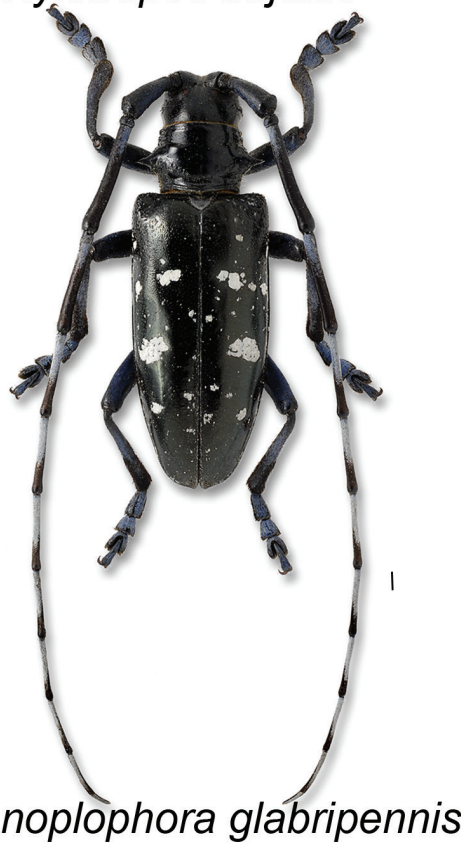

Figures 5-8. Body images in dorsal view: 5, Poecilium lividum (Rossi); 6, Hylotrupes bajulus (Linnaeus); 7, Trichoferus campestris (Faldermann); 8, Anoplophora glabripennis (Motschulsky). Scale bar $=1 \mathrm{~mm}$. 

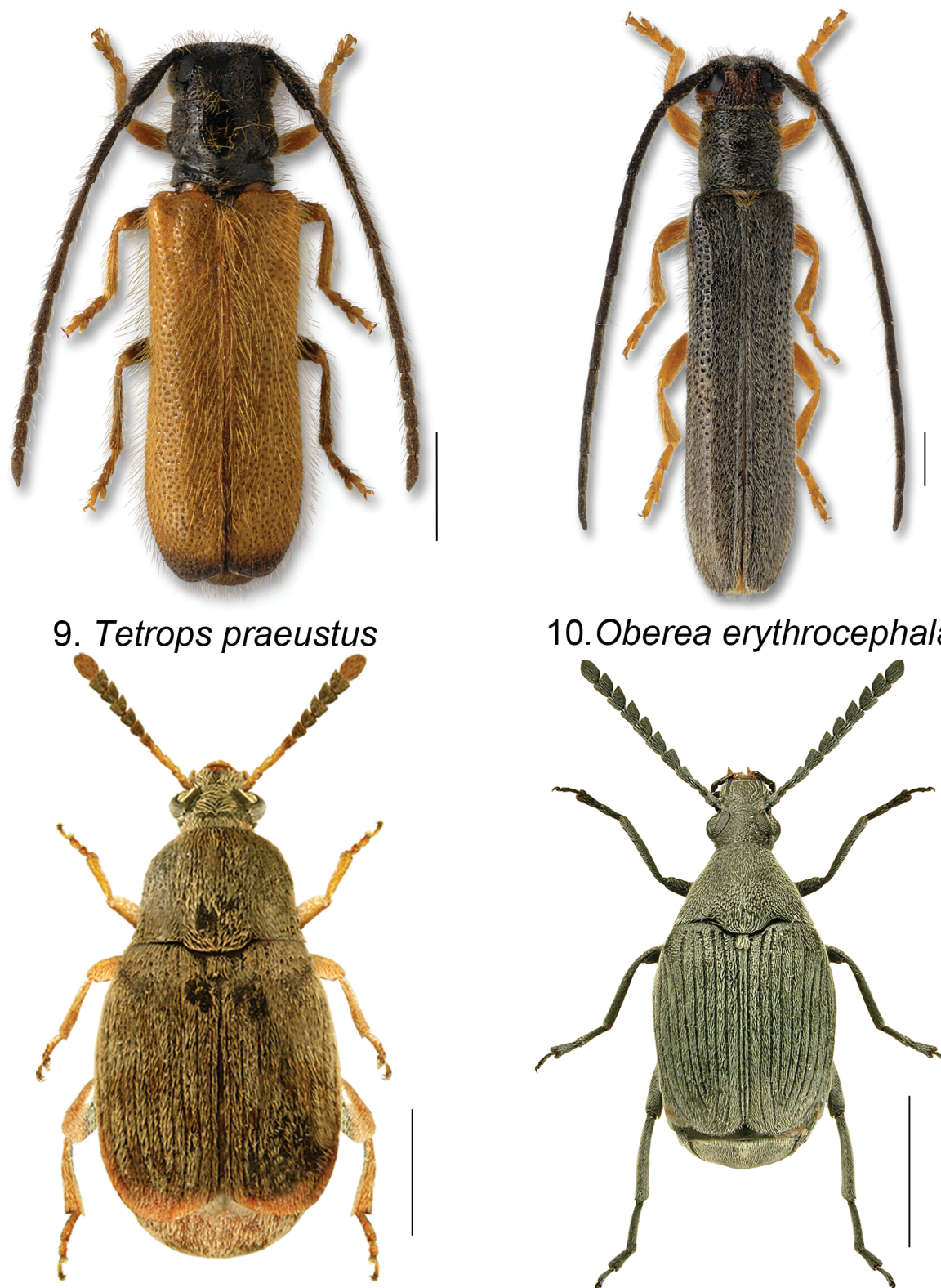

11. Acanthoscelides obtectus
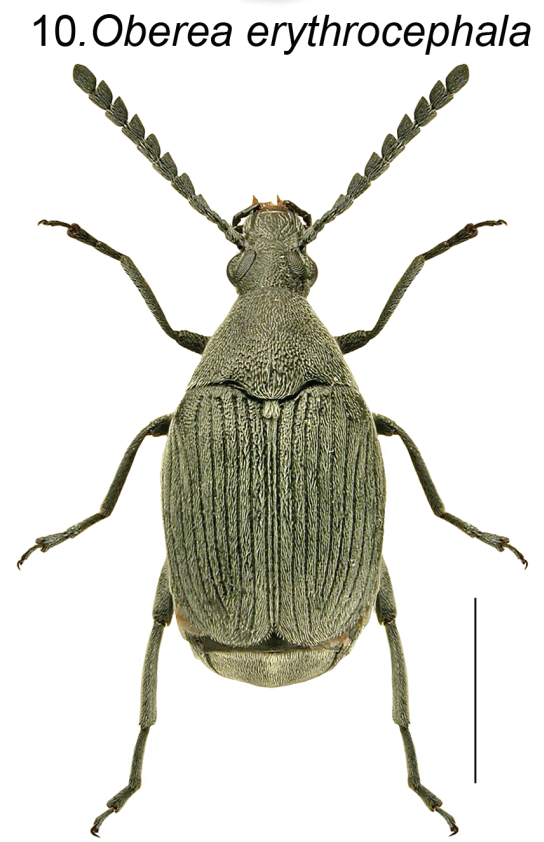

12. Bruchidius cisti

Figures 9-12. Body images in dorsal view: 9, Tetrops praeustus (Linnaeus); 10, Oberea erythrocephala (Schrank); 11, Acanthoscelides obtectus (Say); 12, Bruchidius cisti (Fabricius). Scale bar $=1 \mathrm{~mm}$. 

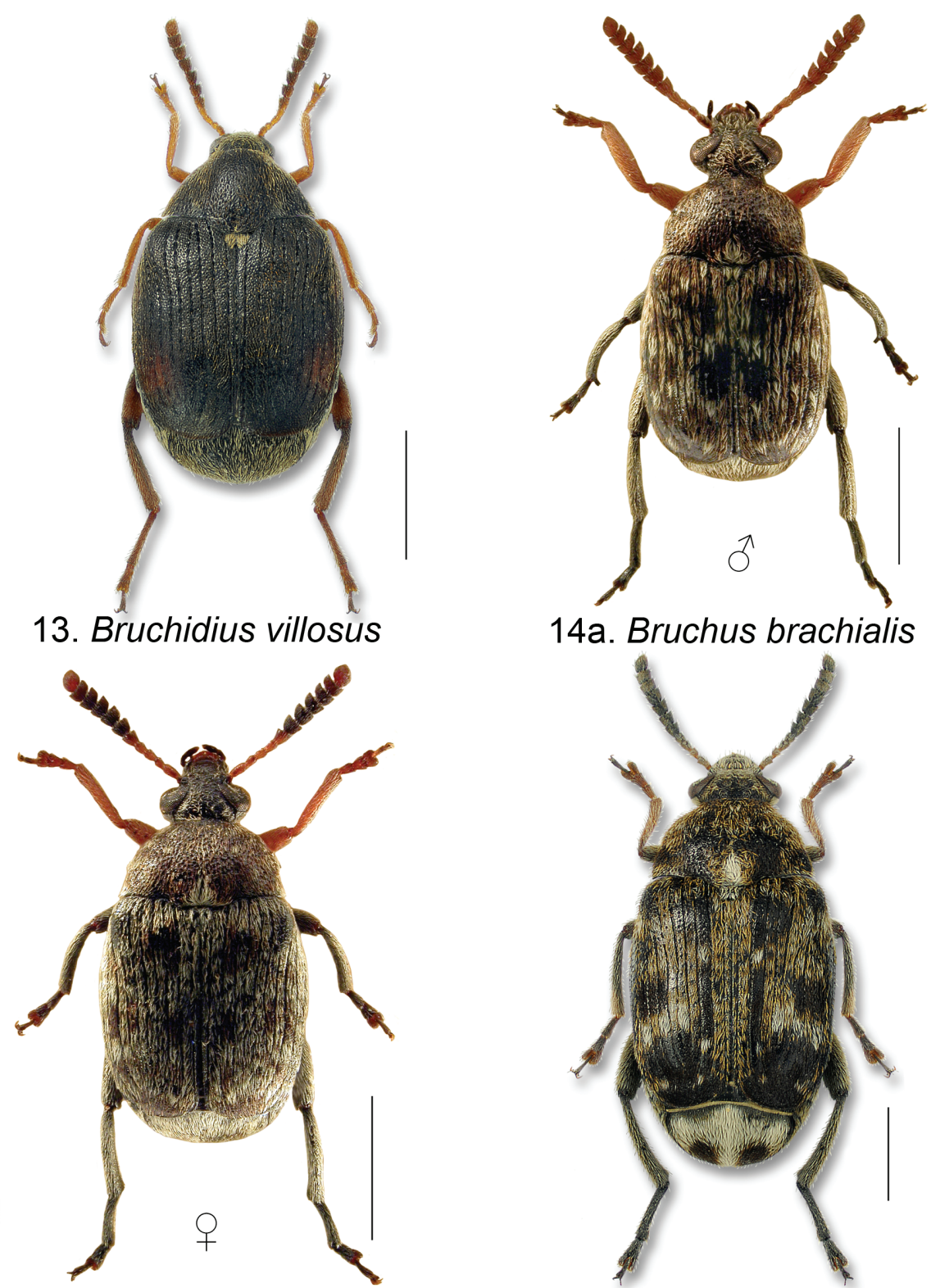

14b. Bruchus brachialis

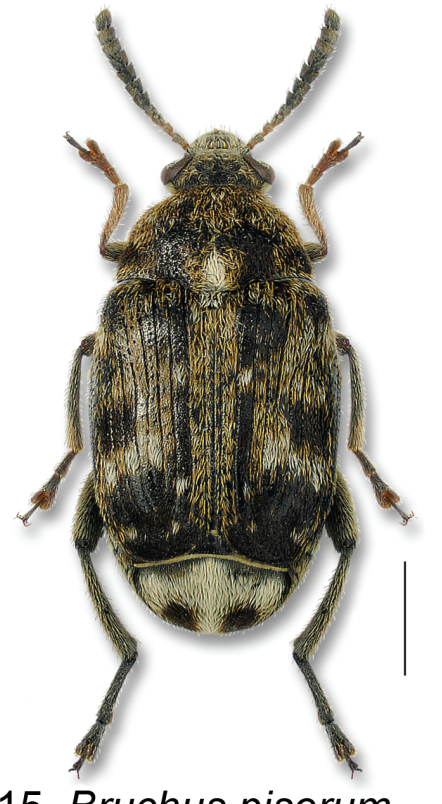

15. Bruchus pisorum

Figures 13-15. Body images in dorsal view: 13, Bruchidius villosus (Fabricius); 14, Bruchus brachialis Fåhraeus, a, male, b, female; 15, Bruchus pisorum (Linnaeus). Scale bar $=1 \mathrm{~mm}$. 


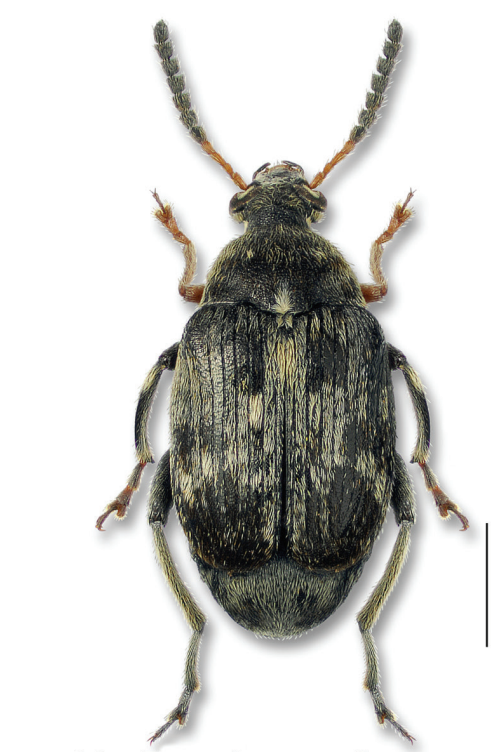

16. Bruchus rufimanus

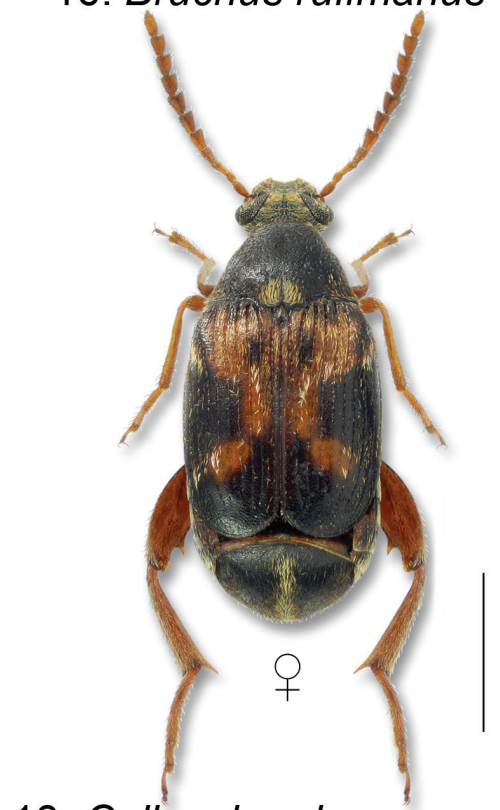

18. Callosobruchus maculatus

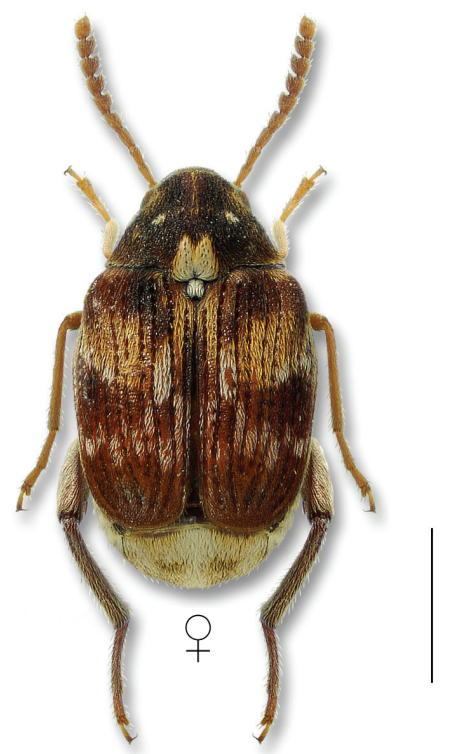

17. Callosobruchus chinensis

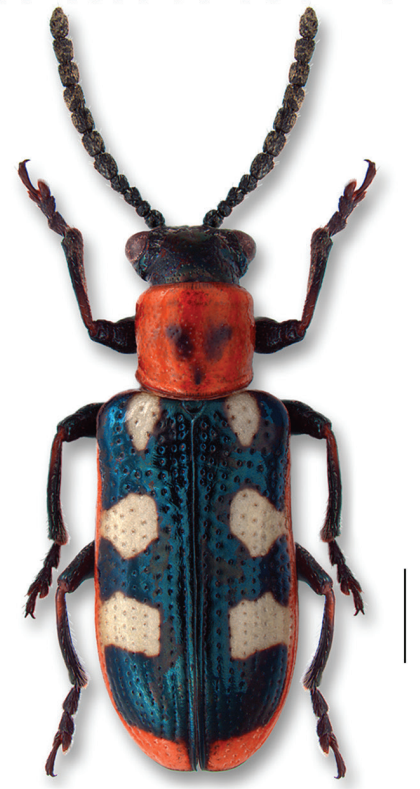

19. Crioceris asparagi

Figures 16-19. Body images in dorsal view: 16, Bruchus rufimanus (Boheman); 17, Callosobruchus chinensis (Linnaeus), female; 18, Callosobruchus maculatus (Fabricius), female; 19, Crioceris asparagi (Linnaeus). Scale bar $=1 \mathrm{~mm}$. 


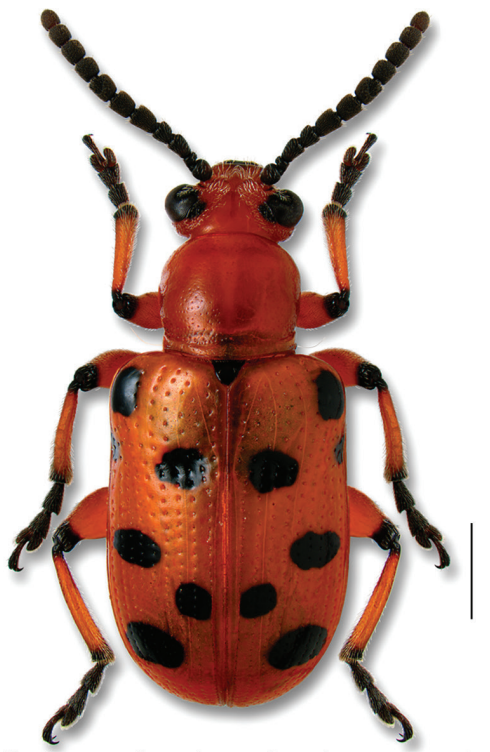

20. Crioceris duodecimpunctata

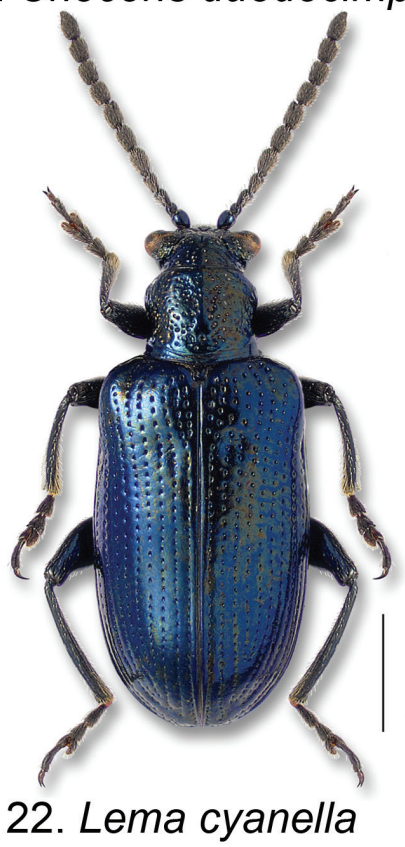

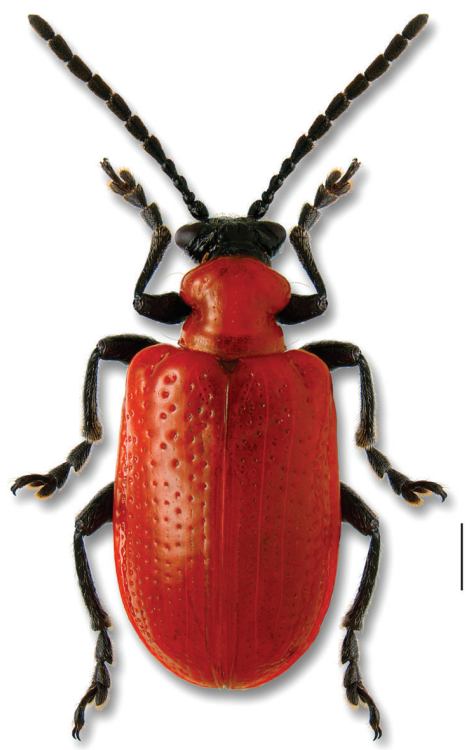

\section{Lilioceris lilii}

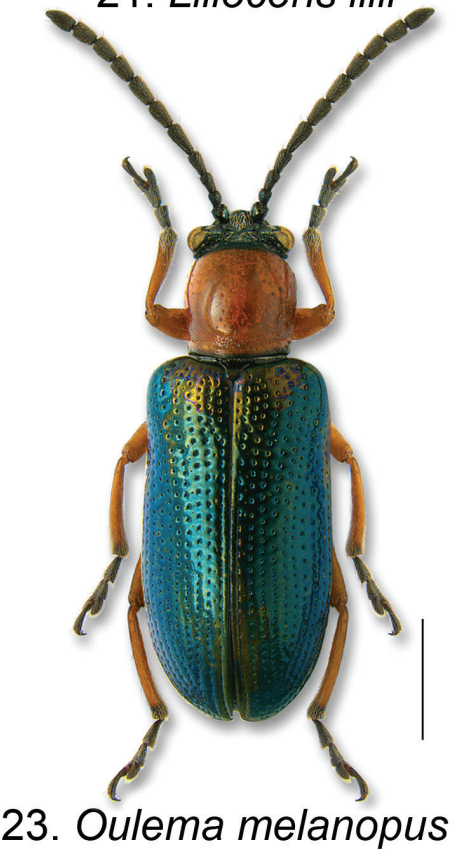

Figures 20-23. Body images in dorsal view: 20, Crioceris duodecimpunctata (Linnaeus); 21, Lilioceris lilii (Scopoli); 22, Lema cyanella (Linnaeus); 23, Oulema melanopus (Linnaeus). Scale bar $=1 \mathrm{~mm}$. 


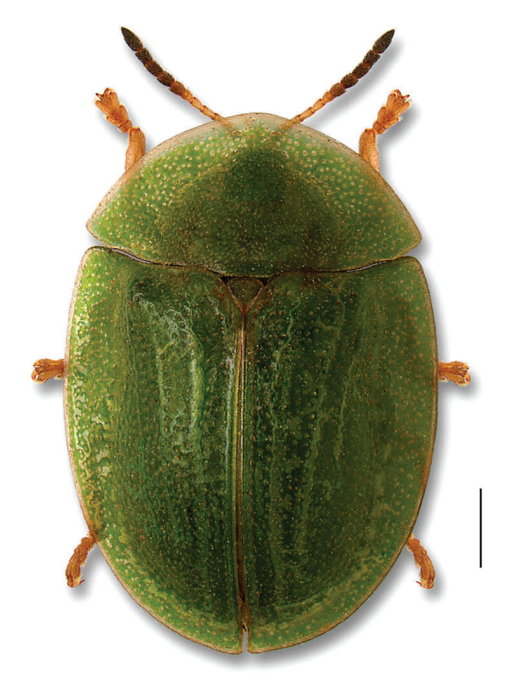

24. Cassida rubiginosa

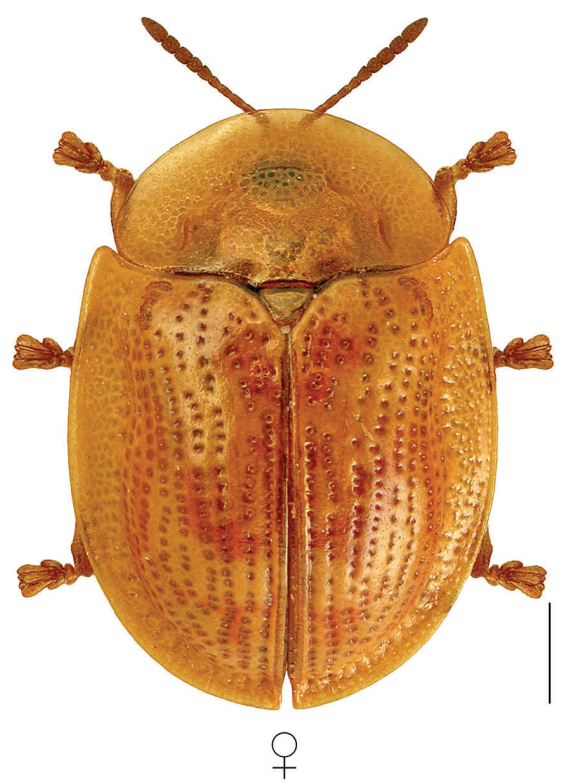

25b. Cassida azurea
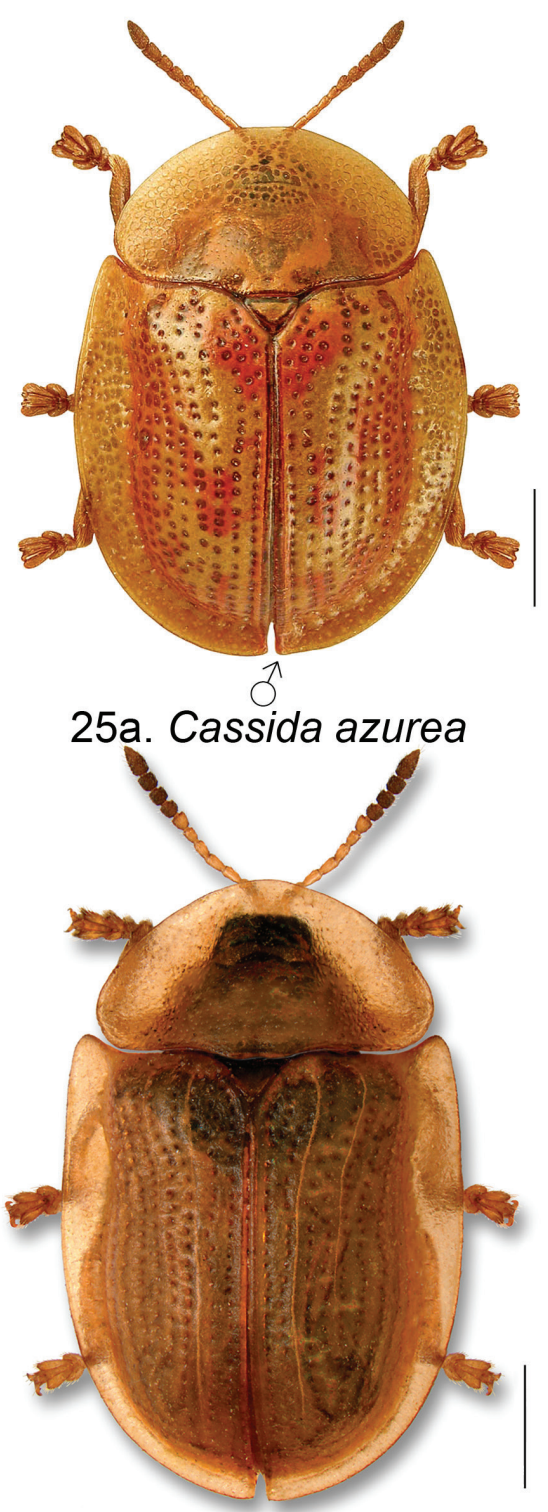

26. Cassida flaveola

Figures 24-26. Body images in dorsal view: 24, Cassida rubiginosa O.F. Müller; 25, Cassida azurea Fabricius, a, male, b, female; 26, Cassida flaveola Thunberg. Scale bar $=1 \mathrm{~mm}$. 

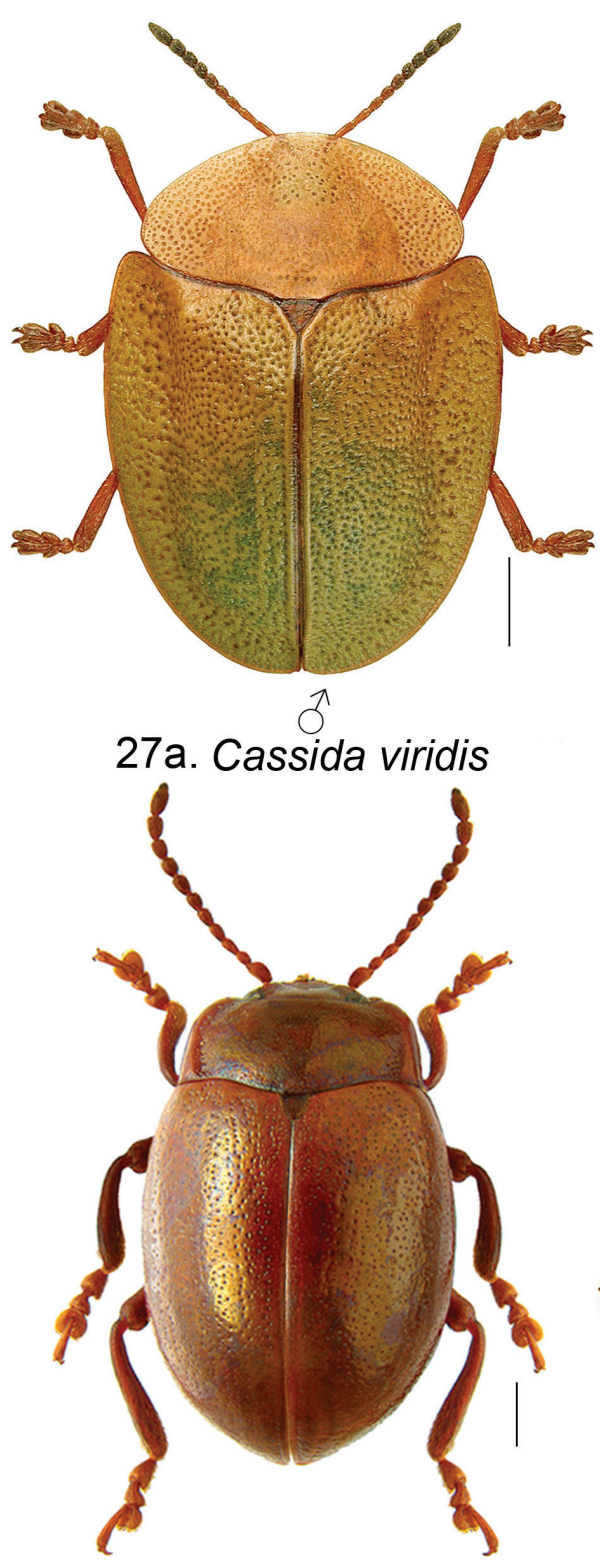

28. Chrysolina staphylaea

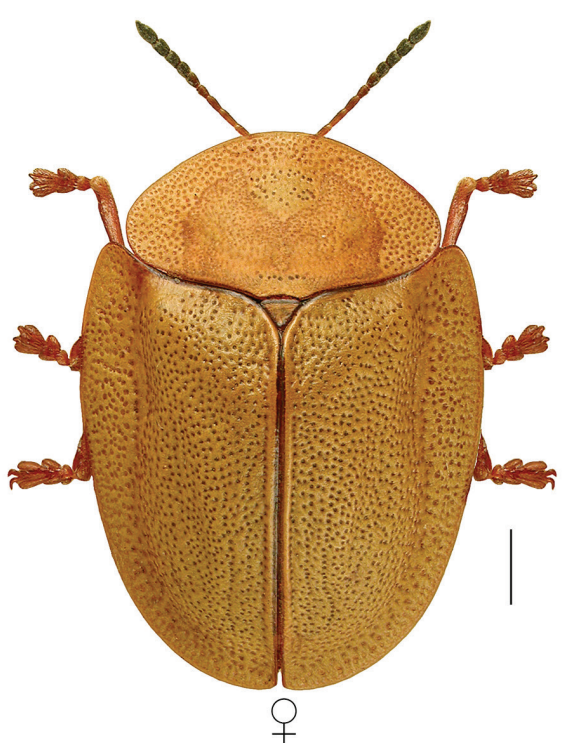

27b. Cassida viridis

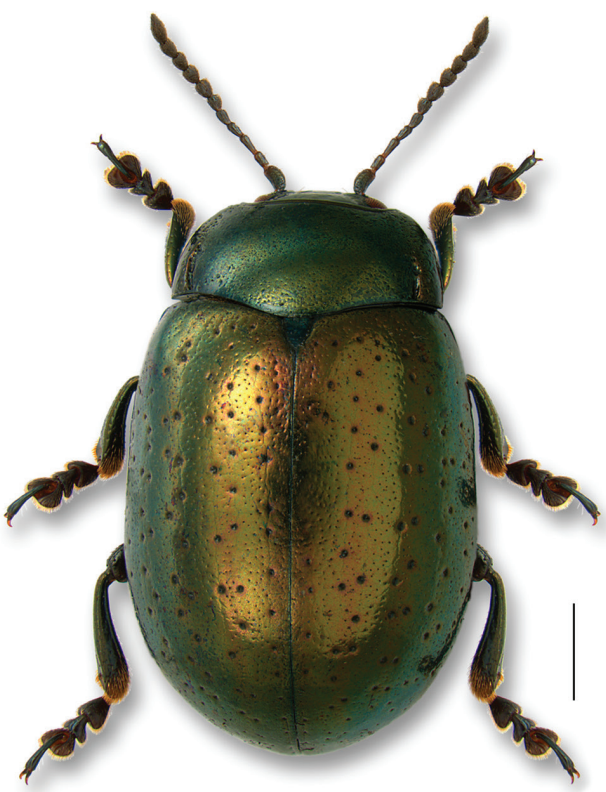

29. Chrysolina hyperici

Figures 27-29. Body images in dorsal view: 27, Cassida viridis Linnaeus, a, male, b, female; 28, Chrysolina staphylaea staphylaea (Linnaeus); 29, Chrysolina hyperici hyperici (Forster). Scale bar $=1 \mathrm{~mm}$. 


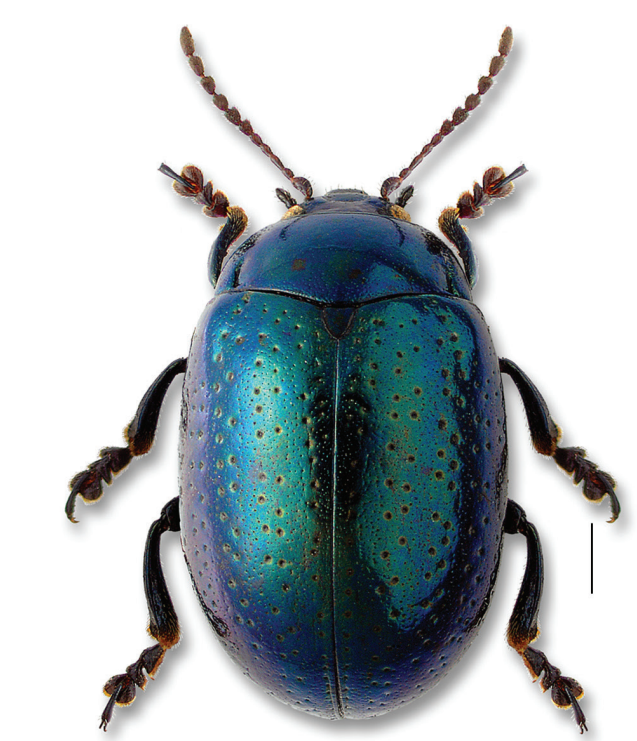

30. Chrysolina quadrigemina

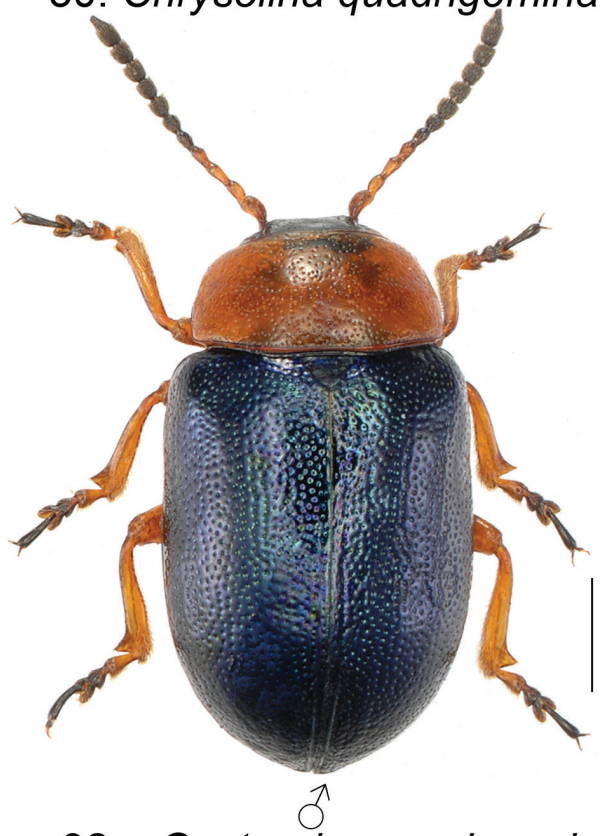

32a. Gastrophysa polygoni

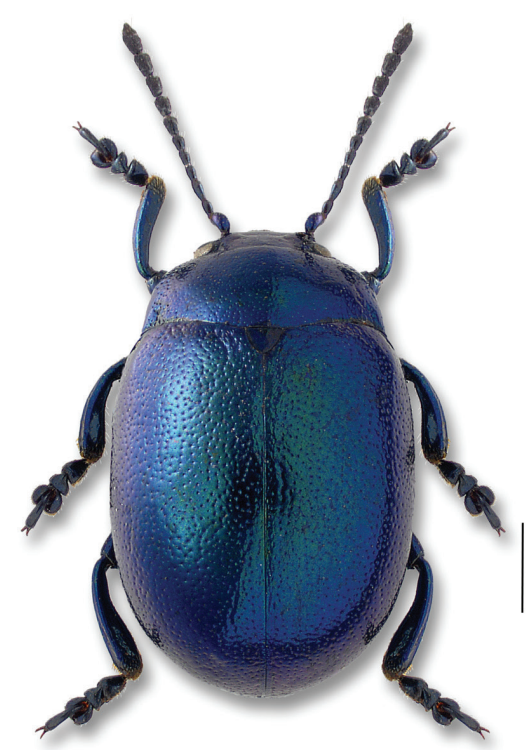

31. Chrysolina varians

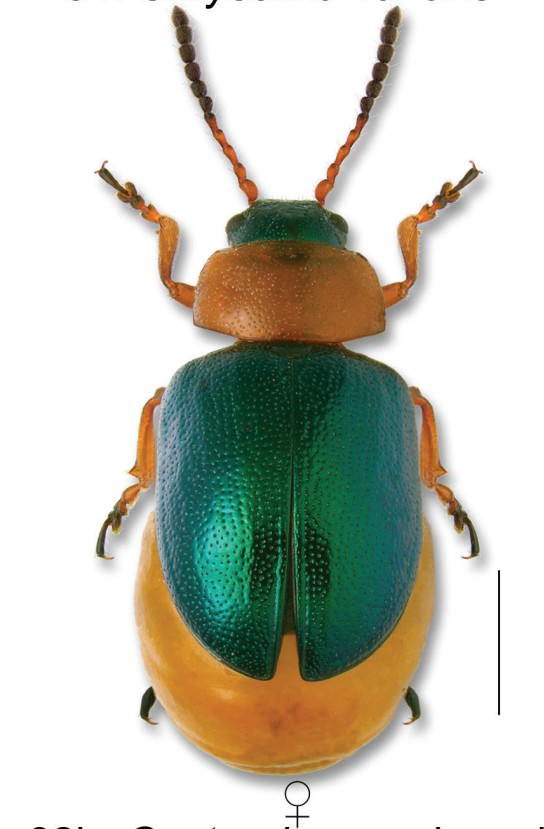

32b. Gastrophysa polygoni

Figures 30-32. Body images in dorsal view: 30, Chrysolina quadrigemina (Suffrian); 31, Chrysolina varians (Schaller); 32, Gastrophysa polygoni (Linnaeus), a, male, b, female; Scale bar $=1 \mathrm{~mm}$. 


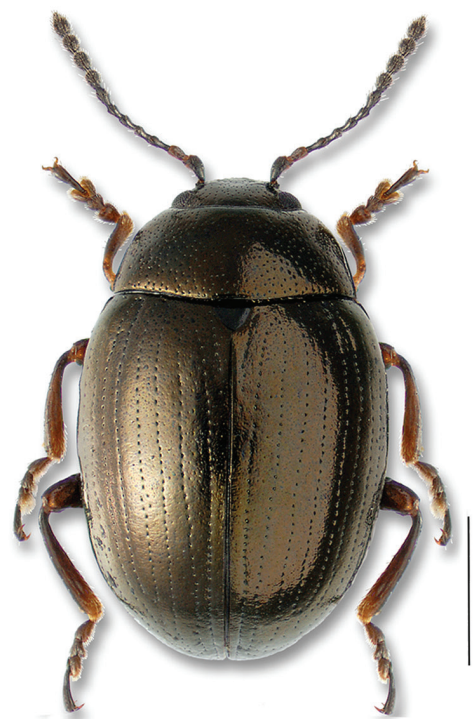

33. Phaedon laevigatus

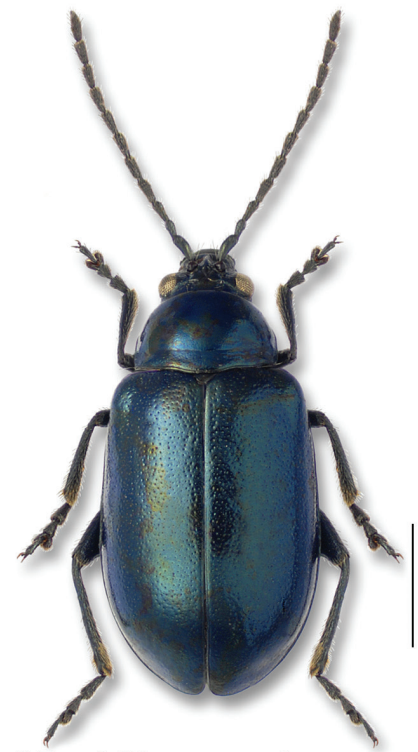

35. Altica carduorum

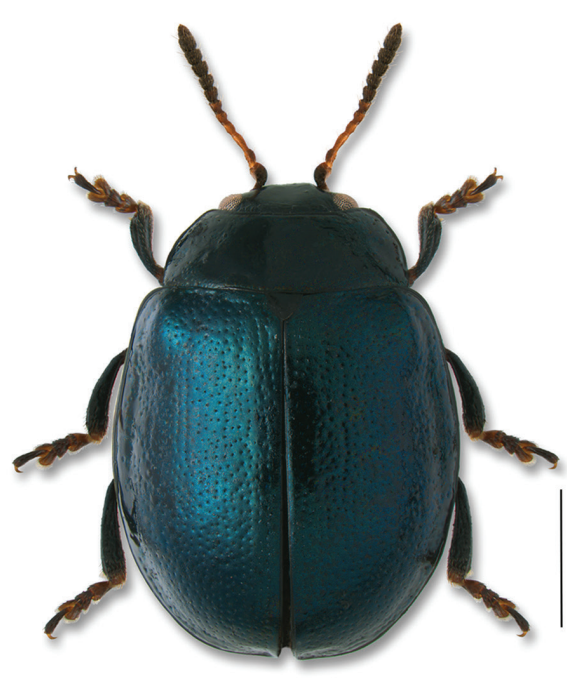

34. Plagiodera versicolora

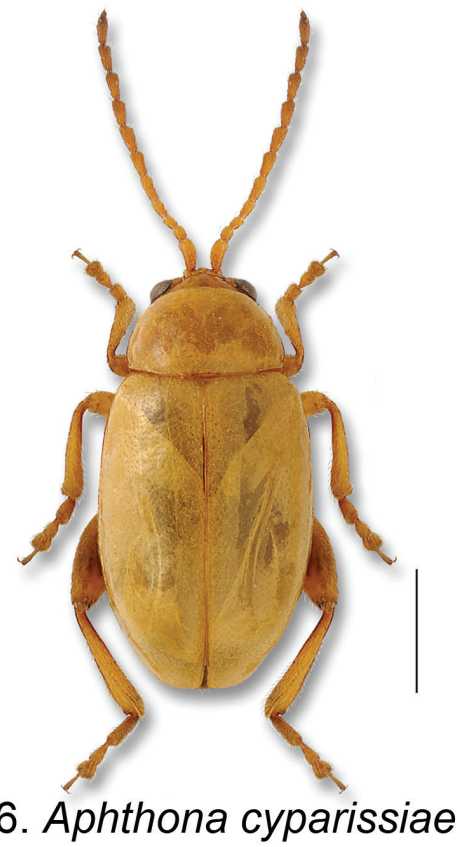

Figures 33-36. Body images in dorsal view: 33, Phaedon laevigatus (Duftschmid), 34, Plagiodera versicolora (Laicharting); 35, Altica carduorum (Guérin-Méneville); 36, Aphthona cyparissiae (Koch). Scale bar $=1 \mathrm{~mm}$. 


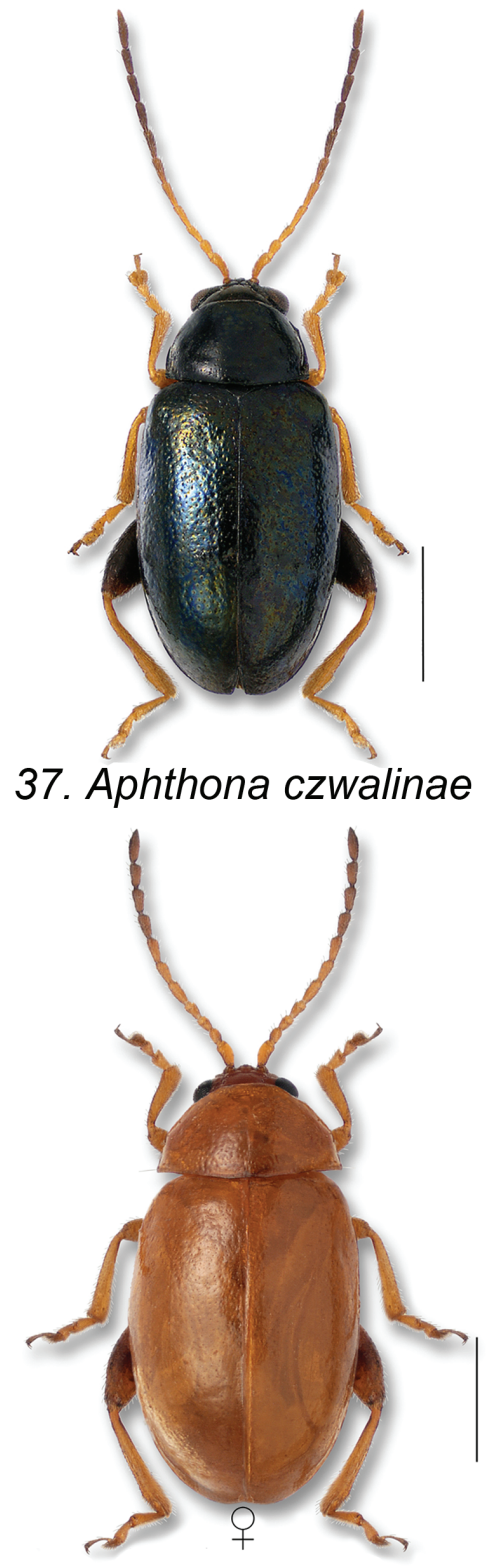

38b. Aphthona flava

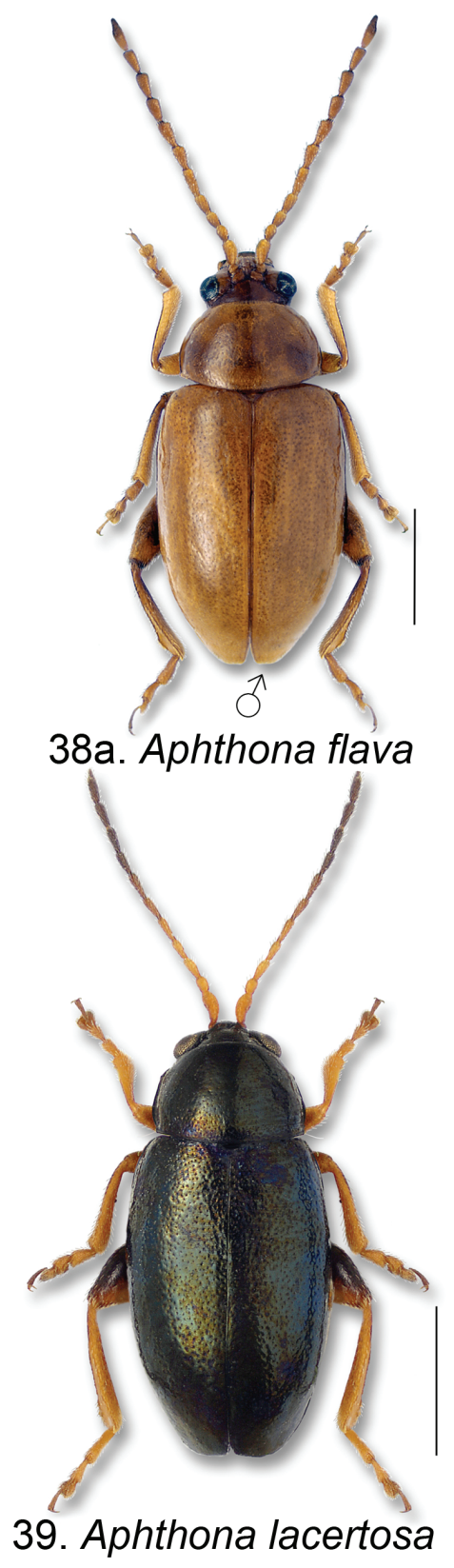

39. Aphthona lacertosa

Figures 37-39. Body images in dorsal view: 37, Aphthona czwalinae (Weise); 38, Aphthona flava Guillebeau a, male and b, female; 39, Aphthona lacertosa Rosenhauer. Scale bar $=1 \mathrm{~mm}$. 


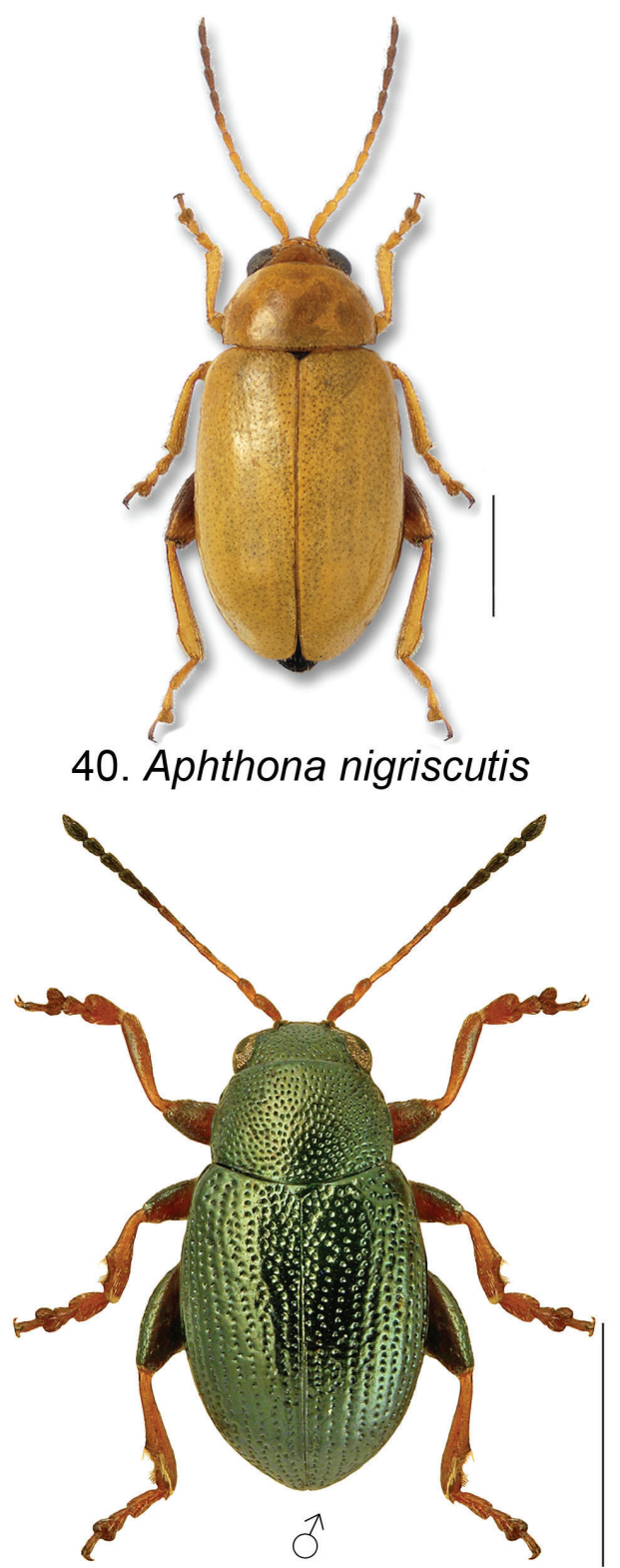

42a. Chaetocnema hortensis
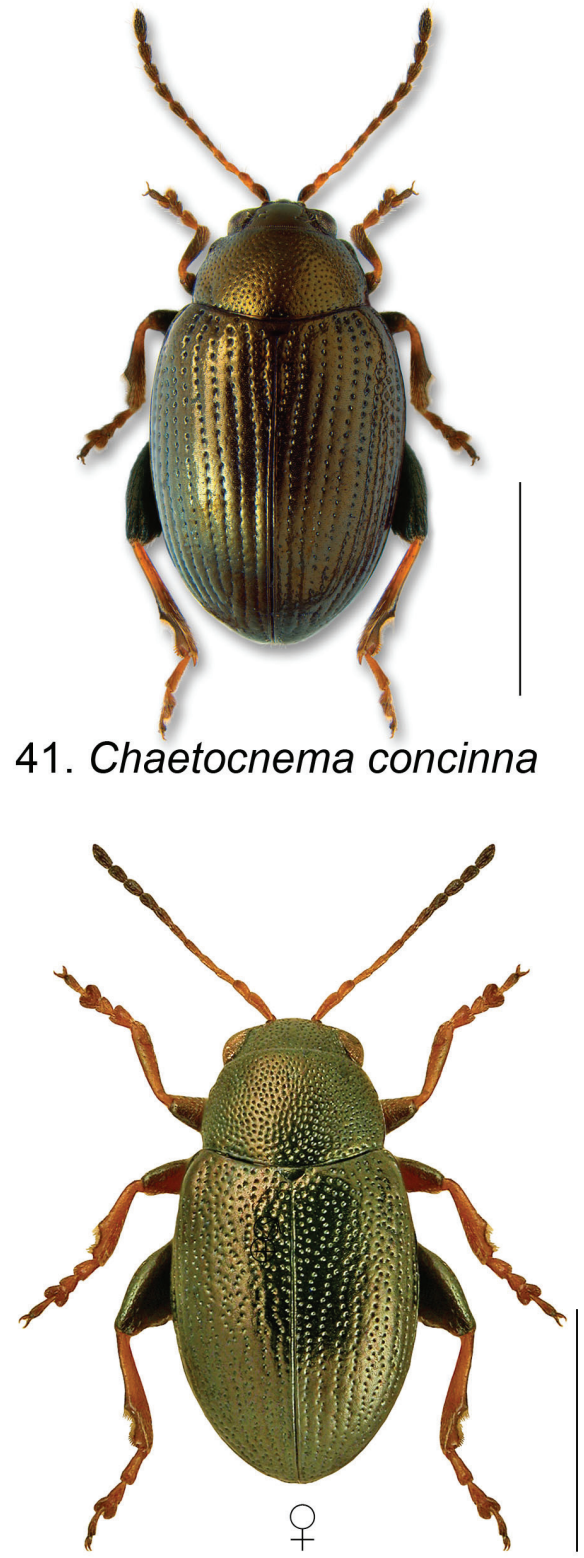

42b. Chaetocnema hortensis

Figures 40-42. Body images in dorsal view: 40, Aphthona nigriscutis Foudras; 41, Chaetocnema concinna (Marsham); 42, Chaetocnema hortensis (Geoffroy), a, male, b, female. Scale bar $=1 \mathrm{~mm}$. 


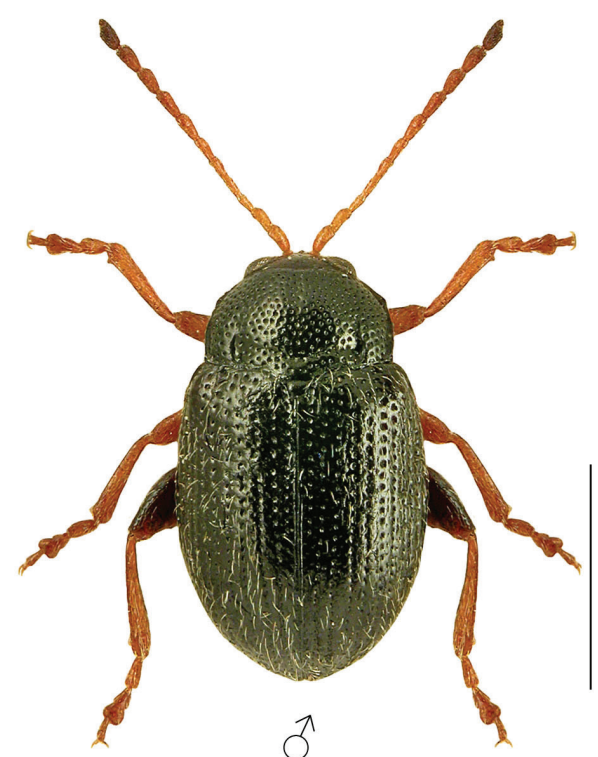

43a. Epitrix pubescens

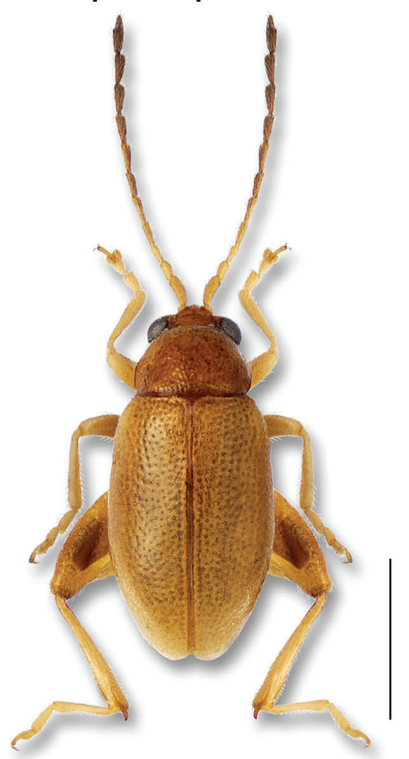

44. Longitarsus ferrugineus

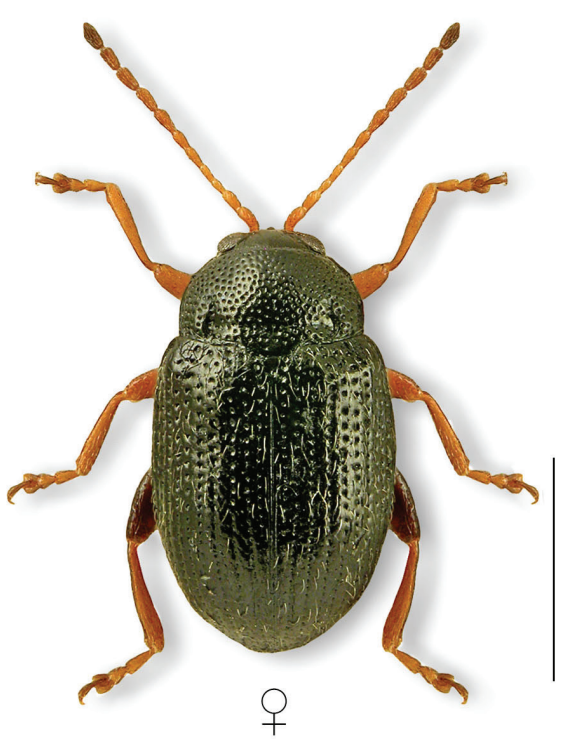

43b. Epitrix pubescens

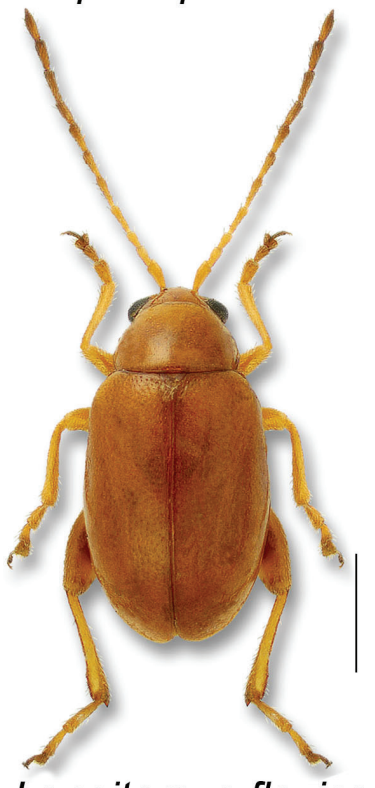

45. Longitarsus flavicornis

Figures 43-45. Body images in dorsal view: 43, Epitrix pubescens (Koch), a, male, b, female; 44, Longitarsus ferrugineus (Foudras); 45, Longitarsus flavicornis (Stephens). Scale bar $=1 \mathrm{~mm}$. 


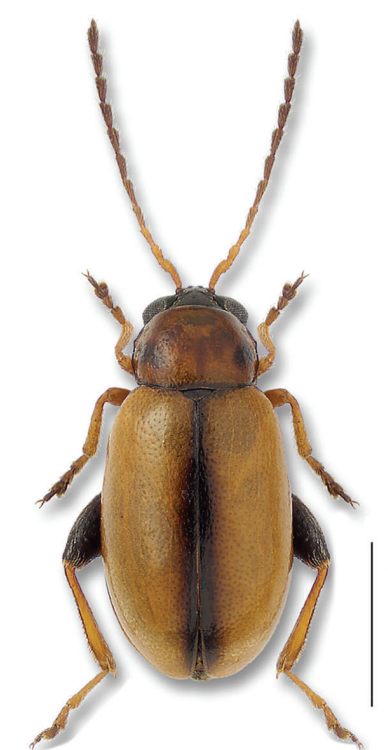

46. Longitarsus ganglbaueri

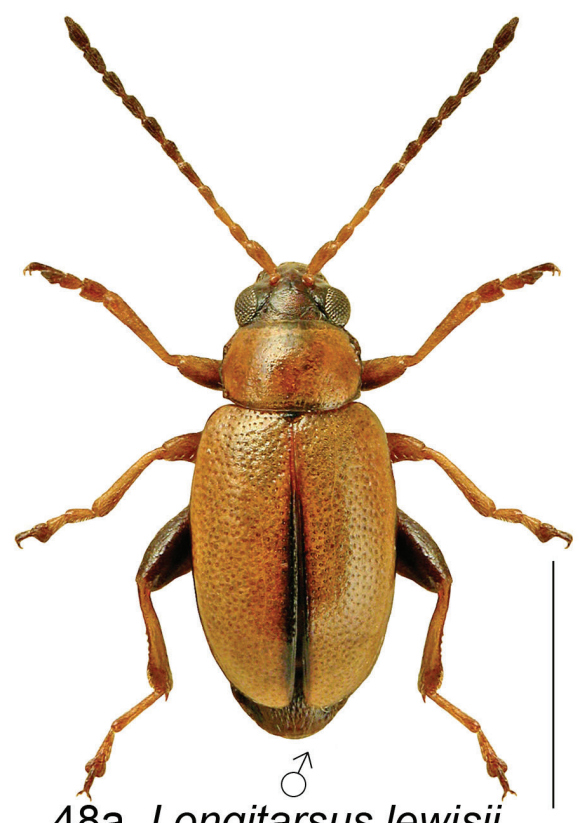

48a. Longitarsus lewisii

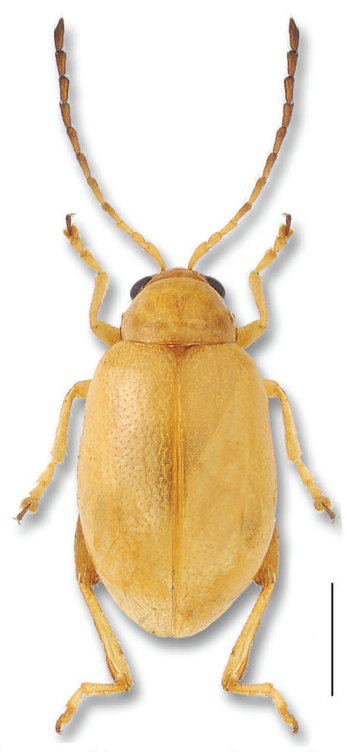

47. Longitarsus jacobaeae

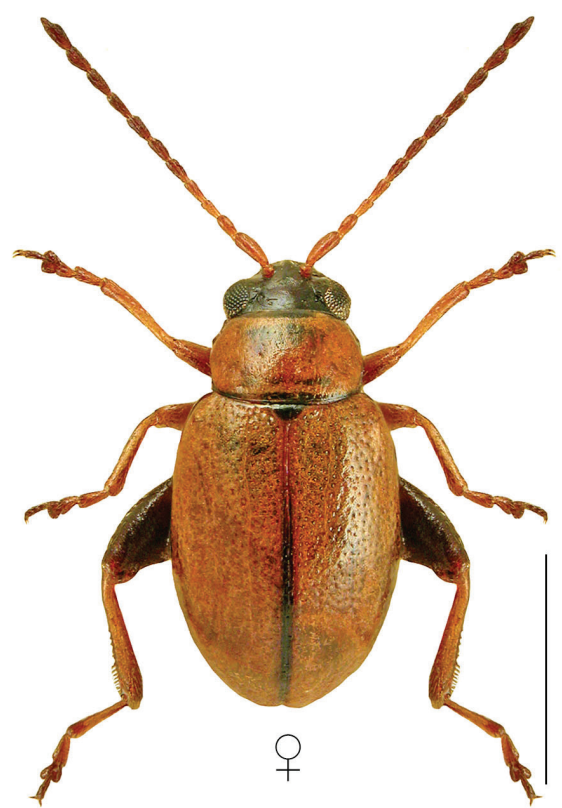

48b. Longitarsus lewisii

Figures 46-48. Body images in dorsal view: 46, Longitarsus ganglbaueri Heikertinger; 47, Longitarsus jacobaeae (Waterhouse); 48, Longitarsus lewisii Baly, a, male, b, female. Scale bar $=1 \mathrm{~mm}$. 


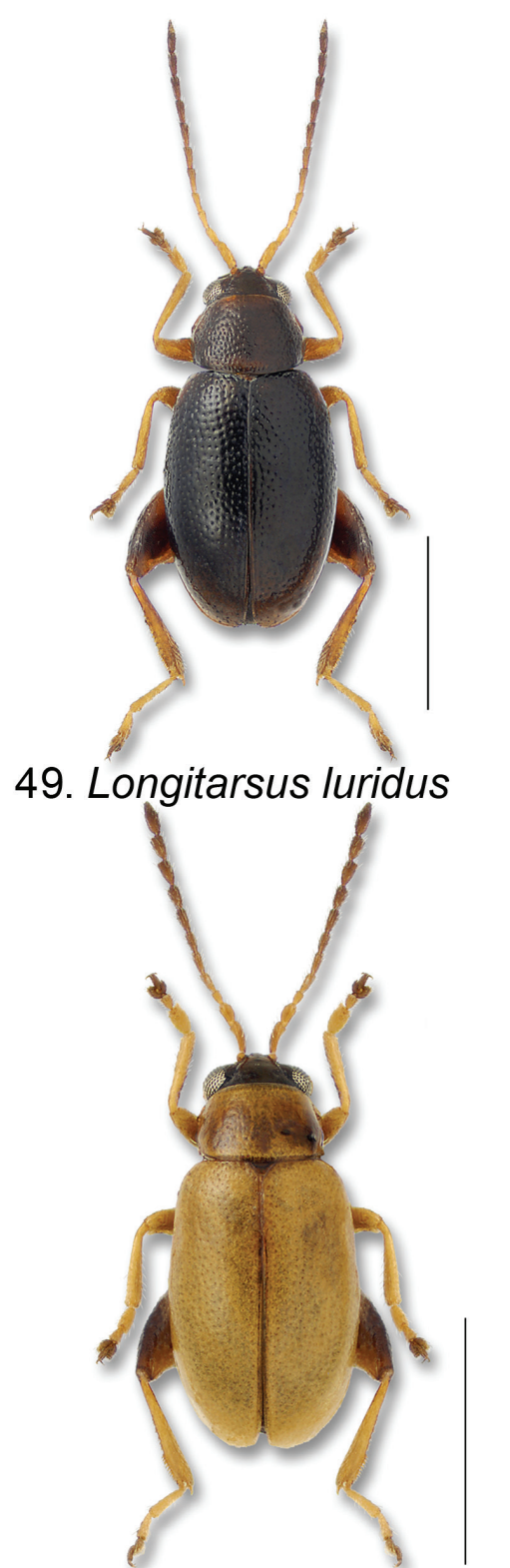

51. Longitarsus pratensis

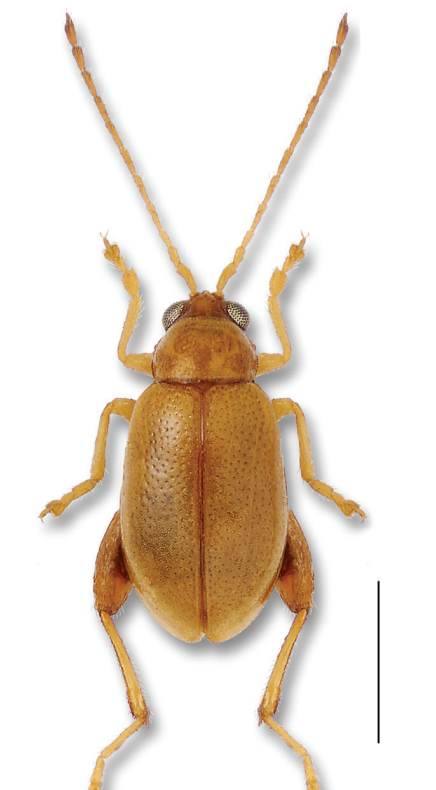

50. Longitarsus pellucidus

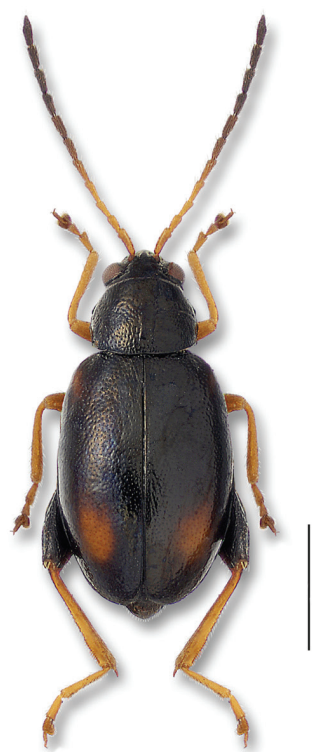

52. Longitarsus quadriguttatus

Figures 49-52. Body images in dorsal view: 49, Longitarsus luridus (Scopoli); 50, Longitarsus pellucidus (Foudras); 51, Longitarsus pratensis (Panzer); 52, Longitarsus quadriguttatus (Pontoppidan). Scale bar = $1 \mathrm{~mm}$. 


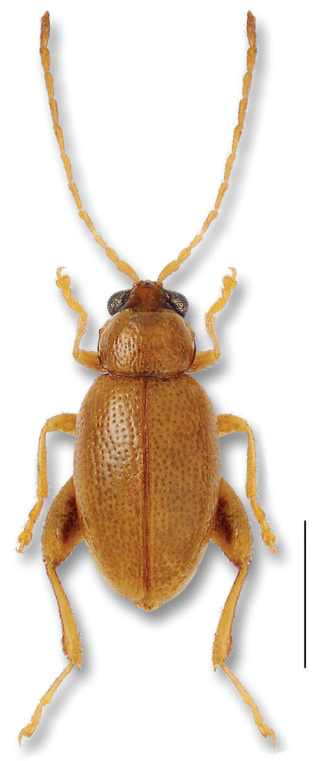

53. Longitarsus rubiginosus

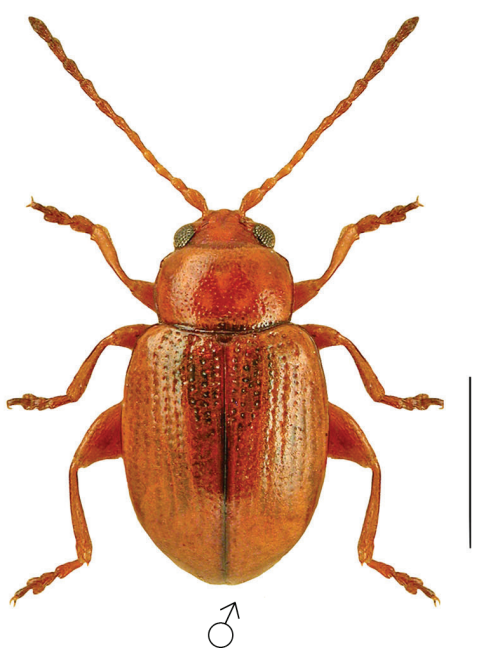

55a. Lythraria salicariae

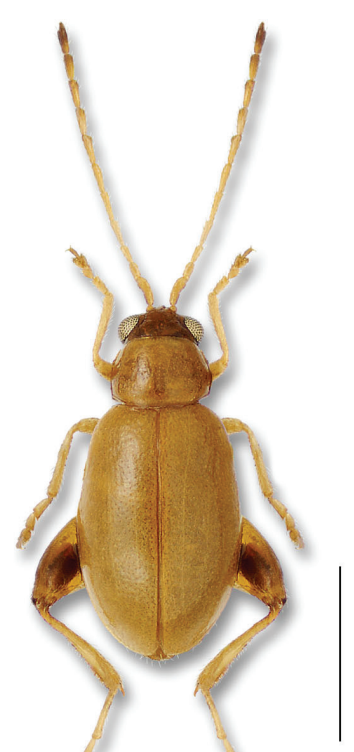

54. Longitarsus succineus

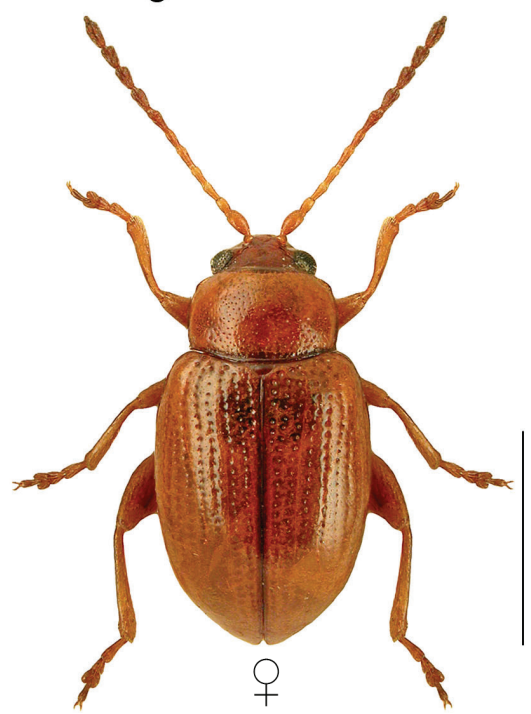

55b. Lythraria salicariae

Figures 53-55. Body images in dorsal view: 53, Longitarsus rubiginosus (Foudras); 54, Longitarsus succineus (Foudras); 55, Lythraria salicariae (Paykull), a, male, b, female. Scale bar $=1 \mathrm{~mm}$. 


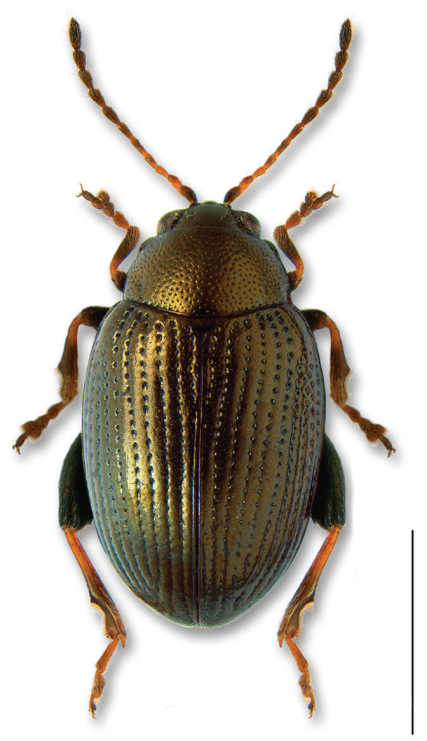

56. Mantura chrysanthemi

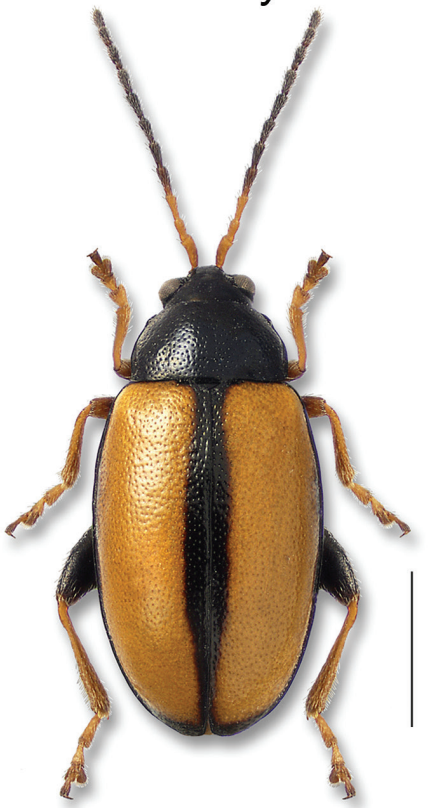

58. Phyllotreta armoraciae

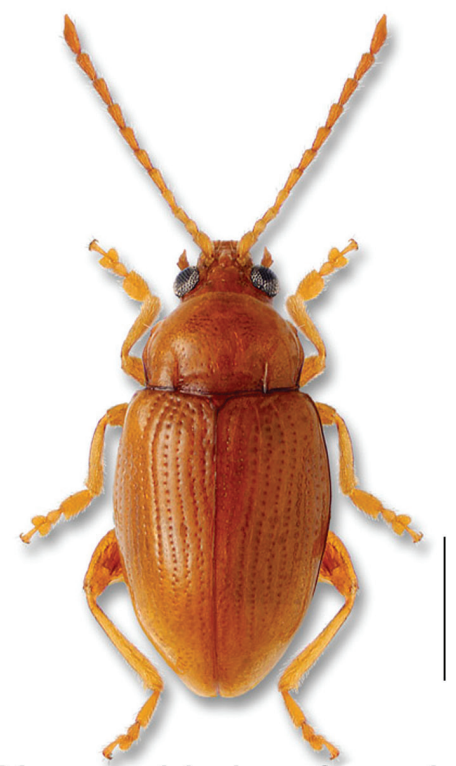

57. Neocrepidodera ferruginea

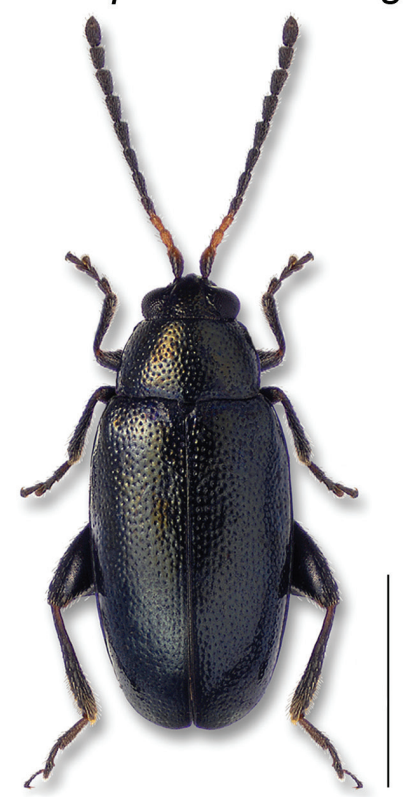

59. Phyllotreta cruciferae

Figures 57-59. Body images in dorsal view: 56, Mantura chrysanthemi (Koch); 57, Neocrepidodera ferruginea (Scopoli); 58, Phyllotreta armoraciae (Koch); 59, Phyllotreta cruciferae (Goeze). Scale bar $=1 \mathrm{~mm}$. 

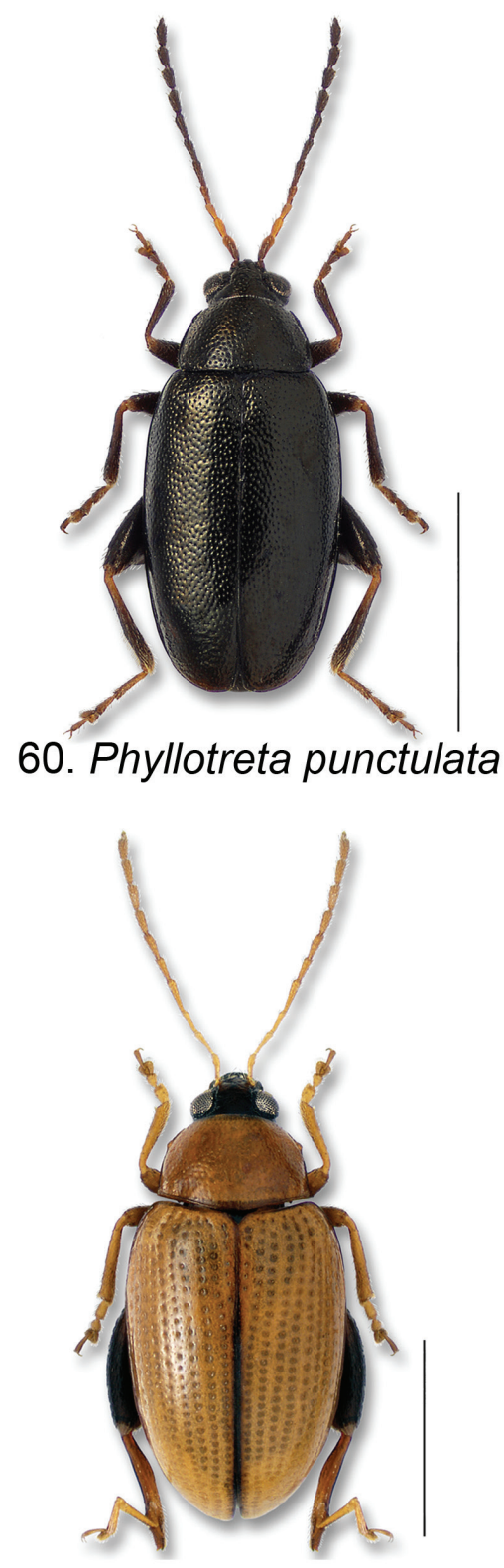

62. Psylliodes affinis

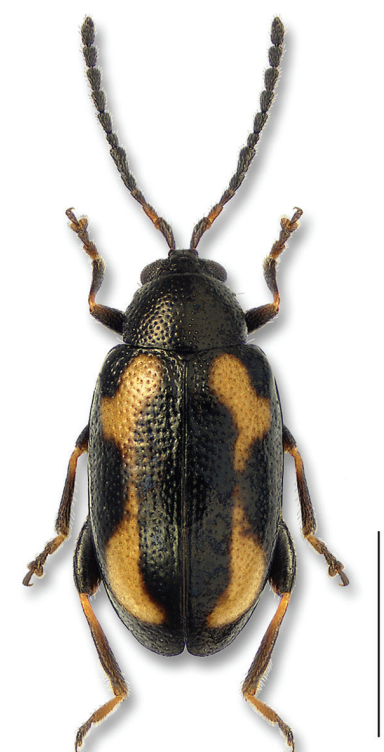

61. Phyllotreta striolata

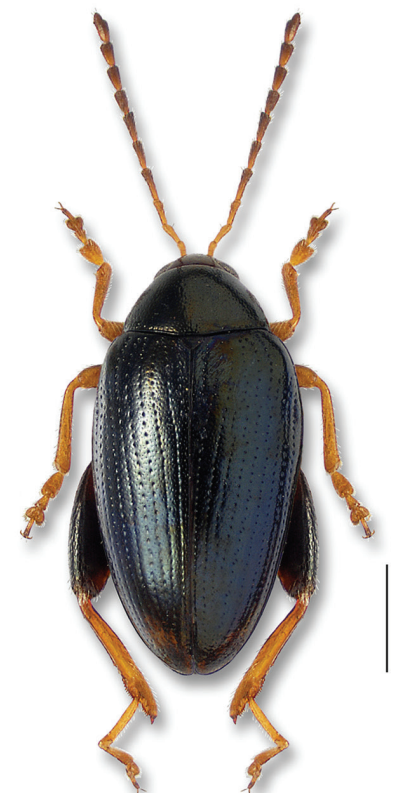

63. Psylliodes chrysocephalus

Figures 60-63. Body images in dorsal view: 60, Phyllotreta punctulata (Marsham); 61, Phyllotreta striolata (Fabricius); 62, Psylliodes affinis (Paykull); 63, Psylliodes chrysocephalus (Linnaeus). Scale bar $=1 \mathrm{~mm}$. 


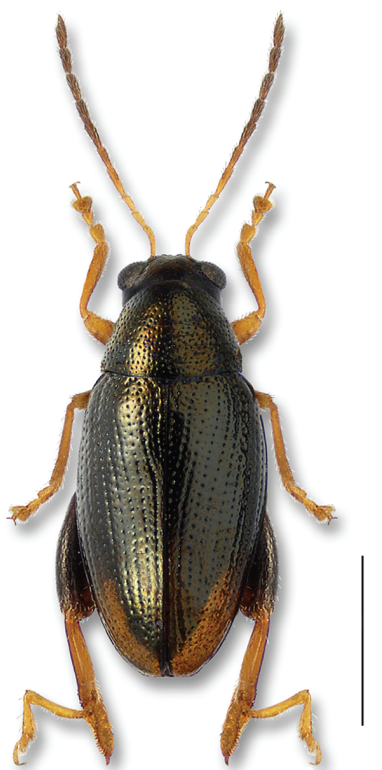

64. Psylliodes cucullatus

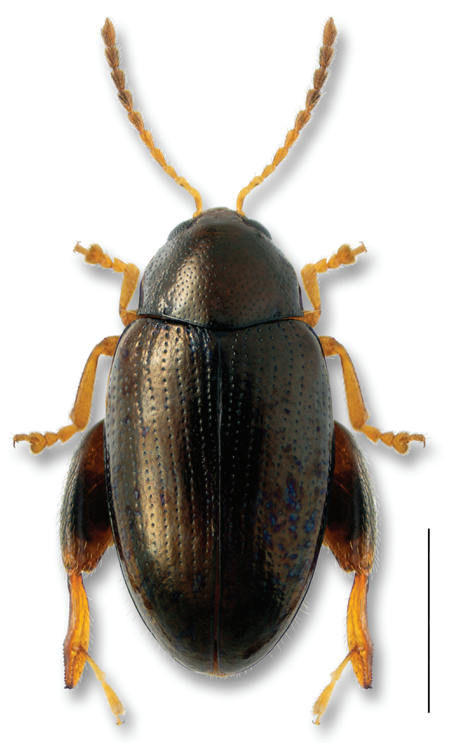

66. Psylliodes picinus

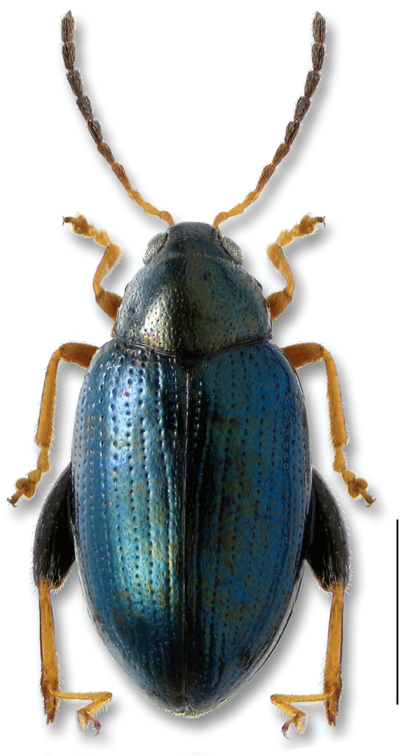

65. Psylliodes napi

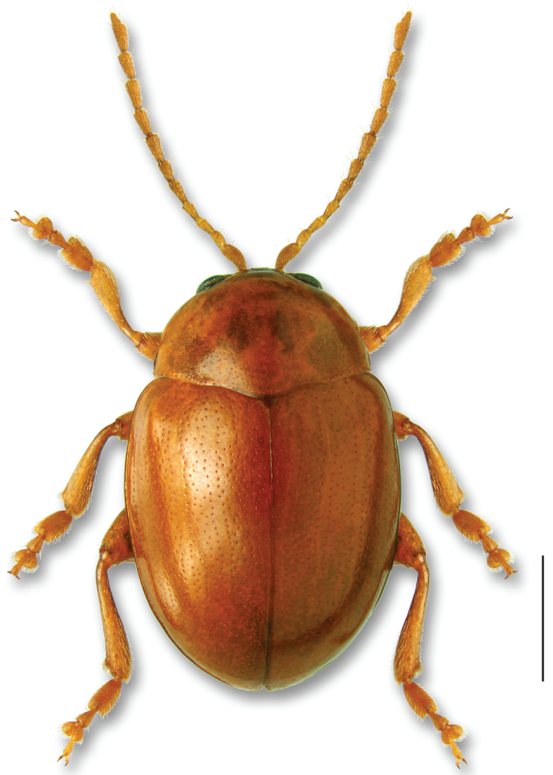

67. Sphaeroderma testaceum

Figures 64-67. Body images in dorsal view: 64, Psylliodes cucullatus (Illiger); 65, Psylliodes napi (Fabricius); 66, Psylliodes picinus (Marsham); 67, Sphaeroderma testaceum (Fabricius). Scale bar $=1 \mathrm{~mm}$. 


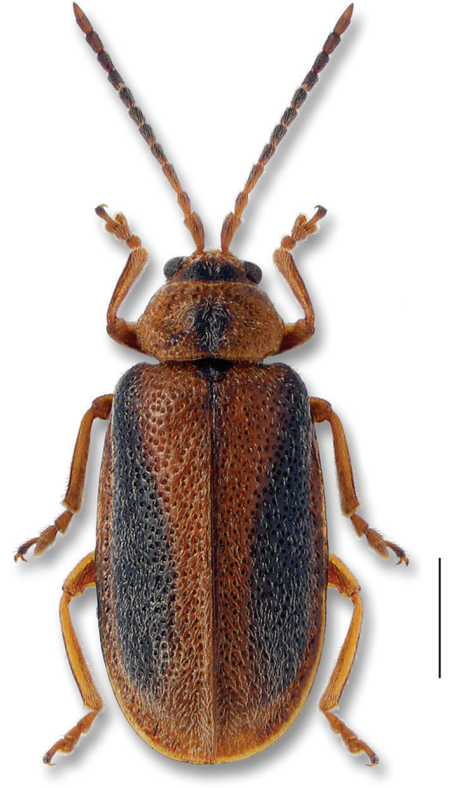

68. Neogalerucella calmariensis

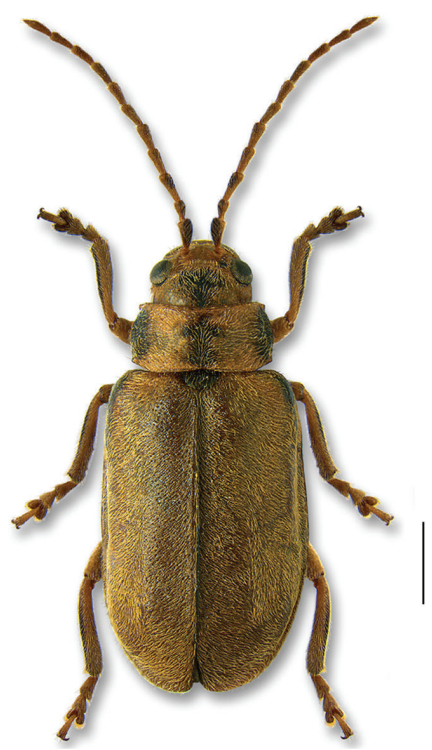

70. Pyrrhalta viburni

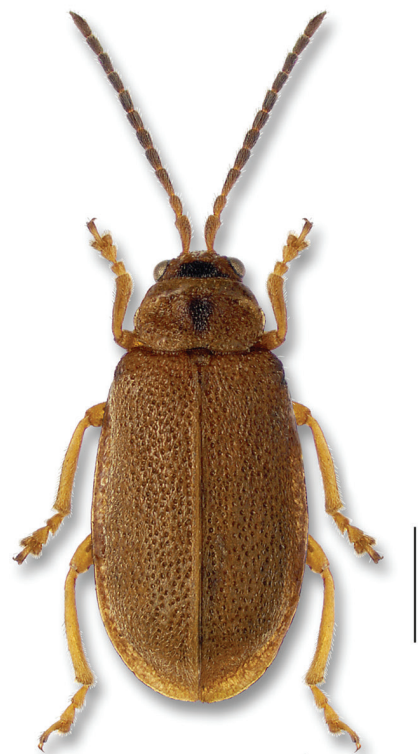

69. Neogalerucella pusilla

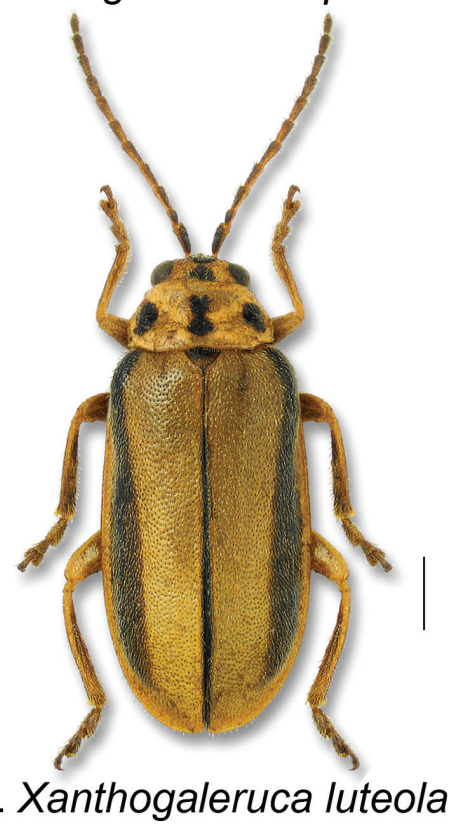

Figures 68-71. Body images in dorsal view: 68, Neogalerucella calmariensis (Linnaeus); 69, Neogalerucella pusilla (Duftschmid); 70, Pyrrhalta viburni (Paykull); 71, Xanthogaleruca luteola (O.F. Müller). Scale bar $=1 \mathrm{~mm}$. 
I48 Synopsis of adventive species of Coleoptera (Insecta) recorded from Canada.

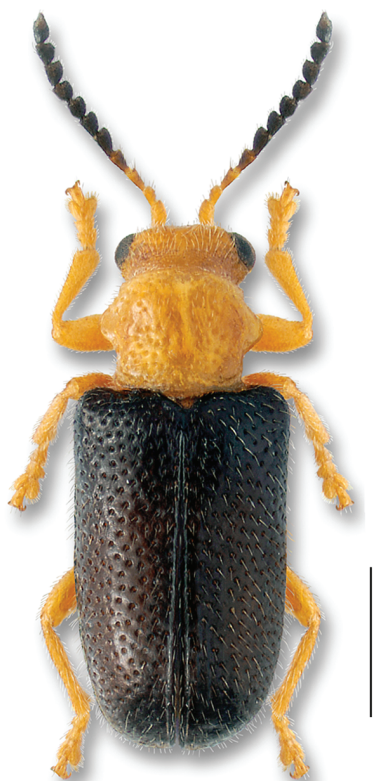

72. Zeugophora scutellaris

Figures 72. Body image in dorsal view: 72, Zeugophora scutellaris (Suffrian). Scale bar $=1 \mathrm{~mm}$. 
Maps 


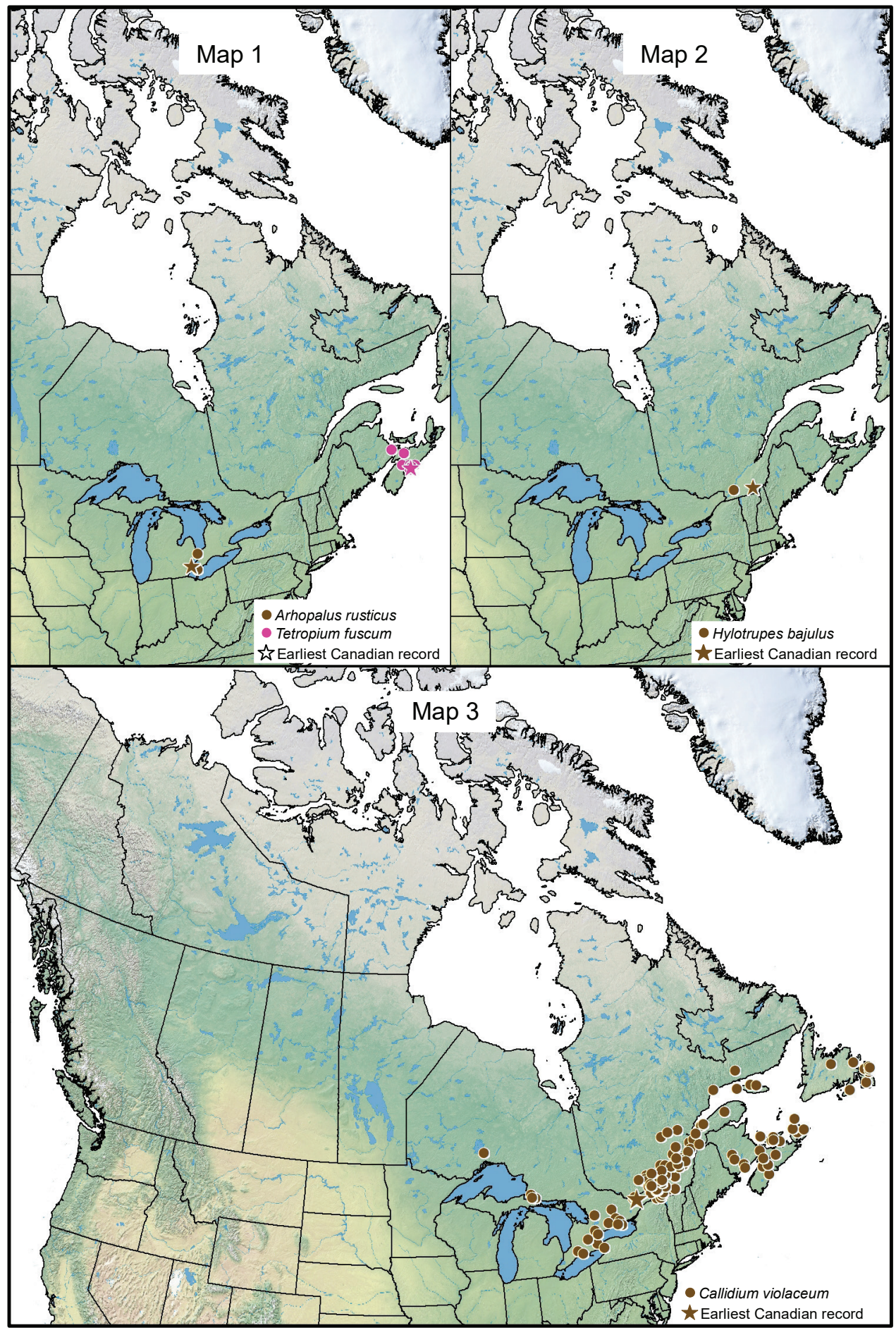




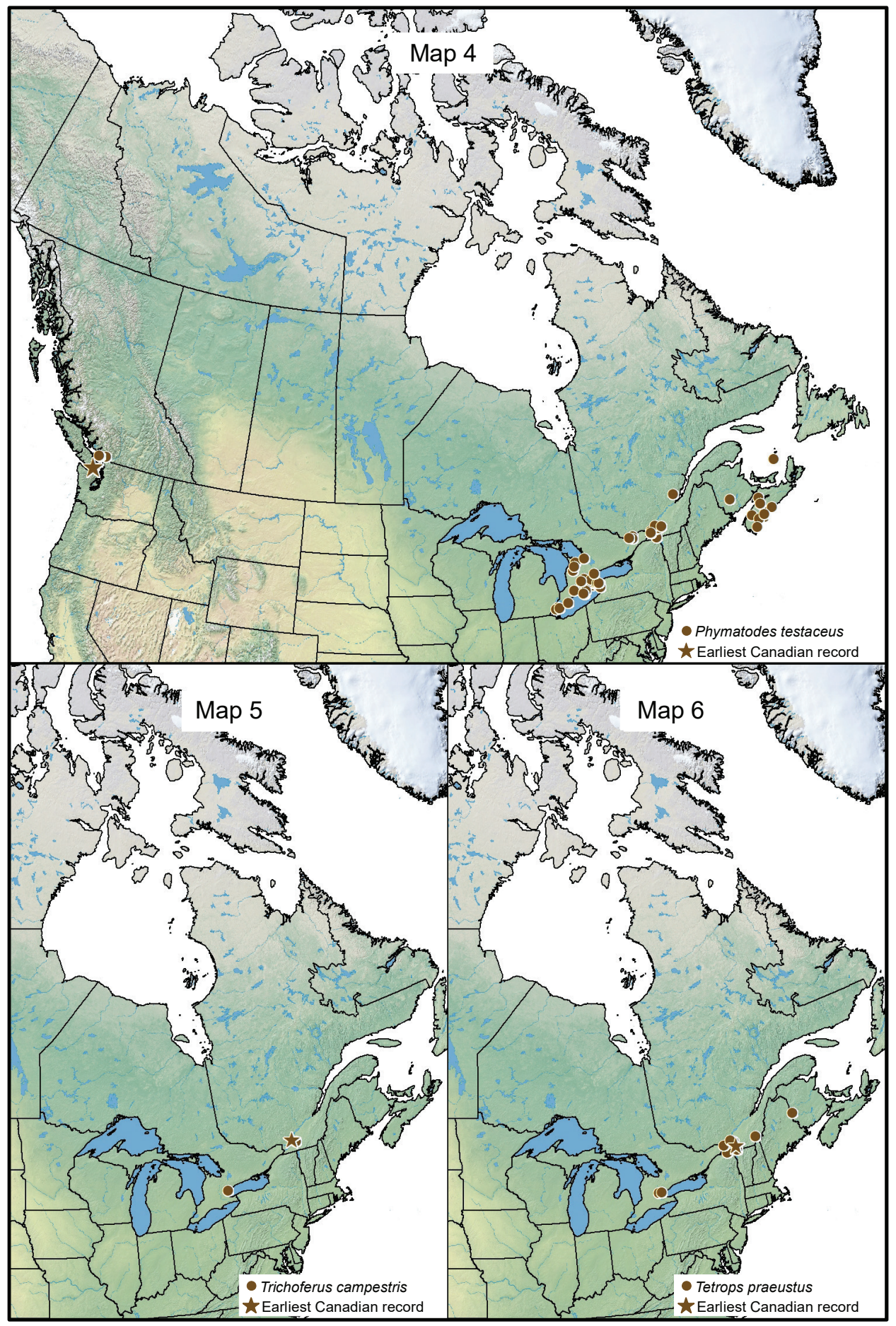




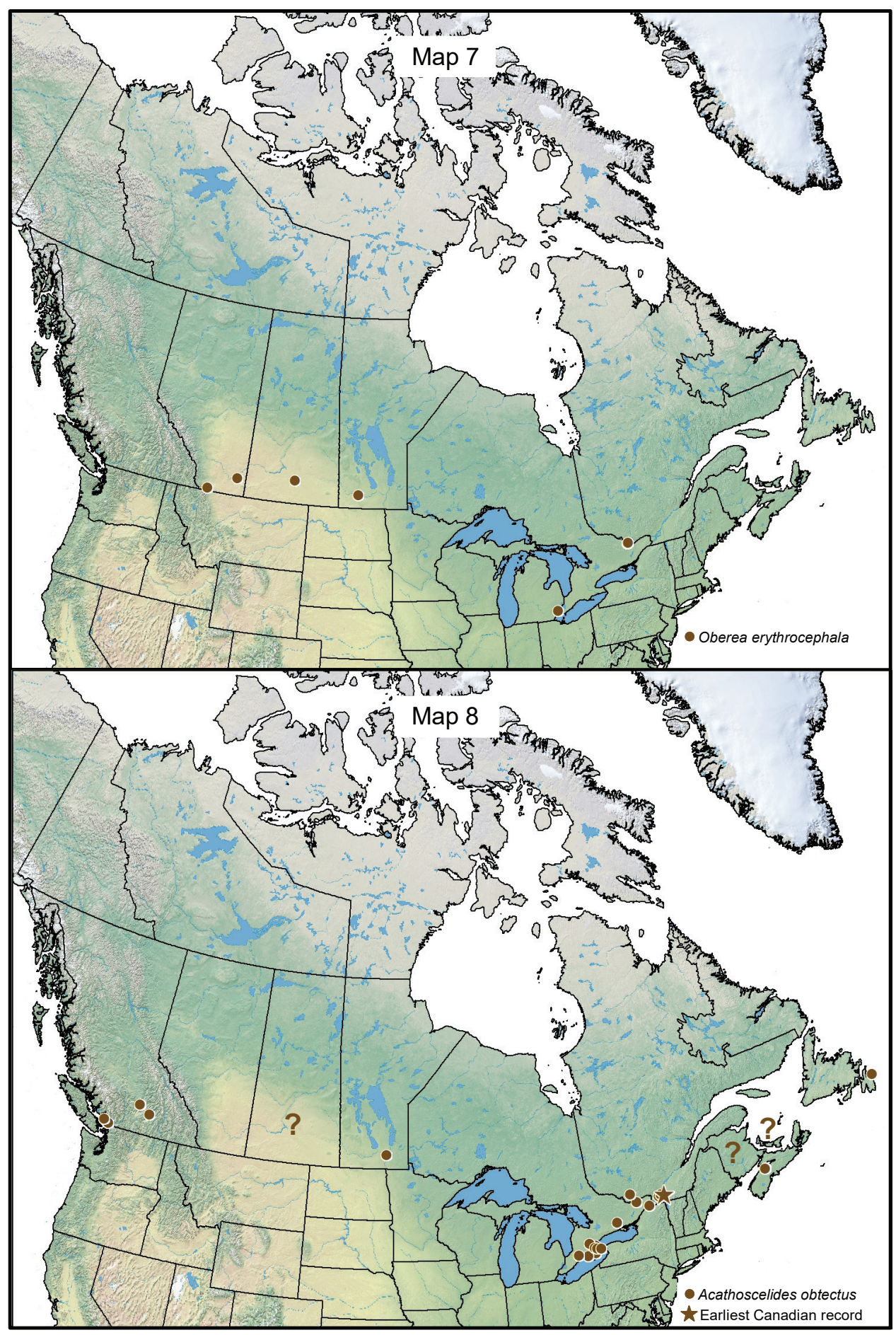




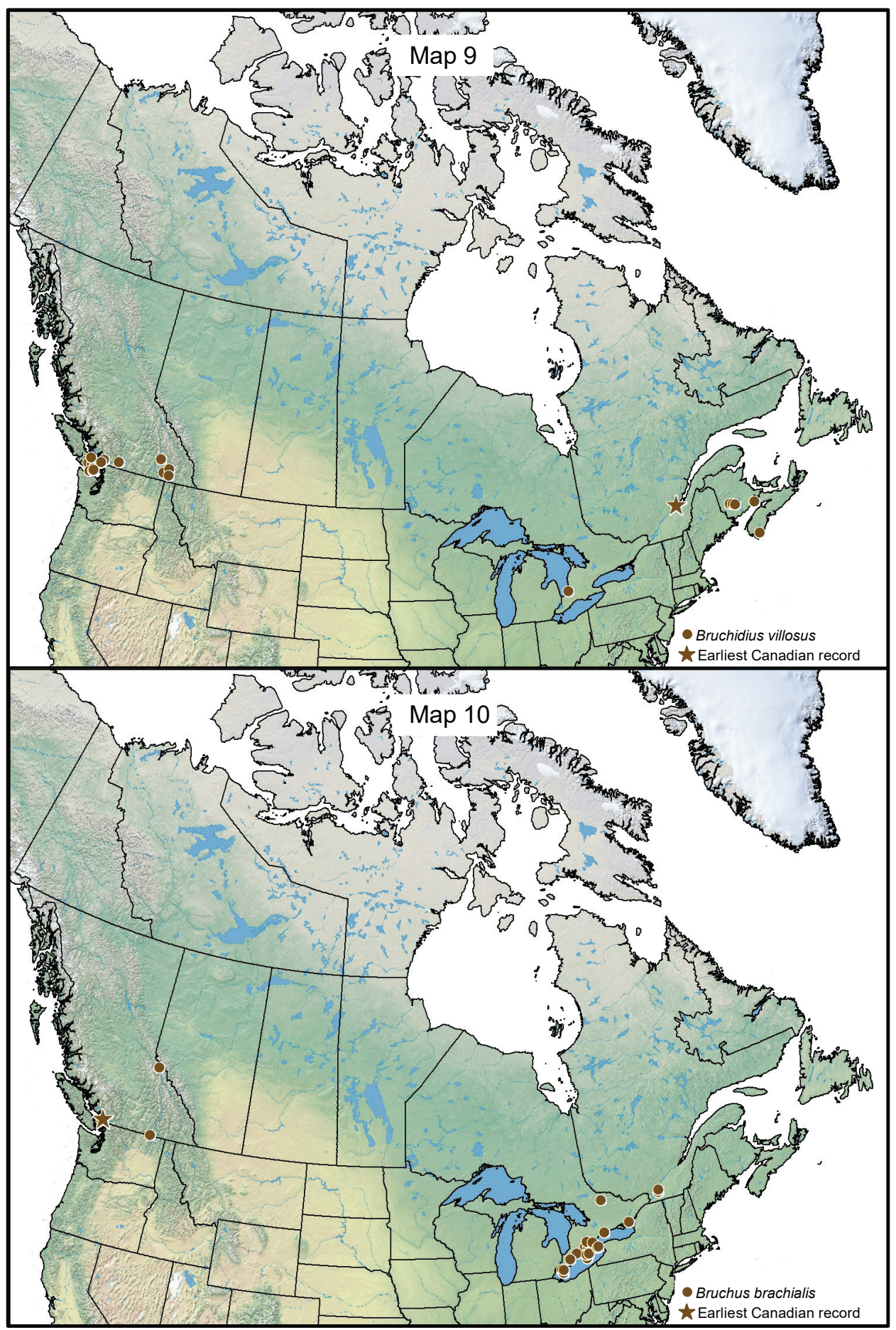




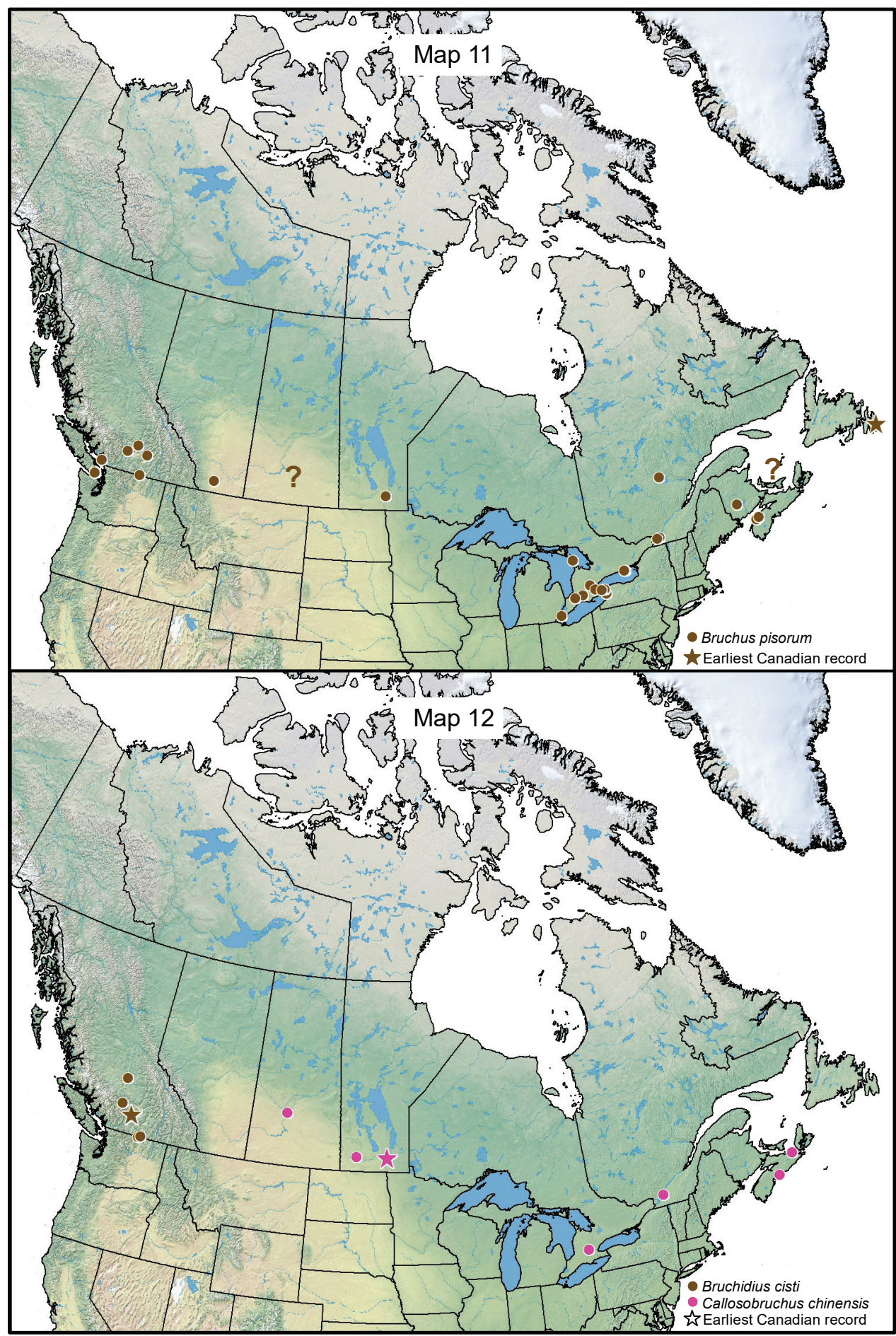




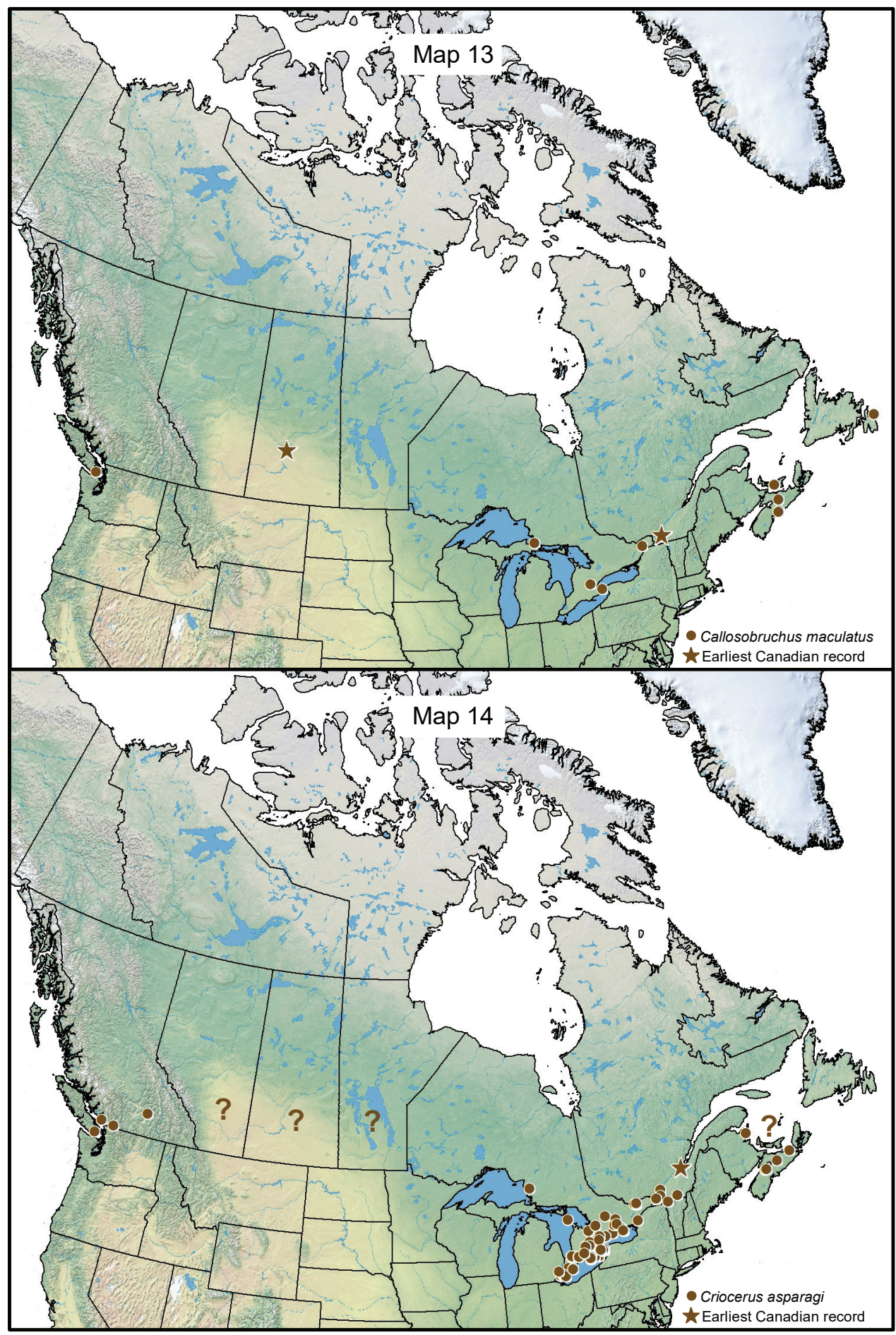




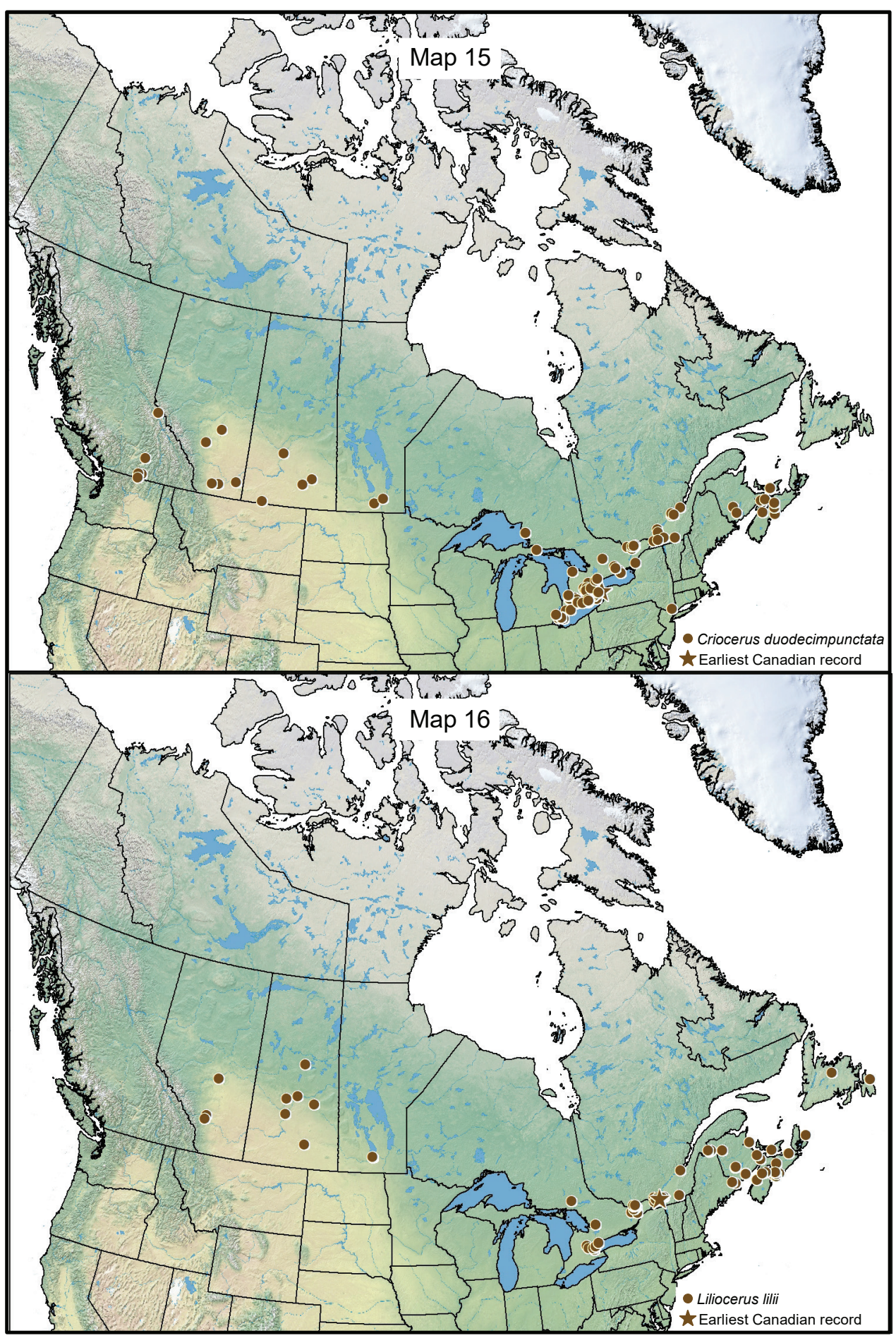




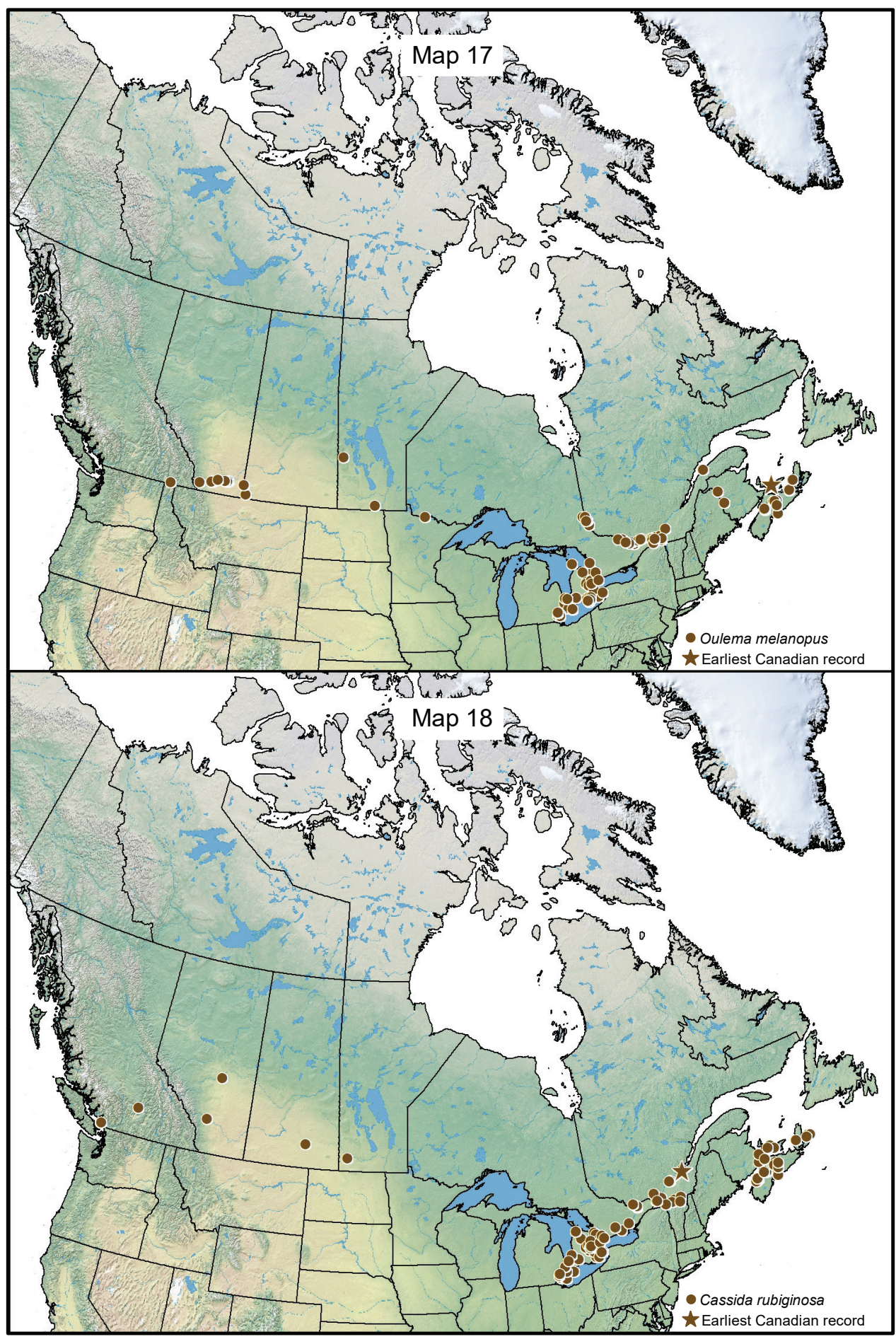




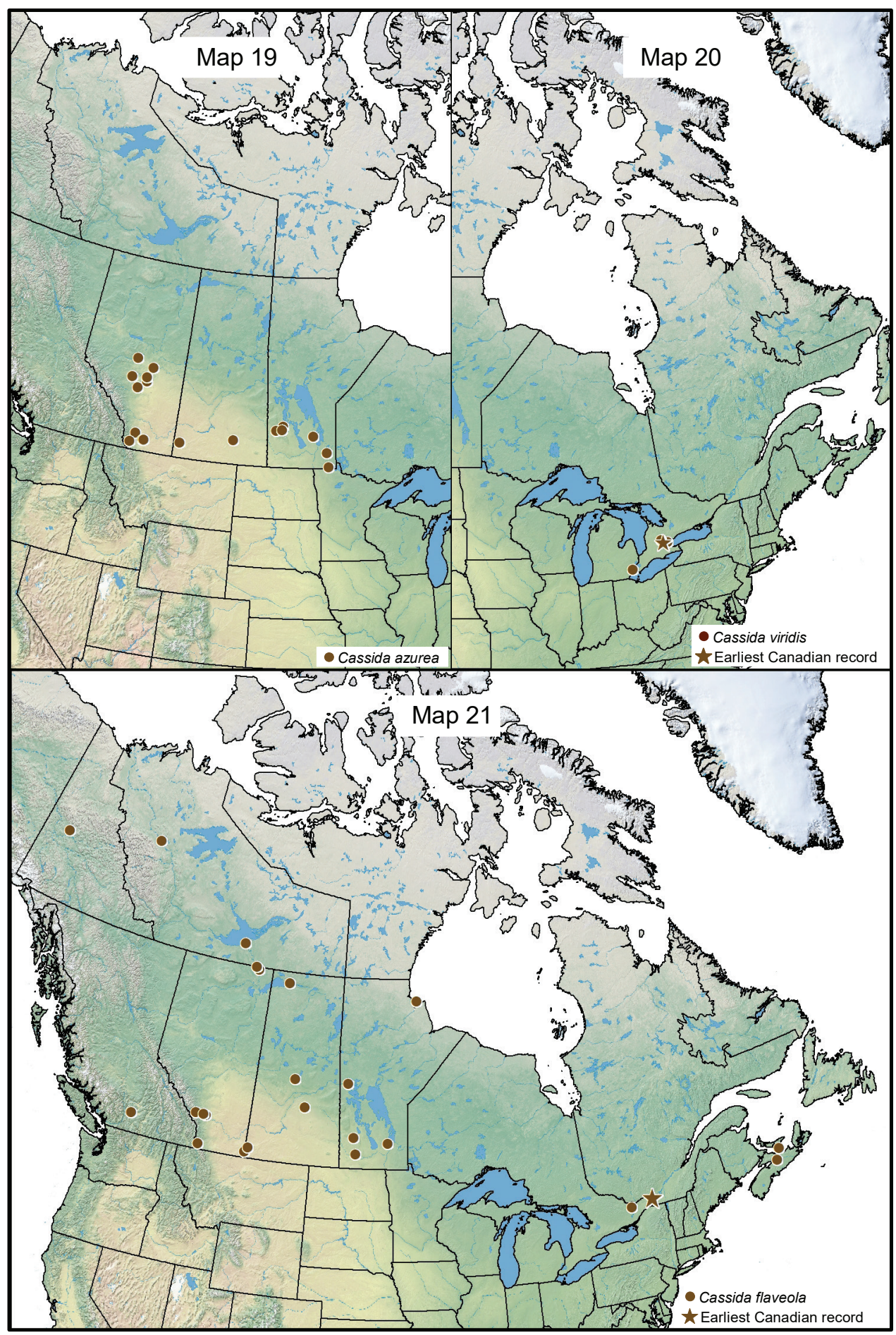




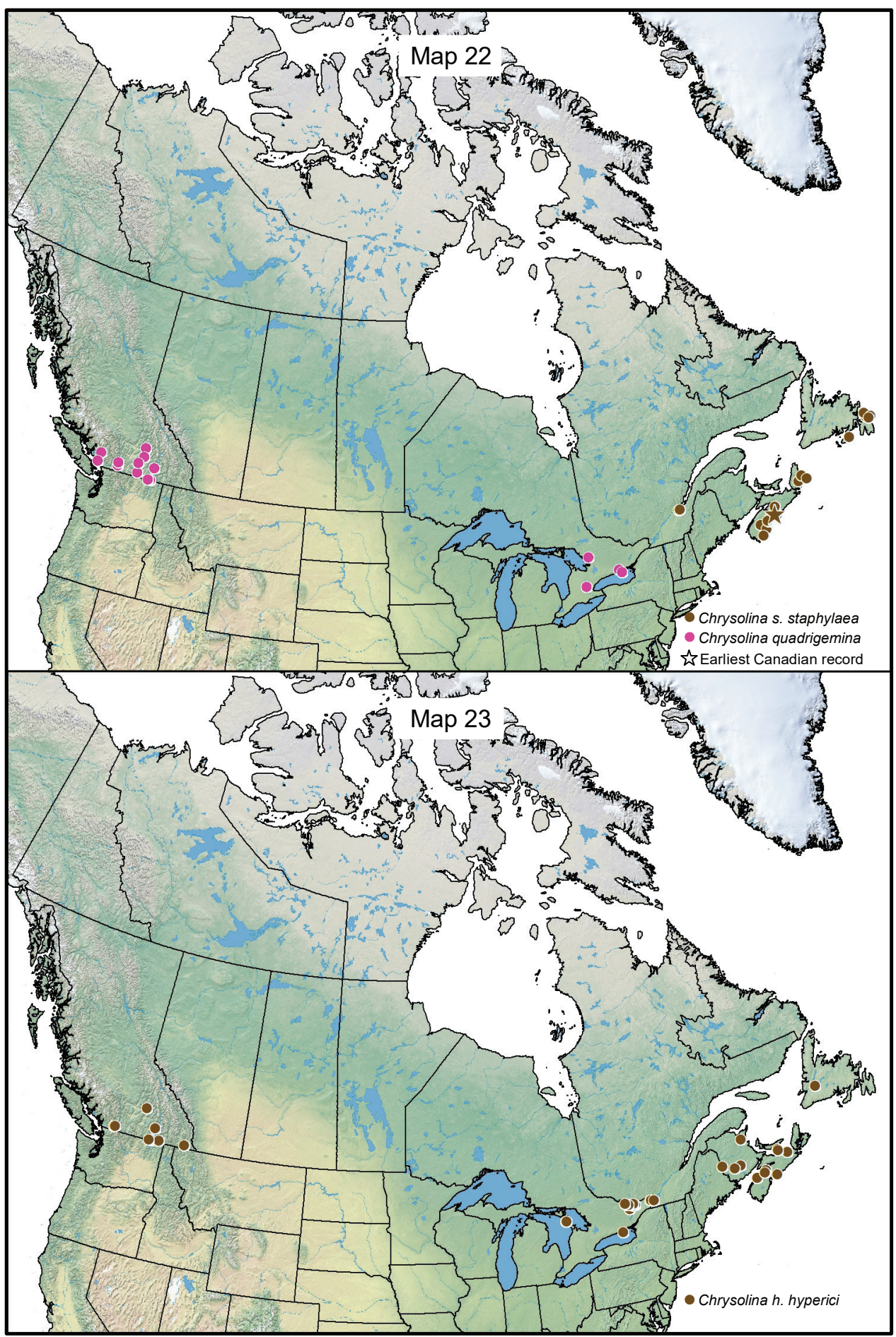




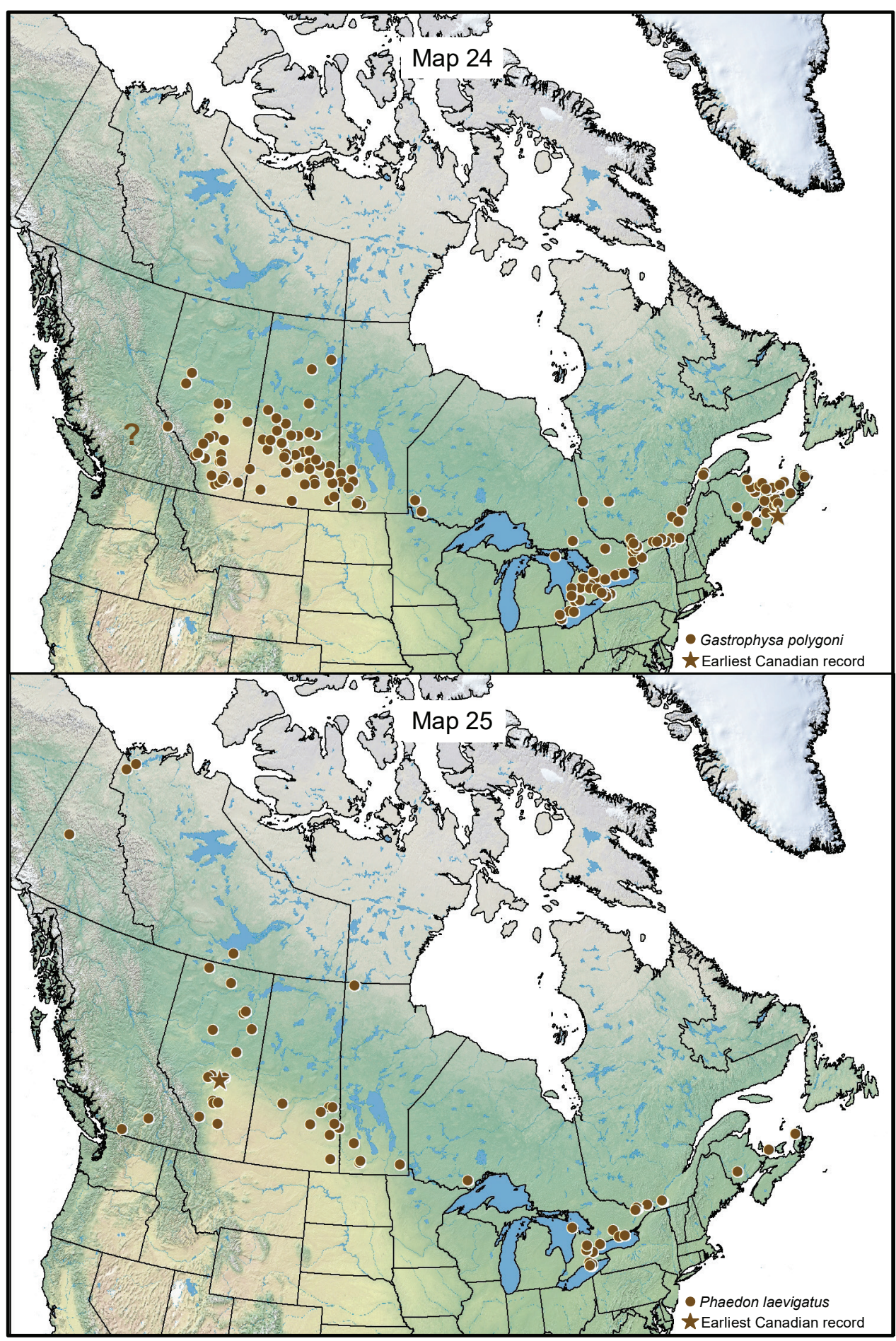




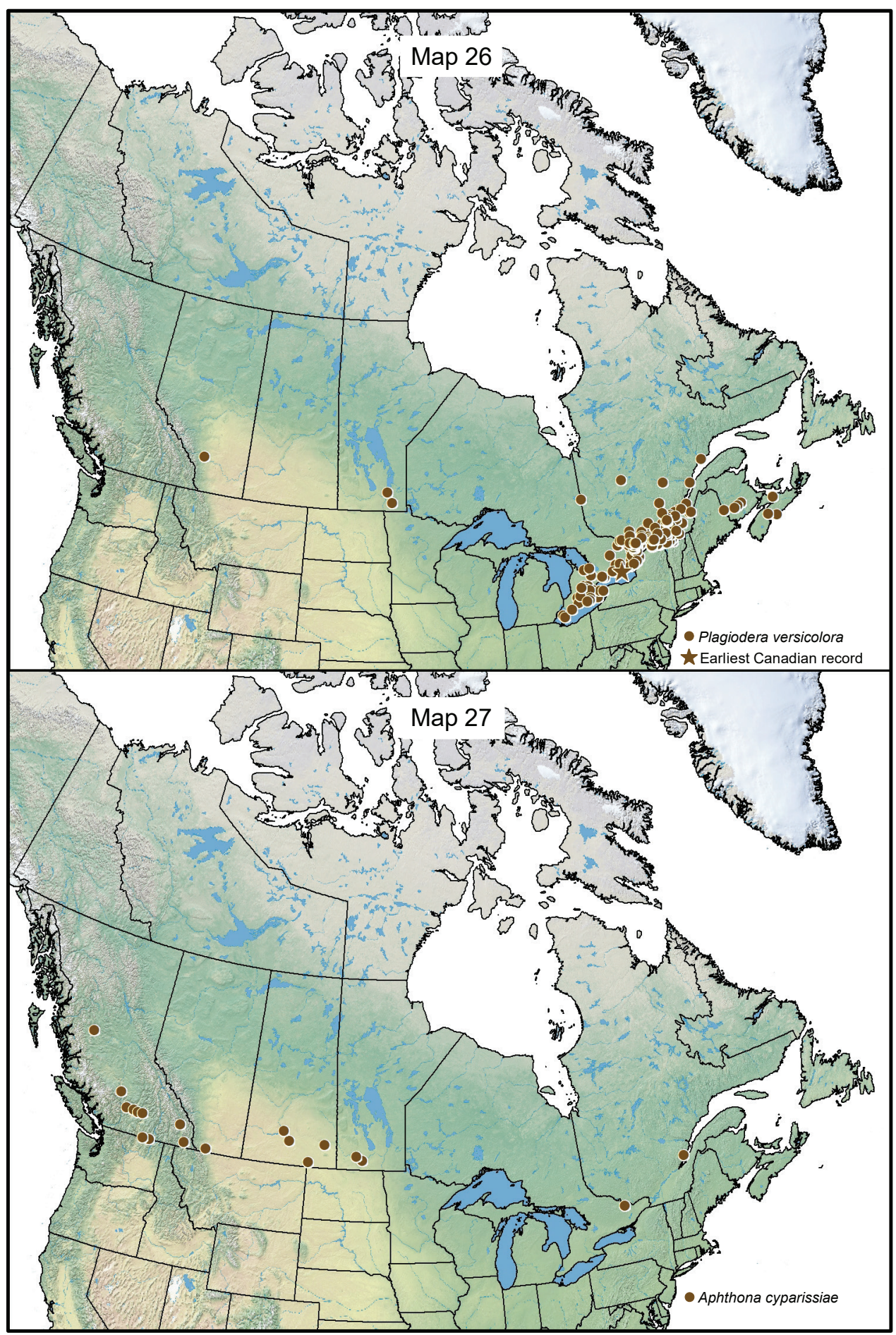




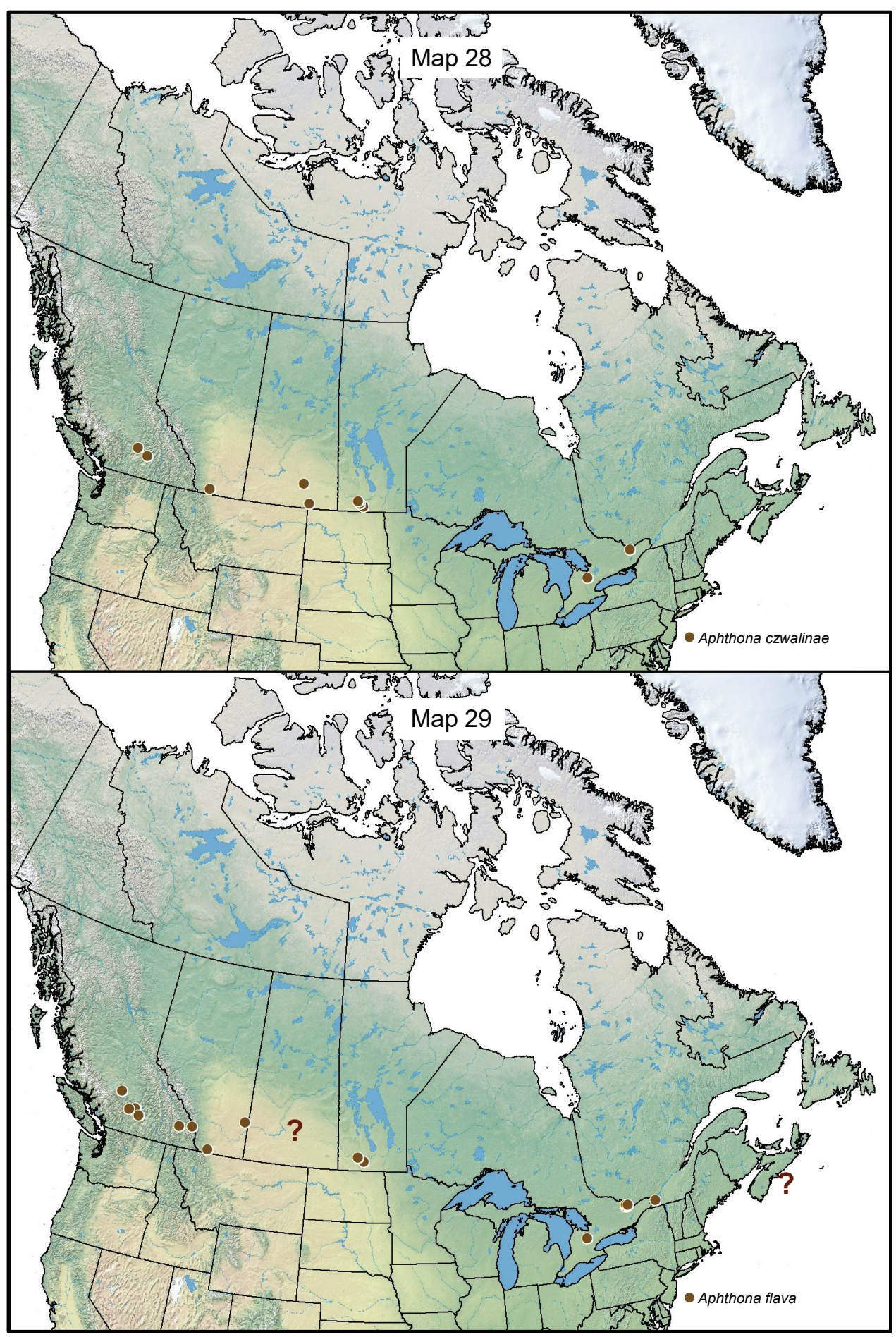




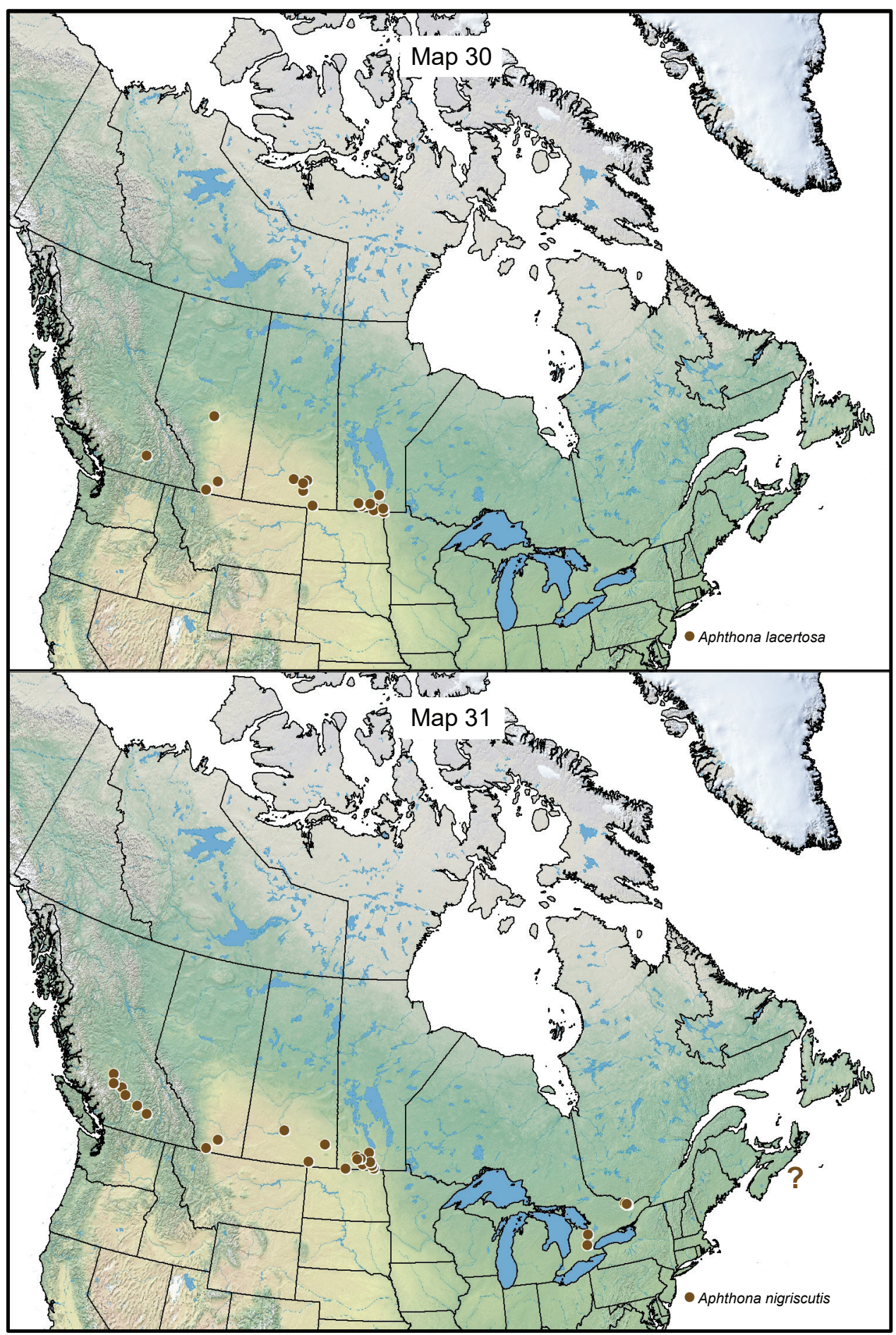




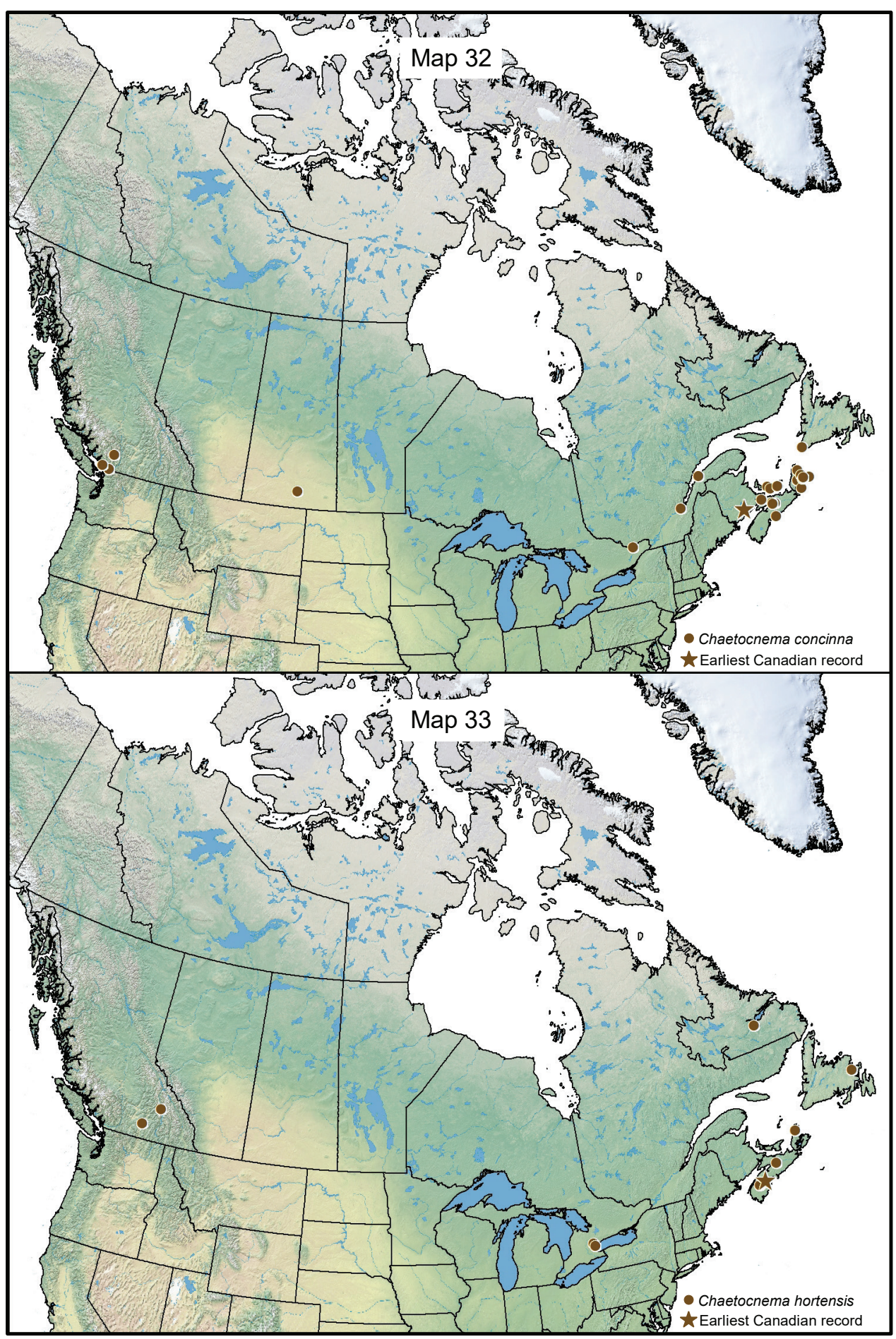




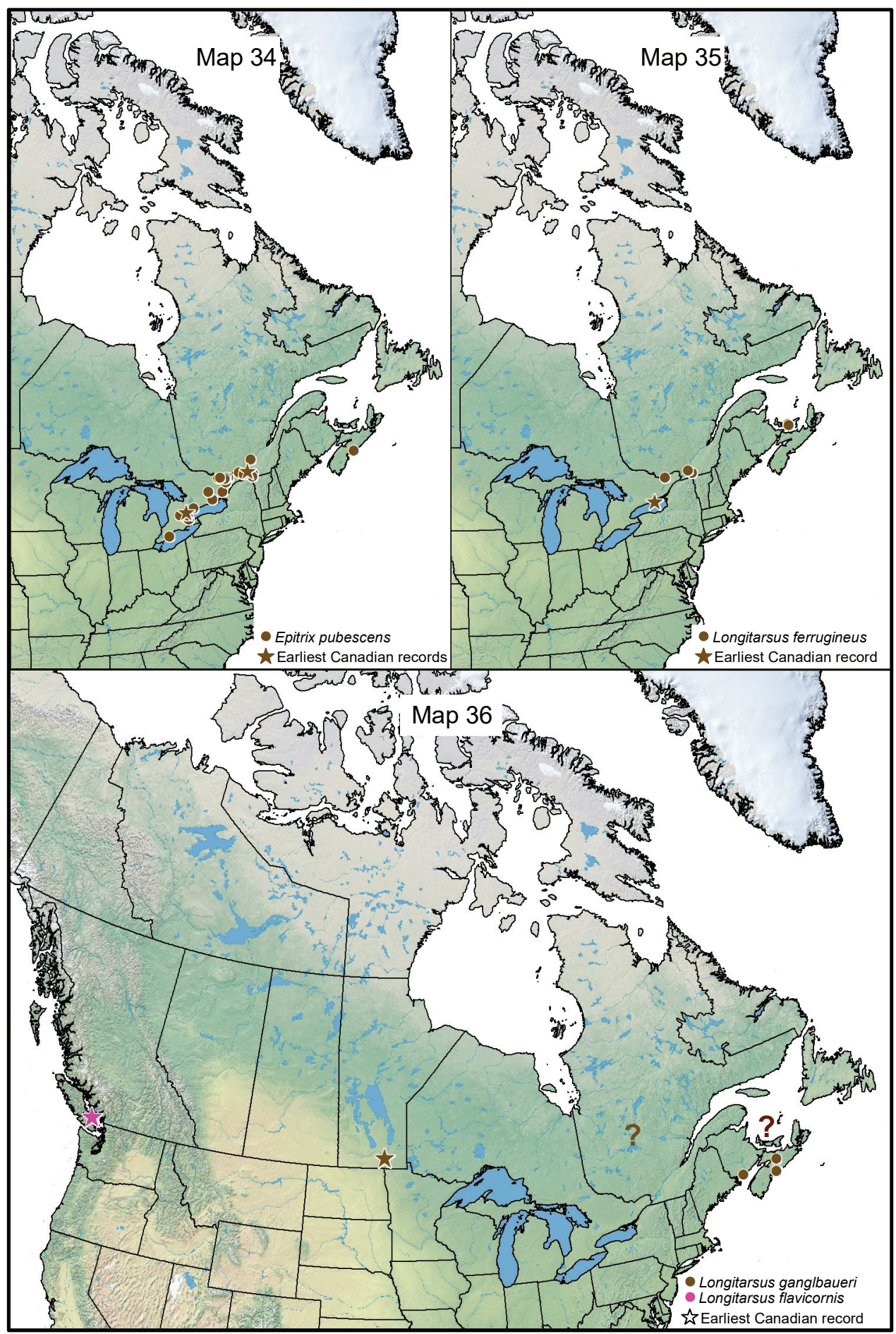




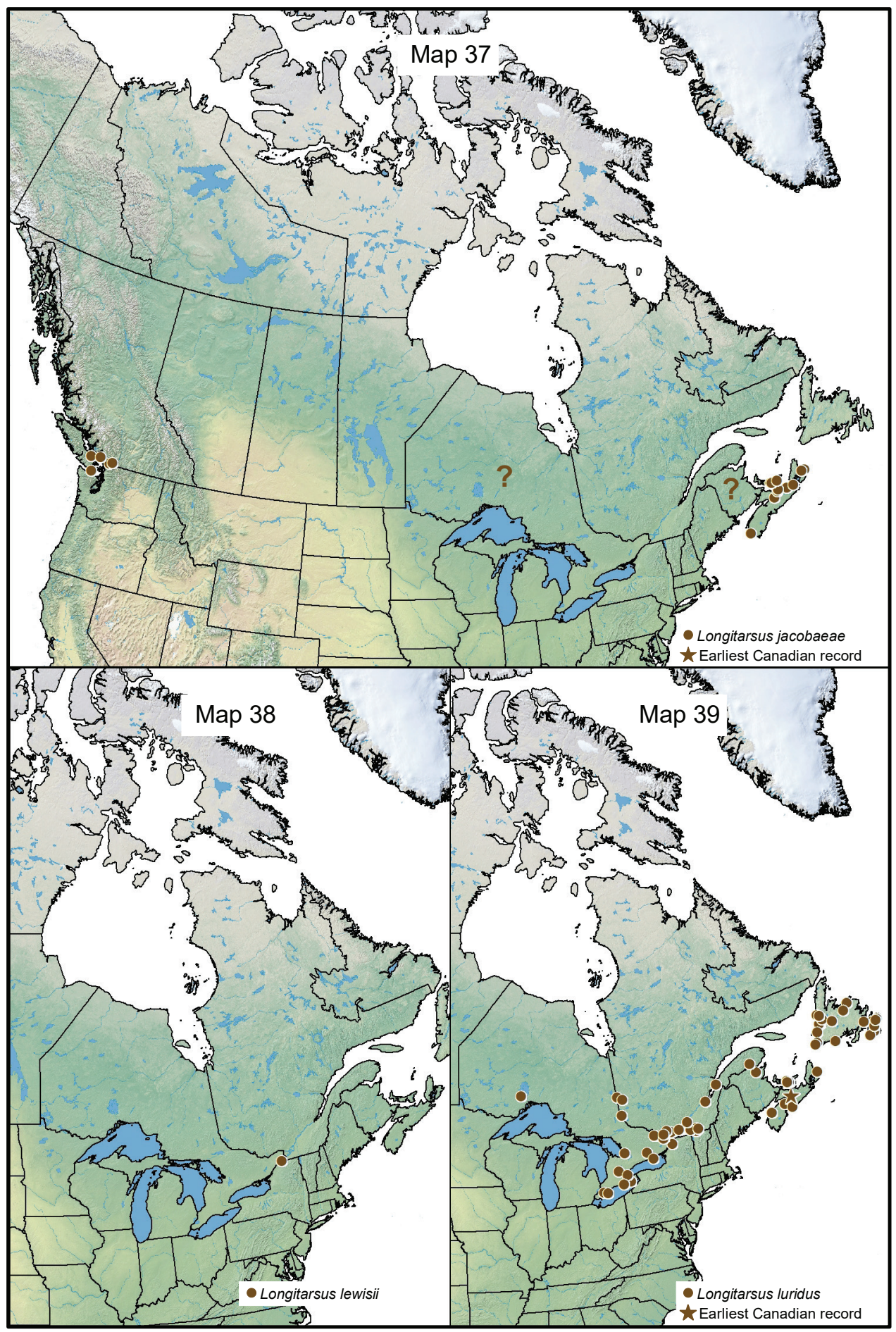




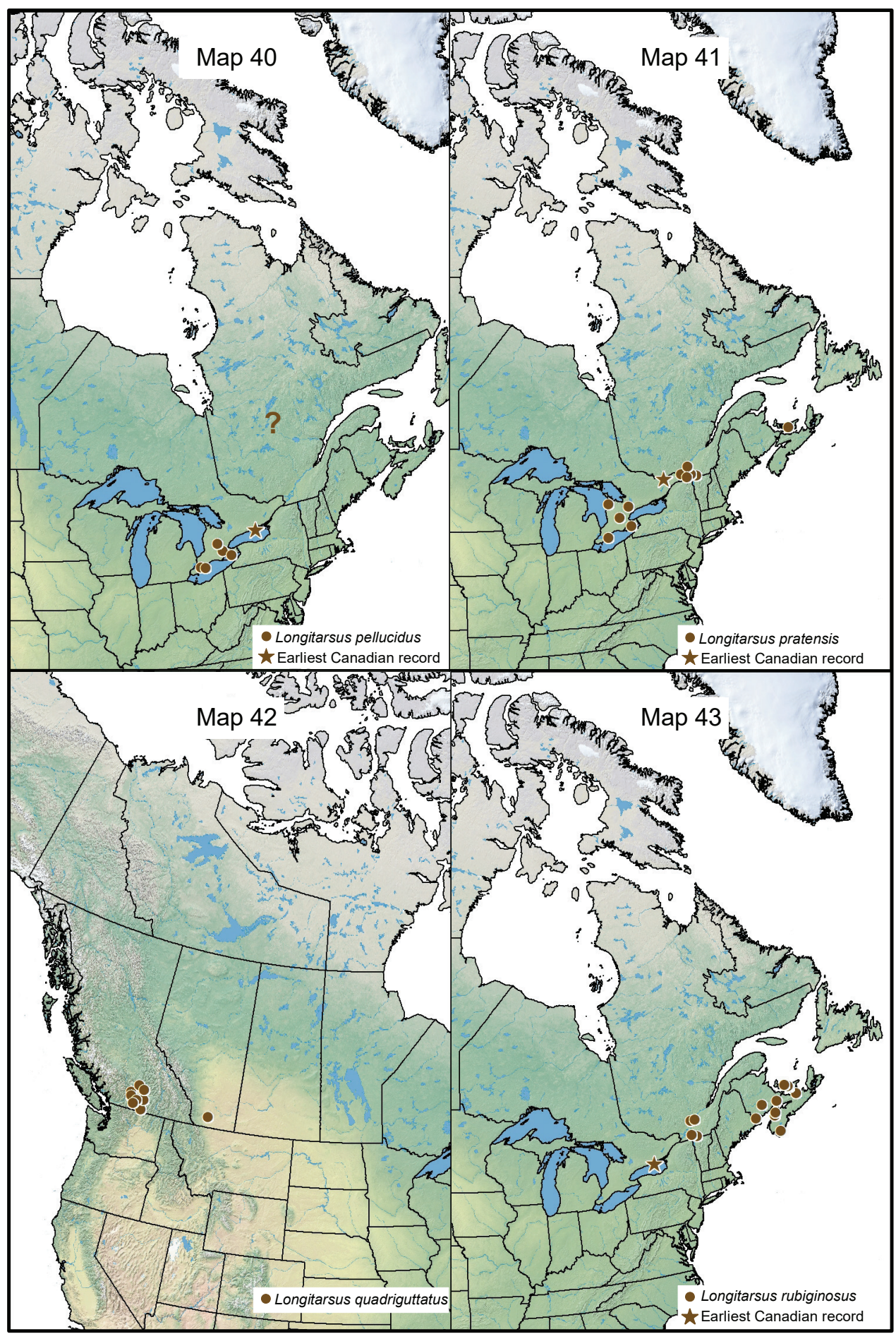




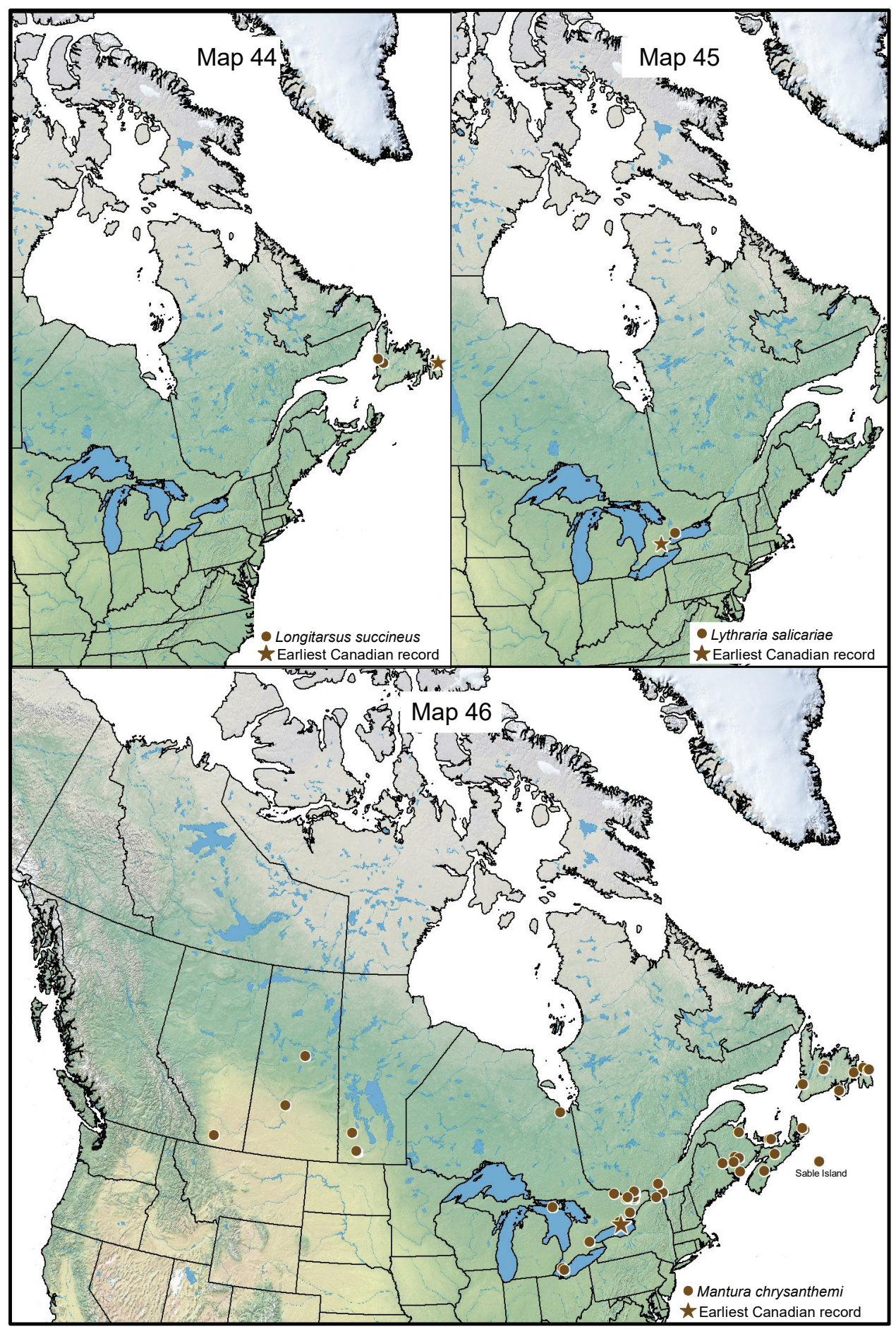




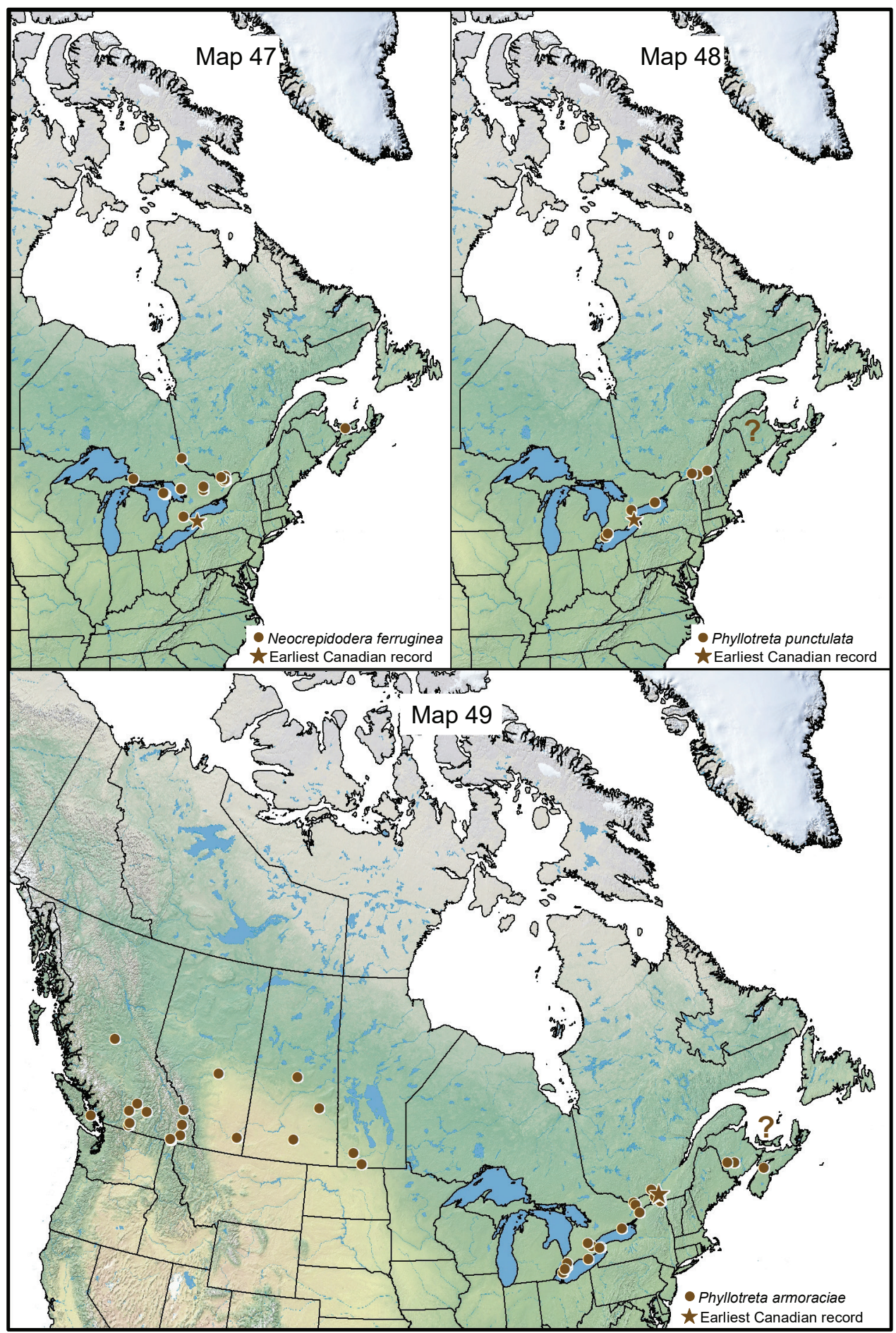




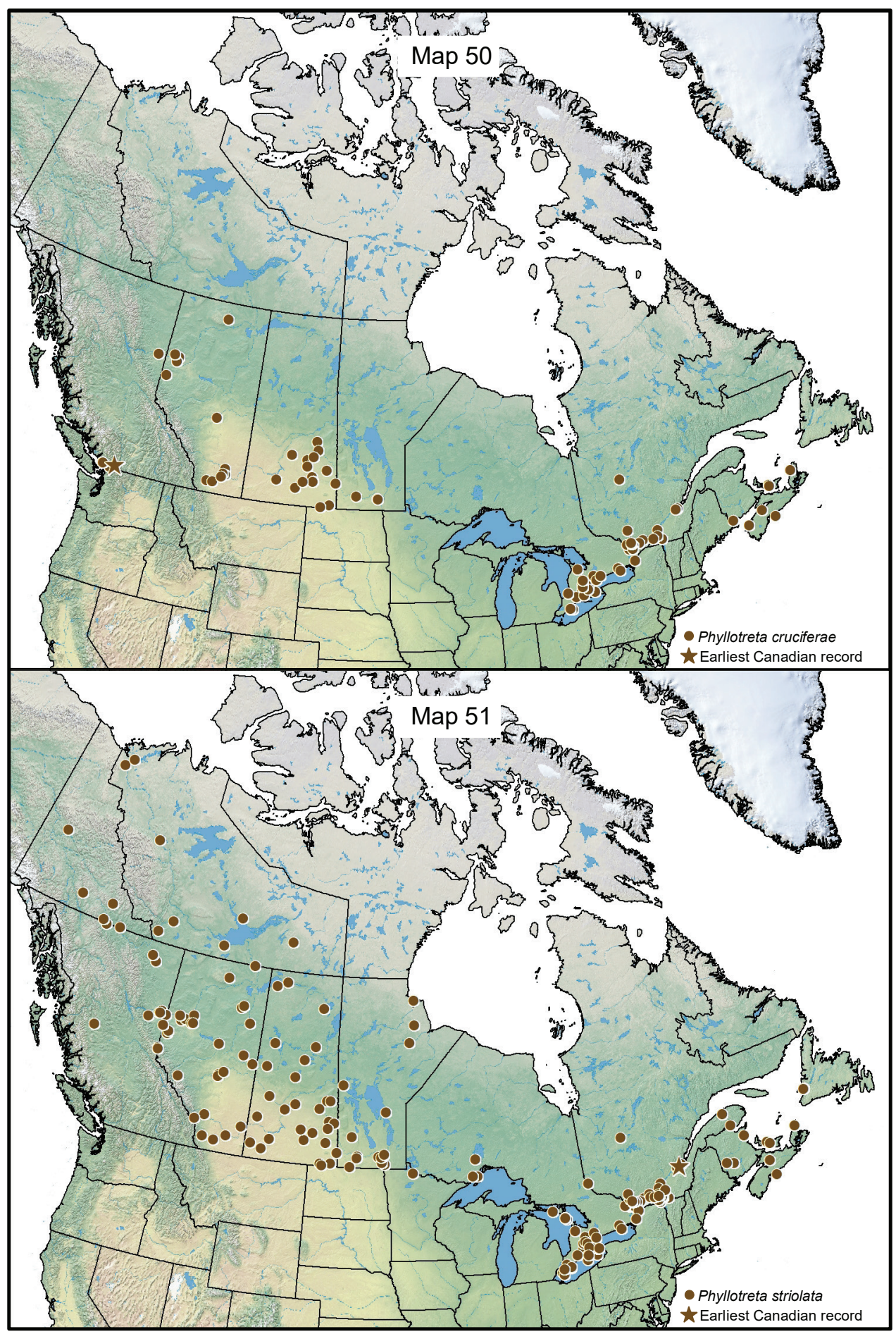




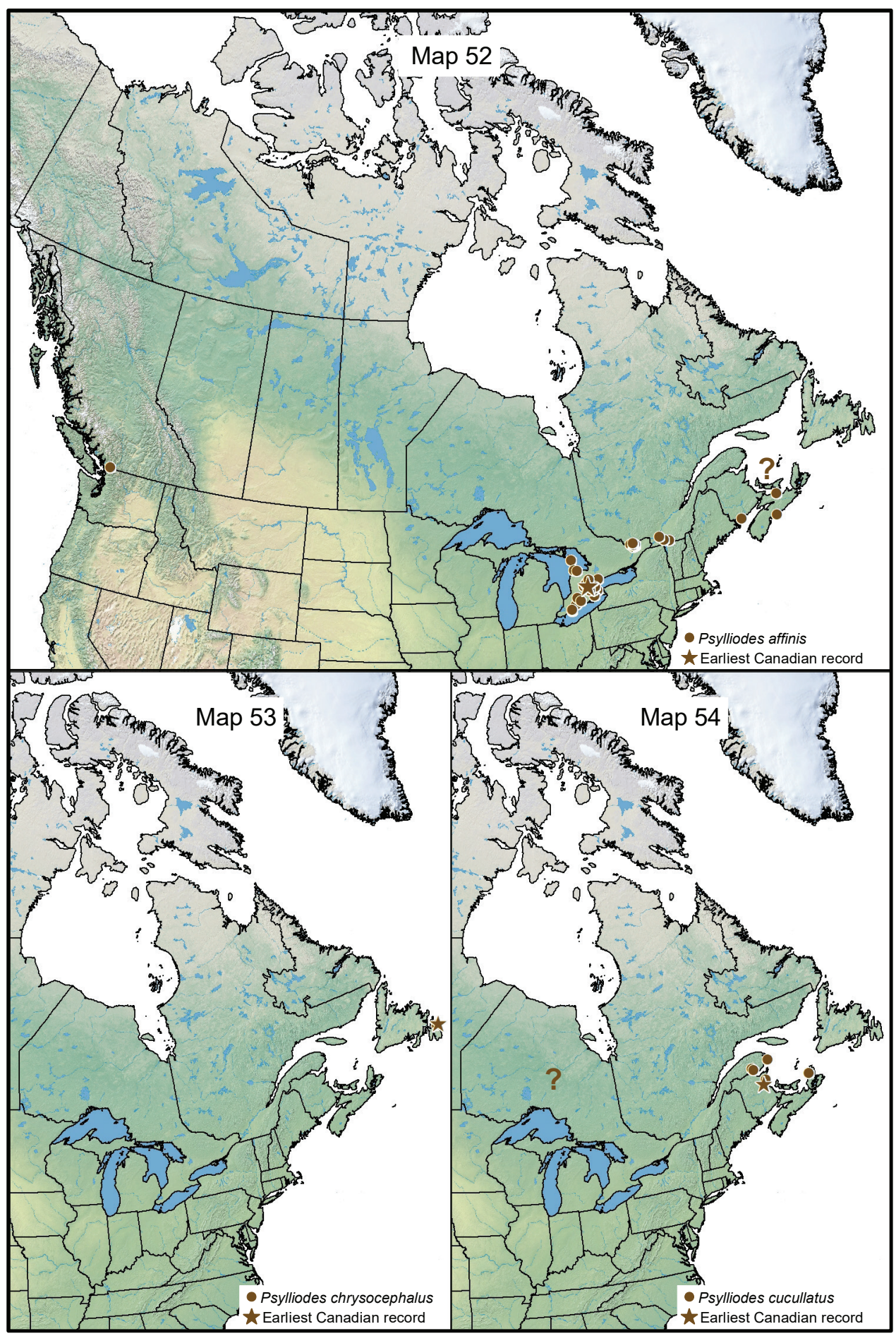




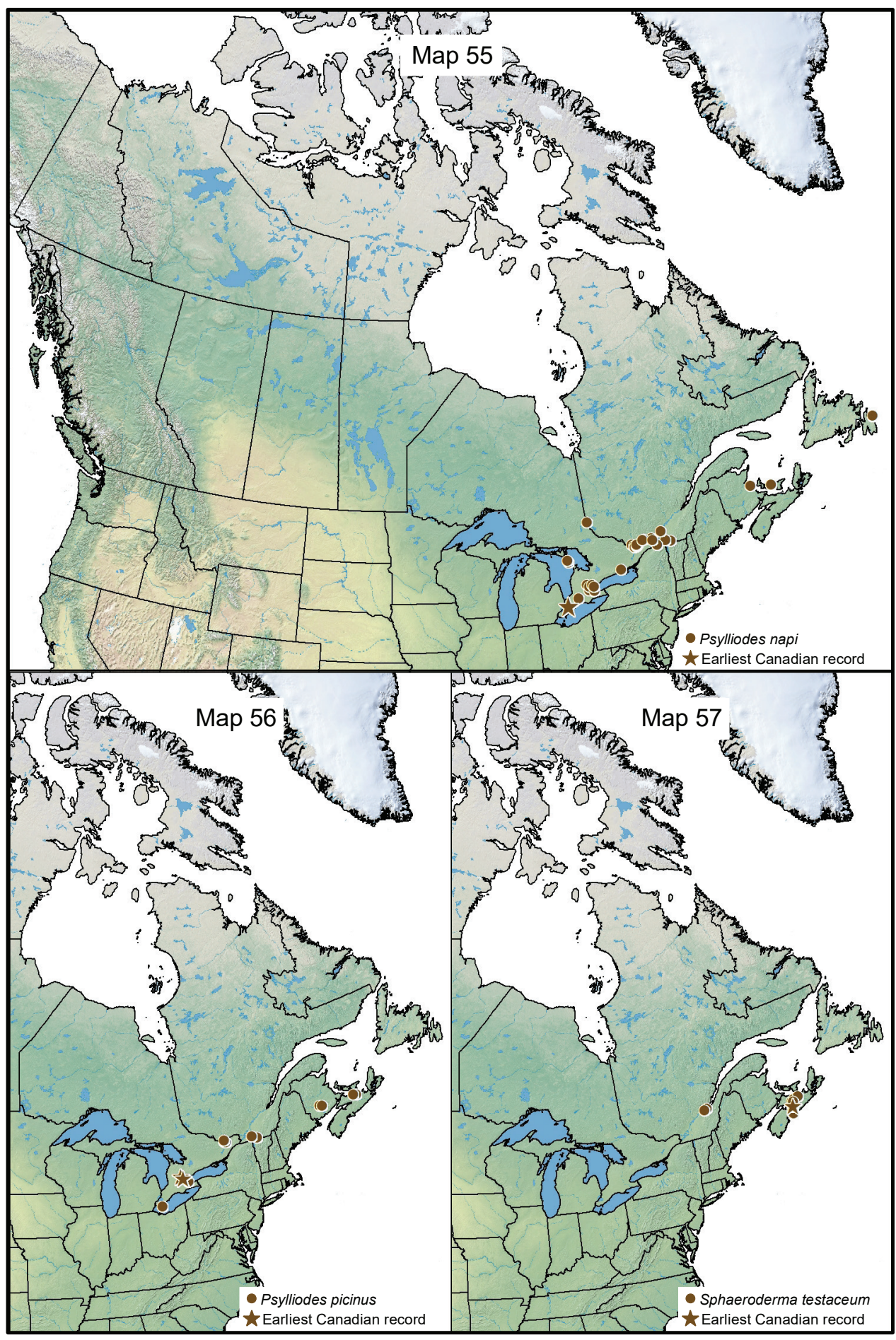




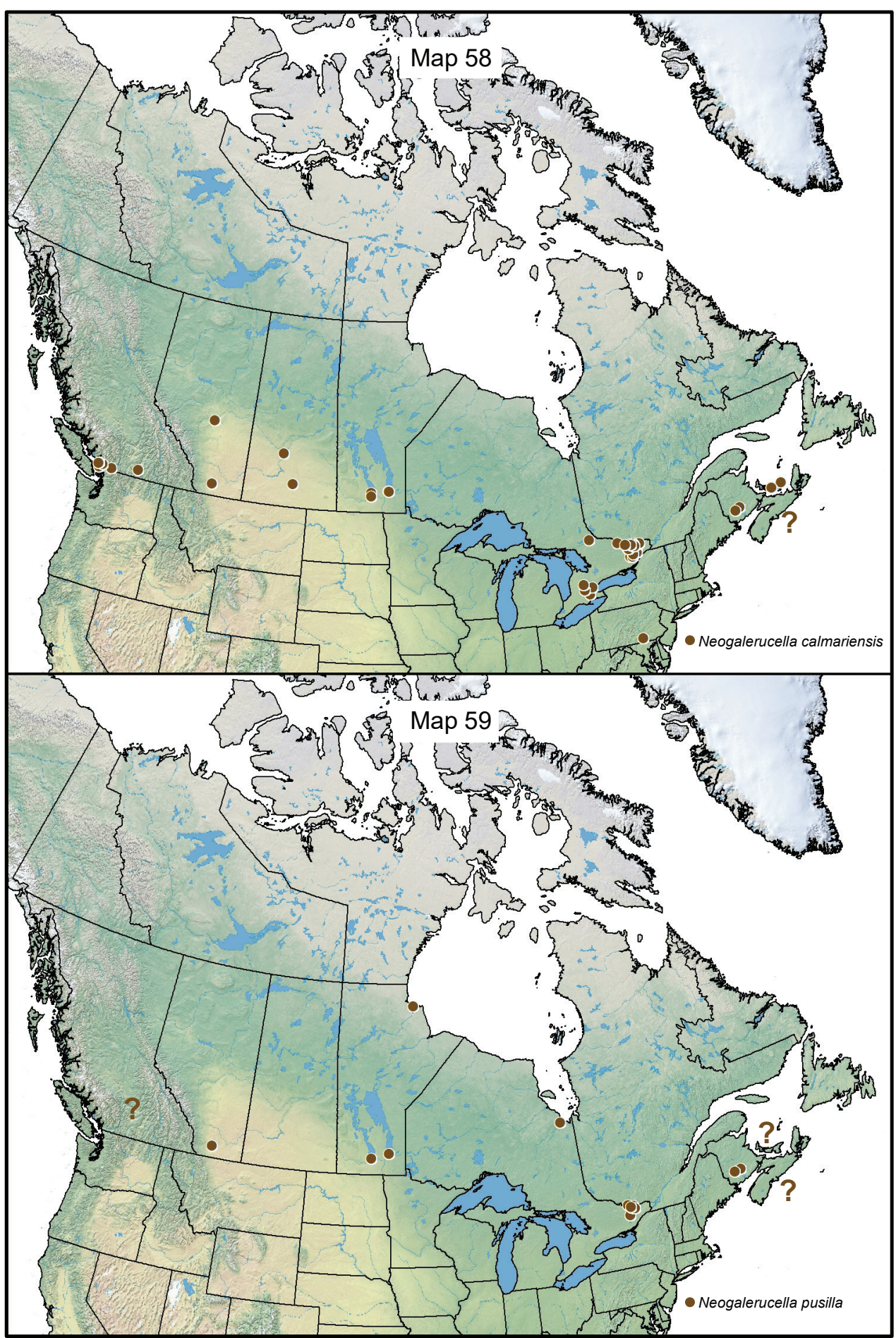




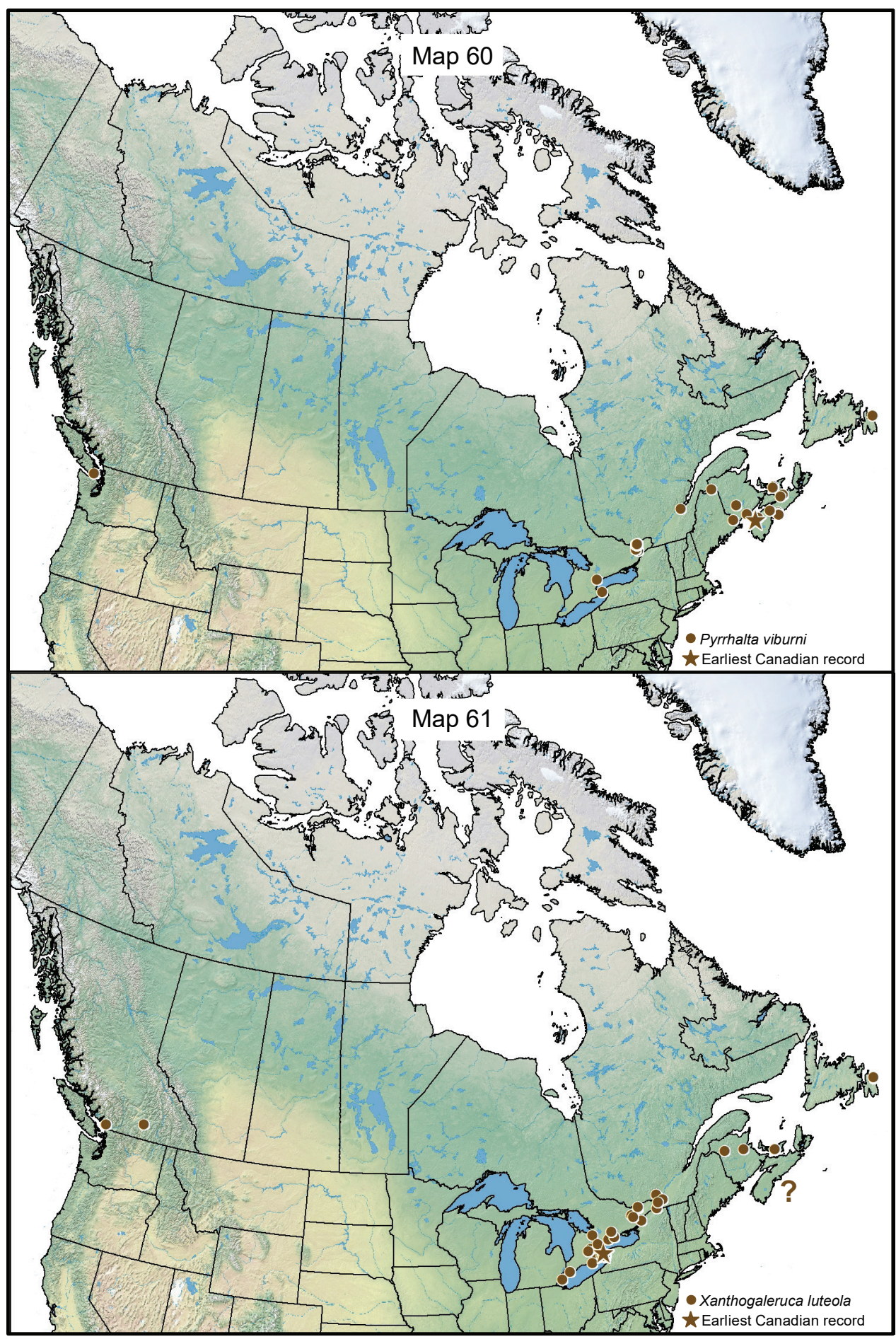




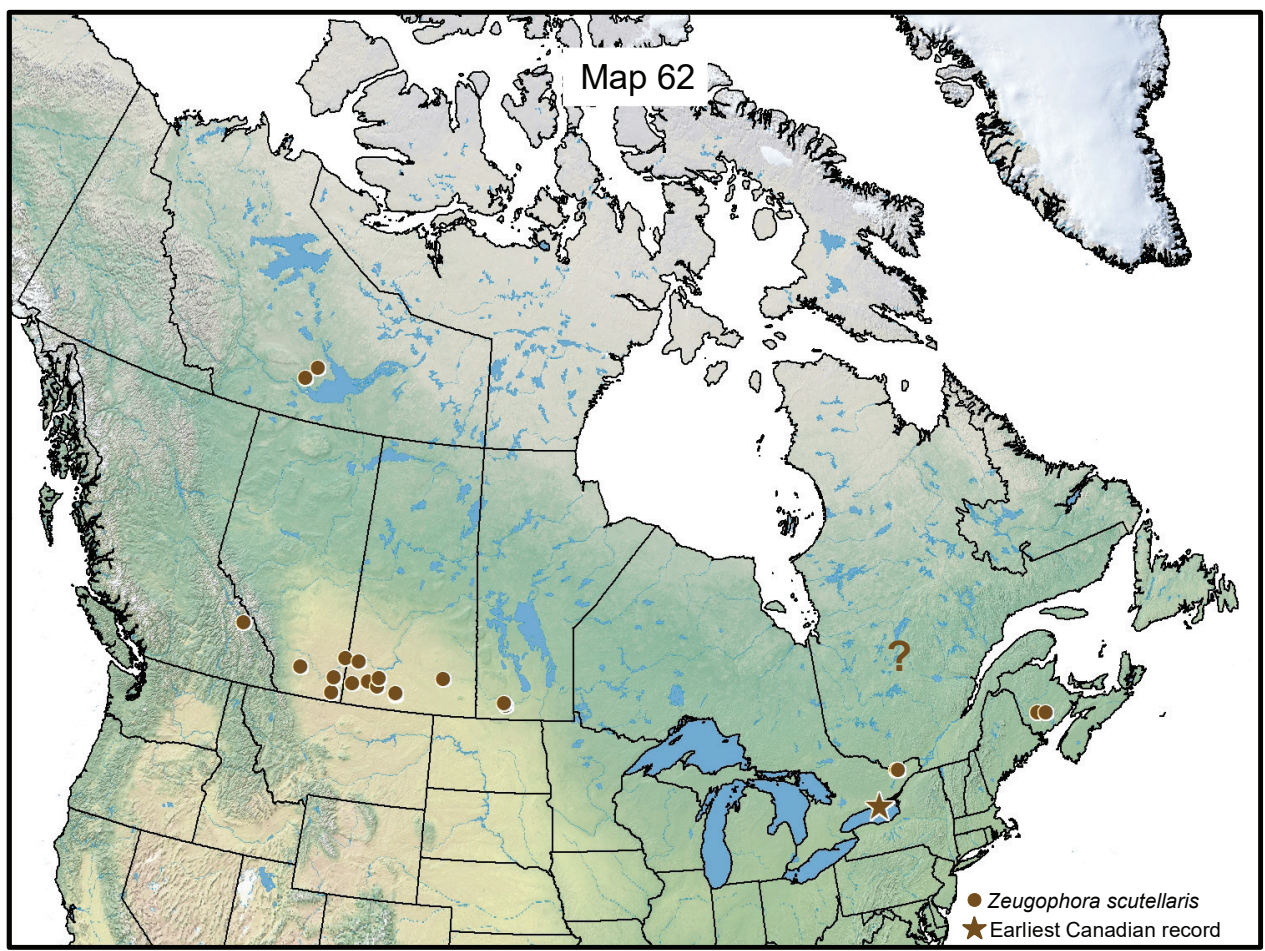





\section{$\Lambda$ synopsis of the adventive species of the Coleoptera superfamily Achrysomeloidea (Cerambycidae, Chrysomelidae, and Megalopodidae) in}

Canada is presented, including 10 new jurisdictional records. In Canada, 72 species in 38 genera and three families are reported as adventive, constituting $7.4 \%$ of the national fauna of this group. Most adventive species belong to Chrysomelidae (61 spp.) followed by Cerambycidae (10 spp.). Many species cause significant economic damage to forests, crops, and stored pruducts. Eighteen species were intentionally introduced as biocontrol agents against perennial weeds. Each adventive species is reviewed and illustrated with color habitus photos. The Canadian distribution for each species is mapped and the general distribution in the USA provided. General habitat information for each species is summarized and a taxonomic diagnosis provided.

\section{Pensoft Series Faunistica No 119}

